Florida International University FIU Digital Commons

$11-16-2016$

\title{
Nationalism as a Process for Making the Desired Identity Salient: Bosnian Muslims Become Bosniaks
}

Mirsad Krijestorac

Florida International University, mirsadme@gmail.com

DOI: $10.25148 /$ etd.FIDC001218

Follow this and additional works at: https://digitalcommons.fiu.edu/etd

Part of the Comparative Politics Commons

\section{Recommended Citation}

Krijestorac, Mirsad, "Nationalism as a Process for Making the Desired Identity Salient: Bosnian Muslims Become Bosniaks" (2016). FIU Electronic Theses and Dissertations. 3004.

https://digitalcommons.fiu.edu/etd/3004

This work is brought to you for free and open access by the University Graduate School at FIU Digital Commons. It has been accepted for inclusion in FIU Electronic Theses and Dissertations by an authorized administrator of FIU Digital Commons. For more information, please contact dcc@fiu.edu. 


\title{
FLORIDA INTERNATIONAL UNIVERSITY
}

\author{
Miami, Florida
}

\section{NATIONALISM AS A PROCESS FOR MAKING THE DESIRED IDENTITY}

SALIENT: BOSNIAN MUSLIMS BECOME BOSNIAKS

\author{
A dissertation submitted in partial fulfillment of the \\ requirements for the degree of \\ DOCTOR OF PHILOSOPHY \\ in \\ POLITICAL SCIENCE \\ By
}

Mirsad Kriještorac

2016 
To: Dean John F. Stack, Jr.

Steven J. Green School of International and Public Affairs

This dissertation, written by Mirsad Krijestorac, and entitled Nationalism as a Process for Making the Desired Identity Salient: Bosnian Muslims Become Bosniaks, having been approved in respect to style and intellectual content, is referred to you for judgment.

We have read this dissertation and recommend that it be approved.

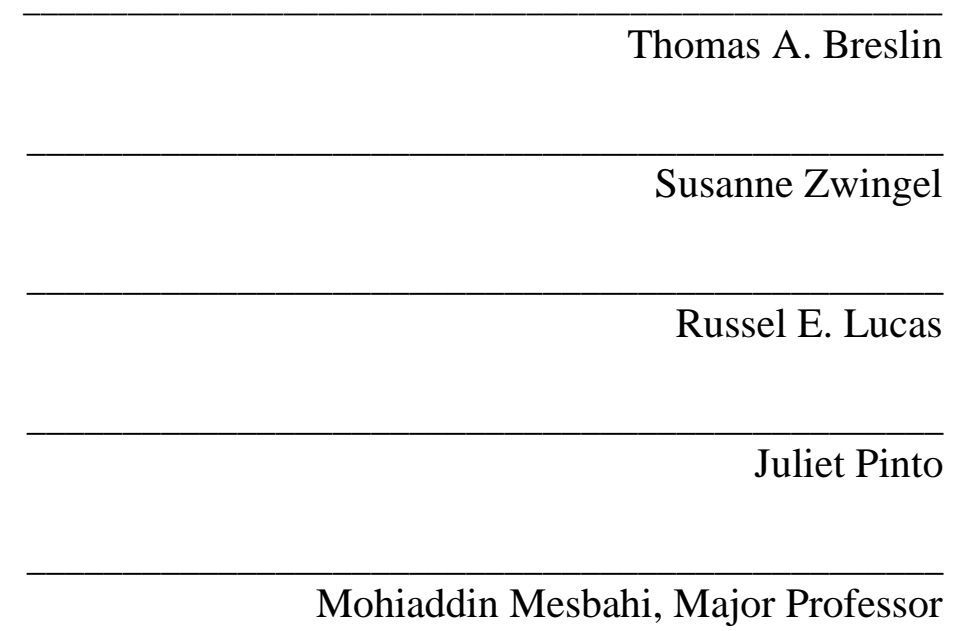

Date of Defense: November 16, 2016

The dissertation of Mirsad Krijestorac is approved

Dean John F. Stack, Jr. Steven J. Green School of International and Public Affairs

Andrés G. Gil

Vice President for Research and Economic Development and Dean of the University Graduate School

Florida International University, 2016 
(C) Copyright 2016 by Mirsad Kriještorac

All rights reserved. 


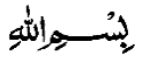 \\ DEDICATION}

To my sister, Dr Sadeta Kriještorac,

and our parents 


\section{ACKNOWLEDGMENTS}

This dissertation is the result of my quest to understand the relationship between nationalism and identity, and what has happened to me, my family, my people, and the country of Yugoslavia, where I was born, which does not exist anymore. Now that I have completed it, I feel that I know more than I knew when I first began this journey. Many people have helped me along the way, and I must thank all of them. Without their help and contributions, I could not have done it!

Before anyone else, I have to thank my sister, Dr. Sadeta Krijestorac, who encouraged me to begin and supported me all the way through this project. Towards the end of my endeavor, my sister Sadeta was diagnosed with the terrible disease of ALS, and I want to dedicate my dissertation to her.

During my time in graduate school, I studied with some amazing people and professors and in the very supportive Department of Politics and International Relations of Florida International University. From the first moment I met with my mentor, Dr. Mohiaddin Mesbahi, and then-graduate director, Dr. Ronald Cox, I received unwavering support. The concern that both of them showed for me and my progress was truly remarkable. It is inspiring to know faculty as supportive of their students as they are. Many other faculty, staff and students also provided full support for me throughout this

journey. I must thank my first mentor, Dr. Russel E. Lucas, with whom I was fortunate to work for several semesters and from whom I learned so much. I must also thank Dr. Thomas Breslin for his patience and help in numerous ways throughout the whole dissertation process. I also want to thank Dr. Maria del Mar Logroño Narbona and Dr. 
Juliet Pinto, who both believed in me while I was their undergraduate student and encouraged me to do this work. I am also grateful to Dr. Susanne Zwingl for her willingness to step in and provide feedback and useful critique of my work. Many thanks, too, to Dr. Kevin Evans and Dr. Adrian Ang for their time and valuable advice regarding the statistical parts of my work. I also wish to thank Dr. Harry Gould, Dr. Clement Fatovic and Dr. Tatiana Kostadinova for their valuable comments and support. I thank the rest of the department faculty who were all forthcoming and always willing to listen and help in their capacity. I also appreciate very much the help and support I received from our Department's Office Manager, Maria Wilkinson-Diaz, and the rest of the staff who all went well beyond their duties to help me survive graduate school and reach this goal.

I cannot fail to mention my dear student colleagues who have all helped me in numerous ways, my friends Bilal Ciplak, Sylvan Lee, Ransford Edwards, Joaquin Pedroso, Ana Podcameni, Nima Baghdadi, T.J. Ligouri, Michael Bender and Therese Sollien. Thank you for your friendship and support, guys.

This work was supported by funding from the FIU Graduate School Fellowships and the Department of Politics and International Relations, for which I am grateful.

Just before I started the research phase of my dissertation, I met an incredible person, our Graduate Librarian, Stephanie Brenenson. What an asset she is for FIU and us graduate students! I don't know if I will ever be able to thank her enough for all the hours she gave of her time and efforts to help me. 
I must also thank FIU's statistical consultants, Alejandra Matamala and Tyler Stout, for their incredible work, help and patience. I am also grateful to Dr Adrian U-Jin Ang, Dr. Fatih Demiroz and Imad Boucekkine for their time and help with the statistical part of my work. I also thank Dr. Diana Bloom for her meticulous work which made this dissertation much better.

I also wish to thank all the following people for their support during my several months of long field work: Hajrudin Čaušević, Samir Karabegović, Suad Obić, Skender Škretović, Sead Alibašić, Bakija Aslani, Muriz Mešić, Senad Agić, Enes Čirkić, Murisa Čirkić, Mediha and Nihad Halilović, Abdurahman Salkanović, Amir Čauš, Djerlek Ruždija, Huso Dedić, Rahima Kano, the Sisters' section of Džemat Sahva, Mesud Kuluzović and the Islamic Cultural Center of Greater Chicago in Northbrook, the Bosnian Islamic Cultural Center Western, and the Sulzer Regional Library in Chicago.

In St. Louis, I thank Muhamed Dizdarević, Dževad Tursunović, Avdulah Pilica, Fuad Fazlagić, Uma Aličković, Muhamed Hasić, Enver Kunić, Elvira Husetovic, Rifet Buljubašić, Amir Kundalić, Mustafa Djerhović, and Akif Cogo, the Department of Political Science of the University of Missouri, Saint Louis, and especially Dr. Terry Jones; the St. Louis International Institute and Paul Costigan, and last but not least, Ahmed Serdarević and Džemat Nur of St. Louis for their hospitality during my stay in the city.

In New York, I thank Mustafa Mrkulić Mrki, Hasan Tahirović, Mehdija Demirović, Mirsad Merhemić, Senahid Halilović, Esko Kriještorac, Faruk Ferizović Dolić, Esad Krcić, and Damir Husamović. 
From other places where data was also collected, I wish to thank Fehim and Emira Kriještorac, Nermin Kabahija, the unknown librarian of the Gazi Husrev Beg's Library in Sarajevo, Sejad Melkić, Edib Makić, Mukrem Kamber, Šemso Kajtezović, Nedžad Halilović, Selva Dedović, Tidža Čaušević, Dr Zuhdija Adilović for their help. I hope they all know that their support meant a lot to me.

Several people from the National Library of the Republic of Serbia helped me and I very much appreciate their contributions; my dear friend Snežana VidanovićZdravković, reference librarian Aleksandra Grozdanić, special event coordinator Svetlana Gavrilović, and archivist Ljubomir Branković.

I also want to thank my mother, Tima Ljaljak, a WWII survivor who never had the opportunity to finish elementary school, but encouraged and supported several of her children to get doctoral degrees. I thank my father, Hanefija Kriještorac, who has taught me the value of education for as long as I can remember and whose dream was to see my dissertation. I also thank my brothers, Sadija Kriještorac and Nedžib Kriještorac who showed me how to be myself.

I am forever indebted for her support to my wife, Lenka Kristić, who has been the most steadfast devotee on this journey. I must also thank my children, Timur, Nora, Dina, Mena, and Hanan, for their help and patience with me. I thank my aunt Izeta Kriještorac, and my brother Salko Kriještorac and his family for their support. Many thanks also to my closest friends, Suad and Sanja Begović, and Jazmir and Belma Bešlija for their support and encouragement during this process. 


\section{ABSTRACT OF THE DISSERTATION \\ NATIONALISM AS A PROCESS FOR MAKING THE DESIRED \\ IDENTITY SALIENT: BOSNIAN MUSLIMS BECOME BOSNIAKS \\ by \\ Mirsad Kriještorac}

Florida International University, 2016

Miami, Florida

\section{Professor Mohiaddin Mesbahi, Major Professor}

This study is concerned with the particular relationship between the process of nationalism and a group's salient identity. It proposes that nationalism as the independent variable serves as a principal factor and facilitator for a change of identity, which is seen as the dependent variable. The Bosnian Muslim emergence as an independent nation with the new salient Bosniak identity was used as a case study to test the main proposition. This case was selected to follow the Bayesian analysis approach which focuses on the appropriateness of a case study selection.

The inquiry was completed through a mixed research method, using grounded theory and the historic process tracing technique, a large survey analysis collected specifically for this study, and a logistic regression as a concluding test. The historic process tracing method describes the Bosnian Muslim group's development from a distinct Balkan Ottoman religious millet group, through a stage of its own ethno-religious cultural crystallization, another stage of nationality during the Communist era, to an independent nation that now shares the country of Bosnia-Herzegovina with two other 
nations. Through their 138-year struggle to survive and re-assert themselves as an important local political entity, Bosniaks built their nationalism upon three important themes: B-H integrity, Bosnian Islam, and the Bosnian language. A 68-question survey regarding these three themes designed specifically for this study was conducted, and 670 survey responses were collected from the Bosnian Muslim diaspora population living throughout the Midwestern and Eastern U.S. in their Appadurai-type neighborhoods. The data collected from those surveys were manipulated in preparation for a final analysis. The two nationalism indexes measuring intensity and type, and six categories of Bosniak identity, were constructed to observe interactions between nationalism and identity.

As the final step, a statistical analysis with multinomial logistic regression confirmed the proposition and showed that the factor which stimulates selection of a new desired salient identity is intensity of nationalism, not type of nationalism .

This work contributes to the ongoing discussion on the true role of nationalism as a collective action. At the same time, it provides the field of comparative politics with a comprehensive description of the emergence of Bosnian Muslims as a nation, and with details of their nationalism project and their new Bosniak identity. 
TABLE OF CONTENTS

CHAPTER

PAGE

I: INTRODUCTION

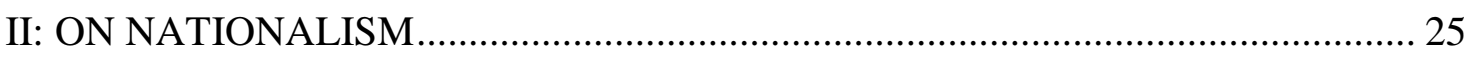

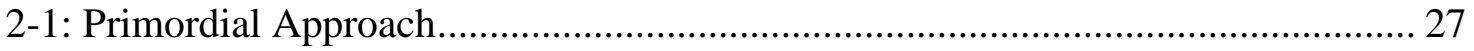

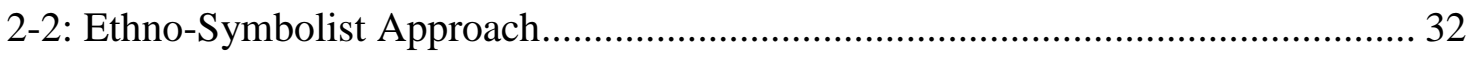

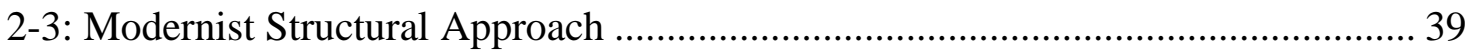

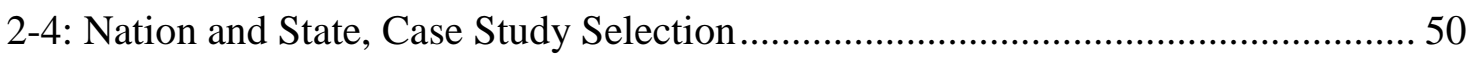

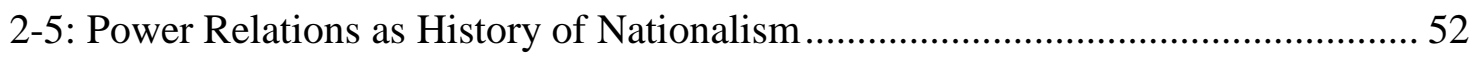

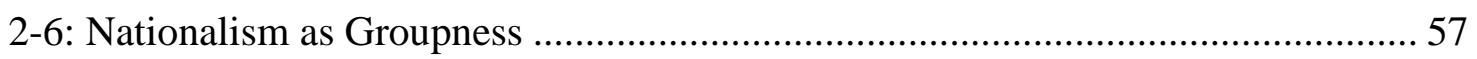

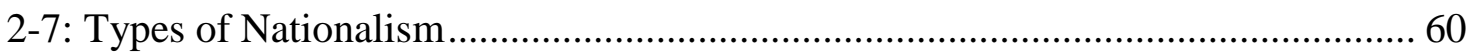

2-8: Conclusion on Issues Relevant for Nationalism Studies ..................................... 62

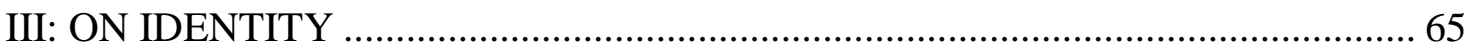

IV: A SHORT HISTORY OF BOSNIAN MUSLIM GROUPNESS ........................ 78

4-1: Bosnian Muslims as a Distinct Group of the Bosnian Pot of People ................... 78

4-2-1: Significant Early History of Bosnia and Its People ........................................ 85

4-3: Bosnia's Ottoman Legacy............................................................................. 88

4-4: The Rise of Independent Bosnian Muslim Elites ......................................... 90

V: THE THREE PILLARS OF BOSNIAN MUSLIM NATIONALISM .................. 99

5-1: Integrity of $\mathrm{BiH}$ as a Territory and an Entity ............................................ 101

5-2: Islamic Foundation of Bosnian Muslims as a Separate Group ......................... 112

5-3: Theological Roots of Official Bosnian Islam ................................................ 115

5-4: Four Phases of IZBiH Interactions with the non-Islamic State ........................ 129

5-5: Bosniaks, Bosnian Language or Language of Bosnia and Herzegovina ............ 143

VI: MAPPING THE BOSNIAN MUSLIM DIASPORA SAMPLE ....................... 158

6-1: Materials and Procedure ............................................................................... 158

6-2: Defining Diaspora and Population Sample.................................................... 163

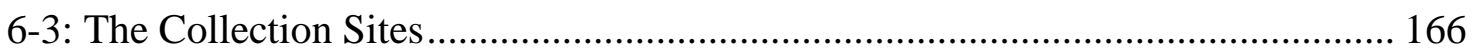

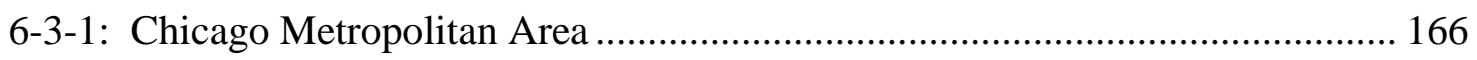

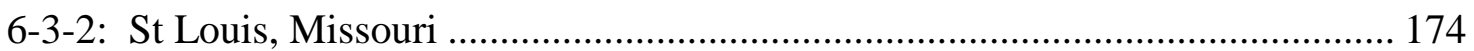

6-3-3: New York Metropolitan Area.................................................................... 178

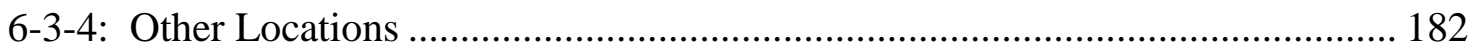


VII: ANALYSIS OF U.S BOSNIAN MUSLIM DIASPORA SURVEY DATA: FREQUENCIES AND DISTRIBUTIONS .......................................................... 184

7.1: Discussion on Operationalization and Level of Analysis ................................. 184

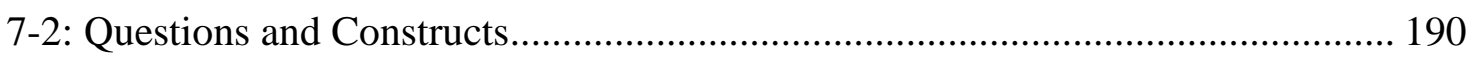

7-3: Representativeness of This Sample of the Bosnian Muslim Population ............ 194

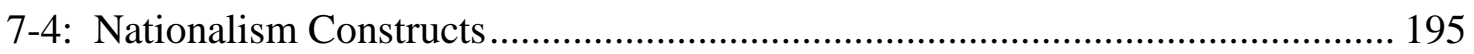

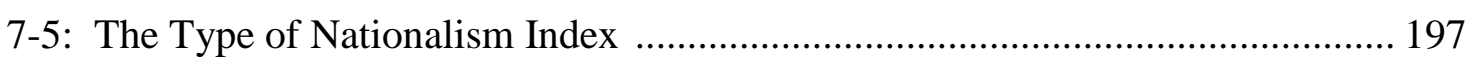

7-7: Nationalism Type - Frequencies of Fourteen Items ...................................... 199

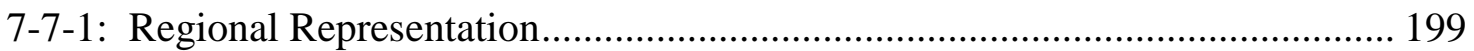

7-7-2: Regionalism and its Manifestations Among Participants.............................. 203

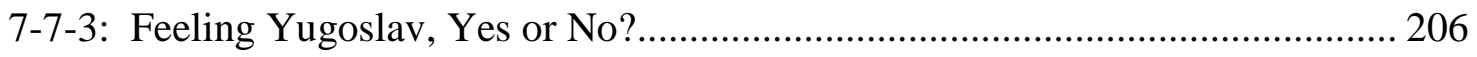

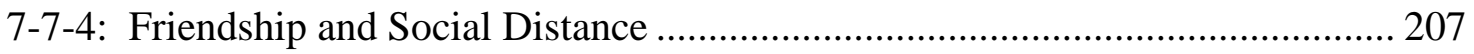

7-7-5: Participant Attitudes Toward Traits of the Group ......................................... 212

7-7-6: Bosnian Muslims as an Endogamous Group................................................ 214

7-7-7: Participants' Perceptions about Bosnian Muslim Culture.............................. 220

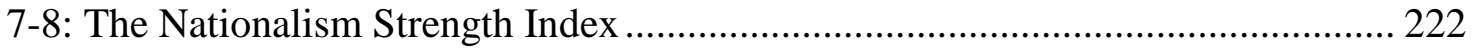

7-9: Frequencies of Nationalism Strength Index Items....................................... 223

7-9-1: Attitudes Towards Fellow Slav Muslims Outside of BiH............................ 223

7-9-2: Regional and Schooling Frequencies ......................................................... 224

7-9-3: Culture and Ties to the Homeland .................................................................. 226

7-9-4: Long-Distance Imagination and Engagement ........................................... 228

7-9-5: Bosnian Language and Intensity of Nationalism....................................... 230

7-10: Controlled Variables Distribution and Frequencies..................................... 232

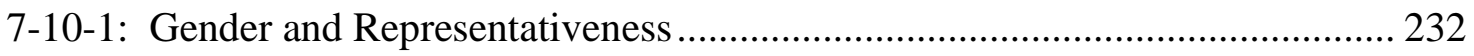

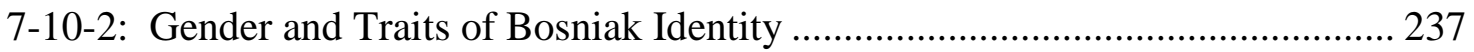

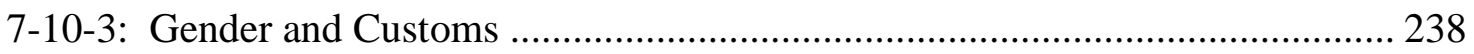

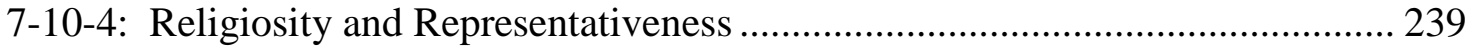

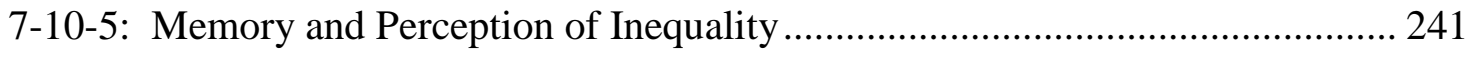

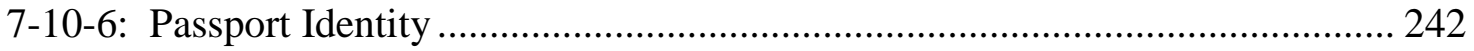

7-10-7: Other Relevant Data Frequencies ........................................................ 243

7-11: Limitations of Data and Study ............................................................... 244

VIII: RESULTS OF THE TEST OF INTERACTIONS BETWEEN NATIONALISM AND DESIRED SALIENT IDENTITY .................................. 248

8-1: Lower Level Analysis ............................................................................. 248

8-1-1: Correlations of Nationalism Strength with Desired Identity, Previous Identity, and Controlled Variables Success............................................................ 249

8-1-2: Correlations between Social Status Categories and Nationalism Strength ...... 249

8-1-3: Correlations between Previous Identity and Nationalism Strength................. 250 
8-1-4: Correlations of Social Status and Previous Identity with Nationalism

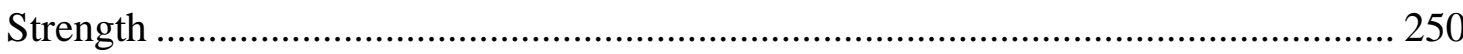

8-1-5: Correlations of Level of Education and Nationalism Strength ....................... 251

8-1-6: Correlations of Nationalism Strength and Age of Respondents...................... 252

8-1-7: Comparison of Nationalism Strength Across Gender Groups ....................... 254

8-1-8: Strength of Nationalism for BiH Property Owners ..................................... 254

8-2: Types of Nationalism Correlations .................................................................. 256

8-2-1: Types of Nationalism Correlations with the Controlled Variable of Age....... 257

8-2-2: Correlations of Type of Nationalism with the Controlled Variable of Gender 258

8-2-3: Nationalism Type and Years of Schooling ................................................... 259

8-2-4: Correlations of House/Apartment Ownership in BiH with Type of

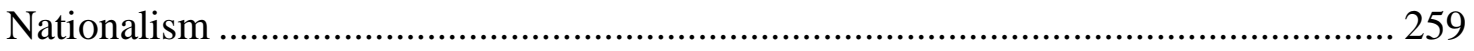

8-2-5: Correlation of Nationalism Type with the Feeling towards Previous and

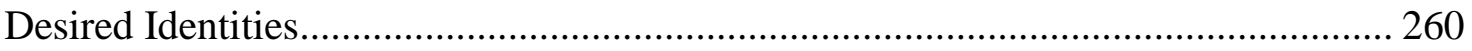

8-3: Multinomial Logistic Regression for Nationalism Strength and Nationalism

Type on Six Bosniak Identity Categories......................................................... 262

8-3-1: Parameter Estimates for SB Relative to VSB ............................................... 263

8-3-2: Parameter Estimates for WB Relative to VSB ............................................... 264

8-3-3: Parameter Estimates for OVSB Relative to VSB ......................................... 265

8-3-4: Parameter Estimates for OSB Relative to VSB.............................................. 268

8-3-5: Parameter Estimates for OWB Relative to VSB ......................................... 271

8-3-6: Discussion on Multinomial Regression for the Case of Bosniak Identity....... 272

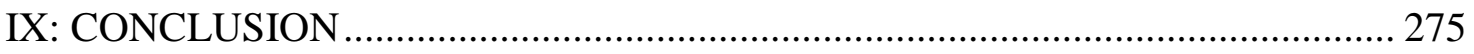

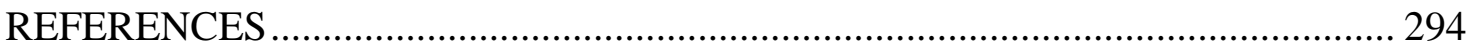

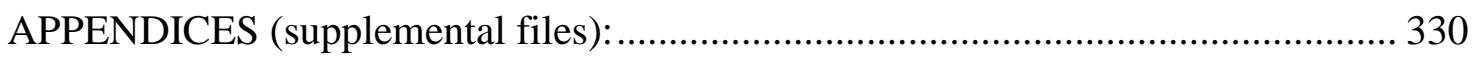

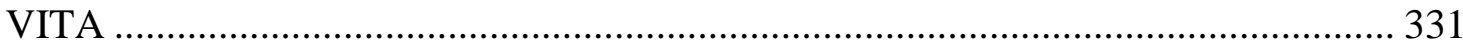




\section{LIST OF TABLES}

TABLE

PAGE

6.1 Respondents interactions with other Bosniaks \& homeland culture 164

7.1 Outcome Variable with Identity Categories

7.2 Case Processing Summary for Bosniak Identity Data

7.3 Feeling of Differences in Customs among BiH Regions .202

7.4 Association with Bosnia and Yugoslavia Among Regional Subgroups ........205

7.5 Frequencies of Bosnian Muslim Friends at Research Sites .211

7.6 Individual Ranking of Importance of Five Elements of Culture .221

7.7 Respondent's Place of Schooling .225

7.8 Gender Distributions among Different Types of Organizations .235

7.9 Respondents Connection with Homeland .237

7.10 Bosnian Muslim Population Sample’s Religiosity .239

8.1 Education among Sub-Categories of Population Sample..... .251

8.2 Nationalism Strength, Age Categories - ANOVA .252

8.3 Mean Differences for Nationalism Strength and Nationalism Type .255

8.4 Correlations among Different Categories of Bosniak Population Sample.....261

8.5 Model Fitting Information .263

8.6 Multinomial Logit for Five Categories of Bosniak Identity .266

8.7 Cross Tabulation for Gender and How Strongly Bosniak .269

8.8 Cross Tabulation for Gender and Respondent Nationality Choice 270

8.9 Nationalism-Strength-Based Hierarchy of Bosniak Identity Groups .272 
Appendix A: Table A.1. Nationalism Strength Frequencies .330

Appendix A: Table A.2. Nationalism Strength Index Composition ..............................330

Appendix B: Table B.1. Nationalism Type Frequencies...............................................330

Appendix B: Table B.2. Nationalism Type Index Composition

330 


\section{LIST OF FIGURES}

FIGURE

PAGE

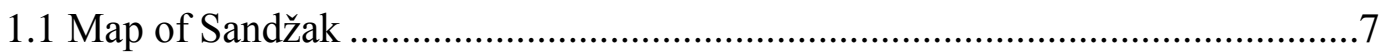

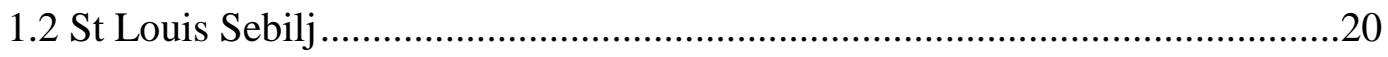

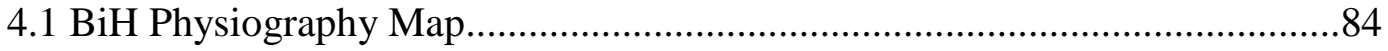

5.1 Bosnian Islamic Cultural Building in Chicago, without Signage ...................129

6.1 Frequency of Years When Participants Left Homeland ..............................162

6.2 Front page for Sabah from Sept. 27, 2013 ................................................177

7.1 Temporal Sequence of Three Stages of a Group ……......................................187

7.2 Nationalism and Salient Identity Model of Interactions ................................195

7.3 Entrance of Tampa Bay Bosnian Muslim Mosque, with Flags and Sign of

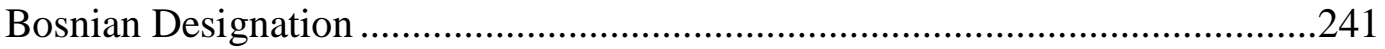

8.1 Correlation of Nationalism Strength with Age Groups ..................................253

8.2 Post-Estimation of Predicted Changes for Five DV Categories of Bosniak Identity Based on the Main IV of Nationalism Strength .....................................2273 


\section{I: INTRODUCTION}

Ever since its emergence as a phenomenon, nationalism in all its forms has been the context structured as the political process or mechanism for production of nations as the backdrop for new elites' desired salient identities. ${ }^{1}$ This structuring is done either by significantly altering or upgrading the previous identity (e.g., as in the recent case of modern Russia after the USSR, or that of the USSR after Tsarist Russia), or by creating a completely new identity (e.g., the cases of Israel, Turkey, Italy, Algeria, Eritrea, and postSoviet Central Asian states). As Ernest Gellner (1983) famously elaborated, "It is nationalism which engenders nations and not the other way around" (p. 54). ${ }^{2}$ The societal changes and identity signifiers brought forward by nationalism are revealed not just through the usual change of name of a group and its members - an act which by itself is important enough to be accounted for by researchers ${ }^{3}-$ but also through changes of context, circumstances, and the roles each member of those groups claiming nationhood

\footnotetext{
${ }^{1}$ The term "elites" is used conditionally here because as Smith (2009, p.15) noted, the key circles are not necessarily elite circles. Perhaps more fitting would be the term "work group" used by Wilfred Bion in his seminal work on groups. "Bion's central thought is that in every group two subgroups are present: the 'work group' and the 'basic assumption group'" (Rioch, 1970, in Burke et al. 2009, p.467). For this work the "basic assumption group" is the so called "common people;" while the "work group" is those who in political science are usually referred to as "elites." This term is usually meant to denote those selected individuals who have the ability to mobilize people either by their charisma, institutional position, or prominence of some kind among members of the group. In this paper "elites" will be used interchangeably with the term "work group." The approach to nationalism as a form of groupness was also suggested by Brubaker (2006) in his evaluation of the phenomenon.

${ }^{2}$ Others, like Tomka (1995), suggested a similar direction of action where identity emerges as the result of social conditions experienced through the emergence of a nation, as when he states that a "nation offers itself as the dominant institution for formulating cultural identities" (p.29).

${ }^{3}$ For Shills (1982, p.19) a name signifies the crucial aspect of interactions between an individual and his/her society. The perception of an individual member's belonging to a society is evoked through selfnaming, which signals that membership does not entail a demand for any particular action, and that a common name provides a sense of a state of being and essential quality of self-perception. Similarly, Smith (2002) considers a name as a fundamental sign of a community "by which [members] distinguish themselves and summarize their 'essence' to themselves" (p.23) so that "the name summons up images of the distinctive traits and characteristics of a community in the minds and imaginations of its participants and outsiders" (p.24).
} 
has, or may perform. Although this research will not observe all those aspects of change, it will show that changes of context and circumstances create a new reality which so significantly shapes the societal and individual awareness of self and the signifiers for identification, that they alone warrant the claim that a new salient identity emerges after the experience of nationalism. The same process occurred during the dissolution of the former Yugoslavia with various nationalism projects and the subsequent formation of allnew states and fitting salient identities. ${ }^{4}$ The ongoing condition of that process invites social scientists to observe the two processes, nationalism and the emergence of the desired identity, and draw conclusions from it. This work will attempt to point to their interactions and show, empirically and historically, that nationalism is a process which comes before new salient identity for a population. Nationalism works through a combination of roles which serve to encourage new identity or identity anew, as producer, propagator, facilitator, encourager or backdrop, in short as an episodic context that demands some previous identity to change. It is important to note here that nationalism and the struggle that it often causes can produce multiple and different, previously non-existent identities. ${ }^{5}$ This inquiry, however, is primarily concerned with the one identity which nationalism desires to be particularly salient for the population.

\footnotetext{
${ }^{4}$ Although in all cases promoters of the newest identity make claims that they are only renewing an ancient identity, Anderson (1991, p.5) correctly noted that for researchers, nation [and its identity] is definitely a modern historic phenomenon, an idea which is commonly disputed by the nationalist, who perceives it as an antiquity, that was always there. The evidence offers is usually the presence of the same name throughout history. However, as primordialist Connor (1994, p.94) reminds us, even though some term or name might have been noted in the past it does not mean it has always actually represented the same thing. The most obvious example of this is the name Greece chose for itself to symbolize continuity with antiquity, although the Greece of today has very little to do with the Greece of the past; and Greekness, even less so.

${ }^{5}$ For example, in her work on IR methodology D'Costa (2006) notes how survivors of a war of national liberation afterwards have "created new identities, with suffering as their hidden narratives, and resistance
} 
Researchers point out that the sense of salient identity is the basis for collective action (see Tajfel and Turner, 1997; van Zomeren et al., 2004), and as such, it is the main drawing force of nationalism for the essentialists. ${ }^{6}$ In that way they imply two things: that nationalism is a form of collective action with willing participants (Barreto, 2012), and that the group's identity remains more or less the same after the whole process of nationalism is over and (if) a desired goal, often seen as self-rule, is achieved. Guiding propositions for this inquiry, however, suggest that, even when there is some prior and formed social identity which undergoes nationalism, it is transformed into a new, or significantly upgraded, one. ${ }^{7}$ The process of nationalism is usually seen as modern and separate from the concept of a nation (Geertz, 1963; Smith, 2009; Gellner, 1983; Connor, 1994; Anderson, 1998), ${ }^{8}$ while identity is seen as a political and social category, "a sort of public good produced by [nationalism] and available to everyone, as 'public

and survival as their primary narratives" (p.149) and in such a way reveals the important fact that nationalism and its accompanying struggle produces multiple previously non-existent identities. In the case of Muslims from Bosnia, previously nonexistent but still often invoked identities for example, include "Babini" (a completely new identity signifying those from Western Bosnia who were loyal to Fikret Abdić in the Bosnian Muslims" fratricidal war); or the identity of "Sandžaklija", elevated into a new meaning to signify those Muslims who are from Sandžak as non-Bosnian Muslims, whose behavior is often explained by such identity, as opposed to "real" Bosnian Muslims. For example, in an interview the Bosniak representative in the BiH Presidency, Bakir Izetbegović, explains why he never went to officially visit Sandžak, "People from Sandžak are hot-blooded. They run ahead of themselves, and this is not good in politics," implicitly differentiating them from the Muslims of BiH (for more, see MTV Igman Pazarić 2015). [All translations are mine unless otherwise specified.]

6 "The essentialism inheres not in the description of identity but in the attempt to derive the practice from the identity - we do this because we are this" (Michaels, 1992:61n, as mentioned by Brubaker, 2006, p.213).

${ }^{7}$ Significantly upgraded identity may be, and often is, sufficient to be considered as a new identity. However, evaluating how much of such an upgrade is enough to consider an identity as new will not be done here.

${ }^{8}$ Historian Huns Kohn notes that the political doctrine of sovereignty is the main factor which makes nationalism modern. For Kohn "in the later Middle Ages the word nation often had no political content whatever, but the revolutions of the XVII century awakened the masses to political and social activism, with the result that the nation came generally to mean the whole political organization" (as mentioned by Snyder 1977, p.28-9). 
pronouncement of status" (Fominaya 2010, p.397). ${ }^{9}$ Therefore, when identity is observed, it is seen as an aggregate of individual and societal responses and interactions. ${ }^{10}$ Because "scholars take identities both as things to be explained and things that have explanatory force"11 (Fernon, 1999), it is hard not only to account for its effects, but also to determine on what side of actions "identity" is, independent or dependent. For that reason, in an exploratory study like this, where identity is treated as an outcome, it is important for the researcher to provide clearer possible definitions of the terms for the study, and to hope that it can produce what Umberto Eco would call "an ideal reader" who will understand the definitions and be able to interpret the study and its results. This inquiry builds upon the grounded theory method and definitions of identity and nationalism provided there. This exploratory research seeks to clarify the relationship between nationalism and identity and to suggest and test through a particular case study the proposal that in their interactions, a salient new desired identity is the dependent

\footnotetext{
${ }^{9}$ As Fominaya (2010, p.397) explained, identity as a product or as a process essentially points to two different aspects of the same phenomenon. Identity as a product is "a public good" that people recognize and respond to, while [as a process it] is the result of an intra-movement social process of identity reformatting, which occurs among the people as they interact with each other or with those outside of the group. Although certain elements of this inquiry will be dealing with the process aspect of Bosniak identity, the primary concern is whether the Bosniak identity as a new "public good" is being recognized as a viable "public good" to be acquired by the group. The primary process which shapes identity as a product here is the process of nationalism, as opposed to an identity, which can emerge out of a social movement. Intragroup deliberations about the exact meaning and traits of Bosniak identity will be addressed partly in the specific chapter that talks about Bosniak nationalism and identity.

${ }^{10}$ For example, Schuessler (2000) effectively explains with his definition of expressive choice that individuals often act "in order to express who they are" (p.5). So through interaction with a group, individuals find confirmation for their identity.

${ }^{11}$ For example, Miller sees that "nationhood is the crucially valid source of human identity" (Vincent, 2003, p.94), yet as Vincent points out, such a position causes ambiguity not only in terms of which social subnational group solidarities take preeminence at different times, but also, if Miller's position is taken as is, in terms of how we explain cases of within-the-nation separatisms.
} 
variable, while nationalism is the independent variable, and to report the results of that observation based on the data collected for this study.

The case study for this research involves observation of the contemporary Bosniak identity and its grounding nationalism, in order to determine whether that desired salient identity is likely to be acquired by the proposed population influenced by nationalism. Bosnian Muslim nationalism and Bosniak identity emerged as the result of various nationalism projects which caused the dissolution of the former Yugoslavia. ${ }^{12}$ Therefore, a new salient identity, under observation here, is being formed largely by the context of local events, as Ervin Goffman (1959) proposed to be the case with identities, in his seminal work on identity formation and identity acquisition.

Bosniak identity is now (re)claimed by those who used to be of Muslim nationality and spoke some of the local Slavic languages in the two former Yugoslavias (Ćerić, 1970). ${ }^{13}$ Therefore their name, Muslim, did not refer to their religious identity, but to the population's proposed ethnic nationality. It was an ambiguous nationality because even under Communism, when the group became officially recognized under that name, the boundaries of such a presupposed Muslim ethnicity were not clear. This was so

\footnotetext{
${ }^{12}$ Bosniaks are now living as a relative majority in BiH, Sandžak (see Figure 1.1), and in and around the town of Prizren in Kosovo, where they come mainly from smaller ethnic groups sometimes called Torbeši and Goranci, while they refer to themselves as Našenci (Na-shen-tzi).

${ }^{13}$ Salim Ćerić, a local Muslim "organic" intellectual, discussed the issue of the rise of national consciousness among Muslims in 1970, noting that the Muslim nation of Yugoslavia was composed of native Slavic people who emerged as a distinct group as the result of broader historical contingencies. So he writes that "five hundred years of antagonistic development within the opposed Islamic and Christian Slavic populations of our region brought about the creation of a separate nation here, the Muslim nation" (p.83). He further clarifies that "it is not extraordinary that there are confusions and dilemmas among today's Muslims about the further emancipation of national uniqueness of Muslims of the Serbo-Croatian tongue. Such confusions always arise among people who find themselves in critical moments of their life, when they need to make some decision that will significantly affect their destiny. Nations are not exempt from that" (p.85).
} 
because Muslims were not allowed to claim Bosnia and Herzegovina's $(\mathrm{BiH})^{14}$ history and cultural developments for themselves exclusively, so that the only recognized remaining boundary of their ethnicity was religion, which in turn was not favored by the Communists. ${ }^{15}$ Therefore, the Muslim nationality was in a constant state of paradox, where religion was accepted as the very basis of their groupness, and at the same time that religious basis was disapproved of in its essential form by the state structure. In such an atmosphere Bosnian Muslims as a group could not actualize their political ambitions and goals at the time in the early 1960s when Serbian and Croatian Communists began to foster their own nationalistic aspirations, despite the fact that Muslims were structurally ready for that step. Interestingly, even that previous Muslim identity was not chosen solely by them; ${ }^{16}$ rather, it was appointed to them by the powers at the time to signify their religion and possible (problematic) loyalty to the Ottoman Empire. ${ }^{17}$ The local

\footnotetext{
${ }^{14}$ The internationally recognized acronym for Bosnia and Herzegovina is "BiH", which will be used in this work as such.

${ }^{15}$ For the Communist vacillations over the so-called "Muslim question" and discussion of " $m$ " versus "M" in their Yugoslav designation, see Hoare 2013, pp.352-359.

${ }^{16}$ It is not uncommon that collective identity is sometimes first imposed on a group by outsiders, especially journalists in search of a shortcut term. A good contemporary example is the use of "Hispanics" in the U.S., as noted by Polletta and Jasper (2001, p. 285).

${ }^{17}$ For that reason Slavic Muslims of the former Yugoslavia were also called "Turks" or "Poturica" - as a derogatory term by their Christian neighbors. "Poturica" has a triple meaning: it refers to those who are Turkicized, but it could also mean those who offered themselves to the Turks; yet in either form and as a third meaning, it is an impure, therefore lower-than-Turk, designation. This name-calling is similarly done in other parts of the Balkans, as in Bulgaria, where local Slavic speaking Muslims are called "Pomak" (Bulgarian: Pomaklar) which sometimes is noted to mean "those who suffered" or "those who help [Turks]"; or in Macedonia, where those who call themselves Našenci or Pomaks are referred to by their Christian neighbors as "Torbesh" (those with bags), which purportedly means that they accepted Islam for a bag of money. What all these "meanings" of Pomak have in common is an implicitly impure designation (Myuhtar-May, 2014, p.108). For the majority of them, however, the term "Poturica" is still widely used in the former Yugoslavia. The most famous use of this term is in a medieval Serbian-Montenegrin epic poem "Mountain Wreath," in a section referred to as "Istraga Poturica" (The Inquisition of the Turkicized), in which the Montenegrin poet-king Petar Petrovic Njegos calls for every Montenegrin, on a Christmas Day
} 
Figure 1.1: Map of Sandžak (Source: Le Monde diplomatique, 2008)

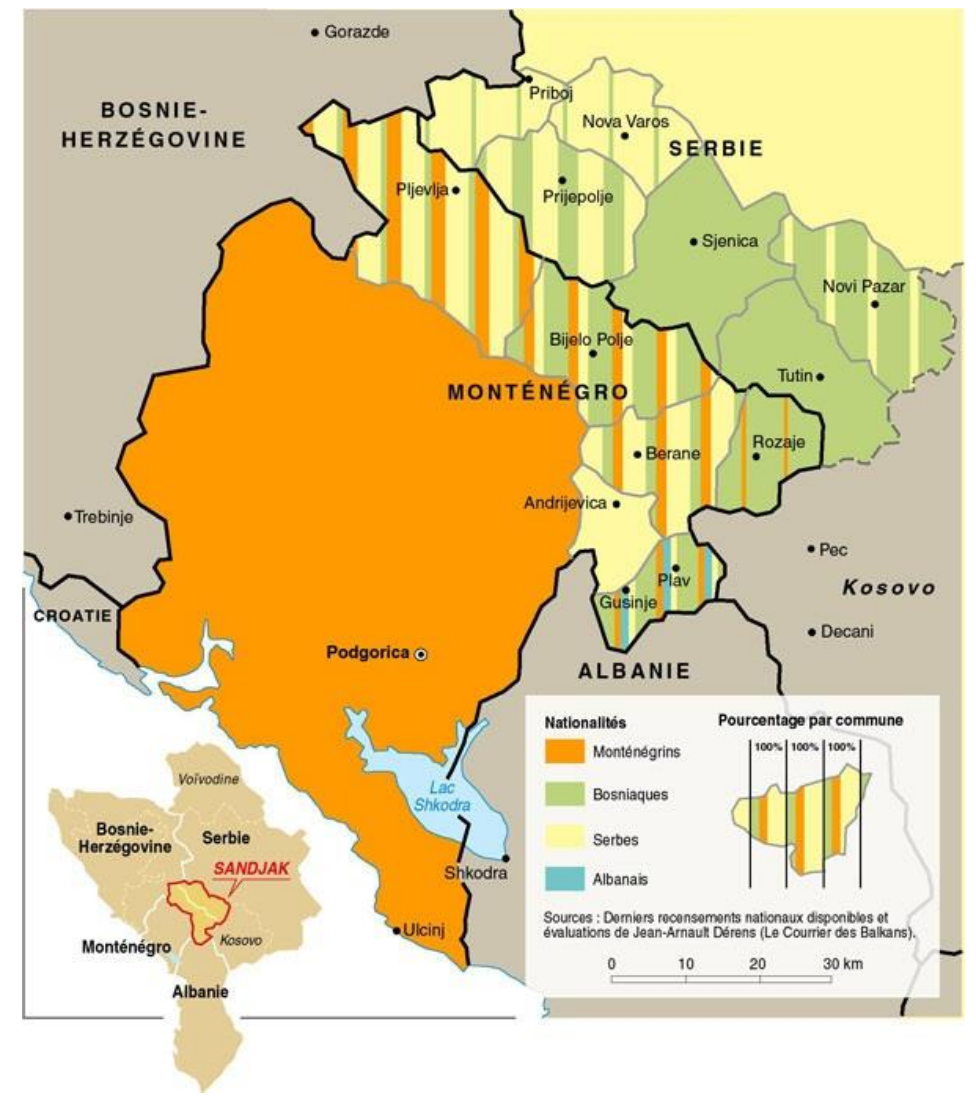

Slavic Muslim population, however, mostly accepted the name "Muslim" as their own designation, in an effort to maintain diacritic boundaries from other neighboring Slavic groups which had developed their own national programs earlier. ${ }^{18}$ Those Slavicspeaking Muslims lived throughout the central and southern parts of Yugoslavia, while a

in the early 1700s, to look for those who converted to Islam and to execute them, even if it is their sister. Several Bosniak authors argued that the poem was the ideological precursor of the latest Bosnian genocide. Sells (1996) notes that one of Tito's Partisan colleagues and a famous local chronicler of the events of WWII in Yugoslavia, Milovan Djilas, argued that the poem with its "Inquisition of the Turkicized indicates a 'process' rather than a single "event"' (p.41) to signal the possibility that the process of inquisition could continue, as it did in the 1990s. This will be discussed further in the chapter on Bosnian Muslim nationalism.

${ }^{18}$ Sekulic et al. (1994, p.84) note "the 1971 [Yugoslav] census was the first to allow "Moslem" as a nationality, and many Moslem Bosnians switched from the "Yugoslav" to the "Moslem" category in 1971," to avoid being identified with the two other dominant groups, Serbs and Croats. 
majority of them still live in $\mathrm{BiH}$, and that is the reason why they are often referred to in the literature and in everyday discourse as Bosnian Muslims. However, this is also a new and previously not well-known or used category, which resulted from their Yugoslavwar-time effort to differentiate themselves from the larger body of world Muslims. Hence, they went through three steps of signification, from the nationality category of "Muslim" in the former Yugoslavia, to "Bosnian Muslims" at the outset of the Bosnian war, and finally to "Bosniak" which emerged during the war and has been emphasized since. $^{19}$

Therefore, this is a case study of an autochthonous Muslim population going through the full process of nationalism, which thus far has been largely absent among world Muslim peoples, ${ }^{20}$ excluding Turkey. However, the Turkish case represents the situation that Anderson (1991) calls "official nationalism," which he defines as "stretching the short, tight, skin of the nation over the [remaining] body of the empire" (p.86), and as such, it is very different from the vernacular type of nationalism of Bosnian Muslims. The Turkish experience of nationalism took a particularly aggressive form, imposed directly from the top of the then-newly-emerging nationalistic state, and the

\footnotetext{
${ }^{19}$ On December 22, 1992 some 300 Muslim intellectuals attended a Congress in the city of Sarajevo when it was under siege, and (re)introduced the Bosniak identity. A good example of their ambivalence about the national name is evident in the introduction of their resolution where all three names are used interchangeably, spelled differently than presently: "Since the 1928 Congress of the Moslems in Sarajevo, the Moslem people have gone through a stormy period of their history ... While judging that period and that year, and at the same time, remembering the dignified past of the Bosnian-Moslem (Boshnak) people, their cultural heritage and spirituality - the Bosnian-Moslem society in Bosnia and Herzegovina in the present war conditions, and its development in the near future, at their Congress in Sarajevo on December 22, 1992, have passed the following ..." (my emphasis) (Kongres Bosnanskomuslimanskih Intelektualaca 1992, p.186).

${ }^{20}$ As Massad (2001) also explained we should "understand their anticolonial nationalism as a strategic essentialism to fight colonial power, [and not as] nationalism for an absolute essence" (p. 277).
} 
subsequent invention of identity was mainly of an official and political nature, to borrow the convenient distinction of nationalism style of Hobsbawm (1992, p. 263). As Ozkan (2012) states, "the notion of common Turkish vatan was deployed to override differences within the society" (p.4), and such a notion could only be promoted from the top of the state. The experience of nationalism for Bosnian Muslims and the project of Bosniak identity, however, came in response to aggressive Serbian and Croatian essentialist nationalisms in the form of a remedial (re)action, as suggested by Brubaker (1996), and it developed without a national state, yet with clear political consciousness. Since the Serbian and Croatian nationalisms were primarily constructed based on the cultural distinctiveness of the "entropy resistant traits" (Gellner, 2006, pp.63-5) of religious differences, the Bosnian Muslim nationalism came as "a reaction of people who feel culturally disadvantaged" (Plamenatz, 1976) by those two groups, and as such it creates a somewhat strange constellation which merges the two ultimately opposing forces of religion and nationalism. ${ }^{21}$ As such, the case of Bosniak nationalism and the identity it might have produced, also represents a different strand of nationalism from the Turkish model, which strongly deemphasized religion, ${ }^{22}$ and this observation of it could potentially be important for the other cases in the Muslim world without strongly

\footnotetext{
${ }^{21}$ However, this merger is not as opposed to religion as were the initial European nationalism projects. Gellner (2006) correctly observes that Bosnian Muslims had secured "the right to describe themselves as Muslims when filling in the 'nationality' slot on the census. That did not mean that they were still believing and practicing Muslims, but rather, to be a Bosnian Muslim you need not believe that 'there is no God but God and Muhamed is his Prophet', but you do need to have lost that faith" (p.70), since faith for them had been mostly transformed into culture, while religion survived mainly through deeply buried local urf-based practices, as is well described by Stulanovic (2002).

${ }^{22}$ In fact, if we are to compare, Bosniak nationalism is more similar to Kurdish nationalism, which Al (2014) notes is being "moderated" by competing Turkish nationalism (pp.15-6) and where Kurds are being principally perceived as "Turks-to-be" (p.11). In the case of Bosniak nationalism, it is in part being "moderated" by Serbian and Croatian nationalisms, and Bosniaks are being principally perceived as Serbsto-be or Croats-to-be by these respective nationalism projects.
} 
developed national states where the masses increasingly demand political self-rule and assume the new identity of citizens. The case of Bosnian Muslims presents itself as a good opportunity to examine how the process of nationalism develops in the absence of a national state, and what kind of identity may emerge from that process.

It is often noted that the main challenge for the discipline of social science to justify itself as a "science" is the lack of experiments. The case of the development of Bosniak identity provides social science with a unique historical opportunity to observe a social experiment of identity formation and acquisition as it unfolds. Since this process is ongoing, the Bosniak case provides a very good opportunity to observe "when identification becomes thick with meaning [which can then] serve as a rule of thumb that structures a wide range of social activities" (Hale, 2004, p.481) needed for a modern nation to be regarded as such and for the proposed members of the nation to ascribe to themselves a distinct shared identity. We cannot go back in social science to the premodern era and observe when the "peasant" became a "Frenchman," 23 so now we can try either to retrace previous processes (Beaune 1991, as noted by Hale, 2004), or to catch up with ongoing nationalisms and development of identity projects. The Bosniak identity project is a contemporary, ongoing case that can provide clear evidence of where and how a modern nation and identity emerges.

It is very important to note that this observation of the emergence of a new salient identity in the case of Muslims in Bosnia, does not imply that they are a newly settled

\footnotetext{
${ }^{23}$ The frequently mentioned title of Weber's (1976) book, Peasants into Frenchman, was often used to signal the direction of action between nationalism and identity.
} 
group in the region that uses nationalism to incorporate itself in the territory, or that the people who are members of this group just "popped up" in the Balkans. Far from that! People referred to as Muslims in Yugoslavia are part of the Balkan tapestry of people, and they have been living there for as long as any other Balkan group. ${ }^{24}$ They were a distinct local autochthonous group of people before they were a nation. ${ }^{25}$ Furthermore, suggestions that they are not autochthonous people of the Balkans have serious implications in the local settings, and could be - and were - used to justify policies of ethnic cleansing and genocide ${ }^{26}$ perpetrated against Muslims in the Balkans several times in the previous century. The cases of Srebrenica, ${ }^{27}$ Prijedor, ${ }^{28}$ Lašva Valley, ${ }^{29}$ and many

\footnotetext{
${ }^{24}$ Although they eventually accepted Islam, and have lived as Muslims among other peoples of the Balkans since the fourteenth century (see Küçükcan, 1999).

${ }^{25}$ There were suggestions and discussions of exactly what type of group they were before they reached the current stage of nationhood, and whether they were their own separate ethnic group, or their own ethnie; however, their separate and distinct groupness was undisputed. For example, see footnote 13 in Ćerić
} (1970).

${ }^{26}$ For an interesting discussion about the legal differences between these two types of war crimes - where ethnic cleansing is seen as an attempt to primarily eradicate a particular population from a certain territory, while genocide is seen as an attempt to destroy it - see Schabas (2009, especially pp.221-235). Although the first often leads to the second, I would argue that ethnic cleansing even more signals rejection of the targeted population - in this case, Bosnian Muslims -- as native inhabitants of the territory. As is obvious from many instances of what Bergholz (2013) calls signs of "sudden nationhood", whenever disputes were interpreted in ethnic terms, Muslims were referred to as "Turks" outsiders, non-natives, while Serbian or Croat actors in those disputes would be called "Četniks" or "Ustašas," which essentially were not such derogatory terms and certainly as terms do not signal non-nativeness. In fact both are often revered as ultimate Serbs, or ultimate Croats, and they are seen by some as a source of pride, not shame.

\footnotetext{
${ }^{27}$ The Srebrenica genocide is the most well-known case and symbol of the Bosnian Muslim Golgotha (for more see ICTY, 2015). After the fall of Srebrenica, a YouTube video clip emerged with Serbian General Mladic congratulating Serbs on their victory in "Serbian Srebrenica" in which he says that "the time finally has come to execute revenge on the Turks" (see TrustSRB, 2009), to show that local Muslims were not natives of the town, while Serbs were. Interestingly, the YouTube channel TrustSRB, which hosts that video clip, also contains much white supremacist' propaganda material, and Mladic's video remains as the most viewed with some 147,000 views.

${ }^{28}$ Genocide in Prijedor started on May 23, 1992, and continued until all Muslim residents, about $44 \%$ of the pre-war population of the town and the surrounding areas, were killed, expelled or disappeared. Some of those missing are now being found in mass grave sites like the one in the village of Tomašica, in the municipality of Prijedor, where investigators discovered remains of more than 370 persons (for more on the Tomšica case, see: Orie, 2015). Near Prijedor the concentration camps of Omaraska and Keraterm were
} 
other local places of carnage, are just the latest episodes in those attempts to eliminate them from the Balkans.

Rather, this inquiry looks at an existing group of people that is emerging into a nation as a new form of grouping resulting from a loosening of previous interdependencies with a larger unit. When that loosening of interdependence happened as the consequence of the breakup of the former Yugoslavia, and previous forms of living unfroze, Muslims in Bosnia were attentive and open to new ideas and changes. Nationalism as a form of episodic groupness particularly facilitates change or restructuring of an identity. So the Muslims of the former Yugoslavia are the same people who were living on their land for centuries and they are now at the stage of forming a new national consciousness and identity, which is often an omitted point in the works on Muslims in the Balkans. ${ }^{30}$ This is similar to the observation of the moments when native peoples inhabiting Ruritania become and gain consciousness as Ruritanians, to use Gellner's (2006, pp.57-61) famous fable in which he described how the process of also eventually exposed. One of many accounts of the treatment of the Muslims kept in those camps states: "Aside from the beatings, the guards humiliated the detainees. On one occasion, military policemen ordered the inmates to stand in a circle and raise their hands showing three fingers, after which they had to drop to the ground and say: "I am kissing this Serbian soil. I'm a Serb bastard. This is Serbian land" (Hall 2013, p.65).

${ }^{29}$ Mojzes (2011) notes that "the Lašva Valley ethnic cleansing practically eliminated the Bosniaks from this area in central Bosnia. Particularly dreadful was the Ahmići massacre during which HVO [Croatian] forces killed as many as 120 Bosniaks - ranging in age from 96 years old to three months old - and destroyed their homes. Some were burnt alive, but most were shot at point blank range" (p.174). On the same page Mojzes notes that about ten thousand people were either killed or expelled from their homes in that valley in a Croatian attempt to ethnically cleanse the area of Bosnian Muslims.

${ }^{30}$ One of the many repugnant examples that first comes to mind is Pranger's (2011) paper "Milosevic and Islamization Factors," in which he is trying to suggest that the Serbian leader Milošević had some "biggerthan-life" messianic role not only to save Bosnian and Albanian Muslims from the ills of their religion, but to save Europe and the global world order from "another rising tide of Islam" in the Balkans; the first presumably occurring with the Ottoman conquest. Similar ideas were expressed by the Norwegian terrorist Brevik (2001) in his manifesto, where he extensively, in more than sixty pages, quotes Serbian authors and sources which suggest the same ideas of Muslims as foreigners in the Balkans and Europe. 
nationalism works to form a separate and specific form of a group out of the people who were previously living in Megalomania without the consciousness of being Ruritanians. Analogously, the Muslims of Bosnia are a group that is in the stage of emergence into a new form of groupness, and they are comprised of people whose lives were already intertwined through various forms of social life and interactions, even though not necessarily as an independent nation. ${ }^{31}$

The data collection for this section of the study of Bosniak identity coincided with the first official national census in independent $\mathrm{BiH}$, held in 2013, where one of the census questions was about the national self-identification of the population. ${ }^{32}$ For the first time, one of the options to answer a census question permitted a person could declare him/herself a Bosniak, which is imagined as an evolved Bosnian Muslim national identification, and which is separate from the eponymic nationality of "Bosnian" which is available to potentially be shared by all ethnicities in $\mathrm{BiH}$.

Following Snyder (1977), who proposed approaching the subject by "clarification of its meaning not by definition but by description" (p.196), the two key concepts of nationalism and identity are described separately.

Nationalism is seen as a superimposed, elite-driven, ideological process that seeks to provide political fulfillment for a particular cultural group of people at the stage of

\footnotetext{
${ }^{31}$ Polletta and Jasper (2001, p. 289) noted that literature on social mobilization considers that such a situation warrants expectations of solidary behavior among people.

32 The census complemented and possibly intervened in this research, since data collection was done at the height of the campaign for the promotion of Bosniak identity via social media, newspapers and lectures, and presentations by various actors from $\mathrm{BiH}$ and the diaspora at the sites where data was collected.
} 
emergence. ${ }^{33}$ As an opportune process, nationalism creates a social context that demands a new or "upgraded" salient identity for members of a group, which becomes acquired by a population as the final outcome of the process if nationalism is successful. Furthermore, this work will rely throughout on Snyder's (1977) observation that "nationalism has two major senses: concrete (geographical, linguistic, political, social, economic, and cultural); and ideal (psychological)" (p.196). Therefore, nationalism may use a combination of all of those elements to fulfill its goal. As a force, it is usually employed by those who may be considered elites at the opportune time in the international arena, ${ }^{34}$ as a possible situational nationalism (Jenne \& Bieber 2014, p. 439).

In the life of any group, the stage of emergence is a very stressful time when norms are being tested, re-evaluated, and replaced, and when, as a result, the self-

\footnotetext{
${ }^{33}$ Emergence is the stage of a group's evolution when the circumstances in which the group exists are changing and the group is moving to another phase. When the uncertainty of such a situation becomes apparent to the individual members of a group, it causes anxiety among them. In that phase, a skillful "work group" may introduce changes to the population which might be more easily accepted, due to the innate human need for stability and structure. As argued by Bennis and Shepard (1956), such situations of upheaval are the time in the group's life when their readiness for change can be channeled by skillful leaders into a "barometric event" such as an outburst of nationalism, when difficult changes like those that deal with identity are possible. The authors further note that the French Revolution, Bolshevik Revolution, and the like are historical examples of significant social changes that occurred at a time of widespread emotional tension, accompanied by some form of anxiety (in Burke et al. 2009, p.451).

${ }^{34}$ Like democratic transitions, which are famously described as waves (Huntington, 1991), it may be said that nationalism also plays a major role in waves on the global stage of international relations as a precursor to democratic transitions. In fact, their concurrence is not only a recent phenomenon. Nationalism has been very closely related to the process of democratization almost since it first emerged at the time of the American and French Revolution. Additionally, similar to nationalism being seen here as an elite-driven process, democracy is closely tied to elites as it is also explained in terms of elites' transitional pack negotiations (O'Donnell \& Schmitter, 1986), with elites' competition during the transitions as a factor that increases the likelihood of transition to full democracy (Munck and Leff, 1997), and finally as elites' agreement about the only political game in town (Linz and Stepan, 1996). So could nationalism be seen as a prerequisite for the social conditions of democracy to work, and as one answer to the question "What conditions make democracy possible?" that Rustaw (1970, p.337) posted long ago? To tease out another point from the same work on transitions to democracy, perhaps nationalism, with its emphasis on a newly desired identity for the population, may be that circumstantial process that might have "forced, tricked, lured, or cajoled" (Rustaw, 1970, p. 345) non-democrats into democrats, by adjusting their beliefs through the process of rationalization or adaptation which are the essential aspects of any nationalism.
} 
understanding and identity of members of that group are often being strengthened, adapted, or completely changed. These changes are sometimes brought about in a gradual way, but at other times they are forced by war, or some other form of destruction or deconstruction of the social order. It is not easy to change or rearrange identity, since change is exactly what identity is trying to tame and slow.

One of the processes that suggests, encourages, and sometimes forces such change is nationalism as an "ideology of order," to use Jurgensmeyer's (1993) description. For him "secular nationalism, as an ideology of order, locates an individual within the universe. It ties her or him to a larger collectivity associated with a particular place and particular history [and such] nationalism, therefore, involves not only an attachment to a spirit of social order but also an act of submission to an ordering agent" (p.31-32). Order brings meaning to change and uncertainty, and through that process also brings about a new or upgraded salient identity. Like religion, nationalism also "contains images of grave disorder as well as tranquil order, holding out the hope that, despite appearances to the contrary, order will eventually triumph and disorder will be contained" (p.32). To recreate equilibrium, a new or upgraded salient identity is produced for the people engulfed in the process of nationalism to acquire, as the result of the rearrangements.

Perhaps the very reason man is a homo-politicus is that he is exposed to continuous internal-external tensions, where inside is order and outside is disorder. Analogously, within a nation, there is order, while outside there is disorder, and on the 
next level, within a state, there is hierarchy, while outside there is anarchy in the world. ${ }^{35}$ Such a constant "inside - order", "outside - disorder" tension seeks to be resolved by an individual and by a society. Identity is an instrumental aspect of that resolution. To step away from "methodological nationalism," as Chernillo (2007) describes it, rather than observing the relation between a nation state and identity, what is looked at here is the relation between the political society of a nation (apart from a state) and identity, where neither is taken for granted.

Identity is seen as "the set of meanings that define who one is when one is an occupant of a particular role in society, a member of a particular group, or claims particular characteristics that identify him or her as a unique person" (Burke and Stets 2009, p.3). As such it is obviously an external signifier that may be ascribed by an individual if he or she finds it salient. As Levy (2014) noted, ascribing identity is not a zero sum game, and in an everyday life situation, an individual is exposed to many possible identities. The concern here is how and why a new one, out of many possible identities, becomes salient in the political sphere for an individual to ascribe it to himself or herself. The proposal here is that nationalism is the main factor which makes the new desired identity salient and ascribed by the group members.

This research utilizes the grounded theory method and examines various theories and disciplines, taking many major works into account regardless of the publication

\footnotetext{
${ }^{35}$ Indeed, although nationalism seems to be a process and force which is primarily group-inwardly directed, it actually responds to two categories of demands, internal and external. Nationalism projects are especially sensitive to regional and global hegemonies of various kinds. Billig (2002) notes the same thing when he says that "nationalism is not an inward-looking ideology, like the pre-modern ethnocentric outlook. It is an international ideology with its own discourses [which address regional and global] hegemony" (p.10).
} 
year. ${ }^{36}$ A comprehensive examination is needed to show that both modern and primordial schools studying nationalism show to varying degrees that nationalism is about change and group emergence from one state to another, consistently over time. Such an approach is warranted because present-day case studies of nationalism and identity building, such as the case of Bosnian Muslims, have elements of different theoretical assumptions built in. Only by taking account of most of them will a more comprehensive picture of the relation between nationalism and the process of new salient identity construction become apparent.

This multidisciplinary approach is necessary, moreover, because the literature which deals with both nationalism and identity comes from various research fields and disciplines, including sociology, psychology, geography, religion, comparative politics and international relations. It will begin with an overview of the literature on the subject of nationalism and identity. The research then moves into an examination of the history of Bosnian Muslims and the origin of their nationalism. This approach will provide an opportunity to observe the early modern period of nationalistic sentiments among Bosniaks, which it will follow all the way up to the present time, to reveal the process of creating a new political identity for the Bosnian Muslim population. The examination of the relationship between nationalism and identity is done with a two-tier approach, using qualitative and quantitative components.

\footnotetext{
${ }^{36}$ Re-reading major seminal works is uncommon among today's political scientists who tend to gloss over, rather too quickly, those works on which the discipline is built, and rely on, sometimes, unreliable literature reviews done by others.
} 
The qualitative component involves participant observation of individual interactions among Bosniaks at multiple sites across the United States (U.S.), and an examination of the existing literature about Bosnian Muslim nationalism and Bosniak identity now available for ascription by the Muslim population from the former Yugoslavia. ${ }^{37}$ The quantitative component is discussed in a separate chapter and contains comparative statistical analyses of the survey data collected from people from the former Yugoslavia who were referred to as Muslim, at ten sites throughout the U.S. ${ }^{38}$ Although the U.S. section of the research provides us with important conclusions, this research is envisioned as just the first step in the investigation of the salience of Bosniak identity among former Yugoslav Muslim populations, while the next two important steps should be to replicate the research in their home environment, BiH and Sandžak, and in Turkey, the previous place of their mass emigration. ${ }^{39}$ Many Muslims from the former Yugoslavia, for various reasons, have lived in diasporic conditions for most of their time

\footnotetext{
${ }^{37} \mathrm{We}$ should note here that there are a few more groups besides the Muslims of $\mathrm{BiH}$ who were part of the Muslim nationality group in the former Yugoslavia, such as Albanians, Našenci (Goranci, Torbeši, Pomaci), Roma, Turks, and a small number of those who identify as Egyptians. The construction of the so-called Bosnian Muslim identity is also a somewhat new development, as it first appeared prominently in the press at the onset of the Bosnian war to describe the people involved in that war. Although it did not exist before as an identifier of Muslims of the former Yugoslavia, the term Bosnian Muslim has taken hold since then, and it has now become widely used by journalists, academics and even the domestic population to identify the group. These peoples of the former Yugoslavia converted to Islam mainly willingly and in stages, starting in 1352, while those in $\mathrm{BiH}$ were the last in that process, from 1463 until 1528, when the final parts of BiH were taken over by the Ottomans (Minkov 2004, p.29).

${ }^{38}$ The site selection will be further discussed in the chapter describing the data. The sites are Atlanta, GA; Chicago, IL; Saint Louis, MO; Detroit, MI; Grand Rapids, MI; Erie, PA; the New York Metropolitan area; Waterloo, IA; Lincoln, NE; and Elmwood, NJ.

${ }^{39}$ Each "diaspora" situation represents a different specific time in the post-Ottoman Yugoslav Muslim experience. In the first period, from the time of the First Balkan War of 1908 until the 1950s, Muslims from Yugoslavia emigrated mainly to Turkey. In the second period, after the 1950s, they began emigrating west, mostly to Germany, as guest workers, and eventually, as the result of the Balkan Wars in the 1990s, many of them ended up in the U.S. Many of those who are now living in BiH came to their present locations as the result of the Balkans'internal population movements from the time of the Ottoman demise until today. This consistent "diaspora" situation of Muslims from the former Yugoslavia will be further discussed in a separate chapter.
} 
as Muslims, since the 14th century. The latest large exodus from their homeland occurred during the wars of the dissolution of the former Yugoslavia, corresponding with the maturation of their nationalism. Such conditions necessitate research on their modern salient identity, including conditions of the population in the diaspora where their identity also persists. Brubaker (2005, p.12-13) argued that this should be done and that the diaspora be treated as a category of practice for the non-territorial form of essentialized belonging to the group, and as a non-territorial condition for the population, which in the case of Yugoslav and Bosnian Muslims has been more or less the constant condition during the 20th century.

The contemporary trans-state nature of Bosniak identity resulted from the 1990s $\mathrm{BiH}$ War, when around two million people, mostly Bosniaks, were expelled and settled all over the world. ${ }^{40}$ Since the U.S. is one of the countries with the most significant number of those $\mathrm{BiH}$ refugees, ${ }^{41}$ any study of the development and acquisition of the modern Bosniak identity should include them in the analysis. Additionally, as Kligman (1992, p.4) reminded us, when nation and state are seen as two different phenomena, as they should be seen, then the term or adjective "transnational" is a misnomer. Although identities as social constructions inevitably do contain some built-in elements of territoriality, we should be mindful that the contemporary conditions of impermanence of

\footnotetext{
${ }^{40}$ Kondylis (2010) notes 1.3 million people. Franz (2005) notes that more than two million people left $\mathrm{BiH}$ as a result of the war. A guestimate is that most of those refugees were Bosnian Muslims.

${ }^{41}$ According to the UNHCR 2000 Report, the United States has offered permanent refuge to 140,000 Bosnians (See UNCHR, 2000). The BiH Ministry of Human Rights and Refugees Department for Diaspora, however, notes that the number of Bosnians in the U.S. is between 250,000 and 300,000 (see Ministarstvo za ljudska prava i izbjeglice, 2014). Although some of them are Bosnian Croats and Serbs, the most significant number of them are Muslims.
} 
Figure 1.2: St Louis Sebilj

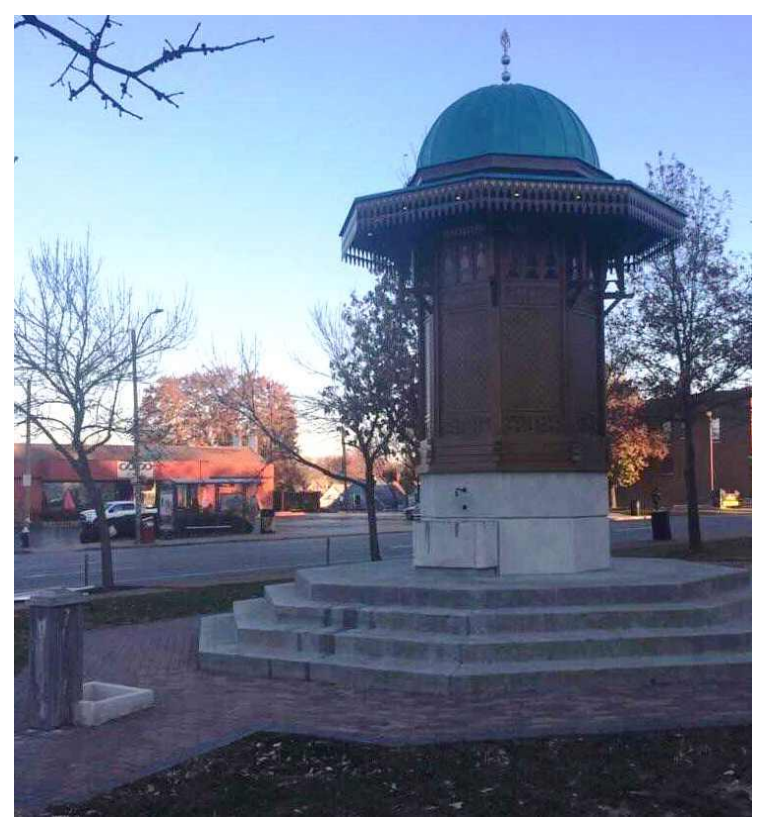

human dwellings are actually not new. Classic anthropological theory still talks about the stage when most humans were primarily nomads and herders moving around in search of food and safety. It seems that the same search is continuing now. Social units and their identities existed in those conditions of constant movements then as they do now. Only the liberal ideology which promulgates a state structure as the best possible lifestyle sometimes blinds us from considering identities outside of state and territorial boundaries. Furthermore, Appadurai (1995) pointed out that this (old) new reality of constant movement of people makes the condition of locality problematic if imagined only in terms of particular territory (p.192). Rather, some other space can become the "place," and that "locality" can be produced and reproduced in whichever "neighborhoods" ${ }^{42}$ where there is knowledge of how to do so, and wherever large enough communities of members of the particular group exist so that exercise of power conceived as "us" apart from "them" relations, can be implemented (1996, pp. 183-7). Therefore, the data for this research was not collected in places where Bosniak

\footnotetext{
${ }^{42}$ This term is used conditionally by Appadurai (1995), to refer to a group's preexisting social form in which its locality is more or less re-realized, whether it is a boat-refugee camp in Hamburg, Germany; Astoria, Queens, in New York, or the Bevo Mill neighborhood in Saint Louis, MO. All these sites are places with a significant number of Bosnian Muslims at present, and sometimes earlier, in the case of Germany.
} 
identity means the most to the group; ${ }^{43}$ it was collected in Appadurai-type (Bosniak) neighborhoods across the U.S.

However, at these sites, locality-as-a-place is not only reproduced by memoryimagination or posters, but also through the Bosnian-language newspapers regularly published and distributed there, through Bosnian-language radio programs, ${ }^{44}$ and through the physical representation of "back-home" identity, such as mosques with tall minarets and other artifacts. ${ }^{45}$ Moreover, others, like Cheah et al. (2013), have shown that cultural and ethnic identity remains prominent for Bosnians in such neighborhoods. ${ }^{46}$

Finally, by including the diaspora in the research design, this inquiry is to some extent avoiding the problem of essentialism of prototypical identity that is implicit in many studies of identity, as noted by Calhoun (1994). His criticism raises the important research design question of how and whether it is possible to observe salient group identities, as is usually done, by comparing them with some type of prototypical identity

${ }^{43}$ Although that could be contested as well, since even the so-called back-home localities are very much destroyed and the social and physical reconstructions of those localities is still an ongoing process and maybe even an unattainable goal (see Dahlman and O'Tuathail 2005). Therefore, any assumption that sees back-home locality as the place of and for Bosniak identity would be problematic.

${ }^{44}$ For examples of the local Bosnian Muslim media, see the Chapter 7.

${ }^{45}$ Anderson (1992) notes how those representations are now easier to imagine because images can travel with a person wherever he is. So "a Gastarbeiter sitting in his dingy little room in Stuttgart ... has on the wall a handsome Lufthansa travel poster of the Parthenon, ... The Parthenon, which he may well never ever have seen with his own eyes, is not a private family memory, but a mass-produced sign for a 'Greek identity' which only Stuttgart has encouraged him to assume." (p.14) For Bosniaks in the U.S. nowadays, the reproducing of a place with space with visual representations of identity includes not only posters and mosques with 107-foot tall minarets built like those "back home," but also numerous cafes and restaurants serving Bosnian "ćevape s kajmakom u somunu," and other artifacts such as Sebilj, on the corner of Gravois Avenue and Morganford Road in Saint Louis (see Hume 2015, pp.6-12). A sebilj is a replica of a Sarajevo Ottoman-style wooden fountain, often seen on posters and postcards from the city (see Figure 1.2).

${ }^{46}$ Although those authors measured salience of regional eponymic Bosnian identity incorrectly considering it as an ethnic identity, they concluded that "a refugee can simultaneously possess both U.S. cultural and ethnic identity salience" (Cheah et al. 2013, p.412). 
which is assumed as shared by the majority of members of a group. The ascription of such shared identity is a precondition for a member if he/she is to be able to effectively participate in the group's social life (Calhoun 1994, p.23). This is particularly problematic today, when any social group and category may and does exist in many places at the same time, and interacts with different ecologies, while the sense of shared identity persists among group members. ${ }^{47}$ Furthermore, this study is not taking the groupas-unitary for granted, but is instead accounting for possibilities of more or less groupness among members, as Brubaker (2004) urged.

The issue of prototype is also potentially detrimental in modern democracies which assume individual participation by all the people of the nation. Bosniak nationalism was conceived in a trans-situational (trans-state) milieu from the beginning, and without clearly defined goals, in contrast to contemporary Serbian and Croatian essentialist nationalisms, which are mainly structured around their own states and religions. ${ }^{48}$ The nationalism-desired Bosniak identity should also respond to many of those different situations the group finds itself in. ${ }^{49}$ Therefore, any research on it should

\footnotetext{
${ }^{47}$ To ensure that, the targeted group for the sample of the population in the data is people over forty years old or those who lived their constitutive years "back home" and who remember those conditions. More than $65 \%$ of the sample is over 40 years old, while $80 \%$ is older than 34 . Only $8.6 \%$ of the respondents are younger than 28 .

${ }^{48}$ Serbian nationalism has roots in the 1860's Russian minister Uvarov's ideas of Orthodox Christian religious universality (Perkins, 2004, p.292), while the Croatian version developed stretched between a Western model ideal and a Catholic response to Uvarov's ideas, and neither had room for any other religions in the state-driven "national" identity projects. For more, see Woolf (1996, pp. 20 - 22). Russians, however, did not universally and indisputably adopt that model with the centrality of Orthodox Christianity for their national project, and they are still contemplating it, especially after the experience with Communism. Merati (2015, Ch.2) notes that even Muslim claim a role in shaping of Russian identity. Therefore, the competing nationalisms in Russia are still fighting over "true" vs. "the best" Russian identity. For more, see the excellent overview of Russian nationalist options by Vera Tolz (1998).
} 
heed Calhoun's (1994) observations and try to avoid the prototypical and territorybounded identity approach, rather, accounting for the diaspora as part of a "wider identity landscape" (Jenne and Bieber, 2014, p.438). By observing the diaspora, this inquiry tries to observe the lowest common denominators that are absolutely essential in order for a social identity to remain cohesive and retain a definable structure before it dissolves into some amorphous shape incapable of serving as any particular identity in terms of individuals belonging to a specific group, and in terms of the group claiming that it is composed of identifiable individuals. ${ }^{50}$ Such an approach allows the concept of identity to envelop the empirical facts and enables one to explore implications of their interactions, as suggested by Barth (1998, p.10). Therefore, in this inquiry, comparisons are made among several identity categories in the diaspora population sample. ${ }^{51}$ Such an approach provides a better possibility of noting the essentials of Bosniak identity outside of its original context, and of noting the group's "criteria for determining membership and ways of signaling membership and exclusion" (Barth, 1998, p.15).

Since this dissertation is essentially a theoretical contribution to the field of nationalism in comparative politics, this discussion of nationalism and identity and their definitions should expand in the next two chapters to examine the foundations for this

\footnotetext{
${ }^{49}$ As Levitt (1998) showed, due to the contemporary nature of travel and communication, social remittances from the diaspora can now influence a homeland group culturally and politically, and so accounting for the diaspora situation of that group provides more depth to the study of its nationalism.

${ }^{50}$ Perhaps in the case of a diaspora group, that moment when things fall apart could be a tipping point when it is no longer the case of a transnational situation, but a new situation when the cascade of assimilation for an individual or a group becomes completely possible.

51 "In stable, self-contained communities, culture is often quite invisible, but when mobility and contextfree communication come to be the essence of social life, the culture in which one has been taught to communicate becomes the core of one's identity" (Gellner, 1997, p.60).
} 
theoretical probe. Since most cases of nationalism are the episodic events of groupness which came about as the result of historical contingencies (Brubaker, 2006, p.12), it is useful to observe the historical process of its development for each case under observation in order to ground its desired identity projects. That is why Chapter Four provides an historical account of the emergence and development of Bosnian Muslims as a group. Chapter Five provides an historical account of the Bosnian Muslim nationalism program and the major structural and political themes upon which it is based nowadays and which are built into its desired salient identity. Chapter Six describes in more detail the Bosnian Muslim diaspora population at the data collection sites, while Chapter Seven provides short discussion on the methodology behind the study, operationalization of the concepts, and frequencies of responses to the surveys collected. Chapter Eight reports the results of the statistical analysis of the test proposed to show the direction of interaction between Bosnian Muslim nationalism and desired Bosniak identity. This inquiry concludes with Chapter Nine, where major points and findings are summarized, and some implications of the findings are discussed. 


\section{II: ON NATIONALISM}

The subject of nationalism as a form of particularization has been studied by numerous scholars in various fields, and that makes the phenomenon difficult, if at all possible, to grasp and define. This is not a surprise, considering that nationalism entails two, at first glance, paradoxical sentiments, the sense of togetherness and the sense of distinctiveness, where the latter employs politics and uses the former to signify itself. All of the authors agree that nationalism entails an emphasis on feelings of togetherness, a "we-sentiment," 52 and a political consciousness that is organized around the idea of independence or some other form of political representation or self-rule. However, these political aspirations are fed and guided by selected norms, whether they come from religion, myths, symbolism, public culture, codes of communication, or other cultural constructions that signify distinctiveness, real or perceived as such. ${ }^{53}$

This is "normal" for at least two reasons. The sense of distinctiveness can be found only in a culture and not in biological structures, since all human beings are biologically the same. Secondly, it is usual that political processes use all elements of social interactions to achieve desired ends, nationalism especially, in its quest for political importance. Every people awakened to nationalism sees political self-determination as its goal, explains Woolf (1996, p.4). Therefore, the phenomenon of nationalism seems to be an intricate part of the process in which society turns from one form into another, whether

\footnotetext{
${ }^{52}$ Sociologists "hold that the one indispensable factor in the nation is the 'we-sentiment,' or the feeling of oneness" (Snyder 1954/1977, p.54).

${ }^{53}$ Constructions of, or emphasis on, the particular norms of distinctiveness, are often part of the power play, or social class codification through establishment of certain rules and hierarchies within the group under emergence. Therefore, right from the start groups are determined and arranged by that hierarchy which structures the differences, national groups more than other type of groups.
} 
tribe, ethnicity or ethnie, into nation. Sometimes this is related to the similar process of turning the old type of society of Gemeinschaft, into the new form, of Gesellschaft (Toennies, $1887 / 1988$, p.34). ${ }^{54}$

Since most scholars find history a relevant starting point in studies of nationalism, for any case study history is the most widely used approach to understanding the emergence of the concept, and it will be used in this case as well. Scholars observe the historical process of nation building through nationalism as deliberate actions of state (Weber 1977; Hobsbawm 1983), or an almost inevitable consequence of a particular approach and type of modernization (Deutch, Gellner, Smith), or as an elite-driven response to the changes in the circumstances in which people find themselves (Plamenatz 1976), or as maneuvering by the defeated old elites to a position where they are to be the main educators of a new prince (Foucault 2003).

Following Smith, studies of nationalism can be clustered into two approaches, primordial and modernist, while Smith's ethno-symbolist approach can be perceived as situated somewhere between these two. An examination of these three approaches to nationalism suggests that nationalism brings about the same change of context and causes the emergence of a specific form of groupness, although they differ when it comes to the degree of inertia. The first two are preoccupied with those elements that increase inertia,

\footnotetext{
${ }^{54}$ The distinction between the two forms noted by Toennies is indeed relevant for those interested in studies of nationalism, since it emphasizes the essential aspect of rationality that modern socio-political forms such as nations usually claim for themselves, as opposed to "feelings" which underscore pre-modern social forms. For Toennies (1887-1988) "there is contrast between a social order [of Gemeinschaft] which being based upon consensus of wills - rests on harmony and is developed and enabled by folkways, mores, and religion, and an order [of Gesellschaft] which - being based upon a union of rational will - rests on convention and agreement, is safeguarded by political legislation, and finds its ideological justification in public opinion" (p.223).
} 
which are usually codified through culture and cultural production, while the modernists primarily observe structural conditions which facilitate change in the form of groupness. Although the main concern of nationalism is an identity as a political construction, it is often difficult to separate the two; nevertheless, it is useful conceptually to keep the two apart and to observe relations between them. As suggested by the grounded theory approach guiding this inquiry, the following nationalism studies literature is treated as data, and the points in it relevant to this study are especially highlighted.

\section{2-1: Primordial Approach}

The factors on which the primordialists' observations are based are those cultural constructions which might have preceded the formation of modern states, which Geertz (1994) notes as assumed blood ties, race, language, region, religion, and custom. As Smith (1988) notes, primordialists draw from the teachings of Edward Shils and go back in history "to see how far its themes and forms were prefigured in earlier periods and how far a connection with earlier ethnic ties and sentiments can be established" (p.13).

In this process of going back, Shils (1982) proposes an "examination of those minimal activities, beliefs, relationships and institutions, which must be present in an aggregation of human beings" (p.8) as a basis for integration of societies in order to show the organic nature of people's organizing into social units of any kind, as a primordial community of a society (p.54) and eventually into a nation. Those are the fundamental elements of the primordial approach. It appears that Shils builds upon Rousseau's (17121778 [1978]) notions of the state of nature, in which man does not live in the state of fear, 
but in the state of ecological harmony with his surroundings and empathy for others (Durkheim [1858-1917] 1975, pp. 69-75). Out of that empathy come the first attempts at socialization, which then becomes a permanent need and serves as a basis for the formation of family, horde, clan, tribe, and ethnic group as a type of moral order which dictates the need of an individual for social identity. As an ethnic group increases its ecological footprint, Shils (1982) explains, those integral parts of society at the periphery of the organization tend to separate and go out on their own; but, even in their separation, smaller units which share genetic history and territory are still bounded by shared memories, beliefs and standards modified to accommodate new distinctive needs. For Shils the norms of primordialism remain with new, modern types of cooperative societies. Even within those larger cooperative societies, all of the constitutive units are still "interpreting each other and performing and exchanging services with each other within a common, bounded territory and possessing a common, all-inclusive authority which makes and enforces rules and suppresses or adjudicates conflicts" (p.54), and therefore ultimately act just like any other primordial unit. When those units begin to rise towards their own self-rule or increased territoriality, they form nations through the process of nationalism which entails, to various extents, a political consciousness of the desired goals. ${ }^{55}$

As is implicitly evident even in from this primordialist approach, the path to selfrule and separation from the "mother" proto unit requires that the process of nationalism

\footnotetext{
${ }^{55}$ It is very important to stress political consciousness as a distinct and apart from group consciousness. Connor (1994) notes that "the group consciousness to which (Weber) refers - that rather low level of ethnic solidarity that a segment of the ethnicity feels when confronted with a foreign element - need not be very important politically and comes closer to xenophobia (or fear) than to nationalism" (p.309).
} 
create fresh signifiers, which then serve as a basis for acceptance of the new "allinclusive authority" for the new unit to start perceiving itself as a separate group. ${ }^{56}$ Although Shils and other primordialists suggest that researchers should go back in the past to find the common primordial elements of a group upon which cohesiveness is built, he does not exclude that nation and nationalism itself are the new forms of groupness and a modern phenomenon. What is new, furthermore, for primordialists is also the construct of the modern state, which should be considered as separate from a nation (Geertz, Connor, and Smith), while the population of such states might have possessed prior forms of homogeneity (Connor, 1994). In fact, Smith (2009) points out that primordialists make two essential claims: that nations are perennial and natural, and should be studied as such, while states are not. Furthermore, for most of those authors, primordial norms upon which societies are established do not interact with states the same way across the globe. They somehow have a stronger effect in the East than in the West. In fact, Geertz, in his often-noted book (1963), said that these primordial notions

\footnotetext{
${ }^{56}$ A good example of such a separation of a group from its proto-unit is the case of the pre-Christians, whose roots were undisputedly Jewish. As Enslin (1956) explains, "the new religion, even before it has come to know itself as a new religion, had been pushed out of the parents' nest. The world into which it was forced was a new and strange one [and] its environment exerted a tremendous influence. Within a score of years [Christianity] had become a gentile cult. It adopted new concepts, took on a totally different character, borrowed from all with whom it came into contact, and through its extraordinary eclectic character was able to rival the older and more firmly established cults" (p. 147) effectively. During those early ages of "pre-Christianity" there arose a need to distinguish themselves from all other cults which emerged at the same time, with similar rites of baptizing, or sacred meal rituals, or a strong belief in salvation and a soon-to-come day of recompense (for more see Ehrman, 2003). So we can see how primordial factors, such as baptism previously practiced by a parent-group as well, but then abandoned, were used by the sub-unit in the process of establishing itself as a new group and for the creation of a subsequent new appropriate salient identity. But to make sure our example is understood in the right way, it should be noted that the case in point is not a case of nationalism; it is, rather, just an example of how a group can separate itself from a proto-unit using primordial norms. When it comes to religious communities, Smith (1988) explains it well when he states that "a community of the faithful may look like a proto-nation; but, as its purpose differs so fundamentally, so do its results. The mobilization of the religio-ethnic community in pre-modern eras, aims to restore the culture or territory of the community, or both; it is an ethnicism rather than ethnic nationalism" (p.168).
} 
somehow work especially well in those societies and states (in the global East and South), which are still undergoing a particular type of "modernizing" process. The nations which are restricted by the circumstances of modernization which demand changes are those where "primordialism often emerges and plays a role in the "parapolitical' spheres of society and the polity of state" (Geertz, 1963, p.127). ${ }^{57}$ In those situations, although a state might change and be new, the "primordial givens" among the population remain strong motivational and mobilizing factors, and the leaders of those new states need to account for them in order to attain exclusive legitimacy and reduce the population's inertia to change, while creating signifiers for a new desired salient identity for the polity. Modern (North-Western) nations, on the other hand, are not "bogged down" by the primordialist norms of their societies in the same way. This global discrepancy in terms of the populations of states in the world is an interesting proposal often furthered by primordialists. Nevertheless, even where those primordial studies and norms are at play, the aim of nationalism is still "a search for an identity, and a demand that that identity be publicly acknowledged as having import, a social association of the self as 'being somebody in the world"' (Geertz 1963, p.108), an identity which should serve as a springboard for modernity.

\footnotetext{
${ }^{57}$ Geertz (1963) notes "in modernizing societies, where the tradition of civil politics is weak and where the technical requirements for the effective welfare government are poorly understood, primordial attachments tend ... to be repeatedly, in some cases almost continually, proposed and widely acclaimed as preferred bases for the demarcation of autonomous political units" (p.31). Those states, but not all of them, are "abnormally susceptible" to primordial challenges which are strong forces of inertia to change. Connor (1994, p.40) is even more explicit about regional determinism when he notes that because of existing primordial norms among the population, the force of nationalism works differently in the new states of Africa and Asia.
} 
In a nut shell, this is the process of formation of social units and nations and the establishment of primordial norms that govern such programs in the studies of nationalism. Smith (1988, p.12) recapitulates the primordialists' approach towards nationalism by noting their assertion about the importance of the role of ethnicity as an extension of kinship, which is the natural conduit for their collectivity and survival. The basic organizing principles of all human associations are based on language, religion, race, ethnicity and territory. Since these principles predate complex political formations and provide a structure upon which they are built, they are considered to be primordial. As is evident by now, the primordial approach is primarily concerned with the higher degree of inertia to change; however, it does not completely close the door to change, either. And so for them, nationalism might be the new manifestation of political aspirations, while at the same time, there is nothing particularly modern about the claims of particularism made by nationalists, and those claims based on primordial givens are not going to disappear any time soon despite modern alterations.

But even if these notions are accepted in that manner, primordialists such as Connor (1994) warn of the danger of equating nationalism with loyalty to the state and note that political and ethnic borders often do not match (p.97). Therefore, modern nations emerge as very complex social formations rather than simple extensions of protosocieties. Since for Connor (1994) nation is primarily self-defined (p.103), the main requisite for the sense of togetherness "is subjective and consists of self-identification of people with a group - its past, its present, and, what is most important, its destiny" (p.4) and as such, nationalism "is unquestionably a very recent creation" (p.98). 
Abstractions such as destiny, memory, and commonality reappear in most of the other observations of nation and nationalism. All of them might easily be employed for upgrading or creating new signifiers for an identity. Quoting Max Weber's ideas about the importance of common descent and homogeneity (p.102), Connor (1994), for example, asserts that "a nation can only be made by a State if the population on which it works already possesses some homogeneity" (p.12), where individual psychological attachments to the "national consciousness" can travel through time and survive into modernity (p.106). The same Max Weber also established that it is difficult to quantify such abstract notions since they are open to different interpretations. This invites new methods in studies of nationalism. Smith, who also builds upon the link between the culture, politics and self-identification of a nation, provides one, which he proposes as a tie between the primordial and modernist schools, or a bridge between cultural and structural approaches. Since Smith is probably the most widely cited scholar of nationalism and considered the pillar of the ethno-symbolic approach, his concepts should be carefully analyzed. His approach might be especially interesting since his concept of ethnie as a community of ethnic groups, and as the precursor for a nation, may be applied to observations of many nations in the Balkans which all have emerged out of the local tapestry of people, although with a somewhat adjusted definition of nationalism's tie with groups identities and their continuity.

\section{2-2: Ethno-Symbolist Approach}

Most scholars agree that the process of nationalism is about turning subjects into citizens (of a nation), but Smith (1988) takes a more primordial route to that occurrence, 
which first happened in Western Europe as a result of the triple revolution, first triggered by the French Revolution (pp.130-6). For him the three revolutions provided for the possibility of the emergence of a nation as a polity: first, the revolution in division of labor, then the revolution in control of administration, and then the revolution in cultural co-ordination. Therefore, for Smith structural conditions caused by modernity provided a foundation for the emergence of a nation which is nested in some pre-political cultural container that he calls an ethnie. Although it is not very clear, nationalism seems to be the precursor of the politicizing of a group, a sort of dark-room where the correct salient identity of a citizen emerges as a prerequisite for a nation's evolution, and for a possible subsequent state. So, nationalism actually occurred as an "accident" of modernity and as an unintentional development, and its unintentional role as an organizing principle is "to place the community in its appropriate temporal and spatial context" (Smith, 2009, p.65) in the new world. For ethno-symbolists, as Gellner (1997, p.19) also explained, the same action between pre-existing cultural groups, which, at the opportune time provided by new structural conditions, rises to assert itself as a political entity of a nation, is continuously (re)occurring ever since it first happened as the spark that broke the perfect circle of power relations in the agrarian world. For Smith (1988) myths and memories constitute the essential elements of a nation, seen by him as a form of its organizational culture (p.2), as well as for its conceipt of ethnie, constituted as a community of ethnic group. Clearly, Smith builds on Shils' (1982) observations; however, he also notes that even "ethnicity is in the eye of the beholder, that it is all situational, a matter of time and context, shifting, fleeting, illusory" (Smith, 1988, p.2). Over time, many cultures and identities have changed, disappeared or transformed into something else due to different 
physical and ideological movements, and therefore we should observe those new social forms built upon the old ones, and their changes. As one of those ideological movements, Smith proposes that instead of going back so far in the past to understand nations and their nationalisms, we should rather look into "the state of cultural identity on the eve of its exposure to the new revolutionary forces in order to locate bases of its subsequent evolution into a fully-fledged nation" (1988, p.3). For Smith those forms are ethnies, which exist "between modern national units and sentiments of the collective cultural units" (p.14). Therefore, an ethnie, which is more than a proto-society but less than a nation, with its perennial manners of collectivity is the linchpin which ties together modernist and primordialist approaches. However, even Smith (1991) notes that it is possible to form nations without ethnies (p. 40-1). Finally, Smith (2009, p.15), like many others, also sees a nation as a project formed out of that previously shaped container of ethnies somewhere between the levels of ordinary peoples and key circles of the group. Hence, he also notes that a "bearer class" could "reshape an ideology to which [the population] is attracted" (p.15), which can surely prefigure a sense of identity. Therefore, we can infer that for Smith also, nationalism as a prime ideology able to materialize the elective affinity of the bearer class may be a mechanism for the configuration of a new identity that fits new circumstances in which an ethnie finds itself once it became a nation. $^{58}$

\footnotetext{
${ }^{58}$ Smith will agree that it is a new identity that has emerged, although it might have come as some form of continuity where a previous identity is more or less re-shaped to fit new circumstances; yet nationalism may still be seen as a mechanism and a facilitator of that transformation (at least) through the stage of emergence.
} 
In his later work, Smith (2009) shifts the entire emphasis from ties of culture with politics and reorganizes his definition of nation to mean "a named and self-defining human community whose members cultivate shared memories, symbols, myths, traditions and values, inhabit and are attached to historic territories or 'homelands', create and disseminate a distinctive culture, and observe shared customs and standardized laws" (p.29). As a constitutive element of nation, ethnie becomes (2009) "a named and selfdefined human community whose members possess a myth of common ancestry, shared memories, one or more elements of common culture, including a link with a territory, and a measure of solidarity, at least among upper strata"” (p.27). As the definitions suggest, the transformation of ethnie into a nation through the process of nationalism shows that the main aspect of the process is about the creation of new signifiers through institutionalizing cultivation and propagation, which are built upon some elements of the shared old (albeit selective) memories and myths. The case study for this inquiry about a Bosniak nation, which stemmed from an "unnamed ethnie" of Muslims of Bosnia (Smith 1988, p.23), is especially concerned with all these elements of transition which clearly suggest change. For Bosniaks that change occurred again when the "sense of community and difference had reached a certain point of consciousness and common awareness, under the pressure of [new] social and political obligations" (Smith, 1988, p.23) towards $\mathrm{BiH}$.

Smith's definition of nationalism is also concerned with identity. He sees nationalism as "an ideological movement to attain and maintain autonomy, unity and identity on behalf of a population" (Smith 2009, p.61). In practice, nationalisms are 
driven by specific programs "peculiar to the historic situation" (p.63) of the people to whom they are happening and whose imaginations they have to satisfy through a form of “political archeology” (p.65).

National identity is seen as "fundamentally multi-dimensional [and as such it cannot be] swiftly induced in a population by artificial means" (Smith 1991, p.14). Therefore, it seems that nationalism may be a mechanism to induce appropriate national identity, albeit only by using appropriate means. In fact, Smith notes the "resolution of identity crisis" as one of the "benign effects of nationalism" (p.18). However, national identity for him seems to be implicitly and explicitly tied to the state in several ways, since it serves to underpin the state and its organs or pre-political equivalents in stateless nations; to legitimate common legal rights and duties of legal institutions; and to socialize the members of a group as nationals and citizens (p.16). This conception of identity provides little possibility to observe many situations where a nation and its nationalism lack a state, or where a group is a part of a multinational state, as in the situation of Bosniaks in $\mathrm{BiH}$.

Furthermore, Smith's suggestion that cultural forms within which ethnies "exist," are unique parts of an ethnie's heritage should be treated carefully. This is so because by now it is established that interactions of peoples produced mixed genetic (Capelli, 2009) and mixed cultural forms which cannot be any more clearly untangled to examine unique expressions of current nations. For example, after expelling Spain's Muslim inhabitants, new Spaniards adopted myths, norms and culture from previous inhabitants but claimed them to be uniquely their own. And in the Balkans, it would be hard to untangle the 
Serbian quasi-history transmitted by the blind folk singer Filip Višnjić, who composed his poems to address all the "deficiencies" of their history, ${ }^{59}$ or to unscramble the standardization of the Serbian language by the path-making Serbian nationalists Vuk Karadžić and Dositej Obradović, modeled on the Austro-Hungarian approach (Plamenatz, 1976) and based on the dialect of a language spoken in Herzegovina. ${ }^{60}$

After the European cultural revolutions, the official historians attempted to codify most of those early Serbian nationalist assertions as a Serbian form of political and social invention of tradition, ${ }^{61}$ but the clash with accurate historical accounts still lingers unresolved. ${ }^{62}$ On the other hand, supporters of Serbian folkloric myths long ago decided to follow exclusively the blind poet's fables about the battle of Kosovo, when the fictional "Serbian Army" chose a "heavenly kingdom over an earthly kingdom" and created Serbs as a specific group and an imagined "chosen" ethnie. ${ }^{63}$ Although Smith (1991) notes that those who control the choice of the myth are often "literally the only

\footnotetext{
${ }^{59}$ A theme often found in the literature of other South Slavists like the Croatian August Šenoa who explained in 1876 that "poetic fantasy should not distort the main, generally known events. (The poet) should not narrate against history, ... but he can alter any accompanying events" (as noted by Hajdarpasic, 2015, pp.69-70).

${ }^{60}$ For more, see Chapter 4.

${ }^{61}$ See Hobsbawm 1983, p.263.

${ }^{62}$ The discussion about purported Serbian history resurfaced again when the President of the Serbian Helsinki Committee, Sonja Biserko , told the Croatian journal "Wreath" that the "entire Serbian history is one big lie," in part, because Serbia has no real access to part of the history that relates to the Ottoman Empire. The imputed ignorance about the facts opened up the possibility for the Serbian myth about the Kosovo battle to flourish. For more, see Tunjić (2015). Perhaps here we should remember Hobsbawm's (2012, p. 12) warning that historians of nationalism should distance themselves from nationalist myths because "nationalism requires too much belief in what is patently not so."

${ }^{63}$ Interestingly, those Serbian myths don't go much further into history, except when a connection with "Mother Russia" needs to be evoked, but even then such a connection is murky since such emphasis opens up the question of who is really the "newcomer" in the Balkans, Serbs or Albanians, who claim to be the descendants of Illyrians, and who is therefore "the owner" of the land.
} 
witnesses" (pp.36-7), as with the historic accounts attributed to the blind bard Višnjić, this is inconsistent with his other assertions. Smith implies that such a strategy can work for pre-historic ethnies, while Serbs perceived as "ethnic nations," are not that and their core ethnic selection myth is also a well-established historic event. Obviously, nationalists are "indifferent to reality," as Orwell (1953, p.83) noted, and they do not take people as they are; rather, their main goal is to transform them through the process of nationalism to be as they wish them to be (Smith, 2009, p.74).

Obviously, creation of the myths involves more forgetting (Renan, 1996; Woolf, 1996; Gellner, 1997) ${ }^{64}$ and alleviation of the perceived group's deficiencies (Kamenka, 1976), than remembering through codified "crafts and minor arts" which Smith (1988, p.14) suggests are clues about the feelings and attitudes of communities. Nationalism, rather, is, in Smith's approach as well, a mechanism for production and mass dissemination of signifiers that certain populations may (or should) adopt as a salient identity. ${ }^{65}$ Therefore, it appears that the ethno-symbolist approach to the study of nationalism keeps open the possibility for a change of a group, but in two different ways. When there is an ethnie as the core of a nation, changes are limited by the preexisting cultural norms and boundaries of the group. In the other situation, when a nation develops

\footnotetext{
${ }^{64}$ As Renan (1882/1996), on whom Smith (1991, pp.165-8) builds his "willed" approach to a nation says, "forgetting, and, I would say, historical errors are an essential factor in the creation of a nation, and thus the advances of historical study are often threatening to a nationality" (p.50). Smith's late professor, Anderson, also considers the will of the members to be the main basis for a nation, and this is especially pronounced in the most neglected Chapter Eight of his otherwise oft-cited work, Imagined Communities.

${ }^{65}$ In fact, with several historical examples, Smith (1988) notes how nationalism and nationalists emerged as the initiators and promoters of an "appropriate" identity. He notes that in late nineteenth-century France, nationalism "emerged to reassert the cultural and historic unity of France against minorities and ideologies that were thought to be subversive of that unity" (p.149); or in the case of "Nigerian "nationalism" among a small minority of politicians, civil servants, officers and intelligentsia" (p.146), yet still without a form called a Nigerian nation.
} 
without an historical ethnie, the possibility of change is wide open, with much less inertia.

\section{2-3: Modernist Structural Approach}

Although at first glance, the elements of time and continuity seem to be the exclusive domain of the primordialists, Benedict Anderson (1991) also considers such elements in his descriptions of nationhood. He is part of the Modernist school, and his is a structural approach in which nationalism and national identity are analyzed as everchanging cultural constructions which are not exclusive to other identities. As such they are most open to changes that groups might undergo through and their approach is primarily concerned with historical observations about how the inertia was overcome by those deriving groups while going through the changes. This approach draws from the seminal work of Fredrik Barth [1969 (1998)] about the persistence of social boundaries of ethnic groups, which occurs, however, at the same time as continuous interactions and mobility among the members of those groups. In such a situation the boundaries of both, ethnicities and their identities, are floating and changing in order to fulfill the intentions and aims of those social containers to maintain their distinctiveness. Barth (1998) criticizes the primordial approach to the study of ethnic groups because it leads us "to imagine each group developing its cultural and social form in relative isolation, mainly in response to ecological factors, through a history of adaptations by invention and selective borrowing." (p.11). Barth would probably also reject even the previously mentioned middle approach of Smith. For Barth (1998) "the elements of the present culture of [an] ethnic group have not sprung from the particular set that constituted the group's culture at 
a previous time" (p.38), by which Smith seems to suggest that we observe ethnies as collective cultural units whose characteristic communal creations persist over time and during the process of their transformation into a nation. ${ }^{66}$ The implicit assumption behind this notion is that without stable cultural elements, an ethnie will disappear and/or be absorbed by other nations or groups. Hitherto, Barth (1998, p.38) suggested that most of the cultural matter can [and will] vary, be learnt, and change, while the feeling of distinctiveness of an ethnic group within its own imagined boundary markers will persist. Finally, Barth (1998) considers that "the critical focus [in investigation should] become the ethnic boundary that defines the group, not the cultural stuff that it encloses" (p.15), and that seems to be different when it comes to Smith, who very much considers as important the "cultural stuff" of the group and its changes throughout history. Barth (1998), however, warns us that "when one traces the history of an ethnic group through time, one is not simultaneously, in the same sense, tracing the history of 'a culture"' (p.38). Therefore, for Barth, change is an essential part of the life of any group and Smith

\footnotetext{
${ }^{66}$ Smith claims (2009, p.23-4) that he also builds upon Barth and suggests that an ethnic group's social boundaries persist and remain the same when it becomes a nation. But in his introduction, even Barth says no group is an island (p.11) and when ethnic groups persist, they persist in constant interaction with their social and ecological surroundings. In the spirit of Barth's approach, we have to take his notion further and understand that when (ethnic or any other) groups become nations, groups exist (and maybe persist) on a global stage and, therefore, in a totally different social sphere. That is a very new and different context, mired by constant impermanence (according to well established IR theory), so Barth's notions would suggest that their behavior changes significantly, accordingly, if they are to persist as a group. Strategies and alliances, for example, are not made only with their close neighbors, against whom diacritical norms are for that reason primarily maintained. In international arenas they may be made and unmade constantly with distant partners as well. The appropriate example perhaps is the very Pathan ethnic group on which Barth (1998, pp.117-34) builds his observation, which, once it became a nation, on the global stage interacts much more intensely with Soviets, Russians, and the U.S. than with the Kohistani and Baluch ethnic groups. Such change of circumstances made the Pathans now participate in elections and agree to the majoritarian principles which are antithetical to their previous, fiercely independent, ethnic orientation. Barth's approach allows for this (as he even predicted radical changes to come) in the conclusion of his chapter, while in Smith's ethno-symbolic program it would be hard to understand such significant divergence from one of the central institutions of Pathan life (Barth, 1998, p.120). So the possibility of a change of any aspect of a group, even discontinuity, has to be part of any observation. It seems that Smith's approach emphasizes continuity, instead of change.
} 
did not completely reconcile with that. Besides the use of the seminal work of Barth, most of the other modernist approaches to nationalism also see a nation as a social unit built by more or less willing members, ${ }^{67}$ in line with Renan's nation-as-plebiscite approach, while many of them also note the issue of "imagined communities" established by Anderson (1983).

For Anderson, nationality, nation-ness, and nationalism are cultural artifacts of a particular kind, which, once formed, become "modular," capable of being transplanted to a great variety of social terrains and able to merge with other political structures (p.4). Those cultural artifacts organize themselves as distinctive groups throughout the process of change and eventually establish themselves as a nation, as a discursive "imagined community." So let's examine his suggestions about the process of reinvention of a previously established territorially delineated social group into a nation through the process of nationalism which encouraged the original and all subsequent imaginations.

An imagined political community, which has the characteristics of being both limited and sovereign, is imagined and not "real" because members of any nationcommunity cannot and will not know all other members of the community, yet in their minds they will see and will themselves into a communion. ${ }^{68}$ Since all of them share this characteristic, communities are to be distinguished primarily by the style in which they are imagined, not by their genuineness. Such an imagined community is limited, because

\footnotetext{
${ }^{67}$ More or less, for example, means that "will" alone is not enough for a nation to exist, and "will" has to be supplemented by coercion and compulsion (Gellner 2006, pp.53-4).

${ }^{68}$ That feeling may be encouraged by "real" difference or by the particular feeling of difference a group may have.
} 
no nation imagines itself coterminous with mankind, and there has to be a point beyond which lie other nations. A nation is sovereign because it replaced the divinely-ordained hierarchical dynastic realm in Europe during the time of Enlightenment and Revolution. And it is imagined as a community because the nation is always conceived as a deep, horizontal comradeship (Anderson 1992, pp.2-7).

Due to its concerns with death and dying in his consideration of a nation, Anderson (1992), like many others, suggests a strong affinity between nationalism and religious imaging (p.10), which relies on the same faculties of heightened emotions and devotion. This affinity perhaps explains how a combination of religion and nationalism can be so deadly, as was observed in the case of the Serbian state, which managed to tie together those two concepts in the recent Balkan conflicts. Another possible parallelism between nationalism and religion may be seen in how they both address the very issue of Bosnian Muslim nationalism, the topic of this inquiry. One of the most important themes that religion is concerned with is the identity that it offers to its followers. Often, the main concern of a religion in its proselytizing mission is the change of identity of a person into a new, religiously desired, and appropriate identity. Similarly, then, the main mission of nationalistic proselytizing is the change or restructuring of the identity of the expected group members into a desired one.

In his search for the cultural roots of nationalism, Anderson observes that the two relevant systems against which nationalism developed were the religious community and the dynastic realm, and that the change of worldview produced by the systems that those systems produced was gradual. Anderson (1991) concludes that change brought about by 
nationalism and the establishment of a nation came after the "three essential cultural conceptions lost their grip on men's minds." The first conception was the idea that only through a particular script-language could one access the ontological truth; the second was the notion that society should be organized as a royal, God-given "node of access to being"; the third was the notion of temporality in which cosmology and history were indistinguishable and time was apprehended with only two reference points, the origin and the end of the world (p.36). Ever since its emergence, nationalism has been the continuously changing variations of those three conceptions. Nowadays it insists that a group have its own national language or culture, be a society organized with anonymous and equal co-nationals, and have its own account of its history with many points of reference to show its separate origin and continuity as a self-evident raison d'etre for its political independence.

As nationalism asserts itself, sometimes in spite of religion, and from its inceptions in Western Europe, where it came in the wake of rationalist secularism, it served as a replacement for religious modes of thought and the previous, religious apprehension of time. As such, it required the transformation of fatality into continuity, because even if the reality of a nation state is accepted as an historical novelty, the nation comes from the immemorial past and it is to remain a guide into a limitless future. And as Anderson (1991) puts it, "it is the magic of nationalism to turn chance into destiny." However, the view of nationalism as the antithesis to religion is ambiguous in the case of many Balkan peoples, such as Bosnian Muslims, since one of the primary boundary markers for their sense of groupness is based on religious notions, unless we note 
Bosnian Muslims' cultural religiosity as primarily an ethnic category, ${ }^{69}$ and almost as just a confessional difference from their "Christian" neighbors, and not some difference of deep theological worldview. ${ }^{70}$ In that case, Bosnian Muslims' "religiosity" can coincide with the notion which Tomka (1995) described as a basis for early European nationalism when Christian "confessions were celebrated as "national" religions in order to produce awareness of the coincidence of national and confessional persecution, or even to provoke resistance" (p.27). This view is especially feasible because real religiosity among Bosnians was totally subdued after five decades of Communism, and, since Anderson and others suggest that nationalism can be well understood by aligning it with the large cultural systems that preceded it, the modern nationalism and religiosity of Bosnian Muslims should be primarily aligned with that period of Communism seen primarily as a cultural system. $^{71}$

Anderson (1991) notes that once the concept of a nation was "invented," it became something that could be sought by political actors from early on, and available for pirating by many different forces. As a reaction to the increased use of vernacular languages and popular national movements arising all over Europe after 1820, a new era

\footnotetext{
${ }^{69}$ After half a century of Communist anti-religiosity, Bosnian Muslims retained only a sense of religion stored as elements of ethnicity similarly to some other Muslim minorities of the Soviet Union, as observed by Bennigsen \& Lemercier (1967).

${ }^{70}$ To show the closeness of its peoples, Bosnia is often referred to as a "multi-confessional state" and it is the case at different events in $\mathrm{BiH}$ when Muslims, Catholics and Orthodox Christians are jointly present, that the events are referred to as "multi-confessional gatherings" instead of multi-religious ones. Even outside of $\mathrm{BiH}$, the same tendency can be observed. For example, in 2008 the prominent German historian, Hannes Grandits, published the book "Power and loyalty in late Ottoman society. The example of the multiconfessional [multikonfessionellen] Herzegovina" using the term to describe interactions among followers of the three religions, rather than confessions. Or a more recent work by Cynthia Simmons (2002) also uses "multi-confessional" and "multi-religious" interchangeably, as if they mean the same thing.

${ }^{71}$ For more, see Chapter Four.
} 
of "official nationalism" ensued, which for Anderson (1991) was a "willed merger of [desires for] national and dynastic empires"(p.86). This historical aspect of European nationalism also played its part in the case of the former Yugoslavia, and especially in the aspirations of the Serbian and Croatian state(s), when many minorities were expected to erase or adjust their ethnic boundaries and memories to be conjoined in the new states' desired salient identities, or be expelled or destroyed. Those separate groups eventually reacted with their own vernacular nationalism projects. As the vernacularizations of nationalism confronted the official nationalism, chauvinistic racism appeared as a reaction among Serbs and Croats, with a clearly defined notion of "upper nation"72 imagined as a race ${ }^{73}$ living in its own (only) "natural" land. ${ }^{74}$ Many observers of the recent Balkan wars point to nationalism as the main ideology of most local actors, and therefore wrongly perceive them as nationalists. As Gellner (1983) warns us not to confuse tribalism with nationalism, to heed Anderson's warning, we should also be careful not to confuse chauvinism and fascism with nationalism.

\footnotetext{
${ }^{72}$ Anderson correctly observes that racism is different from nationalism since nationalism works on a different plane and has a different origin. "For it shows that from the start the nation was conceived in language [primarily of history], not in blood, and that one can be invited into imagined community" (p.145) as today most nations have mechanisms of naturalization for new immigrants. Therefore, Anderson (1991) points out that "seen as both a historical fatality and as a community imagined through language, the nation presents itself as simultaneously open and closed" (p.146).

${ }^{73}$ As is also obvious from the Serbian national anthem, whose refrain continually refers to the Serbian race as follows:

“... God save; God defend, Serbian lands and the Serbian race!” (For more, see Vlada Republike Srbije, 2004).

${ }^{74}$ In the Croatian anthem, on the other hand, the land is anthropomorphized through the nation which resides upon it (see Kelen and Pavković, 2012), and therefore the stress is on the essential tie between the people and the land as indivisible and therefore as a natural, God-given, bond. The Croatian Archbishop from Split, Frane Franić, in 1984 exclaimed in his homily that "God rendered to us Catholic Croats this land in which we have lived for one thousand and three hundred years, and we will not let anyone else rule over us in our own land" (in Perica 2002, p.70).
} 
Since "nationalism thinks in terms of historical destinies, while racism dreams of eternal contaminations," (p.149) racism is essentially ahistorical, as "Niggers were always Niggers" and will always remain so; Jews are considered "forever Jews no matter what passports they carry or what language they speak" (p.149), and similarly, in the case of the Balkans, all local Muslims are forever seen as Turks. For Anderson (1991) the origin of the very idea of racism may also be traced "in ideologies of class, rather than in those of nation" (p.149), and racism essentially manifests itself primarily within national borders rather than outside them (p.150), as in the case of the chauvinistic racism in most of the new states of the former Yugoslavia. Bosnian and other Muslims were usually referred to as "Turks" by Serb and Croat chauvinists, not only to establish the basis for their chauvinistic racism, but also to undermine Bosnian Muslims' claims on the territory in which they lived, calling them by a name that indicates an outsider.

Another often-quoted work of Anderson, also used as a building block for this work, is his unpublished manuscript on long-distance nationalism. In it, he notes that spatial aspects of nationalism and nationhood are undergoing changes due to the nature of capitalism and technological innovations, through which, as people move around, "the mediated imagery of 'home' is always with them" (Anderson, 1992, p.15). This reality has only intensified since he wrote his thesis and such imagery is even more transferable, although in a much less mediated way. That is, since a nation is a matter of imagination, it can be imagined equally well from "here" as from "there." Now, a person who emigrated does "not participate substantially in the political life of [the new country of residence]; instead he lives, through e-mail, by long distance nationalism... His political 
participation is directed towards an imagined Heimat in which he does not intend to live, .... and where he does not vote" (Anderson, 1992, p.19). Many of those great romanticized nationalists about whom people read with awe were actually brewing nationalism from a "long distance." For example, consider the nationalist and main propagator of modern Bosniak identity, Adil Zulfikarpašić, a Communist dissident who spent most of his life in Switzerland, and the one who made it possible for Bosniak identity to fully emerge as the result of that nationalism, Alija Izetbegović, whose grandfather moved to Bosnia from Belgrade in Serbia. ${ }^{75}$

To be sure, the notion of long-distance nationalism applies to the population under observation here; the Bosnian Muslims in this diaspora population sample can be seen as a population that will probably not go back to the land where their nationalistic aspirations are directed. Anderson (1992) clarifies that long-distance nationalism actually pertains to those "émigrés who have no serious intention of going back to a home, which, as time passes, more and more serves as a phantom bedrock for an embattled metropolitan ethnic identity" (p.20). ${ }^{76}$ Therefore, such nationalism is most likely not a transnational phenomenon, since even those "long settled Irish and Jews of the United States in the 1980s serve as an unsettling portent" and their nationalisms are still as potent, or often even more so, as those of nationalists "back home." Hence, long-distance nationalism is not long-distance in terms of sources of nationalism. Each diaspora group

\footnotetext{
${ }^{75}$ As Lord Acton stated long ago, "exile is the nursery of nationality" (Lord Acton 1967, p.146, cited in Anderson 1992, p.1).

${ }^{76}$ In fact, as Demmers (2002) noted, "both multicultural policies and xenophobia in the Western countries enable and force newcomers to continue to define themselves in terms of their ethnic or national origin" (p.94), even more so since integration policies which are primarily to be implemented by host societies are neglected, and it appears that integration is no longer the goal for either hosts or immigrants.
} 
has its own nationalists; it is long-distance in terms of the object of nationalism, which is somewhere out there, outside of the geographic locality in which long distance nationalists currently physically reside. Furthermore, "as a result of globalization, nationalism did not subside, only nationalists began to carry their struggle on the global stage" (Demmers, 2002, p.93); therefore, diaspora groups gained in significance as "forward forces" for any nationalism project, especially those situated in the U.S., as was directly expressed to me in many conversations during the field work. In agreement with Demmers (2002), it can be concluded that the political weight of diaspora communities regarding various aspects of nationalism has increased, and it is indeed as useful to measure and study nationalism among diaspora groups as to do so in their home territory.

Ernest Gellner is another author identified as a modernist and structuralist in his approach to studies of nationalism. In agreement with Barth's observations on the variability of cultural matters and the persistence of the distinctiveness of ethnic groups, Gellner (1997) notes that despite the persistence of some culture forms, cultures vary within as well as among different communities, and it is known that for political reasons societies have changed languages (p.2), and we can add religions, and even territories. With such a position he further opens up the possibility for nationalism to be used instrumentally to create nations and identities when socio-economic structure becomes ripe for that. However, "nationalism engenders nations" (Gellner 1983, p.54) based on some arbitrarily chosen preexisting cultural traits, and transforms a group radically so that - while only resembling the old forms - it can be considered as new. For Gellner that 
transformation is represented through the shift from low, folk culture to a high culture demanded by increased industrialization and centralization.

For Gellner, an economically determined structure and subsequent culture are the basic elements of all social life. Stemming from that, Gellner (1997) defines nationalism as a modern "political principle which maintains that similarity of culture is a basic social bond" (p.3), while the legitimacy to rule is limited exclusively to the members of the group of shared culture which then forms a "nation." So for him nationalism is the notion that ties together economy, organization and culture among the people of a particular territory (p.6). Gellner (1997) emphasizes that such aspirations toward cultural roundedness may be universal and perennial, but nationalism and states are not (p.5). Nationalism only emerged as the result of structural changes in European societies when, due to the possibilities presented by industrialization and urbanization, elites could produce high culture ${ }^{77}$ and diffuse it throughout the willing populace (p.54) and by the force of nationalism make sure that Ruritania is primarily for Ruritanians (pp.58-60).

The social conditions which produced a nation (state) were the products of nationalism, seen as a force of change from a non-egalitarian agrarian society into an industrial society of baseline equality where each member relates directly to the whole society and can, at least theoretically, move up and down the societal strata (Gellner 1997, pp.18-28). Once that change occurred, high culture was imposed upon the population in order to preserve the new societal structure. In the case of $\mathrm{BiH}$ and Bosnian Muslims, such changes were the legacy of Communist rule, which not only pushed for

\footnotetext{
77 “well-defined educationally sanctioned and unified culture” (Gellner, 1997, p.54).
} 
industrialization, but also - often even more forcibly - pushed for social changes and baseline equality. Most importantly, the Communist era also created a situation of almost universal literacy, which then enabled for a dominant high culture to (re)emerge that displaced folk culture in Bosniak society, ${ }^{78}$ and a such development is for Gellner (1997, p.28-9) the essential condition for the success of nationalism. That is why this inquiry pays special attention to the Communist era and the nationalist ideas it produced among Bosnian Muslim elites. Therefore, in agreement with Gellner, Plamenatz, Anderson, Smith and Hobsbawm, this author also sees nation as a top-down-driven project, but in order to fully understand it observes it at both levels of society.

\section{2-4: Nation and State, Case Study Selection}

Most modernist ideas of nationalism stress the tie between the nation and the state as the ultimate driving force behind nationalism. The case study of nationalism here is specific in its effort to preserve the state as a tri-national civic entity, where Bosnian Muslims are neither the dominant nor the overtly eponymic nation. So identity construction is not a state-driven endeavor; rather, it is a result of the process of the substate form of nationalism, as defined by Guirbenau (1999) and Stepan et al. (2011), with many identity engineers and gatekeepers. This inquiry had to take account of that "state

\footnotetext{
${ }^{78}$ An example of how strenuous is the transition from folk to high culture is the discussion among the members of the Congress of Bosniak Intellectuals Forum (Vjeće Kongresa Bošnjačkih Intelektualaca VKBI) regarding the preservation and future of the Bosniak musical form of sevdalinka (soulful) songs. As reported, one of the participants noted that for Bosniaks "nije bitna seoska muzika nego je bitna sevdalinka kao gradska pjesma" ("village folk music it is not important, as much as it it sevdalinka as urban song"), and that whoever denies the sevdalinka, denies Bosniak people. At the conclusion of the discussion another participant expected the society to do more to uphold sevdalinka, saying that at the next national celebration of the conclusion of the month of Ramadan, "besides Bach..., people can also hear sevdalinka at the festive eid-ul-fitr concert" (for more see VKBI, 2001). Another notable example is the transformation of one of the most popular Bosniak folk ballads, "Hasanaginica" (translated by Wolff, 2003 as "The Mourning Song of the Noble Wife of the Hasan Aga"), into an opera piece (for more on the opera effort, see Horozić and Allispahić, 2000).
} 
of nations" reality with a set of questions that treats "ownership of a state" only as a distant, possibly unattainable goal.

Some, like Kosterman and Feshbach (1987), Schatz et al. (1999), and Blank and Schmidt (2003), try to test the relations between national identity, nationalism and patriotism by examining attitudes of Americans towards their state, and West and East Germans towards the German nation and state. Although their attempt is certainly worth the effort, especially to show the empirical difference between nationalism and patriotism, it would be problematic to apply their approach to other cases where the distance between the nation and the state is much wider, and where national history and patriotism did not develop, as in the case of those already (internationally) established nations. Kamenka (1976) already correctly pointed out that there are significant differences between the places where "the community [already] has a political unity clearly defined" (p.15) and the places where this is not very clear. Therefore, context matters a great deal, and cases like contemporary Germany or the U.S. cannot provide us with the necessary conditions to observe the relationship between nationalism and identity, when nationalism has been central to the political life of the community for some time. This is so because the assumptions and condition of one case cannot be used to help explain the emergence of that condition in the case, to paraphrase Gellner's note (2006, p.53). So all those efforts are perhaps appropriate to pursue when considering Billig's situations of (1995) "banal nationalism" and in cases of "nationalism in a weak sense" (Kamenka, 176, p. 16), where state, national history and related patriotism and homogeneity are already developed. Be that as it may, it would generally be very problematic to treat identity as a starting point for the examination of nationalism in cases 
of the emergence of new states and constituent peoples, as is the case with Bosniaks, who have been until now, generally, people without a "national" history. ${ }^{79}$ We should keep in mind that case selection is important in understanding the results of the study in the cases under discussion, those of Germany, with a long-ago-established identity based on the nationalism of the time, and of the Bosniaks, which is still under construction. The same case selection significance is established by the Bayesian analysis approach, which stresses the importance of understanding the context and whether the case may be useful in determining if the intervening phenomenon can be present to begin with. ${ }^{80}$

\section{2-5: Power Relations as History of Nationalism}

Among modernists, it is relevant to note that even Foucault, with his notion of structuralism, contributed to the understanding of the phenomena of nationalism and nation in France. For him nation is envisioned through the body of a sovereign over the state, who became heir to the throne after the king was decapitated. Before his death, the king's inevitable mission was to form the new nation, as a milieu for the new identity, out of groups which used to be different peoples. ${ }^{81}$ The king, as well as his heir, was able to do that by wresting absolute control of the state and its history from the nobility, made up of the Frankish warrior class. The monarch won by intentionally creating favorable

\footnotetext{
${ }^{79}$ For more, see Markovic et al., p.315, in Brunnbauer, 2004.

${ }^{80}$ For more, see Browner and Newman, 1987, pp.2460 - 61.

${ }^{81}$ Foucault (1997) notes that "the role of the monarchy is to forge this extranational mass - the product, the mixture of German subjects, Roman clients, and Gaulish tributaries - into a nation, into a different people" (p.230). And here Foucault also opens up the possibility of a new group as a context for an identity to emerge as the result of the process of group (trans)formation. "What happened was that something new was created within an entity that was once mononational and totally concentrated around the nobility: a new nation, a new people or new class was created" (p.231). It was that class within the social body of a state, which formed the Third Estate and wrested power from the nobility. "The confrontation between these two types of society over the constitution of a state will become the basic motor of history" (Foucault, 1997, p.234), and an overarching norm that was established to be followed globally (p.236).
} 
conditions for an urban populace, which in turn provided the possibility for the emergence of the Third Estate, ultimately opposed to the rural, feudal, order of Nobility. ${ }^{82}$ "The Third Estate is in itself the historical precondition for the existence of a nation, but that nation should, by rights, coincide with the state" (Foucault 2003, p.221). So Foucault explains that the sense of togetherness, among the commoners, clergy, nobility and everyone else who might be present in any particular case, is the necessary precondition for a nation to exist, but that precondition is not enough. That possibility has to be fulfilled by the group's achievement of its own state if the group is to become a nation. For Foucault "what defines a nation is not its archaism, its ancestral nature, or its relationship with the past? [it is] a vertical relationship between a body of individuals who are capable of constituting a State, and the actual existence of the State itself" (Foucault, 1997, p.223). That individuals-State reality, which has become the norm in the international arena, urges everyone globally to try to seek it, and that is how nationalism became a universal process. So Foucault's definition of a nation is tied to the group's connectivity to a state, primarily seen as a structure capable of mobilizing oppressive force to coerce primarily within (and, less so, outside) its borders. Therefore, for a group of people to become a nation just "will" is not sufficient; rather, for Foucault, just as for Gellner (1997, p.52), it is "will" and a "coercion," an ability to administer itself, that constitute a nation as a social reality. For Foucault (1997) "the nation is the active, constituent core of the State. The nation is the State, or at least an outline State" (p.223).

\footnotetext{
82 "And the reason urban society eventually triumphed is not at all that it won something like a military victory, but quite simply that it had wealth on its side, but also an administrative ability, a morale, a certain way of life, what ... gave it such strength that, one day, its institutions ceased to be local and became the country's institutions of political right and civil right" (Foucault, 1997, p.235).
} 
And so Bosniaks also are becoming a nation precisely at the moment when they can claim even partial ownership of a state, when they claim to be the constitutive core of the state of $\mathrm{BiH}$, as is often noted by the members of their bearer class. Bosniaks, therefore, are fighting the main battle to reassert themselves as a nation by asserting themselves as the core national group of $\mathrm{BiH}$ even though they are sharing the state with two other national groups. ${ }^{83}$ So, just as with the emergence of a modern nation and its constituting state, "the State, and the universality of the State, become both what is at stake in the struggle, and the battlefield" (Foucault, 2003, p.225).

Although in his analysis Foucault is very concerned with history, he looks at it differently from the primordialists and ethno-symbolists. For him, history as the source of a nation, is the "concept of nation, which the aristocracy wanted to reserve for a group of individuals whose only assets were common customs and a common status, [but for Foucault that] is not enough to describe the historical reality of the nation" (Foucault, 1997, p.221). He sees history as an instrument of power, not as a force of nature that shapes nations and their possibilities. In fact, for him history usually conceals nature, since "when history begins, nature can no longer speak, because in the war between history and nature, history always has the upper hand" (Foucault, 1997, p.158). Foucault suggests that history should be seen as a "calculation of forces" and for those who look at it, the focus should be to establish "who became strong and who became weak. Why did the strong became weak, and did the weak become strong?" (Foucault, 1997, p.161).The

\footnotetext{
${ }^{83}$ That is why even Bosniak and Muslim leaders from Sandžak adamantly insist that Bosnia is their "matica" (this word "matica" in their discourse is associated with the "queen bee", yet it is to be understood by the intended audience more as "motherland").
} 
source of a nation, therefore, should be sought not in nature, but elsewhere in the conditions that enabled it to emerge as an outcome of specific power relations.

And so, how could those relations of power that enabled the French Revolution to occur and nationalism to play its historical role still be useful for contemporary analysis? Foucault begins his structural explanation by describing the time when the Franks took over Gaul. As a result, for ordinary people, the burden changed just in form but not in substance. Those worst affected by the German and Frankish warriors' conquest were the Gaulish aristocracy, which lost all its privileges, land and wealth. In such a situation, the Gaulish aristocracy took refuge in the church. "The fact that they had been driven off their land and into the arms of the church, gave them influence over the people, but also an understanding of right" (Foucault, 1997, p.161). Hidden there among the ordinary folks, armed with new mystical instruments of influence over the people, the former Gaulish nobility, now priests, eventually aligned themselves with the new monarch against the nobility and created conditions for the Third Estate to emerge and overthrow the nobility. Moreover such an alliance created a subsequent form of absolute government that tolerated no dissent, and that in turn enabled the French Revolution to succeed. ${ }^{84}$

That historical situation is very similar to the several cases of emergence of a nation in the Balkans. As those territories were overrun by the Ottomans, the nobility

\footnotetext{
${ }^{84}$ After the French Revolution, the guillotine as an instrument of the new egalitarian order of democracy was the main tool of the populace in achieving victory. And the fact that even the king was killed by it just testifies to the guillotine's egalitarian principles. After the king, even many of those intellectual leaders of the Revolution, like Robespierre, were themselves decapitated indiscriminately; but, not before they killed thousands of others, to provide a foundation for the creation of the unified new nation.
} 
which lost the war and then the wealth and privileges it had had before, mostly became members of the Orthodox Christian clergy, although many also converted to the new religion. ${ }^{85}$ From there, they became close to the people and, although initially loyal vassals of the Ottoman sultans, they eventually became the foundation for the emergence of the nation which over time materialized into its own state.

For Bosnian Muslims the case was slightly different. When they, as a result of the Ottoman decline, lost their favorable position in the Balkans, some of their nobility also withdrew into the Muslim clergy. Once there, they were forced to erase Ottomanestablished class structures which had separated them from the commoners, and using religion, they forged close ties with the population and maintained control over knowledge production and attainment. As one of the older informants told me, they even discouraged people from attending regular state-run schools, in order to maintain their dominance over knowledge production. ${ }^{86}$ For many decades after that, any person who sought any kind of influence over Bosnian Muslims had to seek explicit support from the imams and their organization, the Islamic Community of $\mathrm{BiH}(\mathrm{IZBiH})$, which was seen by many commoners as the prime legitimator for any influential aspirations within the group. The same organization survived the Austro-Hungarian occupation of Bosnia, the

\footnotetext{
${ }^{85}$ According to some Bosnian Muslim historians, this was especially the case with those who were considered Bosnian heretics by both of the dominant Church orthodoxies at the time. According to them, followers of the Bosnian Church accepted Islam en masse without coercion because they found similarities between the old and the new religions, and more so as an act of protest against the [Hungarian] Catholic Church, which had persecuted them previously (for more, see Imamović 1995, pp.206-12, and Chapter Four of this dissertation).

${ }^{86}$ A person from central Sandžak told me that right before WWII, in the entire region only boys from several wealthy families went to the state-run elementary schools. The rest of the people were persuaded by their local hodžas (imams) not to send their children to the state-run, unbelievers' schools, and that masjidrun local mektebs were providing enough education for all of them.
} 
Kingdom of Yugoslavia, the Croatian Ustaša Nazi regime of WWII, and the post-war Communist Party dominance in Yugoslavia; it always tried, and succeeded more or less, to be close to the dominant power at the time and an arbiter of groupness for Bosnian Muslims.

Although after WWII the imams lost their exclusive control over the production of knowledge, since the Communist regime instituted obligatory and universal public education, ${ }^{87}$ they maintained several IZBiH-run madrasas as their own institutions of learning and memory. When the time became appropriate, many of the alumni of those institutions, like the IZ prime institutions of Gazi Husrev Beg Medresa in Sarajevo, ${ }^{88}$ led the Bosnian Muslims through the turbulent years of the dissolution of Yugoslavia, their process of nationalism, and their emergence as a nation.

\section{2-6: Nationalism as Groupness}

The final scholar whose work is examined for this multi-theoretical review is Rogers Brubaker. He is one of the modernists who stayed the furthest away from primordialist notions about nation and nationalism. For him (1996), also, nationalism is understood apart from nation, because "nation" is a category of practice, not ... a category of analysis" (p.7). Furthermore, he criticizes the primordialist and realist

\footnotetext{
${ }^{87}$ Elementary religious schools, mektebs, were officially closed in 1950. (For more, see Hoare 2013, p.373).

${ }^{88}$ The Gazi Husrev Beg Medresa was established 26. Rajab 943 Hijri year (January 9, 1537), and for a list of some of its contemporary alumni, see the Laureti (Gazi Husrev-begova medresa, 2015). It should be added here that the Medresa should not be seen as the prime national or nationalistic engine. Many, if not all, of those medresas are attended not only by Slavic-speaking Muslims from BiH and Sandžak, but also by many students, and sometimes teachers as well, from Albanian, Pomak-Nashenci, and Turkish groups, as well as a few from the Roma Muslim population. Furthermore, several of the Bosnian Muslim nationalists and significant political leaders openly expressed to me reservations about the hodžas (imams) coming from those medrasas.
} 
approaches which takes a "nation" as a real entity, suggesting that we should, rather, reconceptualize a "nation" as a contingent event, institutionalized form, and practical category. So for Brubaker (1996), it is necessary to avoid the "political fiction of 'nation"" as a reality and a substantial and enduring collectivity, and instead, to capture the reality of nationhood as an institutionalized and political form, nationness as contingent event, and a nation as a category of practice (pp.15-21). Such an approach invites us to perceive nationalism as the political mechanism for the production of possible identity and "treat groupness as an event, as something that "happens"" when it does (Brubaker, 2006, p.12), and possibly crystallizes into an identity which members of a group accept or not. Therefore, nationalism is a context that sometimes produces a new salient identity, but it always demands that the appropriate salient identity be embraced by the people to whom nationalism happens. In such a case the new salient identity is not seen in a direct relation to a previously existing group or ethnic reality, but rather is conceptualized as a "changeable product of collective action" (Brubaker, 1996, p.20). For Brubaker (1996) nationalism is action which is intended to address deficiencies of a political condition, such as lack of adequate polity, or lack of an adequate national base, or in his own words (1996), "polity-seeking [and] polity-upgrading" (p.79) situations. Therefore, nationalism, for Brubaker (1996), is a "political stance [and] not an ethnodemographic fact" (p.5) ${ }^{89}$ The main goal of such a political attitude, which has a

\footnotetext{
${ }^{89}$ Although stateness is not the necessary goal and element of nationalism, it may be noted that when that process is aiming to establish the rule of a state, it also produces an identity which makes a sense of citizenry possible. In that way nationalism is that necessary and essential midpoint between authoritarian situations and democracy, which is a crucial point in the observations about the emergence of new (types of) states and identities in Eastern Europe and possibly beyond. Before we can accept that democratic stability is when "democracy is the only game in town" as Linz and Stephan (1996) established, we have to make sure to have players ready to play that game.
} 
performative character, is to reify the group's existence as an undisputed fact and subsequently provide for its increased unity (Brubaker, 2006, p.10) as a context for a new salient identity. Therefore, a group's cohesion should be treated as a variable, and here it is proposed that increased group cohesion increases the likelihood for a new salient identity. It should be noted one more time here that both variables, group cohesion and Bosniak identity, are not taken for granted and are treated as new realities for the Muslims of $\mathrm{BiH}$ and Sandžak, which they can accept or reject to varying degrees. Therefore, accepting and ascribing to a new salient identity are seen as significant social phenomena that should be carefully observed and analyzed as is done here.

The most important contribution of Brubaker that is applied in this inquiry is the idea that nationalism should be considered as a form of more or less groupness, which directs inquiry towards the literature on group development and maintenance, as Brubaker (2006, p.7) hinted in his comment on the juncture between the sub-disciplines on groups and ethnicities.

Approaching nationalism as a variation of groupness provides the opportunity to address some other important shortcomings often found in studies that see nationalism and nations as given categories with a taken-for-granted consistency. The curiosity about that is best answered when the inquiry includes everyday people as responders, since they are the main recipients of those policies and political projects. According to Enloe (2006, p.26) considering the experiences and responses of ordinary people "is one of the most efficient ways to accurately estimate just how fragile that artifice [of a group] is, just how far off the mark it is to" take the group's consistency for granted. Furthermore, as 
suggested by Enloe (2006), focusing on the bottom level of action enables us to notice the group's different voices and the positions of women, which are often missed or neglected in analyses of nationalism and identity. Since there are only a few women at the elite and policy making level, concentrating solely on that level means avoiding voices already silenced in politics and literature. In order to change this reality, where "margins stay marginal, the silent stay voiceless" (Enloe, 2006, p.24), an attempt is made here to examine responses to nationalism and identity at the level of ordinary people, so that women's attitudes and voices will also be accounted for.

\section{2-7: Types of Nationalism}

Other modernists, like John Plamenatz, see nationalism primarily as a cultural phenomenon, though it can, and often does, take a political form. Of concern for this inquiry is the typology of nationalism noted by Plamenatz (1976). For him Western nationalism is mainly liberal, while the Eastern type is mainly illiberal. Western nationalism is liberal because of the idea of equality of citizenship with which it came into being and is mainly concerned. Eastern illiberal nationalism is the result of the situation in which "leaders or rulers, who take it upon themselves to create a nation or transform it, to provide it with skills, ideas and values it did not have before, are impatient to opposition” (Plamenatz 1976, p.35, my emphasis).

Although Kohn's (1945) and Plamenatz's (1976) typology of Western nationalism as liberal, and Eastern nationalism as illiberal, is controversial, ${ }^{90}$ most, if not

\footnotetext{
${ }^{90}$ Noticing how Balkans, and others who are "east of Western Europe," are framed by Western observers so that they cannot escape their history, Dongaciou (1999) points to embedded Orientalist notions in the
} 
all of the authors who study nationalism do acknowledge that it manifests itself in different ways at different times. Scholars see the typology of nationalism based on its first two successful manifestations, the first being the French model based on the ideological acceptance of nationalism, and the second being the German model, developed in contrast to the French one, built around notions of genuine peoplehood, folklore and other possible elements usually used to describe an ethnic group. The first is seen as based on a willing acceptance of membership into a nation, and it is often referred to as the civic type of nationalism, while the second is seen as being inherited by birth and is noted as the ethnic type of nationalism.

This typology of claims could be problematicized, since both types actually contain elements of coercion, willing acceptance, and possibly some elements of ethnicity among members. However, observations of typology and differences between the two models of nationalism cannot be ignored, and the effects of the typology should be measured to see if they make any difference among the population which is experiencing the process of nationalism, in terms of acceptance or rejection of the desired salient identity. Therefore, in agreement with Billig (2002) and Dungaciu (2000), nationalism here is seen as, one phenomenon, a thing common to "us" and "them", but emphasized more or less, by two, civic or ethnic aspects, which may be present, more or

studies of nationalism, and how "the adjectives used by Plamenatz to characterize this latter nationalism resemble those used by Kohn: 'hostile,' 'imitative,' 'illiberal,' 'disturbed,' 'ambivalent,' 'oppressive' and 'dangerous.' It would not be hard to recall a number of cases in the history of Western Europe where these epithets would fit perfectly. But Plamenatz is not interested in such comparisons. These adjectives belong to the Eastern nationalism, and they must stay there" (pp.8-9). 
less, in any case of nationalism. ${ }^{91}$ For that reason, in this inquiry, nationalism is measured by its two essential characteristics: its intensity or strength, and, on a bi-polar scale, its civic or ethnic nature, to note how those two different aspects of the phenomenon interact with the ascription of identity by the population.

\section{2-8: Conclusion on Issues Relevant for Nationalism Studies}

Although the focus of this inquiry is not to uncover the masculinity behind nationalism, which Enloe (2006, p.107) calls for, an effort is made to note how men and women respond to calls of nationalism. In such a way, the inquiry can report differences, if any, between the two genders when it comes to nationalism and ascription of the new salient identity, and to account for women's less opportunistic and more emotional response to the group's new context, as Hercus (1999) correctly called for. Consideration of the emotional response to the nationalist project is very much needed, because the desired identity it seeks to enact as salient, cannot rely only on the rational calculus of the population to evaluate identity choices in the way that personal interests do, as Polletta and Jasper (2001, p.285) explain. They also correctly note that collective identity commonly carries with it positive feelings towards other members of the group, and not a sense of competition and interest, which are usually associated with rationality.

\footnotetext{
${ }^{91}$ Keeping in mind Baum's (2001) fair criticism that "the neat opposition between ethnic and civic nationalism is easily used as an ideological weapon by liberals and socialists to make people feel guilty over their attachment to their national tradition" (p.121), we should also remember his observation that "the civic nationalism that has created liberal society continues to have ethnic memories" (p.121), and add that ethnic nationalism continues to have civic aspirations of incorporating those who are presently not ethnic kin, but who could become so in the future under certain circumstances. And, therefore, it is indeed possible and useful to measure the extent of one or the other pole of nationalism among the population, as is done in this inquiry.
} 
Therefore, women's responses are noted apart from men's, and any significant differences in their responses are indicated.

As most students of nationalism point out, the process is about creating a particular political consciousness organized around the legitimacy to rule a particular territory and people(s). Because a "nation" is not just the extension of some previous sentiments of ethnic solidarity (Weber in Woolf, p.23), it, rather, needs that political consciousness to be a "nation." To impact that political consciousness of the people affected, nationalism aims to produce a desired identity. Therefore, nationalism is to be conceived as a political process which aims to produce and propagate an identity which can or will be adopted by the targeted group of people on an individual and group level.

By seeing nationalism as a process, we can note its beginning, emergence and maturation, and point to its essence. Furthermore, treating nationalism as a process allows us to note when nationalism becomes an integral part of a society's development, and to note its manifestations and applications as an ideological or policy tool which can be employed and claimed by the political left or right, capitalist or communists, liberators or occupiers. This generalization about nationalism may be problematic, since nationalism is a form of particularism. The most important aspect of particularism is that it contains particularity or case specificity, ${ }^{92}$ and as such any generalizations about it run the risk of conceptual stretching. However, after acknowledging this danger, it should be noted that particularity is an essential element of each case study, while seeing nationalism as a

\footnotetext{
${ }^{92}$ Vincent (2003) notes that the "nominalist perspective, [as] particularity denotes a thing which is not universal, is concrete rather than abstract, is one among many particulars, is something which is unique (or individual), and is potentially more real, immediate and familiar" (p.9).
} 
process is actually a conceptual tool to see how human groups manage to politically emphasize their own particularity.

This short examination of some of the major works and approaches to nationalism provides us with a theoretical foundation to observe the case of Bosnian Muslim nationalism and the possible crystallization of Bosniak identity as a signifier that an individual might claim and adopt to establish her or his social location and conceptualize her or his own self-understanding. ${ }^{93}$

\footnotetext{
${ }^{93}$ When as issue related to an indeterminate person is discussed the male pronoun "he" refers to both sexes here and in the rest of the text.
} 


\section{III: ON IDENTITY}

In everyday conversations, individual identity is usually perceived as a solely internal feeling or sense that somehow plays itself out in a person's life. As established by various social science approaches, salient identity provides a basis for an individual's external activities and social significance, and a basis for participation in the collective action of different groups. Evident in these perceptions is the idea that identity is seen as both, something a person possesses and something a person acts out. That is why most scholars write on identity as something internal, while actually observing person's external activities. In that way they run into a problem described by Brubaker (2006), namely that it is unclear what exactly is a category of analysis: is it an individual's internal feeling or an individual's external actions? $?^{94}$ As Brubaker further suggests, "as a category of practice, [identity] is used by 'lay' actors in some (not all!) everyday settings to make sense of themselves, of their activities, of what they share with, and how they differ from, others" (pp. 31-2). A good way to clarify this issue is offered in the study by Leach et al. (2008) suggesting that identity should be observed as two essential dimensions, those of self-identification and of self-investment, where self-investment is a form of conscious self-identification, ascription of an identity. These two aspects of identity are often seen as relating to Durkheim's (1858-1917) categorization of mechanical solidarity, where identity is based on some recognizable shared traits, while the self-investment part of it is tied to organic solidarity, which is "based in a subjective

\footnotetext{
${ }^{94}$ This often-found level of analysis problem continues despite Turner's (1971) point that "there is an important discontinuity at the level of psychological processes between an individual acting as a differentiated, unique person and an individual acting as a group member, as a relatively interchangeable representative of a social category" (p. 110), which further strengthens the proposal that social identity should be seen as separate from the internal psychological perception of self.
} 
sense of purposeful self-investment in an in-group with which one has chosen to align oneself”' (Leach et al. 2008, p.428).

Of particular concern for this inquiry is the first dimension of identity, selfdefining, described as inclusion of self in an in-group, which Reese et al. (2015, p.428) say "subsumes the lower-level components of self-stereotyping (i.e., individuals" similarity to the in-group prototype) and in-group homogeneity (i.e., cohesiveness and coherence of the in-group)." ${ }^{95}$ Building on the seminal works of Goffman (1959) and Barth (1969), and in agreement with Burke and Stets (2009), identity is seen as "the set of meanings that define who one is when one is an occupant of a particular role in society, a member of a particular [identifiable] group, or claims particular characteristics that identify him or her as a unique person" (p.3). Moreover, as Malešević (2006, pp.14-16) correctly pointed out, identity has some built-in mathematico-logical elements in its

\footnotetext{
${ }^{95}$ The same author notes that the other aspect of identity, self-investment, is "a purposefully chosen categorization of the self and consequential investment into that category or group" (p.248), even though "Individuals can self-stereotype by perceiving themselves as similar to average (or otherwise prototypical) members of their in-group" (Leach et al., 2008, p.146. For more, also see Simon, 1992, p.27). For the case in question of Bosniak identity, the group which is to adopt it is still in its early stages, and without a clearly developed prototypical identity to rely upon or an individual to compare himself with. Therefore, it is very interesting to observe how that process of self-identifying, based on the individual's imagined ideal, and on imagined in-group cohesiveness, is developing. Yet, as observed through research, "social identification, the perception by individuals that they are joined in common category membership is necessary and sufficient" (Turner, 1981, p.100) for a group and identity to exist (for more, see the seminal work on groups by Tayfel et al., 1971). The self-investment aspect of identity should be very much of concern to nationalists, since nation is often seen as a conscious social construct (Connor, 1994). Nevertheless, when observing a group which is aiming to organize itself as an ethnic nation, through a process which Eder et al. (2002, pp.10-18) would call "ethnicization," as seems to be the case with Bosniaks, and to develop an identity category which can be adopted by its members, the first step is to observe the lower level of self-identifying, which should logically precede the higher level of selfinvestment. Finally, it is important to note the distinction by Leach et al. (2008) that a group's selfidentifying "focuses on the abstract psychological connection that an individual has to their in-group as a whole, rather than on the dynamics of interpersonal copresence or coaction" (p. 148) which is perhaps still too early to observe in the Bosniak case, and especially in the case of the diaspora where coaction based on identity is even harder. However, as was concluded by Leach et al. (2004, p.163), still-low self-investment among Bosnian Muslims vis-à-vis identifying as Bosniak, does explain low in-group cohesiveness against out-group threats and the Bosniak image. This is further discussed in Chapter Five, which describes Bosnian Muslims.
} 
meaning, as it signals that something on one side of the equal sign is the same as something else on the other side $(\mathrm{A}=\mathrm{B})$, but at the same time, that it is not equal to another thing $(\mathrm{A} \neq \mathrm{C}$ and therefore $\mathrm{B} \neq \mathrm{C})$. Therefore, identity is seen as a signifier, which becomes available to be claimed and acted on as the result of social interactions and circumstances, as well as ecological adaptations. As described by Turner (1981), identity is a cognitive category that is based on and shaped by social interaction, and, although it is played out only at an individual level, it is actually a part of the social domain, since only there does it actually become meaningful. Having been a social, therefore interpersonal, category, a person's identity is an "individual's knowledge that he belongs to a certain social group" (Tayfel, 1972, p.31).

National (social) identity in this study is observed simultaneously at two levels and as an interaction of the group and individuals, where an individual can ascribe his social identity in certain situations, by mechanisms that we do not yet fully understand, as Turner (1999, p.99) noted in his seminal work on identities. Therefore, social identity first becomes available at the group level, to be possibly claimed later by an individual.

That means that at the first stage, as a result of the catalyst event of nationalism, a group emerges as a nation out of some original or previously existing group(s). Only then, in response to the new circumstances in which the group exists, does there emerge an identity that members of the group can ascribe individually for themselves. Due to the interpersonal nature of identity, the new group (or at least an idea of it) has to emerge first, even if it is just among selected elites. Before the first stage of a group separation, 
the previous, original unit cannot allow salience for an identity which provides the possibility for the individual to be independent from the original group and have loyalties towards the group, or a section, that seeks independence. Such a situation is usually described as awkward and inappropriate, and an individual who has such an identity is pressed by the original group and society to integrate, which actually means to further his interdependence with other members of the original group. An individual usually cannot bear such pressure by himself, and such an un-integrated identity cannot continue. But a group can; however, first it has to use nationalism to change the circumstances of previous interdependence. As in Weber's definition of a state, as an entity with the exclusive right to use force, which exclusive right it will not allow anyone to usurp, the original group also has the exclusive right to shape an identity that stimulates a certain degree of interdependence among members of the group. In the political arena, the original group will even seek to limit some other group, or subgroup, from acting as an interloper trying to create new independence between an individual and the other group or sub-group. All this further supports the notion being proposed here, that nationalism first demands creation of the group, which only then provides the possibility for a new salient identity for an individual to ascribe for himself, which emphasizes interdependence primarily among the members of the newly formed or reformed group. ${ }^{96}$

\footnotetext{
${ }^{96}$ For clarification, as explained in the seminal work of Allport (1924), a group is seen as a collection of individual members and not a real entity with its own mind or nervous system. The interaction between the individuals and the group, as well as the influence the group can assert upon an individual, happens because, once formed, the group becomes a social system for patterning the interactions among those individual members within and without the group. Yet, an individual still has a mind of his own and can choose to conform or not to those patterned standards, or to seek an alternative group and its identity.
} 
As noted earlier, when we discussed modernist approaches to nationalism, since nation and its identity can only be understood if observed at both levels, that of a group's elites and that of its ordinary people, in this stage of the inquiry the attempt is made to observe nationalism and identity at the level of ordinary people in the diaspora and to draw conclusions from it.

Identity is therefore a cross-sectional category: it is ascribed by an individual, while measured through individual responses to the questions designed to measure it as a category of practice of a group. After all, political theory now emphasizes that "the group is morally and sociologically prior to the individual" (Vincent, 2002, p.3), and so it is appropriate to observe identity constructions simultaneously on both group and individual levels, and to draw conclusions from interactions of these two levels of social reality of the group. Ecological adaptations provide the backdrop for interactions and circumstances that provide a signifier for an identity, although adaptations to the ecology, nowadays, less often include adaptations to a particular space due to people's increased mobility. Yet social interactions, here or there, are still paramount for a person's selfunderstanding and identifying. This is because, ontologically, born in a state of ecological harmony or fitra, ${ }^{97}$ a person is a father, mother, son, adolescent, employee, student, believer, romantic, killer, soldier, shepherd, Ruritanian, ... ultimately a human being exclusively as a result of social interactions - and all those identities, or layers of identity,

\footnotetext{
${ }^{97}$ According to Islamic theology, fitra is the natural state and essence of a human being with which any person is born, and as explained through the Prophetic tradition, that human being is then shaped by interactions with the world (for more, see Sahih al-Bukhari, Volume 2, Book 23, Number 441). In some sense it is similar to the stage of the "noble savage" in a state of nature which Rousseau (1978) describes: "Man was/is born free, and everywhere he is in chains" (p.46). Fitra, therefore, is that initial stage of human essence, free from social forms and identities, which come later from the social interactions a person experiences.
} 
mean something only within certian specific social circumstances. For a human being there is no escape from social interactions, and identity is essential for them. As declared in Aristotle's Politics, a human being can fulfill his individual nature and become "good" only as a part of the whole, within the city-state and the social interactions in it (Carnes 2013, pp. 2-5)..$^{98}$ Durkheim (1997, pp.179-180) furthers this notion by explaining that a person fulfills his most intimate instincts to be happy by being part of a society, and consequently he instinctively seeks to be part of one. ${ }^{99}$ Once we are in the realm of instincts, we are in the domain of the state of nature, where, again, a person cannot know who he is without interactions with another human being. For Bion it is impossible to be a human being without having some degree of valency, ${ }^{100}$ which he also sees as the instantaneous, involuntary and instinctive aspect of human behavior. As MacCormick stated more recently, "the truth about human beings is that they can only become individuals - acquire a sense of their own individuality - as a result of their social experiences within human communities" (as mentioned by Vincent 2003, p.93). Therefore, without the disconfirming "other" there is no "I", and only when another person is present can an identity be felt and acted out. Even Eve was created so that Adam could have and be conscious of his identity, which developed through his

\footnotetext{
${ }^{98}$ In the conclusion of his treatise on man and the city, Aristotle proclaims that the one who is out of the realm of social exchanges "is either a beast or a god" (Carnes, 2013, p.5) but not a human being.

${ }^{99}$ For Durkheim the need of an individual for society is the very source of morality and it is beyond consciousness, no matter how large a society is (pp. 331-7).

100 "This is a term used to refer to the individual's readiness to enter into combination with the group in making and acting on the basic assumption" (Rioch, as mentioned in Burke et al., 2009, p.474).
} 
interactions with her, God and the devil, and achieved meaning within the circumstances created by those interactions. ${ }^{101}$

These interactions are even more pronounced when more complex social and political circumstances, whether incidentally or purposely created, shape the demand in an individual to feel, adopt or claim some identity. In what Baum (2001) describes as a Durkheimian argument, "human beings are integrated into humanity not as single individuals but as members of different peoples or cultural communities" (p.111), and that social level is where identities are formed and offered to individuals. As Kedorie (1996) wrote about Poles, "I myself did not know that I was a Pole till I began to read books and papers" (p.115) which were not written by me. Hence, identity should not be confused with "self" - as is also suggested by Elliott (2001, p.9); it exists as a signifier outside of an individual which he can adopt and claim for himself through communicative activities.

Likewise, Bosniak identity is the external signifier which an individual person can or does adopt and claim for himself, and in such a way it exists as both a personal and a social reality. This inquiry is considering it as an interaction of both levels, to find out how strongly it is embraced by individuals through the interplay with nationalism, and whatever elements that identity entails.

\footnotetext{
${ }^{101}$ Ontologically (and perhaps surprisingly for some) Erikson's theory on identity is also rooted in religiously defined interactions. Erikson (1968) writes: “How did man's need for individual identity evolve? Before Darwin, the answer was clear: because God created Adam in His own image, as a counterplayer of his identity, and thus bequeathed to all men the glory and despair of individuation and faith. I admit to not having come up with any better explanation" (p. 40).
} 
From these interactions between the individual and his surroundings, which are institutionalized through an identity, it may be concluded that identity has to have some element of intersubjectivity since it "exists" on both the individual and the group levels. Both levels constantly interact with each other's self-perceptions, and that intersubjectivity often serves to distinguish "us" from "them". Groups can not only provide and assign signifiers to an individual that determine his social position, as Berger and Luckman (1966, pp.74-6) established, but can also influence the individual's own perception of self-identity. But the game does not stop there, and individuals can also create new circumstances which (re)define poles of identity.

Since all groups have their progenitors and subsequent members who have to live and face a constantly changing world, identity becomes an anchor-like category in that ever-changing world. These changes sometimes require new individual actions, which after the process of routinization and social formalization, or significant shared experiences, may become relevant to the whole group's self-perception. These changes may also require the group to expand, contract, alter, and adopt a whole new form of groupness and subsequent identity. ${ }^{102}$

Although identity is certainly a matter of more or less conscious individual and group ascription, it may be externally imposed on a group and subsequently on a

\footnotetext{
${ }^{102}$ Gellner (1997) also noted that it is well known that groups change pillars of groupness such as religion, language, way of life and even names as a result of changes in structural conditions around them. The same changes may also require groups to expand in order to include other groups, or to contract to shed members and sub-groups. All of these situations may be ripe for the emergence of new groups and their identities, and sometimes they are considered a turning point which skillful leaders can turn into a "barometric event", as explained by Bennis and Shepard's (1956) theory of group development (in Burke et al. 2009, pp.450452).
} 
constitutive individual. Woolf (1996, p.29, 30), Hobsbawm (1982) and Anderson (1991) noted well how external impositions by local inhabitants and officials particularly affected European emigrant identities. As a result of mass communications, the same external impositions can now occur on the international level where identities are imposed on states, groups, and individuals, whether they like it or not. ${ }^{103}$ So Muslims today, including Bosniaks, especially those living in or interacting with the West, often have to respond to the externally imposed identity of suspect, extremist, terrorist, of permanent stranger. Whether the person ignores, accepts or rejects such signifiers, those external impositions still affect and shape identity, which partly develops in response to them. Such identity strongly determines the quality and mode of interactions with others, and as a result, one identity might be dropped and replaced by another. But, as Huntington (2005, p. 22) correctly noted, it is easier for an individual to change or modify identity than it is for a group, and the same is true for Muslims in general, and Bosnian Muslims in particular, especially those in the diaspora (see Miskovic 2003, p,224; and Colic-Peisker 2006, p.624). That is why Bosnian Muslims are carefully negotiating ascription and adaptation of any new, or significantly reshaped, identity. Since Muslims are now stigmatized in the post-9/11 West, these conditions might create a further incentive for Muslims from BiH to drop the "old" identity of "Muslim" and adopt the new one of "Bosniak;" however, it is still too early to know.

Two things emerged from observations among the diaspora population sample. First, there is apprehension regarding the old identity of "Muslim" due to the anti-Muslim

\footnotetext{
${ }^{103}$ For more on the regime of external imposition, see Doty (1996).
} 
climate in the West, and second, because of that, they might lose their status as victims, which they paid for with thousands of dead and maimed Muslims in the war and genocide in $\mathrm{BiH}$. Confirmation that these apprehensions are not unfounded, comes from one of the Bosnian diplomats (who represents Bosniaks in the Diplomatic Corps), ${ }^{104}$ who has said off the record that Muslims from Bosnia have paid a huge diplomatic price because of their "Muslim" identity, which denotes their religious affiliation, and who explained to me, a sympathetic listener, the urgency to embrace the new term and identity of "Bosniak."

Obviously, identity seems to be primarily a matter of in-group concern, but it actually responds to two categories of demands, internal and external. In its effort to become salient, a desired identity responds to internal political dimensions and tries to address the needs, shortcomings, and aspirations of a group. ${ }^{105}$ External demands placed on identity are evident not only in a group's decision about who is the disconfirming other that significantly shapes any form of groupness, but also in those external influences that result from the dynamics of international relations, norms and frames originated at that level of politics. Since the international realm is the prime political

\footnotetext{
${ }^{104}$ As in the BiH government, whose personnel is by and large structured by the Dayton Peace Agreement to include representatives of the three constitutional nations of Bosniaks, Serbs, and Croats at all levels of national government. So in the critical diplomatic missions to the U.S., the position of BiH Ambassador is assigned to a representative of one group by the principle of negotiation among those who were in the $\mathrm{BiH}$ national government at the time. However, as the Ambassador is from one $\mathrm{BiH}$ national group, his deputies are from the other two. That way, not only is the bureaucracy expanding in the BiH diplomatic corps, but also those representatives can in theory control each other's work and report what is going on to their respective groups "back home." That is how the diplomat I spoke to is aware of the "diplomatic price" that Muslims of $\mathrm{BiH}$ are paying because of their identity name.

${ }^{105}$ It is important to remember that nationalism is an action which is intended to address deficiencies in political conditions, such as a lack of adequate polity, or a lack of an adequate national base, or in the words of Brubaker (1996), "polity-seeking [and] polity-upgrading" (p.79) situations in which a group can find itself.
} 
domain where the nation is acting as a collective, the dynamics of international relations are very important for the nation, as they significantly frame possibilities for movements and processes which concern a group's and its members' identity.

Framing an identity is strategically important in the process of appealing to the target population. The interplay of internal and external demands on a group that aspires to nationhood is actually a matter of the everyday life of the group's members, as well as of greatest concern to the group's leaders, who are choosing between conformity with, or protest against, framing when constructing the desired identity. ${ }^{106}$ For that reason Doty (1996) notes that geopolitical productions of representations of regions and peoples are an important aspect of any inquiry since they "underlie the production of knowledge and identities and [in such a way] these representations make various courses of actions possible" (Doty, 1996, p.5). The same was noted by D'Costa (2006) when she stated that marginalization of identities, groups and nations often occurs on the international level as they tend not to notice women's plight in certain countries as opposed to others. In other case studies from the global South, Iyob (1995) described well the thirty-year-long national liberation struggle of Eritreans to assert their right to exist against the longmaintained Ethiopian hegemony in Black Africa. These few examples show how international relations do influence the internal dynamics of nationalism and their desired

\footnotetext{
${ }^{106}$ For example, Miskovic (2007) notes, "Regardless of their racial invisibility, in the atmosphere of loud and widespread American nationalism that dominates the post 9/11 United States, foreign accents and names that do not sound Anglo-American make [Bosnian Muslim] immigrants visible. Thus, they feel threatened in two ways: as being perceived as a foreign and terrorist threat" (p.538). Such threat perceptions certainly significantly influence not only the calculations of people who are to acquire a new salient identity but also the strategies leaders might use to cajole people into joining the nationalism project and accepting the new identity.
} 
salient identity projects, especially in regions such as the Balkans and for the Muslims as a people.

For Bosnian Muslims, the geopolitical production of representations affects their identity project in at least two ways. First, they are Muslims, and international representations of Muslims and Islam are significant factors in their strategic interactions with others as well as among themselves, and as it is observed, their elites are aware of such negative representations as they push for the new identity of Bosniak to be salient, rather than the old identity of Muslim. Second, as a nation from Bosnia they are part of the regional tapestry of the Balkan peoples from the South who are often epitomized by Northwestern Europeans as the "others within" (Neofotistos, 2008), while the region in which they live is seen as Europe's internal Orient. ${ }^{107}$

Both aspects of the geopolitical representations play a role on the level of international relations, as they significantly affect Bosniak identity, and the kind of identity Muslims of Bosnia can safely claim. Although data for this research was gathered in the conditions of the group's diaspora, I will argue that the same issues affecting the diaspora affect the homeland population as well, while the two groups are responding to those pressures somewhat differently. For example, both groups make an effort to distinguish themselves as "different Muslims," claiming that they are European or, more often, Bosnian Muslims, where "Bosnian" is an adjective which is supposed to

\footnotetext{
${ }^{107}$ McCarthy (2009) notes "Orientalism was indeed at its peak in the Balkan wars when the putatively secular Muslims of Bosnia-Herzegovina were besieged by Serbs. The West (intellectuals and tabloid media alike) dressed its fascination as anti-Orientalism in their eagerness to describe the Bosniaks as 'like us' and, therefore, cast the Serbs as the alien then in us - a situation aided by the fact that ethnic Serbs indeed lived among Bosnians" (p.127).
} 
describe an especially tolerant kind of Muslims, as opposed to the rest of the global Muslims, who are perceived exceedingly negatively at the international level. ${ }^{108}$ The Bosnian Muslim diaspora groups in the U.S. and elsewhere in the West, ${ }^{109}$ however, appear to exert more effort to distinguish themselves as a separate group from other Muslims in the U.S., especially if they try to maintain their religiosity. They try very hard to establish their own mosques, even when they build a Bosnian Mosque literally right next to the mosque attended by all other Muslims in the area, ${ }^{110}$ as well as to cultivate their own separate relationship with non-Muslim neighbors in the places where they live in significant numbers. Muslim elites in Bosnia, along the same line, emphasize more their Europeanness to signal both that they are European natives and that they are therefore more tolerant Muslims. ${ }^{111}$ Yet, evidently, both Bosnian Muslim groups, those "back home" and those in the U.S., are essentially responding to the framing of Muslims which is done at the international level.

\footnotetext{
${ }^{108}$ In a recent interview, the Bosniak member of the BiH presidency publicly noted that Bosnian Muslims practice "inclusive Islam," as opposed to some other types of Islam which, presumably, may be found elsewhere. For more, see Tanjug 2016.

${ }^{109}$ See, for example, Colic-Peisker 2005.

${ }^{110}$ As, for example, in the case of the Islamic Cultural Center Behar in Grand Rapids, MI at 3425 E. Paris Avenue where they built a beautiful mosque right next to the already existing Al Tawhid Islamic Center at 3357 E. Paris Avenue, while they sometimes share each other's parking lots.

${ }^{111}$ Bosnian Muslim elites are trying to position themselves as autochthonous Europeans as opposed to nonautochthonous Muslim European immigrants, and they seek to be the voice of Islam in Europe and to gain leadership of the group. A good example of this is the effort of the former Bosnian Reis Ulama Dr. Mustafa Cerić to position himself as the leader of European Muslims by devising and circulating a Declaration of European Muslims, while being perceived skeptically by other Muslims in Europe and even by other Muslims from the Balkans. One of the leaders of the Macedonian Islamic Community, Jakub Selimovski, who was also the last Reis Ulama of the joint Yugoslavia's Islamic Community - which was largely dismembered by Cerić himself - "raised the point that the Declaration might imply geographical divisions within Islam, while 'Islam is one'" (quoted by Merdjanova 2013, p. 128). (For more on the issue, see Merdjanova 2013, pp.126-8).
} 


\section{IV: A SHORT HISTORY OF BOSNIAN MUSLIM GROUPNESS}

\section{4-1: Bosnian Muslims as a Distinct Group of the Bosnian Pot of People ${ }^{112}$}

At the outset of a brutal war waged against the Muslims of Bosnia with genocidal intentions to destroy and expel them from their homeland of $\mathrm{BiH}$, eight hundred of their notables $^{113}$ gathered in Sarajevo on December 22, 1992, and issued a declaration in which, in passing, they mentioned the name Bosniak (Bošnjak) in reference to their own people. At a second, better organized, meeting held a few months later with more than three hundred selected participants from all over the country, they definitively agreed on behalf of their population to give up the group's old name "Muslim," and adopt "Bosniak" as their new name and identity. This decision can be seen as their major step towards secularization of their identity and their choice to give up "Muslimness" and adopt "Bosniakness." "114 This act was noted as the fulfillment of the long-sought historical right and dream of Bosnian Muslims to reclaim, or claim, ${ }^{115}$ not only the name for themselves, but also the role of a decisive political factor in the newly independent country of $\mathrm{BiH}$ and the right to decisively tie their origins to it. ${ }^{116}$ The decision was then publicized as a

\footnotetext{
${ }^{112}$ Bosnian Pot (Bosanski lonac) is a famous Bosnian dish known for its taste and for the flexibility in the ways of making it. It is basically a stew slow cooked over a direct fire in a clay pot, made out of whatever ingredients a person might have at the time. It usually includes chunks of different meats and vegetables. It is used here to symbolize the process of the emergence of the Bosnian Muslim group out of the milieu of local peoples and the contingencies of history.

${ }^{113}$ The notables were mostly intellectuals from various disciplines, since during the Communist era no other type of elites could clearly develop, while the Communist school system did produce a good number of intellectuals.

${ }^{114}$ Kukavica 2013, p.13.

115 Orwell (1953, pp.80-83) wrote about the characteristics of nationalist thought and indifference to reality. Anderson (1991, p.5) also noted the tension between the vision of an historian vs. the vision of a nationalist that can be observed in this deliberation about the antiquity of the modern Bosniak identity.

${ }^{116}$ Indeed, as Simmons (2002) noted, the "term of identity 'Bosniak' (Bošnjak), gives evidence of their connection to the territory - rather than the appellation foisted on them by the Yugoslav government in
} 
major step forward for Slavic Muslims of the former Yugoslavia living within and without $\mathrm{BiH},{ }^{117}$ as well as those recent refugees living in the diaspora.

The city of Sarajevo, where the first and second meetings were held, was under siege and intense shelling by the former Federal Yugoslav Army (JNA) and Serbian paramilitaries from the nearby hills. It was the first year of war and the normal lines of communication and traffic had all been destroyed. It was extremely hard and dangerous for Bosnian Muslims to travel around BiH. So very few of them did. So those hundreds of men and few women who gathered on December 22, 1992, and decided on the name change were mostly residents of Sarajevo. They made the decision on behalf of the rest of the population, about three million Muslim people of the former Yugoslavia and the diaspora. Among the attendees were some notables who had moved to Sarajevo from other regions of $\mathrm{BiH}$ and Sandžak but all of them had lived and worked in the Bosnian capital for some time before the war and the decisive meeting. In his book about the city, Donia (2006) documented how Sarajevo emerged as the Bosnian Muslim elites' main power-base and how the city outmaneuvered and outstripped other important Bosnian cities of power and influence. Because of that, Sarajevo-based elites one more time played a decisive role in making the profound decision about the name of the Slavic-

1963 -Muslim (Musliman)" (p.634). For that reason they overwhelmingly voted for the independence of $\mathrm{BiH}$ in the internationally mandated referendum held on March 1, 1992. Some Bosnian Muslims now celebrate that day as the $\mathrm{BiH}$ Independence Day, while Bosnian Serbs do not.

${ }^{117}$ Although the decision about the name was intended to put an end to the discussion of whether Muslims are a purely religious group or a politico-historical community of $\mathrm{BiH}$ that happens to be Muslim, instead, many new important questions emerged within the group, such as who Bosniaks are, and what that name and identity mean. Kukavica (2013, p.14) also notes such differences in understanding even among Bosnian Muslim elites. 
speaking Muslims of the former Yugoslavia and $\mathrm{BiH}$,not, however, without some vacillation.

From the title of this historic event, the "Kongres Bosansko-Muslimanskih Intelektualaca" (The Congress of Bosnian-Muslim Intellectuals) and through the contributions and documents from the event, it can be observed that the Muslims of $\mathrm{BiH}$ were referred to in several different ways. They were mentioned as just "Muslims" (with capital $M$ according to the Serbo-Croatian language grammar rule to denote a national group); as "bosnioherzegovinian muslims" (both with lowercase letters to denote a regional religious group); "muslims" (with lowercase $m$ to denote a religious group); as "Bosnian Muslims" to denote an initiative for a new national name for the group; ${ }^{118}$ and somewhat shyly as "Bošnjaci"119 (Bosniaks). From all these variations we can sense their uncertainty and indecision about the name. ${ }^{120}$

The people who were to accept the new name responded with mixed reactions as well. Older people were confused about the change, and many of them rejected it completely. For them it meant discontinuity of their previous, primarily religious, ethnic identity, which they had gotten used to carrying, despite all they had to pay for it, especially since the Ottoman withdrawal from the Balkans. ${ }^{121}$ Others, mainly from the

\footnotetext{
${ }^{118}$ For example, Maglajlić (1994) argued that "Bosnian Muslims is the best name-option for the current phase of life of the people who are, in the last few months, faced with criminal intent of their extinction" (p.51).

${ }^{119}$ The name was usually noted only in brackets next to the term "Bosnian Muslim," to make it clear to whom they were referring.

${ }^{120}$ For more, see "The Declaration" (in Kamberović 1994, pp.185-8).

${ }^{121}$ Palairet (1997, pp. 29-33) notes the significant regional de-urbanization that came as a result of the number of homes and their Muslim inhabitants that were lost after the Ottoman withdrawal from the
} 
younger generation, more readily accepted both the name "Bosniak" and the claim that it was not new but only a reclaimed forgotten old identity that members of the group carried proudly during the time when they were the most important political subjects of BiH. The middle generation of Bosnian Muslims, who grew up during the time of Communist-led Yugoslavia, and who "made a choice" to be Muslims for the first time by a self-assertion in the census of 1961, and finally also were officially recognized in the census of $1971,{ }^{122}$ now remained the decisive section of the group in this name-changing project, since their decision would tip the scale toward acceptance or rejection of the Bosniak name. For this reason, through careful observation of the reaction of this section of the population, we can measure the "success" of Bosnian Muslim nationalism in its mission of engendering a political nation.

The term Bosniak was sometimes used, in addition to other names, throughout the time of the Ottoman Empire to note and distinguish Muslims of Bosnia from all other Muslim groups of the Empire, ${ }^{123}$ and sometimes to distinguish them from non-Muslim

Balkans. Professor Justin McCarthy of the University of Kentucky is one of the most prominent historians who raised awareness of the issue of the ethnic cleansing and genocide of Muslims from the Balkans following the withdrawal of the Ottomans. Those "cleansings" were carried out differently throughout the region. Palairet (1997, p. 29) notes that, in comparison with Bulgaria and Serbia, the pogroms of Muslim inhabitants were most severe in Montenegro. My parents come from the border region of Sandžak, now squeezed between Serbia and Montenegro, and they still remember well the pogroms they experienced and other older ones that their parents recounted to them. Everything they experienced was because of their Muslimness and for them the particular term "Muslim," as their national identity carries a special significance.

${ }^{122}$ See Sekulic et al. (1994, p.84).

${ }^{123}$ For example, Miran (2009, p.120) notes the last name of "Bashnak" for several families of "Askeri origin" among the current residents of the Red Sea city of Massawa (off the coast of present-day Eritrea), an important deep-sea port held by the Ottoman Empire steadily till 1813 (and intermittently till 1885). They were descendants of the Ottoman soldiers from Bosnia, who came to serve in this important cosmopolitan city, married locally and stayed even after their units were gone. Now they carry the last name to denote their origin from Bosniaks. 
subjects of neighboring Balkan territories. However, Bosnian non-Muslims were also sometimes referred to as Bosniaks. ${ }^{124}$ Many Bosnian Muslim intellectuals, Professor Mustafa Imamović (1994) among them, argue that Bosniak was the term primarily used to denote Bosnian Muslims, and only during the years when Ottoman control over $\mathrm{BiH}$ was being replaced by Habsburg rule did both empires try to push for the term to be used by all three confessional groups in order to stamp out growing Serbian and Croatian nationalisms. The empires' administrators were not successful in their attempts, and the groups never jointly adopted the name, argue Bosnian Muslim historians. However, perhaps inadvertently, they managed to push Bosnian Muslims out of the Bosniak name designation. ${ }^{125}$ In order to differentiate themselves further from the Orthodox-Christian Bosnian Serbs, and the Catholic-Christian Bosnian Croats, Bosnian Muslims chose to identify themselves simply as Muslims, sometimes with the adjective "Bosnian," but more frequently without it. During that whole time, Bosnian Muslims spoke a Slavonic language which was referred to by the demonym "the Bosnian language," after the land where they lived. ${ }^{126}$ Since it was also the language of a particular Muslim group from

\footnotetext{
${ }^{124}$ Bošnjak is sometimes used as a last name among Catholic Croats of both Croatia and BiH. It is also used as a last name by some people in Serbia, mainly among Muslims, but also by a few from Orthodox Christian backgrounds. Finally, there is also a village in Central Serbia with such a name, now occupied exclusively by Orthodox Serbs. In Kosovo, when used by Albanians, Bošnjak can also have a derisive connotation. When the accent is on Boš (Bosh), the first syllable of the name, it purportedly means "nothing" in the Albanian language. In that way, non-Slav Albanians try to insult Bosnian Muslims and assert their own nationalism against them to make them give up their Slavness - since they are not well treated by other non-Muslim Slavs anyway - and push them to adopt Albanianness, primarily by abandoning their Slavic language and adopting the Albanian language as their own. This is particularly well known to the Muslims of Sandžak and Macedonia, and by the Nashenci and Goranci of Prizren, who frequently interact with the overwhelming Albanian majority.

${ }^{125}$ For more, see Maglajlić 1994, p. 51; or Imamović 1994, p. 14.

${ }^{126}$ During medieval times, some Bosnians also used bosančica, a Bosnian version of a Cyrillic script, now often found on Bosnian monumental medieval tombstones (stećci) from that time. The same script was also sometimes used by Catholic churches in Dalmatian coastal areas. For more, see Zelić-Bučan (2000).
} 
which came many military and civil dignitaries of the Ottoman Empire, ${ }^{127}$ the Bosnian language became one of the languages of the Porte. Yet, it should be noted here that it was not the systematized and organized Bosnian language, written in Latin script, that it is today. ${ }^{128}$

The variations of these same three issues, of territory, language, and a new religion which propelled the group to the level of active subjects of the Ottoman Empire, became factors of groupness for the newly formed assembly of Bosnian Muslims which emerged from among the locals as the result of the Islamization of Bosnia. It took time for a tip and cascade effect of Islamization to occur, ${ }^{129}$ but when it did, the new form of groupness was more readily accepted by younger people, ${ }^{130}$ the usual vanguard section of a society. In the permissive environment of the Islamic Ottoman Empire, Bosnian Muslims over time developed their own elites, which gradually began to have their own strictly local interests. Ever since that time, Bosnian Muslims have continued to exist in their homeland as a more or less coherent group, without their own state, but with their

\footnotetext{
${ }^{127}$ For example, Biščević (2006, pp.470-86) notes at least 84 different governors of Bosniak origin who ruled in Bosnia, while Ramić (2009) notes 29 Bosnian Muslim kadis (judges), and six governors in Egypt.

${ }^{128}$ During Ottoman rule, Bosnian elites adopted the same interests as Ottoman elites and often wrote in the primary languages of literature of that time, Arabic and Persian, and sometimes in arebica, a Bosnian version of Arabic script adjusted to denote Slavic sounds and used especially to write alhamijado literature. The word alhamijado derives from the Arabic term al adjemia (foreign, non-Arabic). Muhsvin Rizvić (1990) provides a good bibliography of interesting Bosnian contributions on this topic, while Algar (1994) has written about the Persian language contributions of Bosnian Muslim authors.

${ }^{129}$ The first to accept Islam were spahis from among the remaining small landowning class, and they were followed by peasants. The tipping point for a cascade of conversions corresponded with the demise of Hungary in 1526 after which people in Bosnia accepted Islam collectively and in large numbers (Handžić 1975, pp.121-2).

${ }^{130}$ Filipović $(2005$, p.103) notes that Islam was initially accepted by the younger generation as can be observed in Turkish tefters from that period which often note a Christian father and one or two Muslim sons. The same can be observed in the Ottoman court records, as Buturovic $(2015, \mathrm{p} .6)$ noted in her interesting work.
} 
own, more or less capable, elites whose rule was instrumental in the important turns the group took throughout its history.

Figure 4.1: BiH Physiography Map (Source: Perry-Castañeda Library MapCollection, 2015)

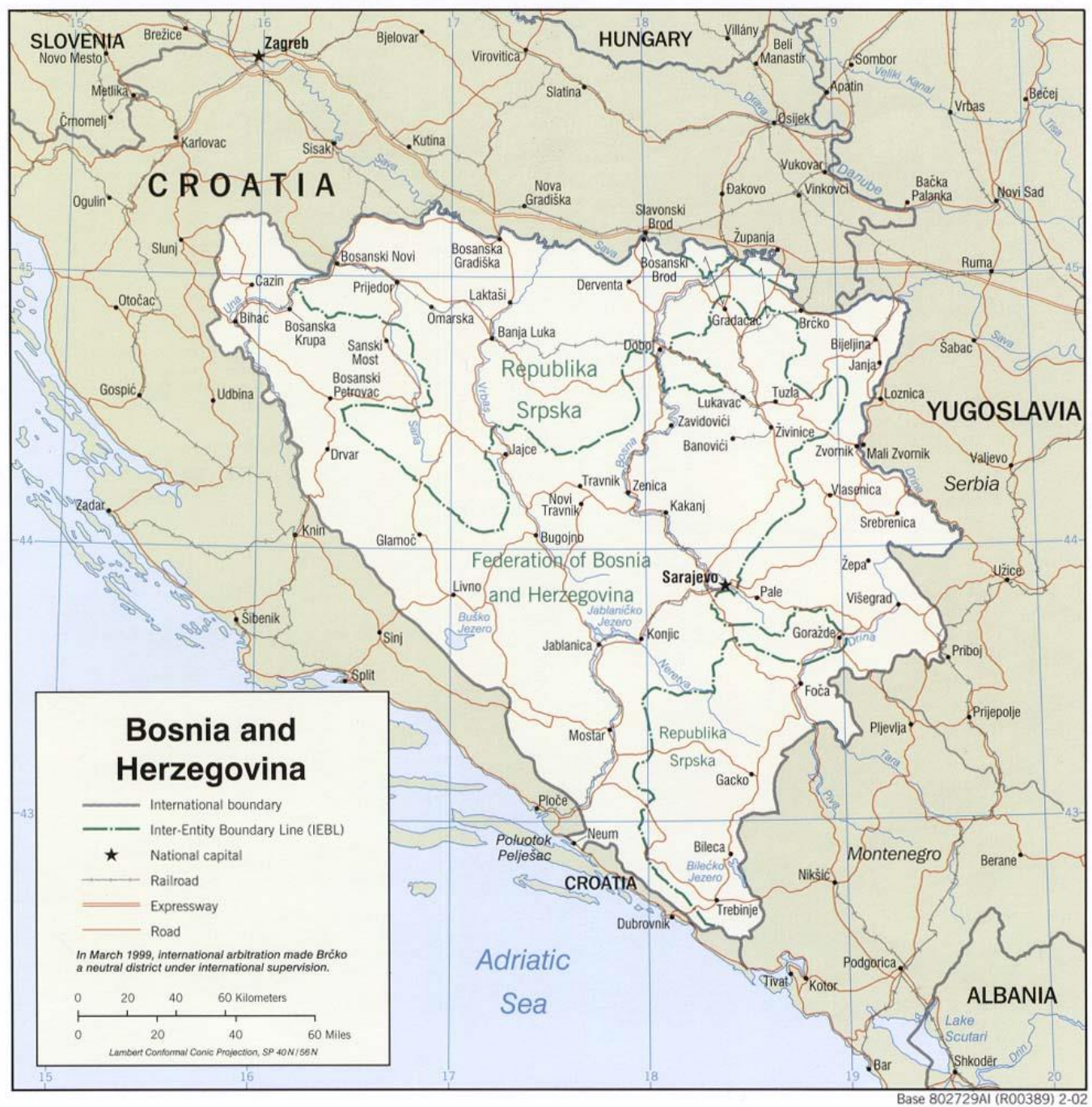

Using an historical, although not chronological, approach is useful to provide the background for this study of the project of contemporary Bosnian Muslim nationalism and Bosniak identity, and to review the historical development and the composition of the Bosnian Muslim elites. 


\section{4-2-1: Significant Early History of Bosnia and Its People}

The eminent Bosniak laureate, Abdulah Sidran, ${ }^{131}$ once simplified the history of the central Balkan territory by saying, "the history of Bosnia is the history of the attempts to grab Bosnia." That statement is truly an accurate representation of the story of $\mathrm{BiH}$ and its people, who are inevitably at the center of those efforts to win over the land, which is now internationally recognized as the Republic of Bosnia and Herzegovina. For the last 138 years, Bosnian Muslims have been the exclusive Bosnian group that tied its own survival to the survival of $\mathrm{BiH}$ as an entity. Since all people's stories in Bosnia begin with Kulin Ban, ${ }^{132}$ the relevant "history of grabbing for Bosnia" can also be said to have started in 1192, when the jurisdiction over Bosnia ${ }^{133}$ was transferred by Pope Gregory IX from the Archbishop of Dubrovnik to the Archbishop of Split. It was an act orchestrated by the Hungarians, who sought ways to assert their authority over Bosnia via Split.

Although Christianity had existed to some extent throughout Bosnia from the $5^{\text {th }}$ century on, Slavs who came to the Balkan peninsula in the $6^{\text {th }}$ century were still not Christianized until the $10^{\text {th }}$ century. ${ }^{134}$ Their Christianization, however, should be seen as partial, since they were only adopting some of the major Christian rituals of the time,

\footnotetext{
${ }^{131}$ A self-declared Bosniak, Abdulah Sidran is a BiH author who wrote the screenplay for several worldacclaimed films such as the Oscar-nominated "When Father Was Away on Business," "Kuduz," and "The Perfect Circle," among others.

132 "Od Kulina Bana i dobrijeh dana" (from the time of Kulin Ban and the good old days) is a common phrase regularly used by Bosnians to denote the ultimate beginning of "any" good long story. Kulin Ban was the ruler over Bosnia from 1180 to 1204, who brought stability to the medieval Bosnian state.

${ }^{133}$ The name Bosnia will be used according to historical records. The name Bosnia and Herzegovina began to be used during the last period of Ottoman rule, and after the Austro-Hungarian takeover.

${ }^{134}$ Fine 1975, p.113.
} 
albeit in localized form. ${ }^{135}$ The lack of proper knowledge of Christianity allowed for various deviations and local practices to develop, and in 1270 the Inquisition was dispatched to the land of Bossona (Bosnia) to investigate alleged heresies. ${ }^{136}$ Although Kurtz (1983) proposes that "every heresy implies a political stance" (p.1087), in the case of Bosnia the "heresy" was more the result of an absence of a centralized religious hierarchy and a consequent lack of knowledge, than of a political stance. Yet, designating such conditions as heresy was indeed a matter of political stance. Since the Bosnian ruler Kulin Ban ignored the transfer of the Bishop's authority and continued to maintain close relations with Dubrovnik, the Hungarians escalated their plots against Bosnia in their efforts to take over the land by claiming that it was a hotbed of heresy. ${ }^{137}$ The accusation of religious sacrilege was followed by the Crusades, which ravaged Bosnia from 1234 till 1238 and a second time in $1241 .^{138}$

The Hungarians withdrew from Bosnia only after the Tatars invaded their land in 1241, but they left behind a great hatred for those Hungarians, and by extension, for the official Catholicism which they represented while occupying Bosnian lands. In his pioneering work on the dualist Bosnian Church, Fine (1975, pp.140-155) writes that only after those Hungarian Crusades in Bosnia, did nativist movements give birth to the independent Bosnian Church with its own hierarchy and its own version of Catholicism

\footnotetext{
${ }^{135}$ For example, the Bishop of Bosnia, Radigost, was consecrated in 1189 in the Slavic language since he knew no Latin or any other language (Fine 1975, p.115).

${ }^{136}$ As reported in the Second Inquisition Treatise, "Tractatus de Hereticis," of Anselm of Alexandria (Fine 1975, pp. 119-120).

${ }^{137}$ Fine 1975, pp. 120-123.

${ }^{138}$ For more, see Lock 2013 pp.172-3.
} 
mixed with local traditions, as well as elements of Manicheism and dualism found elsewhere in the Balkans. Animosity toward Hungarians enabled the Bosnian Church to continue and to keep the land from being dominated by any single religion, as well as without a coherent religious core belief of a Bosnian state. This situation also provided an opportunity for the eventual emergence of the Orthodox Christian influences that began in the 1440's and the late 1450's, but not before that primarily in Herzegovina. ${ }^{139}$

Eventually, the animosity towards Hungarians turned Bosnians closer to the new regional hegemon of the Ottomans, until they came completely under Ottoman rule in 1481, when the last parts of Herzegovina were taken over. In the decades after the Ottoman takeover, Bosnian Muslims emerged as a political factor in the lands of Bosnia and Herzegovina. Sources note that by the $16^{\text {th }}$ century travelers mentioned Catholics, Orthodox, and Muslims in Bosnia, signaling that by that time some natives were fully Muslims, and that the Bosnian Church no longer played a role in local affairs even if some individuals continued to practice some forms of the Bosnian nativist Christianity. ${ }^{140}$ This very brief venture into the pre-Ottoman history of the region is useful since some contemporary Bosniak narratives are trying to tie Bosniaks, and their acceptance of Islam, to the "heretic" Bosnian Church and its purported mass conversion to Islam, as well as to the animosity towards Hungarians and the Pope as a catalyst of Islamization. ${ }^{141}$ However,

\footnotetext{
${ }^{139}$ Fine $(1975$, p. 327) points out that despite the popular notions of Bosnia as a battleground between the two versions of Christianity, this was generally not the case until the mid- $15^{\text {th }}$ century, when Orthodox Christian religious teachings started to appear in Bosnian regions, while still without a significant Serbian presence.

${ }^{140}$ Fine 1975, p.375.

${ }^{141}$ For example, I was told by a Našinac from Prizren, Kosovo (who now lives in Chicago), that they prefer the Bosniak identity because they share not only a common religion now, but also the history of the same
} 
such assertions are either ignored or sometimes accepted - but with strong hesitation - by the Bosnian Islamic ulama.

\section{4-3: Bosnia’s Ottoman Legacy}

Right before the Ottoman Conquest, Bosnia was beginning to enter the feudal era, when landowning was the main source of wealth and warfare was the main tool for the increase of wealth. Due in part to its geography, being a rugged terrain where the plains of Slavonia turn into hills and eventually mountains, some over 2,000 meters high whether a person was going south from Austria towards Serbia and Greece and further into the Middle East and Asia over the Bosporus Bridge, or from Russia going west towards the Adriatic sea and the Mediterranean - Bosnia became a natural frontier for the powerful kingdoms of the North-west and South-east, with all the implications of a frontier. The designation of a territory as "frontier" usually means it is a place for "natural" expansions of powerful people and civilizations. Additionally, it often also means a place which needs to be tamed and "civilized" by those same powers, and that is a much uglier aspect of designation as a frontier. ${ }^{142}$ Both happened to the Balkans in general and to Bosnia in particular, where over time many intruders came and left traces of their presence. That is why Bosnia was a meeting place for Illyrians, Hellenic Greeks, Romans, Macedonians, Avars, Huns, Thracians, Celts, Goth, Gepids, and others, who were eventually all overcome by the southern Slavs who came to the Balkans between

medieval heresy of Bogumils, or Kristijani, with Bosnian Muslims. Fine (1975, p.85) notes that the last Bosnian Kristijani family, the Helež, who lived near Konjic, BiH, accepted Islam in 1867.

${ }^{142}$ Such an opinion was held about America's West, and it resulted in the obliteration of Native American populations. This comparison of the Balkans and its people with Native Americans was already made in 1895, in the conversations of the American President Theodore Roosevelt with the novelist H.G. Wells about the "queer little ape like figures" of [Balkan] Morlocs. For more, see Wolff (203) pp.48-9. 
540 and $800 \mathrm{CE}$, and overwhelmed all other groups, mainly through warfare and the imposition of Slavonic languages. ${ }^{143}$

The Ottomans began to encroach on the Balkans after the acquisition of Gallipoli in 1354 and eventually seized Bosnia (with Herzegovina) in $1481 .{ }^{144}$ For the Ottomans, Bosnia became the Empire's westernmost point, especially after the Karlowitz Agreement of 1699, which established the westernmost borders of the Empire. Even though several times they tried hard to expand northwest and northeast, they were eventually pushed back to Bosnia.

It may be argued that the Karlowitz Agreement created a new sense of purpose for Bosnian Muslims, as it manifested itself in two ways. Having learned from the plight of fellow Muslims from neighboring territories which were taken away from the Ottomans in the wars prior to the Agreement, Bosnian Muslim elites realized not only the symbolic importance of Bosnia as their mother-land, but also that they had to rely on their own capacities for their defense, and that strategic towns and regions were important for their collective defense needs, which were not necessarily the same as the larger Ottoman Empire's needs. So they insisted on retaining every inch of Bosnian territory in all subsequent agreements the Ottomans tried to make with the Habsburgs.

This intense concern about Bosnian territory by Bosnian Muslim elites was already obvious during the negotiation of the next treaty, the Passarowitz Agreement,

\footnotetext{
${ }^{143}$ For more, see Wilkes 1992, pp.269-73.

${ }^{144}$ In part due to the ruggedness of the terrain, it took over 40 years to completely occupy the entire territory of the present BiH (for more, see Hupchick 2002, pp.104-121), while Šabanović (1982, p.5) notes that the last Bosnian stronghold of Bihać fell to the Ottomans even later, in 1592.
} 
twenty years later. The negotiations over the borders around Bosnia's northwestern-most town of Bihać were particularly hard. The territory around the town protrudes deeply into Habsburg territory (which is now considered "the belly" of Croatia, see Figure 4.1), and the Habsburgs wanted very much to take control over it, and were ready to give the Ottomans more territory elsewhere in return. Yet the sultan's negotiators resolutely refused to cede Bihać, realizing that its cession would jeopardize the rest of Bosnia's security for years to come. Virmont [of the Habsburgs] and Ibrahim Agha, the chief Bosnian negotiator, had a particularly heated debate about the eyelet's new border with Venetian Dalmatia, a subject of little interest to Ruzzini [of Venice]. Agha wanted the province to retain its previous borders. Numan Pasha Koprulu also busily lobbied all the Ottoman dignitaries at Passarowitz not to let the Austrians get "a single inch of Bosnian territory. He was even ready to take military action over this" (Pelidija 2011, p.119). This approach, therefore, has had a profound impact ever since on the history of both $\mathrm{BiH}$ as a territory and Bosnian Muslims as a people.

\section{4-4: The Rise of Independent Bosnian Muslim Elites}

The reality of being the Ottoman Empire's northwestern border land meant that Bosnia was also the last military staging ground for all the attempts to expand the territory, as it was also the military bastion for the defense of the Empire. Pelidija (2011) notes that after the Treaty of Karlowitz was signed, "the Ottoman government laid particular emphasis on Bosnia's military and strategic organization. The best example of this organizational structure was the kapetanijas (smaller military-administrative territories under a captain's rule)" (p.114). By 1716, from twelve kapetanijas, the 
Ottomans had increased their number to 25 , creating a strong defense network throughout Bosnia that kept peace and security at the borders as well as within the Ottoman eyelet of Bosnia. Kapetanijas were a significant military-administrative structure numbering up to 20,000 recruits. During the first decades of the 18 th century, that number grew to 60,000 men (20,930 of them being the standing army), and eleven new kapetanijas were created deeper in the Bosnian countryside to further bolster the military and provide more recruits. ${ }^{145}$ Eventually, most of those kapetanijas were commanded by native Bosnian officers (kapetans), and with them the power of domestic military elites became significant. As an illustration of their power, one of the kapetans, Husein Kapetan Gradaščević, led the unified Bosnian troops against the Sultan's forces in the second Battle of Kosovo, initially routing them. Nevertheless, the Kapetan eventually lost when troops from Herzegovina led by the Bosnian Bey Ali Agha Rizvanbegović joined the Sultan's troops and together they attacked and defeated Gradaščević. ${ }^{146}$ Initially, Kapetan Gradaščević rose to protest the Ottoman reforms and abolition of the janissary corps. ${ }^{147}$ The support for his revolt was also driven in part by the Ottomans giving some traditionally Bosnian territory to the semi-autonomous Serbia in the early 1830 's. ${ }^{148}$ The Kapetan wrested control of Bosnia from the local vizier in 1831, occupying the town of Travnik in Central Bosnia, and even tried, unsuccessfully, to assert himself as governor

\footnotetext{
${ }^{145}$ Pelidija 2011, p.114.

${ }^{146}$ For more on Gradaščević and Rizvanbegović, see Koller 2009, p.93.

${ }^{147}$ See Palairet 2002, p.132.

${ }^{148}$ That also shows the early intense concern of the Bosnian Muslim elites over the integrity of Bosnian territory. For more, see Banac 1993, p.133; and Donia 2006, p.27.
} 
of Bosnia. Sultan Mahmud II exiled him from Bosnia to Istanbul, where he died on May $17,1834$.

This incident is very important to Bosnia for several reasons. The figure of Kapetan Husein Gradaščević, whose forces at the time included even some Bosnian nonMuslims, is now often invoked by Bosnian Muslim nationalists as the first unifying Bosnian leader. "The Dragon of Bosnia", as they refer to him, was the first Bosnian nationalist who fought for Bosnian autonomy. Recently, the Bosnian Cultural Association "Preporod" from Gradačac $(\mathrm{BiH})$ even started an initiative to relocate Gradaščević's grave to Bosnia from Istanbul. ${ }^{149}$

The second battle at Kosovo Polje is also important because it occurred when the region of Herzegovina first became administratively separated by the Ottomans from the eyelet of Bosnia. As the reward for his support of the Sultan's troops against Bosnian (and Albanian) rebels, Ali Agha Rizvanbegović was awarded rule over the reconstructed Herzegovina. $^{150}$

With such a huge number of soldiers, ${ }^{151}$ Bosnia became militarily a very important territory for the Ottomans, as well as for other powers who wished to control the region after them. Furthermore, such conditions provided not only for the formation

\footnotetext{
${ }^{149}$ See Kujraković 2015.

${ }^{150}$ The first Battle of Kosovo is much more famous, than the 1389 battle when Sultan Bayazit defeated the Serbs and others, and opened up the Balkans for further expansion north. The first Battle of Kosovo is epical for Serbs nowadays, and it is a foundational myth for their nation.

${ }^{151}$ Just to put the number of 60,000 soldiers in some perspective, it may be noted that sixteen years later, in 1732 , that number would constitute over $17 \%$ of the total population. The Bosnian population was then about 340,000 people (Koller 2009, p.92). Of that number, Bosnian Muslims constituted less than half of the population, and at that time they were the primary fighting force of $\mathrm{BiH}$.
} 
of the military elites, but also for the emergence of a class of all types of service providers supporting such a large military contingent. The service providers were the builders who were instrumental in constructing and reinforcing fortifications, the landowners and merchants who furnished everyday provisions for the military and other people, and the local religious elites who tended to the spiritual needs of all the people, especially in big cities. Pelidija (2011) notes that after the Treaty of Karlowitz, the Ottoman Porte repaired many old fortifications and constructed new ones, with help from provincial and local nobles. Such an undertaking required a lot of resources and skilled craftsmen. He notes that "overall, the bulk of the funds and almost all of the necessary construction material were secured in Bosnia. Along with other leading figures, the Bosnian wali also made a major contribution. Between 1699 and 1714, there were around ten governors in Bosnia [and] of those seven were Bosnians. The same was true of the sanjak-beys, as well as of other civil and military officials, almost all of whom hailed from BiH" (pp.114-5).

Those who were military leaders in Bosnia were mostly from janissary troops, out of which grew landowning elites who got control over large land parcels given to them by the Sultan for their military services, ${ }^{152}$ while some of them became merchants and shop owners who supplied military troops with the provisions for their needs. ${ }^{153}$ Although those janissary soldiers were initially conscripted from among the general Muslim population and rewarded with land parcels for their bravery and service, eventually they became selected blood-nobility who inherited both the leadership of the

\footnotetext{
${ }^{152}$ Alličić 1996, p.42.

${ }^{153}$ Donia 2006, p. 25.
} 
troops and ownership of the land that over time began to grow and consolidate in fewer hands. ${ }^{154}$ After the schooling of local boys and men in the Empire's centers of learning, Bosnia's own religious and the state-supporting bureaucratic elites ${ }^{155}$ emerged as well. ${ }^{156}$ Eventually the military elites transformed themselves mostly into landowners, traders, and shop owners. Together with the Ottomans, the military class slowly disappeared, while the state-supporting elites, particularly the religious functionaries, remained and actually increased their influence over the population while balancing the new rulers. The members of those elites were of course not strictly separated, and some of them were parts of multiple groups, yet it is important to note that Bosnian Muslim elites relied on those three types of economic and social power sources. As they formed, those three types of elites became the key players in Bosnia for the next few centuries, as things did not change much in the economic and societal sense until Austro-Hungary defeated the elite-less but popular Bosnian resistance and took control of Bosnia in $1878 .{ }^{157}$ On the heels of the Habsburg takeover, Hungarians returned to Bosnia to rule once again. ${ }^{158}$

\footnotetext{
${ }^{154}$ Filipović 2005, p.95.

${ }^{155}$ Since the Ottoman Empire was a religious-based empire, both could be seen as part of the same type of elites.

${ }^{156}$ Šabanović $(1982$, pp.5; 58) points out that it took over 150 years for Bosnian eyelet (pašaluk) to form, with all its auxiliary administration to support the state and permanently stationed Ottoman troops, while Buturovic (2015) notes that Bosnia developed its own religious elites "within a century or two" (p.18).

${ }^{157}$ Donia (1981, p.6) notes that at the time Austro-Hungarians were taking over BiH, there were three types of elites: "religious functionaries, commercial entrepreneurs, and the landowners." According to the same author, thirty-five years later, in 1910, the same three groups of elites constituted about $17 \%$ of Bosnian Muslim heads of household, while $66 \%$ of those were landowning elites.

${ }^{158}$ Pinson (1993) notes that both "Gyula Andrassy, the imperial foreign minister in the 1870's, and his colleague, Benjamin Kallay, prominent head of the Austro-Hungarian administration in Bosnia [after 1882], were both Hungarians" (p.87).
} 
Such a situation, where Bosnian Muslims were abandoned by their elites, repeated itself several times afterwards, resulting from their specific socio-economic situation prior to the Austro-Hungarian takeover. During the $18^{\text {th }}$ and $19^{\text {th }}$ centuries, when the ideology of nationalism began to reach Balkan shores, Bosnian Muslims were on a different trajectory from their Slavic non-Muslim neighbors because of their different history up until that point. For that reason, it can be noted that Bosnian Muslims shared the territory of the Balkans with their neighbors, but actually did not share a history with them, especially in the case of their elites. Although the Ottomans occasionally did mobilize Christian Serbs to fight local wars, generally Serbs were not involved much in Ottoman affairs or the military. On the other hand, as Muslim subjects in the Ottoman Empire, Bosnian Muslims were regularly mobilized into Ottoman armies to serve and fight wars on the European, Asian and African continents. As such, they were in more or less constant contact and interaction with various peoples from that Empire. All that had an impact on demographics in Bosnia, Herzegovina, and Sandžak, where a large number of males were often absent, and especially at the time when nationalism began to play a greater role locally. Some of those males survived and came back to Bosnian areas bringing with them stories and experiences from the distant places where they served, which must have impacted the consciousness of their people, ${ }^{159}$ and supported the idea of universalism on which the religious empire was built, and for which all those men had fought and died. Their local Slavic non-Muslim neighbors did not have such views, and

\footnotetext{
${ }^{159}$ A trace of that consciousness may be seen in the survey respondents' attitude towards Bosniak identity and non-white people. In stark contrast to other neighboring Slavic nationalities, over $80 \%$ of respondents indicated that they are open to non-whites being Bosniaks. For more, see Chapter Seven.
} 
they saw their experiences differently, even in the cases when they, too, had fought for the Ottomans. ${ }^{160}$

When it comes to the elites, these differences were even more profound. It is hard to find a biography of any prominent Bosnian Muslim from the Ottoman era who had not spent time studying or living in some of the cosmopolitan centers of the Empire, in Edirne, Istanbul, Damascus, Cairo, or even further, in Africa. They could do that because they could afford it. Although different from European feudalism, the logic of Ottoman feudalism created rigid economic and social stratification as well, especially after Bosnian blood-nobility was established. ${ }^{161}$ Such a situation encouraged Bosnian Muslim elites to feel a sense of superiority vis-à-vis both ordinary Bosnian Muslim people, and especially, towards their non-Muslim Slav neighbors. The difference was further exacerbated by the dissimilar economic circumstances they faced, which produced a

\footnotetext{
${ }^{160}$ In addition to Uvarov's exclusive notion in the 1860's about the nation hailed by Serbs which was discussed in the introduction, and Khomyakov's 19th century epistle to a Slav nation, an example of Serbian historical attitudes towards foreign and different may be observed in the people's ballads about the Serbian King (1371-95) and Ottoman vassal, Marko Kraljević (1335-1395), often portrayed as the ultimate heroic figure by the Serbian people. In one such ballad, he was saved from captivity by an Arab princess, who then runs away with him. In the morning, when he sees the princess's skin color, he is disgusted by it and cuts the princess in half. But, let the ballad tell the story:

"On a morning, as day dawned,

I sat me down to rest,

And the Moorish maiden took me, Encircling me with her black arms, and when I looked on her, mother, On her black face and white teeth, A loathing got hold on me; I drew the rich-wrought sabre, And smote her in the silken girdle, That the sabre cut clean through her ..." (Low 1922, p.106).

${ }^{161}$ Even now, the classification among prominent Bosnian Muslims is often driven along those lines, and it is noted if a prominent person comes from an old begovske (bey's) or hodžinske (imam's) family. See, for example, Ključanin's (1993) article on the great Bosnian Muslim Communist era writer Skender Kulenović, defined as a descendant of a prominent Bosnian bey's family, "who became a Communist partisan fukara." In this instance, fukara means both, wretch and begger.
} 
strong and different class consciousness among Bosnian Muslims themselves, as well as a different cultural consciousness between Bosnian Muslims and non-Muslims. Both of those worked against nationalism within the Bosnian Muslim group, as well as among Bosnian people from the same common territory.

Local Serbian elites at that time were mostly illiterate and hardly ever wandered outside of their immediate Balkan locality. ${ }^{162}$ Things began to change in the $18^{\text {th }}$ century, when a small number of Serbs went to Vienna to be educated. Even fewer of them actually returned and tried to engage and impact their local co-religious population, either because it was too costly for them or because the Ottomans would not let them return. ${ }^{163}$

The situation was slightly different among Catholic Croats. As the direct subjects of the Hapsburgs, for them the roads to European centers of learning were more accessible. ${ }^{164}$ However, only a small number of Croats actually pursued an education, and an even smaller number of those who did, could resist the strong Germanization or Magyarization to which they were exposed in those schools. Furthermore, even fewer of them returned to their towns and villages after schooling, since they had nothing to do there, due to the mostly inadequate development of those regions in the Empire. ${ }^{165}$ The Croatian elites' situation was even more disparate than that of the Bosnian Muslim elites,

\footnotetext{
${ }^{162}$ The Serbian King, Miloš Obrenović, who was known to be an illiterate pig merchant, is a good example of that.

${ }^{163}$ In his book, Hajdarpasic (2015) writes about the Ottomans not allowing educated Serbs to return and agitate the local Christian population.

${ }^{164}$ For more, see Hajdarpasic 2015, pp.135-8.

${ }^{165}$ The famous Croatian literary laureate Miroslav Krleža wrote that around the city of Zagreb at that time, the Croatian people were living in destitute poverty. And Ugrešić (2010) wrote an essay about the poverty of provincial Austro-Hungarian Croatia and the Croatian literary themes of that time.
} 
when it came to the Croats of Herzegovina and Bosnia, who were mostly left to fend for themselves until the $\mathrm{BiH}$ takeover by the Austro-Hungarians. ${ }^{166}$

Although such conditions might seem advantageous for Bosnian Muslims, it actually worked differently. Apart from the extraordinary situations of war and destruction, when Bosnian Muslims were collectively endangered because of their religion and were solidary in defending their lives, the lack of a sense of base-line equality within the Bosnian Muslim group caused their in-group differentiation to strengthen. Given the class structure, coupled with the urban-rural difference, often reinforced by differences in literacy, even their Islamic-based culture could not bridge the gaps to create full horizontal solidarity and a sense of togetherness for the group, which is necessary for any nationalism project to operate properly. The neighboring non-Muslim groups were therefore structurally in a better position to use nationalism to their advantage, and that, to a great extent, explains the late arrival of Bosnian Muslims on the scene of the local nationalism projects. Another aspect that helps explain that late arrival was their specific relations with the Ottoman state, which were significantly impacted by the change of rule after the Berlin Congress Resolution of 1878, which signaled the beginning of a new era for Bosnian Muslims and will be further discussed in the next chapter.

\footnotetext{
${ }^{166}$ Neumayer and Schmidl (2008, pp.120-22) note that in 1910 the Croats were considered the poorest segment of the population in $\mathrm{BiH}$, and that things began to change for them only after the AustroHungarian takeover, when their population doubled as a result of those changes.
} 


\section{V: THE THREE PILLARS OF BOSNIAN MUSLIM NATIONALISM}

When observed from the group's current elite level, land and territory, language, and a (new understanding of) religion, have all emerged as the most visible factors supporting the notion of contemporary Bosnian Muslim political consciousness and identity. The joint expression of these three issues is today's Bosniak identity, put forth to the Bosnian Muslim population by their present elites. The foremost factor is the religious framework out of which Bosnian Muslims emerged as a distinct group and which has determined many of their circumstances, especially the development of the elites in the group's early, formative times. ${ }^{167}$ The second factor, which can be seen as a separate and more strictly political issue, is the integrity of $\mathrm{BiH}$ as a territory - now an independent state - and as the only place where they represent a real political force. The integrity of the territory here means the survival of $\mathrm{BiH}$ as an entity, and contingent upon that, the existence of Bosnian Muslims as a political factor now, and as they have been for the past five centuries. Additionally, after the demise of the Ottoman Empire, landowning elites emerged as the most important group among Muslims in $\mathrm{BiH}$, and for them the issue of land and territory was the most important economic issue that they struggled for. The complications stem from the fact that $\mathrm{BiH}$ is not only theirs, for the Bosnian Muslims have to share it with two other peoples who often wanted Bosnia to

\footnotetext{
${ }^{167}$ Elites are also an essential part of the authoritative structure which is an element that scholars, such as Shills note as the first step in the formation of a new community. For Gellner (1983), they are the ones who first came up with the ideas of "Ruritania for Ruritanians".
} 
dissolve. The third issue is the Bosnian language, as their mother tongue and as a concept of self-assertion in the world for Bosnian Muslims today. ${ }^{168}$

Over the past 138 years, these three main factors have become the building blocks of Bosnian Muslim political consciousness ${ }^{169}$ which became the foundation for contemporary Bosniak identity. Although one might advocate the inclusion of more elements in the mix ${ }^{170}$ these three loom largest in the contemporary conditions of the Slavic Muslims of the former Yugoslavia. The combination of these issues emerged as the result of the historical development of the group's elites and their internal and external struggles, ${ }^{171}$ as well as their response to the other two regional nationalisms which encroach upon all three elements of the Bosnian Muslim national project. Since nationalism is an episodic event which occurs as a result of historical contingencies, it is useful to observe the process of the development of the pillars of any nationalism in order to understand its desired salient identity projects.

\footnotetext{
${ }^{168}$ A form of self-expression which Geertz (1963) would recognize as "a social association of the self as 'being somebody in the world'” (p.108).

${ }^{169}$ After the disappointment over the lost, short-lived, idea of limited BiH autonomy negotiated by the Ottomans in the San Stefan Treaty with Russia in the spring of 1878 (for more, see Finkel 2005, p.485), conditions changed. The Berlin Agreement, reached in the summer of 1878 among the Western powers plus Russia, placed $\mathrm{BiH}$ under the administrative rule of the Austro-Hungarian Empire. Although initially reluctant to accept the new ruler, Bosnian Muslims finally understood that they had been left to fend for themselves after 400 years of serving the Islamic Ottoman Empire.

${ }^{170}$ Such as the myth built around the heretical Bosnian Church as the Medieval Bosnian core group, or Bosnian Muslims as the descendants of Illyrians, the original inhabitants of the Balkans - although that myth is now pretty much taken over by Albanians, who have been pursuing it actively since WWII (see Wilkes 1992, pp.10-11 and 27) - or other similar myths and stories. Interestingly, Bosnian Muslims do not want to claim such associations with other ancient local Balkan peoples, such as the Vlach or Morlacchi, who also lived throughout the Balkans at that time, even though one of the original Bosnian Muslim folk poems, "Hasanaginica," translated and praised by Fortis, Goethe, Herder and Pushkin, was originally (mis)described as "a masterpiece of the Morlacchi" people. See Wolff 2003, p.45.

${ }^{171}$ As Foucault (2003) approached the birth of nationalism in France. For more, see Chapter Two.
} 


\section{5-1: Integrity of $\mathrm{BiH}$ as a Territory and an Entity}

The Austro-Hungarian takeover was not just a simple change in the governing entity, but a much more challenging change in the structure and type of state. With the takeover, the concept of unity of belief and state (deen we devlet) was broken, and relationships within the state that Bosnian Muslims, and especially their ulama, had to adjust to when Muslims were no longer privileged political subjects, changed as well. The implications regarding the religious elites were profound and central for the project of Bosnian Muslim emergence as a distinct socio-political group, and they will be discussed separately. Politically, the impact of the changes of the type of rulers had repercussions which lasted until the end of WWII. ${ }^{172}$ Under the Ottomans, in circumstances where privileged status was acquired by birth or religious conversion, there had not been not much need to build alliances based on political programs or ideologies. Rather, all political strategies and alliances were personalistic and opportunistic. A similar situation, but in new circumstances, permitted a personalistic Muslim political block to form over time. During the initial Hapsburg rule, Bosnian Muslim representatives with some political power were mostly chosen and appointed by the new rulers. Their main concern at that time was preservation of the privileges which they had had during Ottoman rule and issues regarding religion. ${ }^{173}$

\footnotetext{
${ }^{172}$ Until then, Bosnian Muslims were represented almost exclusively by the Yugoslav Muslim Organization (JMO). During the war, some individual Communist and peasant leaders emerged, but not as a separate Muslim political party or group.

${ }^{173}$ The Austro-Hungarians understood that and tried not to disturb Bosnian Muslim landowning privileges (Neumayer and Schmidl 2008, p. 96).
} 
The integrity of $\mathrm{BiH}$ was well protected by the Berlin Agreement, which determined the fate of $\mathrm{BiH}$ territory, which the new ruling Empire could not change on its own. However, there were some issues regarding the territory of Sandžak, which was initially seen as part of $\mathrm{BiH}$, but with Article 25 of the Berlin Agreement, and the subsequent 1879 Agreement of Novi Pazar, partial control of Sandžak was ceded, first to the Ottomans, ${ }^{174}$ and then, after the first Balkan War of 1912, to Serbia and Montenegro, when the borders of $\mathrm{BiH}$ became close to what they are now. Yet, since Sandžak had its own independent nobles, Bosnian nobility did not see it as part of $\mathrm{BiH}$ and did nothing about it. Eventually, some alternative political leaders emerged among the religious and political elites in $\mathrm{BiH}$. They, however, had very different goals and ideas about the Bosnian Muslim national project. Some of them pushed the Bosnian idea proposed by Austro-Hungarians. Others argued for closeness to and identification with the Serbian national project. A third group argued for getting closer to the Croats, and the smallest group of individual intellectuals joined the project of South Slavic (Yugoslav) unity. Religious elites were reluctant to fully endorse any of those initiatives, as their membership was also split along the same lines and any specific endorsement would mean serious intra-group cleavages. Eventually Bosnian Muslim elites led by the Mostar

\footnotetext{
${ }^{174}$ The leader of the Bosnian Muslim resistance to the Austro-Hungarian occupation was Mehmed Šemsikadić, the Mufti of Pljevlja, an important town in Sandžak at that time. After his southward withdrawal from Sarajevo and Bosnia to Sandžak, the prominent members of the 1878 Prizren League in Kosovo threw their support behind him. That significantly increased the number of troops under his command and made takeover of Sandžak very difficult. That became clear to the Austro-Hungarians as well, so they modified the Agreement to have the presence of troops in only a few major cities, but control of the province was to remain with the Ottomans. For more, see Crnovršanin and Sadiković 2001, pp.152168.
} 
Mufti Ali Džabić managed to create their own cultural movement under the name the Muslim National Organization, officially registered in $1906 .{ }^{175}$

Eventually, after the Habsburg demise and South Slav unification, when $\mathrm{BiH}$ became part of the new Serbian-led state, the first real political parties began to form. Initiated by Bosnian Muslim religious dignitaries as a cultural movement in 1906, the leadership was taken over in 1919 by more secular-leaning Bosnian Muslims represented by the Juguslovenska Muslimanska Organizacija (Yugoslav Muslim Organization; JMO), and from 1921, its longtime leader was the Vienna-educated lawyer, Mehmed Spaho (1839-1939). All of the scholars who have discussed the JMO and its leaders ${ }^{176}$ noted that the primary objective of the party was the preservation of $\mathrm{BiH}$ integrity ${ }^{177}$ and support of the Bosnian Muslim landowning elites in their attempts to protect their properties and economic base, and that the party also occasionally supported the efforts of the JMO's religious elites. ${ }^{178}$ Even in the 1923 text by the party's leader about the reasons for the formation of the JMO, the lack of any political ideology is obvious, with only existential and pragmatic reasons noted as motives for the creation of the party. ${ }^{179}$ During that time, their specific ethnic and national uniqueness was completely denied to Bosnian Muslims,

\footnotetext{
${ }^{175}$ For more, see Pinson 1993, pp.103-110.

${ }^{176}$ See, for example, Purivatra 1974; Crnovršanin and Sadiković, 2007; Kamberović 2009, among others.

${ }^{177}$ The famous instance of their focus on the integrity of the territory of BiH was the inclusion of the socalled "Turkish paragraph" as Article 135 of the 1921 Vidovdan Constitution, "which ensured that BiH alone, in its pre-war borders, would form a single region among the twenty-six into which the Serb-CroatSlovene kingdom came to be divided. The 'Turkish paragraph' was the outcome of Mehmet Spaho's efforts and policy, a result of the JMO's constructive approach and votes, which secured the adoption in 1921 of the so-called Vidovdan Constitution" (for more, see Bajić 2009).

${ }^{178}$ Such as the instance in 1936 when they supported the Serbian Radical party government in exchange for returning the seat of the Yugoslav $(\mathrm{BiH})$ religious hierarchy to Sarajevo, among a few other things.

${ }^{179}$ See Spaho, 1923.
} 
who were urged, rather, to declare themselves as Serbs or Croats. Eventually, under the influence of the Serbian Radical Party leader Milan Srškić, even BiH territorial integrity and $\mathrm{BiH}$ as an entity within Yugoslavia ended in $1929 .{ }^{180}$ Bosnian Muslim elites could not forget that Serbian-led episode, and the memory of the loss of $\mathrm{BiH}$ integrity influenced local alliances for a long time.

The 1929 episode of $\mathrm{BiH}$ disintegration was further exacerbated by the 1939 agreement between the Serb and Croat political leaders. The so-called "Cvetković-Maček Agreement," completely dividing $\mathrm{BiH}$ as an entity between Serbian and Croatian autonomous units of Yugoslavia, was seen as the most serious endangerment of Bosnian Muslim existence. "The division was accomplished by discounting the Muslims altogether” (Banac 1984, p.376). The prominent Bosnian Muslim intellectual Mahmutćehajić (2000) notes that the Agreement provided "possibilities for municipalities in $\mathrm{BiH}$ to be considered, where convenient, as either Serb or Croat, even when the proportion they contained was minute. This principle is the principal source of their national ideologies whose inherent goal was to erase the Muslims from the Bosnian map" (p.133). The Agreement was a prelude to what ensued during WWII when the entire territory of $\mathrm{BiH}$ was ceded by the Germans to the Nazi-led Croatian state of Nezavisna Država Hrvatska (NDH).

\footnotetext{
${ }^{180} \mathrm{BiH}$ was divided into parts to become included into four (out of nine) new administrative units, banovine, always joined with Serbian, Croatian, or Montenegrin majority districts. See Banac 1993, pp.138-9.
} 
During WWII, under new leadership, ${ }^{181}$ JMO made the wrong choice, siding with the Croatian Ustaša's anti-Serb Nazi movement. Because of that, JMO not only disappeared as a party, ${ }^{182}$ but it also tarnished the reputation of Bosnian Muslims as Croatian helpers and Nazi supporters, even though that was far from the truth. ${ }^{183}$ During the war, ordinary Bosnian Muslim people faced the possibility of complete annihilation. ${ }^{184}$ As the only Yugoslav group without a real and well-organized military force, they tried very hard to survive and to make sense of what was going on. ${ }^{185}$ Not only were Bosnian Muslims left leaderless, but they were courted by very different groups to join and support them. The Germans brought the Jerusalem Mufti to convince them to join the infamous SS "Handžar Division," but with only limited success. The Croatian Ustašas worked hard to win them over for their project, even converting a building in the Croatian capital, Zagreb, into a mosque to stress their closeness to

\footnotetext{
${ }^{181}$ Mehmed Spaho died suddenly in a Belgrade hotel room soon after he arrived to negotiate better terms for Bosnian Muslims at the time when the new Yugoslav Constitution, which was to deny $\mathrm{BiH}$, was being discussed between Serbs and Croats. Many Bosnian Muslims believe that he was poisoned by the Serbian side to disrupt the balance that the Muslim side provided in any Serbo-Croatian negotiations. For more, see Crnovršanin and Sadiković 2002, pp.408-14; and Kamberović 2009, pp.147-50.

${ }^{182}$ Although some members were eventually reintroduced into public life, such as the prominent Bosnian theologian Muhamed Đjozo, who was brought back to service after a few years when the Communist rule was stabilized.

${ }^{183}$ Banac (1993, p.142) elaborates on that.

${ }^{184}$ Dedijer and Miletic (1990) wrote the most comprehensive account, not only of the Muslim victimhood during the war, but also of the intent of Draža Mihajlović and his Četnik forces to eliminate as many Muslims as possible from Yugoslavia (see, for example, the document shown in their book on p.26).

${ }^{185}$ Perhaps the best illustration of Bosnian Muslim wandering is the true story of Husko Miljković described in Bjedić's (1968) book. Several times during the war, Miljković changed sides, sometimes even in a single day, as he tried to make sense of what was actually going on and how to best protect the people of his Cazinska Krajina in BiH. Eventually, he decided to join the Partisans and with that, provided for their decisive victory in his region and beyond. Nevertheless, he did not live to see the end of the war as he was killed in an ambush a few months later. Although the Communists claimed that he was killed by the Ustašas, clear responsibility for his death was never determined. Miljkovic's name and role during WWII are still considered controversial, while he is hailed by local Muslims as their hero and protector.
} 
Muslims, ostensibly labeled as best Croats. Fascist Serbian bands of Chetniks tried to win over some Muslims, with even smaller success. Some local Bosnian Muslim leaders tried to organize regional Muslim militias to protect the population. Finally, Tito's Partisans actually succeeded in winning the Muslims over, and after 1943, especially after 1944, Bosnian Muslims by and large supported Tito's Partisans. ${ }^{186}$ In a rare book that specifically deals with the Bosnian Muslims' role in WWII, Hoare (2013) correctly points out that their support for Tito and his Partisan movement was in fact crucial for Tito's victory at the end of the war. To further support Hoare's notion that Bosnian Muslims' support for Tito's Partisans was their strategic choice, we can add that even present-day Bosnian Muslims consider and celebrate November 25, 1943, as the official $\mathrm{BiH}$ National Independence Day. On that day, the Communist-led State Anti-Fascist Council for the National Liberation of Bosnia and Herzegovina (ZAVNOBiH) met in the Bosnian town of Mrkonjić Grad and reinstated $\mathrm{BiH}$ integrity as a condition of the future Yugoslavia after four years of its non-existence following the 1939 dismemberment. ${ }^{187}$ After 1943, Bosnian Muslims decisively threw their support to Tito's Partisans, who eventually won the war and took over the reign of Yugoslavia, urging a new era of cooperation among Yugoslav ethnic groups.

\footnotetext{
${ }^{186}$ Probably in exchange for the promise of BiH integrity and autonomy, for which only Muslims strived during the war. See, for example, Avdo Humo's report from the Communist-led State Anti-Fascist Council for the National Liberation of BiH (ZAVNOBiH), in Ćemerlić (1968, p.229), or, throughout the same book, the numerous other declarations and propaganda materials about $\mathrm{BiH}$ remaining an autonomous federal unit of the new Communist-ruled Yugoslavia in exchange for the Muslim support of the Partisans.

${ }^{187}$ It should be mentioned that in this age of historical revisionism by both Serbs and Croats, who are both trying to distance themselves from their Communist past, the BiH national Independence Day, celebrated mainly by Bosnian Muslims, is still the day of the Communist-led ZAVNOBiH meeting when $\mathrm{BiH}$ integrity was reinstated. For an example of Serbian revisionism, see Nećak 2010. For Croatian revisionism, see Pavlakovic 2010.
} 
Nevertheless, the policy of urging Muslims to choose a Serbian, Croatian, or Montenegrin nationality ${ }^{188}$ continued until 1968, when they were finally declared to be a separate Muslim nationality. ${ }^{189}$ They readily accepted their newly-acquired right, as was seen by the percentage of them selecting that option in the census held that year, and abandoned the previous options of "undecided" or "Yugoslav" that many of them had chosen in previous instances. During those times the motto "bratstvo i jednistvo" (brotherhood and oneness) ${ }^{190}$ was the official Communist national pluralism policy. ${ }^{191}$ Bosnian Muslim elites, mostly from among the Communists, tried to contain the

\footnotetext{
${ }^{188}$ It is often neglected in the literature that during the Communist era, some Bosnian Muslims were "offered a choice" to be nationally "Montenegrin," in addition to the well-known options of "Serb" or "Croat." See, for example, Lakić 1992, p.74. Even now, the Montenegrin government is actively trying to court Slavic speaking Muslims of Montenegro to be Montenegrin and not Bosniaks, and some of them do accept that identity (see The Montenegrin Parliament 2016). Halep (2013) notes that those Muslims mainly live around the two southeastern Montenegrin coastal towns of Bar and Ulcinj. In the data set compiled for this study, members of those Montenegrin Muslims in the diaspora are now living in Chicago, with only a few in the New York City Metropolitan area.
}

\footnotetext{
${ }^{189}$ Many people credit the Bosnian Muslim Džemal Bjedić, one of Tito’s favorite Muslim Communists for that. Bjedić was the Federal Yugoslav Prime Minster from 1971 till 1977, when he died in an unexplained plane crash, which many Bosnian Muslims see as an assassination. Kamberović (2013, p.48) notes that Bijedić was the key player who argued for more BiH equality within the Yugoslav Socialist state during the 1960's and 1970's, and with it more equality for the largest Bosnian group, Bosnian Muslims. In my conversations with them, both Nedžib and Muhamed Šaćirbegović (Sacirbey) repeatedly expressed great admiration for Bjedić as a tribune of the Bosnian Muslim people. Another Bosnian Muslim intellectual, Redžić, even then argued instead for the "Bosniak" appellation (For more, see Redžić 1970, and Promitzer 2004, p.79). For more on the issue of recognition of Muslim nationality, also see Lucic 2012.

190 "Bratstvo i jednistvo" does not mean "brotherhood and unity" as it is often wrongly translated in the literature. Bratstvo does mean brotherhood, but jedinstvo is derived from the noun jedan (one) and it does not necessarily mean unity of many different individuals. In local Slavonic languages such unity of diversity would be referred to as "zajedništvo" unity and togetherness while different. Zajedništvo is derived from the word "zajedno" together, and implies and allows for differences among units joined together. Jedinstvo means oneness (singleness) implicitly without retention of individuality, not unity in difference, as it is usually used in English. That oneness without individuality was the intended meaning in the Yugoslav context as well.

${ }^{191}$ Which was a slightly upgraded policy instituted previously by the Kingdom of SHS and Yugoslavia, called "narodno jedinstvo" (people's oneness). Serbian King declared his official nationalizing policy to be Yugoslavia as one nation with three tribes (not three nations or ethnicities). Such approach worked well for communist totalitarianism as well. Although Jelavich also translates jedinstvo as "unity," it is a type of unity that also suggests the state of being one in number, so it implies sameness and oneness without retention of difference of those united people. For more, see Jelavich 2003, pp.95-6.
} 
assimilation aspect of the policy of "brotherhood and oneness," and urged, instead, "brotherhood and equality" (ravnopravnost). ${ }^{192}$ Eventually their efforts succeeded, and their group was recognized as a separate nationality, albeit without its own specific republic, as the other nationalities had. ${ }^{193}$ That put Bosnian Muslims at a disadvantage, for which they paid dearly during the Bosnian War, when they were, again, the only group without any effective paramilitary or military force to protect them. The Serbs relied on the national JNA in addition to their own paramilitary civil defense forces, which each republic and town had. Slovenes and Croats built their forces on top of their own civil defense units and their police. Since Bosnian Muslims shared BiH with Serbs and Croats, they did not have control over either of those organizations and entered the war for $\mathrm{BiH}$ independence unprepared and very much, again, relying on Croatian good will to help them.

In 1994, when Croatian paramilitaries turned against Bosnian Muslims, their battle for a unified $\mathrm{BiH}$ was lost, but the other battle, for BiH integrity, continued. ${ }^{194}$ The only way to preserve the integrity of the territory was to agree to the U.S.-brokered Washington Agreement with the Croats in 1994, and then to the Dayton Peace

\footnotetext{
${ }^{192}$ See, for example, Ćemerlić 1968, p.190, or p.220.

${ }^{193}$ For a good overview of the discussion regarding the recognition of Muslim nationality in 1968 and the unequal position of Bosnian Muslim intellectuals regarding the importance of BiH, see Lucic 2012.

${ }^{194}$ As indicated above, from the time of the Ottomans, Bosnian Muslim elites understood that they were an important regional political factor only with the existence and integrity of $\mathrm{BiH}$, where they remained as a significant population. If $\mathrm{BiH}$ were diminished, their significance would also be severely lessened, and almost nonexistent. So judging from the history thus far, Bosnian Muslims have focused on preserving the integrity of $\mathrm{BiH}$, even if that means losing territorial sovereignty and the integral $\mathrm{BiH}$ becoming part of some larger empire, kingdom, or entity, like Yugoslavia.
} 
Agreement in $1995 .{ }^{195}$ The Dayton Peace Agreement effectively split BiH into two administrative units: the Republika Srpska (controlled almost exclusively by Bosnian Serbs who dream of separating from $\mathrm{BiH}$ and joining Serbia), and the Federation of $\mathrm{BiH}$ (jointly controlled by Bosnian Muslims and Croats, who also look over the border into Croatia as their national state, and wish to separate from BiH and join Croatia). ${ }^{196}$ But as the Bosnian Muslim leader Bakir Izetbegovic noted in a 2015 interview, an integral "Bosnia brought in its sovereignty into SFRY [whose structure is the basis on which all new former Yugoslav states are internationally recognized], ... and if [Republika Srpska] questions the first paragraph of the Dayton Peace Agreement called 'the continuity of BiH' it will bring into question its own continuity as well [since it did not exist during SFRY]. $" 197$

Nevertheless, with $\mathrm{BiH}$ integrity severely endangered, the Bosnian Muslim nationalism project and Bosniak identity became issues somewhat neglected by the elites. That became especially obvious on the eve of the first post-war BiH census, in 2013, when many of them had to publicly urge Bosnian Muslims to adopt the name "Bosniak" as their identity choice in the census, and the Bosnian language as their national language. Based on the results of the data, which will be discussed in the next chapters, they were

\footnotetext{
${ }^{195}$ For more, see Dahlman and Ó Tuathail (2005). To see the Washington Agreement, see Framework (1994).

${ }^{196}$ Bugajski (2014) notes that "one of the primary goals of the November 1995 Dayton Accords was to give the three nations a stake in a single country through a protective veto over decision-making. However, the agreement was not designed to build an integrated state in which the central government in Sarajevo possessed decisive authority" (p.41).

${ }^{197}$ For more, see NIN (2015) interview with Bakir Izetbegovic.
} 
relatively successful, since a large majority of survey respondents did select the name "Bosniak" for themselves.

This brief examination of the issue of $\mathrm{BiH}$ integrity as one of the main pillars of the Bosnian Muslim nationalism project may be concluded with a note about the referendum for $\mathrm{BiH}$ independence from Yugoslavia, held on March 1, 1992, when over $63 \%$ of $\mathrm{BiH}$ residents voted for independence. ${ }^{198}$ For many Bosnian Muslim nationalists, the day when $\mathrm{BiH}$ regained its independence after centuries of being ruled by various foreigners, is considered one of the most important days in the modern history of Bosnian Muslims. By stressing that significance, they signal the importance of $\mathrm{BiH}$ for the Bosnian Muslim nationalism program. However, at that time Bosnian Muslims constituted less than $50 \%$ of the population of $\mathrm{BiH}$, and it is obvious that they were not the only ones voting for independence. It is assumed that an overwhelming number of Bosnian Croats voted for $\mathrm{BiH}$ independence as well, while only a small number of Bosnian Serbs did. For that reason, the date March $1^{\text {st }}$ is sometimes used as a symbol of the platform for unitary Bosnian nationalism, as opposed to separate Bosnian Muslim, Croatian, and Serbian nationalisms. ${ }^{199}$

Unitary Bosnian nationalism also feeds itself on similar issues of interest to Bosniaks, and it is likewise primarily concerned with $\mathrm{BiH}$ territory, where both

\footnotetext{
${ }^{198}$ The referendum was mostly boycotted by Serbs, and that is why $99.7 \%$ of those who actually came out to cast their ballots voted for independence (for more, see Woodward 1995, p.218).

${ }^{199}$ Unitary Bosnian nationalism, and its salient Bosnian identity, are often seen as an extension of unitary Yugoslav nationalism and identity which, according to Čengić (2015, pp.225-7), both had strong roots in the $\mathrm{BiH}$ of the 1980s, but were then overrun by the Bosnian Muslim, Serbian and Croatian nationalisms of the 1990s.
} 
sovereignty and the integrity of $\mathrm{BiH}$ are equally important. Of concern to unitarists too is the Bosnian language, but to be the official language of the people of the country, not only of a single $\mathrm{BiH}$ group.

The most significant difference between the two nationalisms is the issue of religion. While Bosnian Muslim nationalism considers Bosnian Islam an essential aspect of its groupness, unitary Bosnian nationalism is trying to build its platform on civic ideas of $\mathrm{BiH}$ or Bosnian citizenship (sometimes excluding Herzegovina from its name). As such, unitary Bosnian nationalists have their own preferred salient identity project. ${ }^{200}$ They are arguing for a Bosnian identity for the whole Bosnian population, including Bosnian Muslims. ${ }^{201}$ For that reason, unitary Bosnian nationalism most significantly impacts the Bosnian Muslim population and, judging from conversations during the field work, many Bosnian Muslims are unsure about the differences between the two. ${ }^{202}$ Yet, as this study's survey data reveals, a significantly larger number of respondents indicated that Bosniak identity was their primary identity, rather than Bosnian identity, and that

\footnotetext{
${ }^{200}$ Hoare (2013) refers to Bosnian as "the shy nationality" which was "avoided not only by the [Communist] regime, but by its own Muslim people, even though, when abroad, all of them were proud of the Bosnian name" (p.355).

${ }^{201}$ There is a whole rainbow of organizations, some smaller and radical like the Bosnian Movement of National Pride (see Bosanski Pokret Nacionalnog Ponosa 2014), some more visible and vocal like Bosanski Kongres (Bosnian Congress), and some moderate groups joined together through the "March 1st" Coalition, which wants to ensure and support the rights of all $\mathrm{BiH}$ citizens, especially $\mathrm{BiH}$ returnees and those still in the diaspora to vote and participate in the homeland political process (Boračić-Mršo 2012). Interestingly, there are several such groups operating in the U.S. as well, like the Bosnian Congress, run primarily by activists from Boston (for more about the organization, see Fazlic et al., 2013); the Advisory Council for $\mathrm{BiH}$ (formerly the Bosniak American Advisory Council for $\mathrm{BiH}$ ), with its principal office in Washington (for more, see The Advisory Council for Bosnia and Herzegovina 2016), and the "March $1^{\text {st" }}$ Coalition (see Prvi Mart Coalition 2012).

${ }^{202}$ See, for example, Karamehic-Oates 2015.
} 
they feel more intensely Bosniak than Bosnian. Therefore, as a diacritical factor of Bosnian Muslim nationalism, the religious foundation should be examined more closely.

\section{5-2: Islamic Foundation of Bosnian Muslims as a Separate Group}

Even though some local activists now claim that Islam came to Bosnia a few centuries before the Ottoman conquest, ${ }^{203}$ it is commonly thought that Islam took hold in Bosnia with the Ottomans. Contrary to some local Bosnian Muslim claims, it took a rather long time for the locals to embrace Islam. ${ }^{204}$ It should be noted that Bosnia was never a land or country of one religion. Even before Islam, as noted above, at least three broadly defined religious practices existed in Bosnia: Catholic Christianity, the unstructured practices of the "heretic" Bosnian Church, and the least common at that time, the Orthodox Christian practices in Herzegovina. It may be argued that besides the different topography and lifestyles of the people in Bosnia, the practices of those different pre-Islamic beliefs also influenced how Islam was perceived, received, and observed in $\mathrm{BiH}$. Its slow embrace was most likely not the result of doctrinal issues, since prior to Islam Bosnians practiced only peasant rituals loosely connected to Christianity, and often some that were not connected. It was more likely due to the nature of communication at that time when information travelled slowly, as well as the nature of the initial measured

\footnotetext{
${ }^{203}$ In his historical novel, the Bosnian professor Imamović (2012) claims that he found evidence that some Muslims settled near the Bosnian town of Kalesija in the 12th century, long before the Ottoman takeover. Professor Imamović is not alone; claims like his are noted by local Bosnian Muslim authors. For example, Kukavica 2013, p.6, also indicates that Islam was present in Bosnia four centuries before the Ottomans. However, all those claims have yet to be substantiated with more research. Nevertheless, it is interesting to note those efforts to assert pre-Ottoman Bosniak ties with Islam.

${ }^{204}$ Fine 1975, p.33.
} 
phase of the establishment of the Ottoman administrative structures ${ }^{205}$ and millet system of ruling, which provided room for other faiths to continue practicing their religions but without much space for growth.

The official Ottoman court of that time followed Sunni Islam, based on Hanafi jurisprudence, and the Sufi-influenced Maturidi creed. ${ }^{206}$ The same doctrinal approach was also adopted by the Muslims in Bosnia, and it is still followed by the majority of Bosnian Muslims, as the official religious organization Islamska Zajednica $u$ BiH (Islamic Community in $\mathrm{BiH}$; $\mathrm{IZBiH}$ ) frequently emphasizes in its declarations and announcements. $^{207}$ Some Bosnian imams claim that such a combination means Hanafi jurisprudence and its understanding and commentary by the imam Abu Mansur al Maturidi. ${ }^{208}$ Yet most ordinary people and imams do not know much about those high level theological discussions in Islam ${ }^{209}$ passed down to them by the official governing body of the IZBiH. ${ }^{210}$ Nevertheless, in that way the IZBiH claims that adherence to such

\footnotetext{
${ }^{205}$ Initially, the Ottoman regional administrator Ishak Beg was seated some 300 miles south, in Skopje, Macedonia. For more on the Ishak Beg ruling, see Šabanović 1982, p.25.

${ }^{206}$ Karčić (2006) notes that "the process of spreading Islam in BiH under the Ottomans, was at the same time the process of spreading the Maturidi creed (aqida) of the Islamic belief and the Hanafi understanding of Sharia law" (p.54).

${ }^{207}$ For example see the decree about the obligation to comply with Hanafi jurisprudence by Ceric 2007; or "About Us" at the Islamska zajednica u Bosni i Hercegovini 2014. Interestingly, the specific creed (aqida) is mentioned only in the Bosnian language version of "About Us", but not in English.

${ }^{208}$ It is reported that Imam Abu Ansar al Maturidi was from Samarkand (in present-day Uzbekistan). He lived between 852 and $944 \mathrm{CE}$ and was an important Islamic scholar on issues of creed, as a leading teacher of one of the major branches of Islamic schools of creed within Sunni Islam (for more, see Cerić, 1995).

${ }^{209}$ When I asked some Bosnian imams what such a mix means, they could not really explain it to me and they admitted that it is not clear to them either.

${ }^{210}$ Interestingly, one of the few books on Imam Al Maturidi written originally in English was based on the dissertation of the former leader of IZBiH, Reis-ul-Ulama Dr Mustafa Cerić (See Cerić, 1995).
} 
an approach and understanding of Islam is the main element of the Bosnian Muslim tradition, which provides an historical anchor and stability for the community. However, that disparity, between the official pronouncements of the IZBiH and the lack of knowledge among the religious people on the ground, leaves room for local, often nonIslamic, practices to remain part of the rituals among different Bosnian Muslim communities. ${ }^{211}$ Some local authors refer to those practices as "people's religion" (narodna religija). ${ }^{212}$ But the influx of the local is observed not only in practices of narodna religija by ordinary folks, but also in a different way, at the official level of understanding and practice of Islam in BiH. The "people's religion" in the case of Bosnian Muslims is not what is sometimes referred to as a "folk religion" for at least two reasons. First, Bosnian Muslims have lived largely in urban settings since their acceptance of Islam, apart from Empire's non-Muslim subjects. ${ }^{213}$ Second, folk religion is usually conceptualized and practiced in opposition to the official religion. ${ }^{214}$ In the case of Bosnia, though, the people's religion actually represents a synthesis of both folk practices and the resolutions of high Islam. In such a situation, as an institution of the neo-ijma, ${ }^{215}$ the $\mathrm{IZBiH}$ becomes the main negotiator between those two strands, and the

\footnotetext{
${ }^{211}$ Well described in Bringa's 1995 book, especially in Ch. 5.

212 See Karčić, 2006, and Karić 2010, pp.44-5.

${ }^{213}$ Donia 1981, p.5.

${ }^{214}$ In his seminal work, Yodder (1974) notes that "folk religion exists in a complex society in relation to and in tension with the organized religion(s) of that society" (p.11), and concludes that "folk religion is the totality of all those views and practices of religion that exist among the people apart from and alongside the strictly theological and liturgical forms of the official religion" (p.14). That has not been the case with the people's "Bosnian Islam."

${ }^{215}$ Piscatori (1991, p.20) suggests this to be the Islamic consensus among current national leaders, as opposed to the traditional views, where consensus is an exclusive privilege of Islamic scholars who lived closer to the time of the Revelation.
} 
primary judge of what is to be included in the "people's religion" of Bosnian Islam, as it is now also sanctioned by state law. Navigating between those different tendencies, the IZBiH occasionally publicly declares and sanctions practices and teachings, not as "unIslamic," but essentially as "un-Bosniak." It should be added that among Bosnian Muslims, the two levels of folk and official religious understanding and practice exist as well, and tensions are present within each level, between those two levels, and between both of them and the non-Islamic, social and official spheres. ${ }^{216}$

\section{5-3: Theological Roots of Official Bosnian Islam}

Although a very specific and highly specialized discussion about the Islamic creed is beyond the scope of this study, ${ }^{217}$ it will be useful to try to explain in a few words what the practical implications of Hanafi jurisprudence and the Maturidi creed are for Bosnian Muslim practices, since they are not much discussed in the literature. ${ }^{218}$ Both great Islamic scholars were non-Arab Sunni Muslims, living and working outside of the core of Arabia. Of Persian lineage, with an Afghan father, Abu Hanifa was born in Kufa (Iraq), ${ }^{219}$ while Al Maturidi was from the small town of Maturid, near Samarkand

\footnotetext{
${ }^{216}$ Eickelman and Piscatori (1996) see that as "Muslim politics" that "involves the competitions and contest over both the interpretation of symbols and control of institutions, formal and informal, that produce and sustain them" (p.4).

${ }^{217}$ For that I recommend Piscatori 1991, pp.3-10.

${ }^{218}$ This attempt is based on Kant's encouragement to us to dare to be wise. However, my bravery to understand and to explain this very broad and multifaceted concept in just a few words is a risky proposition. In that way, by essentializing the beliefs of Bosnian Muslims and the schools of thought which are the basis of their belief, I run the risk of orientalism in my attempt to better explain their nation building project. That, however, is not the intention of this work, and the Bosnian Muslim faith and reality in which they live are much more complex and multivariate than what could possibly be explained here. This work should be seen only as a small step towards a better description of Bosnian Muslims as a group.

${ }^{219}$ He lived between 699 and $767 \mathrm{CE}$ and his actual name was Nu'man ibn Thabit. For more, see Jackson (2006), p.25.
} 
(Uzbekistan). ${ }^{220}$ As they both came from places far from Medina and Makkah, where many of the disciples of the Prophet Muhamed lived and where, in general, rulings were primarily based on the memorized and exactly recorded Prophetic sayings and Arab customs of the time, both Abu Hanifa and Al Maturidi employed analogical deductions and rationality in their rulings and understandings of the religion. ${ }^{221}$ Abu Hanifa was a scholar of theology and jurisprudence, and based his method on the principle of group discussion that he used with his students, and on the principle of preparing for hypothetical situations before they occur. ${ }^{222}$ Furthermore, besides the primary sources of religious law, Abu Hanifa's method also utilized qiays (analogical deduction), istihan (preference based on strength of proof), and urf (customs). For a wider audience he was primarily a jurist, paying special attention to the forms and rules of behavior in accordance with Islam. ${ }^{223}$ Since "religious behavior is historically, socially, and culturally informed," 224 Abu Hanifa had to "translate" some of the Islamic rules derived from understandings of Arab culture at the time of Revelation and the Arabs' norms of

\footnotetext{
${ }^{220}$ For more, see Leaman (2009).

${ }^{221}$ At the time of the emergence, Hanafi's approach was primarily contrasted to the approach of the Medina jurist Imam Malik ibn Anas and his students.

${ }^{222}$ See Philips 2006, p.65.

${ }^{223}$ It is important to note that it is not being argued here that Islam is an Arab religion or that its rules are meant for Arabs only. Ramadan (2009) clarifies this well by saying that "the classical tradition of the fundamentals of law and jurisprudence [and Abu Hanifa was an especially important part of it] has always approached the founding texts with the deepest respect and devotion and that, while reference to the historical and social environment was always present, it mainly served to shed light on the meaning of the texts or how they should be implemented. The Universe, the social and human context, has never been considered as a self-standing source of law and its production" (p.82).

${ }^{224}$ Hann 2006, p. 18 .
} 
behavior, ${ }^{225}$ to non-Arab people by using qiyas, istihan, and urf, in addition to primary

Sharia sources of the Qur'an and the prophetic tradition. ${ }^{226}$ Therefore, the role of Abu

Hanifa as a translator of those specific social and cultural contexts into other situations

was extremely valuable, since he established an important model and method of how to

transfer those customs and norms of behavior. ${ }^{227}$ For example, his rules are strictly

followed in regard to the rules of prayer, and the rules regarding the dress code, such as

that a beard is mandatory for Muslim men. ${ }^{228} \mathrm{He}$ is therefore considered a founder of the

Islamic world's most widely followed madhab (school of jurisprudence), especially

among non-Arabs, and his work is the basis for the religious practices of Bosnian

Muslims as well. ${ }^{229}$

${ }^{225}$ Ramadan (2009) notes that "in early societies on the Arabian peninsula, the social and human context was in itself a source of law that was so fully integrated by interpreters of texts that they had only to refer to it implicitly, without any particular insistence, to be understood" (p.85).

${ }^{226}$ For more, see Philips 2006, pp.66-7.

${ }^{227}$ Perhaps, for that reason, notables from other schools of Islamic jurisprudence say that Abu Hanifa's method is useful and needed by all other schools of jurisprudence. The issue of cultural history is so important that all major theological Islamic Universities in the world study pre-Islamic Meccan Arab customs and practices as a mandatory part of the curriculum.

${ }^{228}$ These two rules are mentioned because they have lately become points of controversy among Bosnian Muslims. Calling upon Bosnian Muslims' unspecified tradition, many commentators and local Bosnian Muslims now view the widely practiced norms among younger people of wearing longer beards and shorter pants, as "foreign" Islamic practices. This is so despite the Hanafi School rule specifying the necessity of both beard and shorter pants for men. Furthermore, during Ottoman times Bosnian Muslims were traditionally those who most fiercely opposed any attempts to reform. Donia (2005, p.30) notes, for example, how they refused to rid themselves of turbans in favor of the new hat, the fez. Obviously, as Hann (2006) pointed out, the era of "socialism was still a basic point of reference in the 'lived history' of most residents" (p.1) of post-Communist states. The primacy of that experience over Islamic rules is therefore obvious when social and official "judgment" on those practices are issued, not in terms of whether they are "Islamic" or "not-Islamic," but in terms of whether they are "Bosnian" or not. Obviously, the era of Communist rule is an important point of reference for Bosnian Muslims as well.

${ }^{229}$ For more, see Abderrazzaq (2007), who also notes that "the Hanafĩ school is generally viewed as the most liberal of the Sunni juristic schools and is commonly regarded by many contemporary Muslim thinkers as the school of Islamic law most compatible with reform." To balance such a notion, which runs the risk of normative subjectivity, it may also be noted that some of the most reactionary and traditionalist 
Imam al Maturidi came a century after Abu Hanifa and was primarily concerned with the understanding of the higher principles of Islamic law and forms. ${ }^{230}$ Although Cerić (1995) warns us that "al Maturidi was not a man of systematic definitions" (p.115), it may be said that, in some way, he was trying to normalize relations between perennial knowledge based on Revelation and worldly, acquired knowledge, and his "primary concern was to prove the soundness of Islamic doctrine as opposed to Indo-Iranian dualism, Judeo-Christian entangled monotheism, and the profanity of Greek philosophy" (Cerić 1995, p.109). Al Maturidi was responding especially to the anthropomorphist ideas of the Mushabbihah and the ultra-rationalist movement of the Mu'tazilites. He believed that it was possible to have a fruitful discussion with all of these groups only if mutually accepted arguments based on the senses and reason were employed. ${ }^{231}$ İskenderoğlu (2006) explained that Imam al Maturidi argued that "there are three sources of knowledge: reports, sense experience and reason, and he tried to support the principles of religion through these sources," and while Revelation is always superior and the starting point of any true knowledge, the senses and reason should not be ignored. In the words of a commentator describing Al Maturidi's approach, "he created a much stronger synthesis

\footnotetext{
movements in Islam, such as the Taliban, are also part of the Hanafi madhab. Yet they are of a slightly different school of creed than Bosnian Muslims.

${ }^{230}$ The Islamic scholars who come from that line of thought argue that Islamic law should be understood "in light of the higher objectives and human interests on behalf of which they were brought into existence" (al-Raysuni 2005, p.337).

${ }^{231}$ See Cerić 1995, p. 109, and p.187.
} 
between tradition and reason ... recognizing the necessity of reason to properly [through Islamic rationality and logic] understand the revealed text.",232

The discussions and differences within a particular school of jurisprudence are sometimes divided between the understanding of God's attributes which are mentioned in the Qur'an, and those mentioned in recorded Prophetic narrations. Some Islamic scholars take the position that those attributes should be seen literally as they are mentioned in the Revelation, while others argue that those attributes should not be understood literally; rather, they should be comprehended rationally and speculatively using Islamically structured logic and deduction. ${ }^{233}$ Such was the position of Imam al Maturidi, who argued that the principles of understanding of Islam should not use tradition blindly; rather, the understanding should also utilize the senses and reason, because through them we actually comprehend God. ${ }^{234}$ Out of that discussion about the exact attributes of God and the use of rationality, came also a different approach to issues regarding the affirmation of faith. The Maturidi approach is that it is enough that faith is in the heart of a person and it does not have to be affirmed by tongue and actions, ${ }^{235}$ while others within the same

\footnotetext{
${ }^{232}$ Yusuf 2007, p.22.

${ }^{233}$ To better understand the meaning of "Islamically structured rationality and logic," see Adilović 2011.

234 “Al-Māturīiñ argues that what we see around us provides evidence that the world was created by a Divine Being, and reason leads to the conclusion that He, unlike His creation, must be eternal" while his attributes are beyond our comprehension, beyond what God has revealed about himself (Leaman 2009).

${ }^{235}$ An example of this situation is mentioned in the famous hadith of the Prophet Muhamed's ruling, where he noted that although a person, Amar bin Jaseer, denied his Islam with his tongue to save his life, while still holding the belief in his heart, he was still a believing Muslim. The Prophet's ruling was then reaffirmed through the revelation of Surah An Nahl, verse 106: "Whosoever disbelieved in Allah after his belief, except him who is forced thereto and whose heart is at rest with faith" and in other places in the Qur'an with the same point that God truly knows what is declared and what is concealed. For the hadith see Tafsir Ibn Kathir, in er-Rifa'I 2002, p.730. For Qur'anic Chapter Sixteen, Verse 106, Al-Hilali and Khan's (2003) English language translation is used in this work
} 
Hanafi school of jurisprudence argue otherwise. Although faith is primarily a matter of heart, the actions of a human being are the result of divine decree and divinely decreed individual free will. Therefore, the conditions that an individual can find himself in are aslo based upon those two. The Godly-decreed individual free will opens up room for the senses, analogy and reason to play a role in human life, as is explained by Imam Al Maturidi.

Although this discussion of matters of Islamic creed may appear pretentious on my part, since it is frequently mentioned by Bosnian Muslim activists, it is necessary to attempt to provide at least its basics tenets as they do play a role in the self-understanding of Bosnian Muslims, especially on the level of their official Islam and Islamic elites.

The introduction of analogy and reason into official Bosnian Islam may be seen in the Bosnian Muslim interpretation of the notion of islah, a critical concept for understanding the IZBiH's continuing evolution. In his glossary of terms, Sayeed (2006) notes that islah indicates "a reform, the idea of returning to Islam's original message that has been obscured owing to misinterpretation and distortions," and as a concept it was often invoked by reformists after the $18^{\text {th }}$ century, to urge the return to Tradition and the reassessment of Islamic solutions and organizations. For the IZBiH, then, islah means a constant reform of their own organizational structure, while relying on the particular tradition and specific experiences of Bosnian Muslims, with the Tradition being secondary. Such an approach may be seen in the declaration of the governing body of the IZBiH urging all Bosnian imams to interpret Islam according to the official teaching, based not only upon the high-Islamic principles of the Qur'an and the Sunnah of the 
Prophet Muhamed, but also according to "our Bosnian-Herzegovinian experience." 236 There are also different implications on the level of ordinary people of such an approach, which emerged from the conditions in which Bosnian Muslims found themselves living, similar to the case of other Muslims who lived under the reign of Communist parties. As the ruling party, Yugoslav Communists were somewhat tolerant of, but not accommodating to, religion, as they often legislated against Muslim religious practices and norms, making it hard or impossible to practice Islam properly in accordance with religious tradition. $^{237}$

Although the distancing of Bosnian Muslims from their religious law started at the beginning of the Habsburg rule over them, the process was gradual and reached its apex during the reign of Communism, when in 1946 all Sharia courts were banned. In the words of Štulanović (2002) "the positive Sharia law system was reduced through the Islamic ethical code to private and social norms and customary law," and only in that way did Islam remain relevant in the lives of the people. In such a situation, the approach to the particular creed where by faith does not have to be affirmed with the tongue or with

${ }^{236}$ See Cerić 2007.

${ }^{237}$ Such was the Yugoslav legislation adopted in 1952, which forbade Muslim women to wear the veil. Communist rule made it hard, or impossible, to proselytize or visibly practice any religion. Any attempt to proselytize or advocate religion, privately or publicly, would have been perceived as "anti-systemic", and those who tried to do this were imprisoned, or their civil rights were restricted. Even those who were trying to practice religion privately had to conceal it. An elderly woman told me she would get up before sunrise and have her morning meal during Ramadan without turning the lights on, so that no one would know that she was fasting. And boys from the towns would be circumcised back in their village, where some relatives lived, by a barber or imam, not in hospitals. In general, the norm at that time in BiH and SFRY was that if a person was trying to practice any religion, it was very difficult or impossible to move up in his career, whatever he was doing, because his religiosity was a sign of an undeveloped Communist consciousness and therefore seen as "anti-systemic" (for more, see Hadžišehović 2003, pp.120-5 and p.153; also Donia 2006, p.220). As was discussed in the introductory chapter, this situation created a paradox for Bosnian Muslims, whose very basic form of groupness was being recognized, even as its practice was disapproved at the same time. 
practice, was then very helpful for Muslims in BiH. Since many of them held only a very scant idea that they were Muslims without practicing the faith at all, their Islam mostly retreated into the practice of localized culture and traditions. In 1983, Gellner wrote that "to be a Bosnian Muslim you need not believe that there is no God but God and that Mohamed is his Prophet [this is the essence of the Islamic creed], but you need to have lost that faith" (p.70). Yet, even then, a Bosnian Muslim was considered a Muslim by his co-nationalists, and by other Muslims. ${ }^{238}$ In her work, Bringa (1995) also describes such a situation. "The relationship between being a Muslim and a Communist (and atheist) was problematic to many of the Muslims [but] to most of the Muslim villagers I knew, a Muslim was necessarily a believer, although he did not have to be devout or regularly observant. [It] did not mean that individuals from Muslim families and with Muslim names who were declared Communists were not perceived as 'Muslims"” (pp.163-4). Obviously, it was understood by the Bosnian Muslim population that these negotiations between political activism and open religiosity were difficult, and compromises had to be made. Yet, since it is enough for the faith to be in a person's heart, which no one can look into, generally a person will be perceived as Muslim despite all of his shortcomings. Interestingly, the same approach towards Bosnian Muslims was the case with the Serbian and Croatian armed forces, which also did not differentiate between "muslims" and "Muslims," or "observant" and "non-observant" Muslims during the Bosnian War. ${ }^{239}$

\footnotetext{
${ }^{238}$ See Azymardi 2002, especially pp. 145-7.

${ }^{239}$ For example, a Serbian political scientist, Miroljub Jeftić, has argued that under Yugoslav conditions, each Bosnian Muslim is an Islamic Fundamentalist because, even if he is not religious, he certainly belongs to the "secular Islamic Fundamentalism" or "Communist Islam." Obviously, Jeftic "stretched his definition of "fundamentalism" to denote "secular Islamic 'fundamentalism' and 'Communist Islam' in order to
} 
Nevertheless, the IZBiH embraces all those experiences that Bosnian Muslims have gone through and incorporates them into its own understanding of Islam. It responds to those who try to annul such Communist experiences by saying that "IZ is a gift from God, and it should not be denied, or belittled. Whosoever does not understand that, cannot pass judgment on Bosnian Muslims; whosoever does not respect that, does not have the right to teach Bosnian Muslims anything - neither religion which they know, nor loyalty to the Umma to which they hold on staunchly."240

In numerous other pronouncements, the official Islamic organization tries to reiterate that line of Bosnian Islam that incorporates both high-Islam discussions and the tendencies of Bosnian Islamic scholars, and the folk-Islam practices of ordinary Bosnian people and the remaining Bosnian Sufi groups. As it tries to balance the approaches and practices of those two strands of Bosnian Islam, it sometimes employs the power of a state in order to achieve that balance. Although "the general trend of the official Islamic thought of Bosnian-Herzegovinian Muslims in the twentieth century was modernist, enlightened and reformist”, Karić (2010, p.45), himself very much part of the official $\mathrm{IZBiH},{ }^{241}$ actually refers to the high-level scholarly discussion among the members of the

encompass anyone and everyone who is in any way a Muslim," concludes Cigar (1995, p.28). (For more on the role of Serbian academia in the Bosnian genocide, see also Cigar 2001). Framing on the Croatian Catholic side was slightly better, as Muslims were usually seen simply as "Turks." For example, Abazović et al. (2007) note that "in Herzegovina another clerk, Vinko Mikolić, adds that the Bosnian government is "just like the Turkish aggressors"” (p.28). Malešević (2006) described very well how all those organic Communist intellectuals turned overnight in to ideologues of ethnic cleansing and genocide and became the "chief media propagandists disseminating the images and language of hatred and fear for the national cause" (p.196).

${ }^{240}$ See the previously mentioned amended Rijaset resolution in Cerić 2007.

${ }^{241}$ Karić was a candidate for the Reis-ul-Ulema, the Head of the IZBiH in 2005, and currently he is also a member of the Vaqf commission run by the IZBiH, as well as of the Faculty of Islamic Studies at the University of Sarajevo and the former Minister of Education, Science, Culture and Sports for the Republic 
official organization, and not to the knowledge and practices of ordinary people. On the ground and in its public declarations, the official IZBiH tries very much to balance the positions of the two, and to maintain the Bosnian application of Islam in a non-Islamic environment, as IZBiH see it is approved by the Hanafi School, which they follow. ${ }^{242}$ A good example of that balance is the way the official IZBiH took over the annual gathering in Ajatovica and other places of local Sufi pilgrimages, which they used to see as unacceptable but which they now sanction as the very place of public expression of Bosnian Islam. Now, these rituals and places are not only acceptable, but are actively promoted and advertised as the places to be visited by all Bosnian Muslims.

The knowledge discrepancy between the two levels of practice and understanding in the Bosnian Muslim community provides a feeling of difference and the possibility for ordinary people and local imams to use (or not) the IZBiH-ratified Bosnian Muslim practices as evidence to construct the diacritical marker for their own group and to separate themselves from other Muslims when needed. ${ }^{243}$ This is especially pronounced in the Bosnian Muslim diaspora, where the IZBiH hierarchy is also present, and where the "disconfirming other" for them is the Arab, Pakistani, Albanian, Turk - essentially a non-Bosnian Muslim - and such differentiation is often used to seclude themselves from

\footnotetext{
of Bosnia-Herzegovina. So he is very much part of the official version of Islam in Bosnia, and it is not an exaggeration to consider him its main voice.

${ }^{242}$ As the IZBiH claims is the case now, and in the past, Durmišević $(2008$, p.218) notes that the Hanafi school allows Muslims to live under non-Islamic rulers, under the condition of an autonomous judicial system which provides for sharia norms to rule in the private sphere.

${ }^{243}$ Due to the mix of perceived political costs and stigmas attached to Islam, and different Islamic practices of other Muslims elsewhere.
} 
others, ${ }^{244}$ or to justify the building of their own Bosnian mosque, sometimes right next to an existing "Arab or Pakistani mosque." 245 The same mark of difference is lately being used in $\mathrm{BiH}$ as well, to counter influences and teachings now coming to Bosnian Muslims from different foreign sources, ${ }^{246}$ and from the Bosnian Muslim students who were studying throughout the Muslim world and are now back in $\mathrm{BiH}$ teaching what they have learned elsewhere.

In this way the process of Bosnian particularization distantly resembles the turning of Jewsh universalism into "Jewish ethnicism," well described by Baron (1971), or in another way, their wrestling with Islamic universalism brings to mind what happened as Christians encountered Germanic tribes in Northern Europe when the "Christianization of the Germanic tribes was matched by the Germanization of Christianity," and such localizing of religious universalism later provided accommodation for nationalism to grow along confessional lines within the religion. ${ }^{247}$ How did that feeling of difference come to play a role in the case of Bosnian Muslims?

The propensity towards peasant or folk religion in $\mathrm{BiH}$ was there even before the arrival of Islam, ${ }^{248}$ and many of those folk religious practices have continued throughout

\footnotetext{
${ }^{244}$ During my field work, one of the Bosnian Muslims in Chicago told me that the Bosnian mosque recently established in the city chooses not to put a sign outside the building so that it does not attract nonBosnian Muslims to come in and use the facility and affect their Bosnian Islamic ritual practices (see Figure 5.1).

${ }^{245}$ Like the one in Grand Rapids, MI, that was mentioned in the previous chapter). Since Bosnian mosques and organizations are meant to serve only one ethnic community, in this work they are considered primarily as ethnic interest organizations, as is argued by Fennema's (2004, p.441) approach as well.

${ }^{246}$ Heing 2012.

${ }^{247}$ For more, see Conzemious 1995, p.17.

${ }^{248}$ For more on those pre-Islamic practices, see an excellent description in Fine 1975, pp. 9-23.
} 
the lives of Bosnian Muslims. ${ }^{249}$ Those who maintain those local ceremonies often engage in power struggles with each other over various issues, from who controls the venerated sites, to the exact order and forms of practice of their rituals. ${ }^{250}$ Then there are the tensions which have existed throughout time between folk Islam practices and the efforts of high level religious reformers to adjust and correct them. ${ }^{251}$ As elsewhere in the Islamic world, those tensions were between the two t's ( $\mathrm{t}$ and $\mathrm{T}$ ), local Islamic traditions, and high Islamic Traditions. ${ }^{252}$

Ever since their acceptance of Islam, Bosnian Muslims have been educated throughout the Ottoman Empire and some of them reached such a level of prominence that they left a strong impact in $\mathrm{BiH}$ and the region concerning the understanding of Islamic orthodoxy. Locally, they were very much part of the level that is usually considered high Islam. It should be noted, however, that among the scholars at that level, there are sages from different branches of Sunni Islam, from various Sufi orders, from the early $20^{\text {th }}$ Century Islamic reformers, ${ }^{253}$ and from the various orthodox Traditionalists. ${ }^{254}$

\footnotetext{
${ }^{249}$ See Duranović 2011; or Bringa 1995.

${ }^{250}$ See Heing 2012.

${ }^{251}$ For more, see Karčić 1990, pp.204-48 (or English summary pp.253-5); and Adilović 2013, pp.103-113 and 139-141.

${ }^{252}$ A good source for the examination of high and folk religion tensions in Islam is Gellner's (1992) book on postmodernism, reason, and religion.

${ }^{253}$ For an interesting review of the early $20{ }^{\text {th }}$ Century Bosnian Muslim reformers, see Karic 2008 . The reformer tendencies which have occurred in the wider Muslim world, exemplified especially in the works of Abduh and Arslan, reached Bosnian Muslims as well (Alibašić 2014, p.453). Many Bosnian Muslim religious scholars joined the reformer camp and wrote trying to teach the population how to correct preIslamic and Christian practices that local Muslims continued to observe even after they embraced Islam, or those new ones that they have adopted from their Christian neighbors (see, for example, Vlahović 1968, pp.153-9; and Đozo 2006, especially Books 4 and 5.).
} 
That is where the IZBiH steps in to play a critical role, as arbiter among all those strains. Perhaps for that reason, from its beginning as an official organization, it has been referred to as Zajednica (a collective community) ${ }^{255}$ to emphasize the desire for collectiveness, despite all those differences. In $\mathrm{BiH}$ today, all those tensions in and around the religion are mediated by the $\mathrm{IZBiH}$, primarily in terms of Bosnian or nonBosnian traditions, and their resolutions might be called, as they often are, Bosnian Islam. ${ }^{256}$ The IZBiH does not use the term "Bosnian Islam" in its official documents. Instead, in its Constitution, the IZBiH uses the construct the "Islamic tradition of Bosniaks," together with (and after) the Qur'an and Sunnah (the Tradition of the Prophet Mohammed), as a source of its resolutions, in line with the Hanafi approach and "the demands of time." ${ }^{257}$ But even that equating in a single sentence of Bosniak-specific tradition with the primary sources of Qur'an and Sunnah is theologically tense.

\footnotetext{
${ }^{254}$ Most visible among them nowadays are those who are often referred to by locals, as well as Western academia, as "Wahhabis." Since the term "Wahhabi" is used in a disparaging way, in this sense, even Western academia has become an interpreter of local Islam, and its "contributions" add to the local tensions among Bosnian Muslims. Yet strangely enough, such an active role and such normativeness on the part of academia is acceptable, as it may be found throughout the various disciplines which are concerned with Muslims in general and Bosnian Muslims in particular.

${ }^{255}$ The word zajednica is often translated simply as "community" or "association." It should be added that zajednica is actually a derivative of the adverb zajedno (together), and it points to togetherness despite the differences which form a community. That was especially pronounced during the time of Yugoslavia, when the name of the organization which represented Muslims within the state was called Islamska Vjerska Zajednica (Islamic Religious Community; IVZ) as it represented very different Muslim groups, including Bosnian Muslims, Pomaks, Turks and even a small number of Egyptians who live throughout Kosovo and Macedonia, as well as Albanians who live in great numbers in Kosovo, Macedonia, and Montenegro, and Torbeši, Goranci, Našenci, and Romas (see OSCE Mission in Kosovo 2009).
}

${ }^{256}$ See Bougarel 2007. Furthermore, in his voluminous work Karić (2004) discusses the issue (pp.37-42) and concludes that he supports the notion of Bosnian Islam, explaining that "Islam in Bosnia is universal in its belief, but culturally Islam in Bosnia is Bosnian Islam" (p.42).

${ }^{257}$ Both are pointed out by Karčić (2006, p. 52), who also notes that IZBiH never defined exactly what the "Islamic tradition of Bosniaks" and "the demands of time" mean. Rather, they left it open for interpretation, intentionally or not, and to leave ample room to respond strategically to "the demands of time" in the future. 
Although the Bosnian Muslim experience of Islam is now closely tied to the resolutions and decrees of the $\mathrm{IZBiH}$, it is important to note that the $\mathrm{IZBIH}$ was not there from the beginning of Bosnia's acceptance and practice of Islam. ${ }^{258}$ Just as it took time for Bosniak consciousness to emerge as a form and a practice, it took time as well for the IZBiH to become central for their comprehension and expressions of Islam. The roots of the IZBiH emerged in 1882, only after the Austro-Hungarian takeover of $\mathrm{BiH}$. After the occupation of $\mathrm{BiH}$, in part due to international obligations, the Habsburgs tried very hard to preserve a semblance of social continuity, in spite of all the reforms they initiated. As already noted, the change in the type of state when the concept of unity of belief and state was broken had a profound influence on Bosnian Muslim ulama relations with the state. ${ }^{259}$ Over the past 138 years, there have been four broadly defined phases of the changes in their modes of interaction with the new states which they encountered.

\footnotetext{
${ }^{258}$ Despite all my efforts, I could not find a clear definition of who actually are the members of this specific "Islamic community." Supposedly, all Bosnian Muslims are part of it, but they are not actually consulted about that membership. The IZBiH constitutions throughout time (1909-1997) have had different definitions of members, ranging from all Muslims from $\mathrm{BiH}$, to all those who feel a part of this group. IZBiH is perhaps a neo-millet institution, where membership is ostensibly acquired by the sheer chance of birth into a Bosnian Muslim family, since Reis-ul-Ulema Cerić noted that Bosnian Muslims are now "Bosniaks by birth" (Cerić 2013). Therefore, the IZBiH is a very abstract organization, whose members are not clearly identified, and whos structure was created and exists primarily within the non-Islamic official sphere, which has a strong continuous influence over it. At the same time the IZBiH is also part of the Bosnian Muslim social and the BiH public sphere. During all this time that structure, the "Islamic community", has been outside the reach of ordinary Bosnian Muslims, who cannot directly choose or elect the members of the religious hierarchy. They are, rather, chosen by the imams themselves and by selected prominent Bosnian Muslims, whatever that "prominent" designation means at a particular time. So they are not elected representatives of the Bosnian Muslim population, nor are they directly responsible to them, yet they speak and interpret Islam on their behalf, as they claim in the Bosnian media to be exclusively authorized to do by the BiH Law about Churches and Religious Communities. However, the law actually does not say that. Nevertheless, as such the IZBiH is a unique organization in the Islamic world. For the text of the BiH law, see the Ministry of Justice of Bosnia and Herzegovina 2012.

${ }^{259}$ The term ulama usually means Islamic scholar(s); however, in the case of BiH and the former Yugoslavia, it is liberally used to include most religious workers, and sometimes even the village hodža (imam of the mosque) who might have only the equivalent of a high school diploma, or less, and is certainly not a scholar. The same tendency of calling any Islamic workers part of the ulama, nowadays, is not exclusive only to Bosnian Muslims; it can be observed world-wide.
} 
Throughout those times, as Durmišević (2008, p.218) notes, the Hanafi school rationale has provided for Bosnian Muslims to live under non-Islamic rulers, on the condition of an autonomous judicial system which is to provide for the Sharia norms to guide and rule the Muslim private sphere. This condition offers a religious justification for the creation, existence and continuous improvements through reforms of the religious hierarchy, which they see as part of $i$ slah, embodied in the $\mathrm{IZBiH}^{260}$

\section{Figure 5.1: Bosnian Islamic Cultural Center Building in Chicago, without Signage}

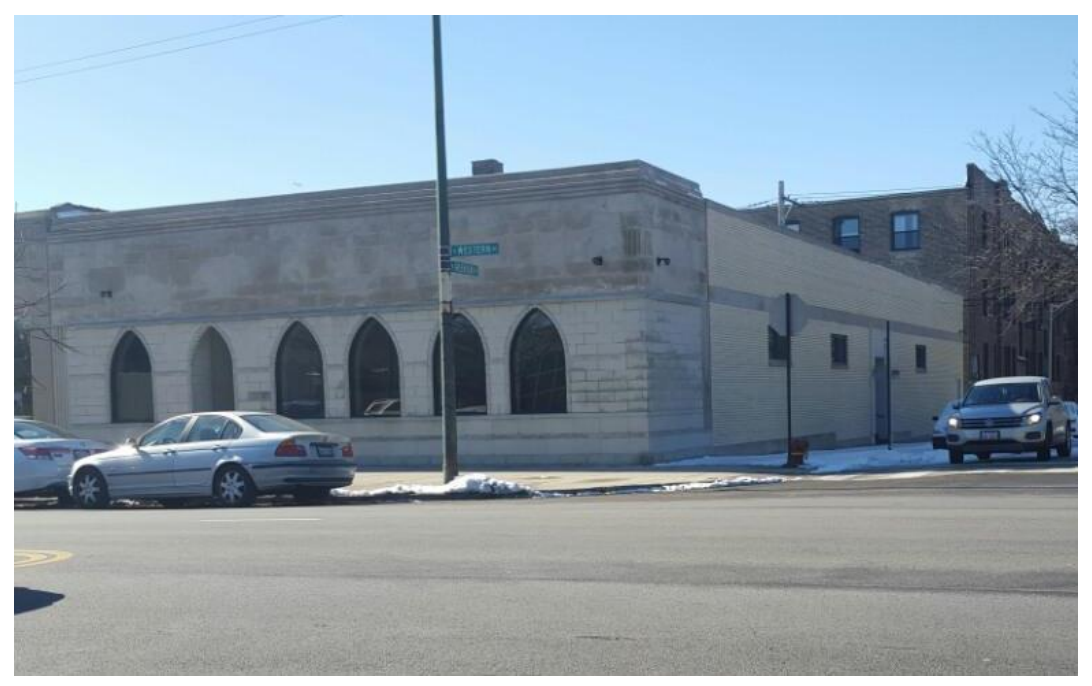

\section{5-4: Four Phases of IZBiH Interactions with the non-Islamic State}

With the Austro-Hungarian takeover, after the Ottoman concept of unity of belief and state was broken, the Bosnian official religious hierarchy had to align itself with the, rational and bureaucratic European model of a state. ${ }^{261}$ In the old model, there had been

\footnotetext{
${ }^{260}$ Furthermore, the IZBiH considers the Ottoman document of Hatti şerîf od Gülhane, from 1839, issued at the time of the Tanzimat reforms, as an institutional basis for their creation. The 1839 document called for the creation of new solutions and institutions, to provide answers for the new circumstances in which Muslims lived. For more, see Durmisevic 2008, p.224.

${ }^{261}$ This is how Kallay described the Austro-Hungarian mission in Bosnia in an interview for the London Daily Chronicle, in 1895 (Donia 1981, p.14). Also noted by Neumayer and Schmidl 2008, p.105.
} 
some semblance of balance between belief and state. Religious supremacy in the Ottoman Empire was in the hands of the Sheikh-ul-Islam, who was based in Istanbul, the political center and the seat of the Sultan, who was the leader of the Muslim religious community, and who was in essence the embodiment of the state as the Caliph. The state had its own coercive powers; however, Islamic scholars and even ordinary people still had the possibility to call upon the higher law established by the power above the state. The new European model broke that balance, and the state became the top authority, over and above any and all other hierarchies. Such a situation was new for Bosnian and most other Muslims, and they had to respond somehow. The whole process happened gradually.

In the first phase, when the Hapsburgs were just administering Bosnia, Islamic law was still officially recognized legislatively and normatively, and it was still able to insert itself into the official and even the international sphere. ${ }^{262}$ The official ulama were still able to apply pressure on the state in matters of great concern to them, such as the controversial conversions episodes. ${ }^{263}$ This made the Austro-Hungarians push harder in their attempts to sever ties between Bosnia and Istanbul. Since at that point those ties were primarily religious, they created a new religious hierarchy, based in $\mathrm{BiH}$ and controlled by the Habsburgs. ${ }^{264}$ They accomplished that gradually, first by encouraging 58 prominent Sarajevans in 1878 to write a petition to the new authorities asking for

\footnotetext{
${ }^{262}$ The Bosnian ulama occasionally tried to raise its issues to the international level through the Ottoman Sultan, who was still nominally in charge of Bosnia. The Austro-Hungarians, at least initially, tried very hard to avoid any challenge at that level, as they were "sensitive to Great Power opinions concerning upheaval or signs of popular discontent" (Donia 1981, p.14) in Bosnia.

${ }^{263}$ For more, see Donia 1981, pp.116-120; and Donia 2006, p.100.

${ }^{264}$ For that, the Habsburgs were supported by Sarajevo Bosniak elites, notes Durmišević 2008, p.214.
} 
more religious independence. In 1880 the Hapsburgs prevented the new, Ottomanappointed, Bosnian Mufti Hilmi Omerović from coming to Bosnia and assuming his position. They kept him at bay until 1882, when they formalized the post of Reis-ulUlema as the head of an official body independent of the Sheikh-ul Islam in Istanbul; it was, essentially, an organization able to interpret Sharia law autonomously. The new post of Reis-ul-Ulema became the head of the Bosnian Muslim religious hierarchy, which the Austro-Hungarians recognized as the Rijaseti ilmije (for short, the Rijaset, or the presidency of the ulama). On October 17, 1882, the Austro-Hungarians officially appointed the same Hilmi Omerović, ${ }^{265}$ with the salary of 8,000 gouldens a year, to the new post. ${ }^{266}$ Although the Ottomans did not establish or recognize the position of the Reis-ul-Ulema and appointed Omerović only as Mufti, the new hierarchy nevertheless used that appointment ever since as the source of religious legitimacy for its existence.

The next significant step occurred in 1884, when the new Regional and District Vaqf Commission was inaugurated to regulate the use and ownership of waqfs, ${ }^{267}$ and in this way, all independent financial sources for religious workers were eliminated or placed under state control. Essentially, this process of transforming the Bosnian Muslim

${ }^{265}$ Omerović himself was one of the 58 signatories of the letter.

${ }^{266}$ After intense diplomatic lobbying by the Austrians, on February 9, 1882, the Sheikh-ul-Islam appointed an Austrophile, Omerović, to the post of Mufti and the head of a small legal Sharia system composed of some 50 judges and their courts. However, he was never confirmed as the Reis-ul-Ulema, a previously nonexistent title and institution in the Ottoman Empire or Islamic world. The post of Reis-ul-Ulema is still a unique institution, found only among the Muslims of the former Yugoslavia. For more, see Durmišević 2008 (pp.215-20), or Donia 1981 (pp.20-23).

${ }^{267}$ Kriještorac [2015 (a), p. 285] notes that a waqf is "a religious endowment as a voluntary and irrevocable dedication of property, where the value of these properties become restricted on a perpetual basis, to serve the Islamic objectives prescribed at inception." Traditionally, waqf was also a financial support for a lot of independent religious institutions and scholars (see Donia 1981, p.22). With the new law of 1909, waqfs were permanently cut off from the possibility of serving as an independent financial base for any religious activity not sanctioned by the state. 
religious hierarchy into the new model of a state, was fully completed in 1887, with the opening of the new school for Sharia judges in Bosnia "away from any foreign influences," 268 primarily away from the Ottomans, of course. In that way, judges and all other Muslim religious dignitaries, in fact, became fully part of the new state bureaucracy and agents of a state again, albeit this time a non-Islamic state. ${ }^{269}$ Their role was to be moderators between a strong society and the state, an essential bureaucratic task for a modern state that tries to position itself as the final arbiter. Ever since then, to justify their role as state agents, monitoring and keeping the Muslim religion in check, or balancing religion between the state's needs and the population's religious demands, Bosnian Muslims' official religious hierarchy began associating Islam with "Bosnian tradition."

In that first phase of Bosnian Muslim adjustments to a new type of a state, the Austro-Hungarian state worked hard to accommodate Islamic rituals, and most of their efforts at modernizing the state and society were built along the reformist laws previously established, but not upheld, by the Ottomans. The Sharia courts continue to exist, dealing primarily with family and individual issues, but their number was never increased to the point where they could be sufficient and effective in administering even those provisions of law. Nevertheless, when they passed judgment, the Austro-Hungarians had to accept them or run the risk of upheavals.

\footnotetext{
268 Durmišević 2008, p.212.

${ }^{269}$ For example, from 1882 they became the officially appointed military imams in the Austro-Hungarian army (see Neumayer and Schmidl 2008, pp.110-13).
} 
The second phase of adjustments for Muslim religious elites, ${ }^{270}$ by then completely dependent on the new non-Islamic state's good will to support and tolerate them, ${ }^{271}$ occurred during the time of the initial South Slav state attempt. ${ }^{272}$ With the new state, the Islamic law became only normatively consulted and applied exclusively among Muslims, and only in the case of family matters and certain customs. ${ }^{273}$ However, at that point, the new state could freely ignore any of the judgments or suggestions made by the Sharia courts, which, in fact, it did, even though the state continued to pay the salaries of all Muslim religious functionaries. During that phase, the Islamic community was living through its worst period. It was the time of the decay and complete disorganization of most of the old social structures, ${ }^{274}$ as seen through the total unpreparedness and horrendous massacres Muslims experienced during WWII, ${ }^{275}$ when Bosnian Muslim

\footnotetext{
${ }^{270}$ Salkić (2008) divides this period into three sections, 1918-1929, with small changes; 1929-1935, when the seat of the Rijaset was moved to Belgrade in Serbia; and 1935-1940, when the Rijaset returned to Sarajevo.

${ }^{271}$ To make matters even worse, at the end of WWI, BiH and its Muslim residents found themselves on the losing side of the war and without anyone to champion specifically Muslim rights and interests. See Part XIV, Annex II, Article 381 of the Treaty of Saint-Germain at the Australasian Legal Information Institute, 1999.

${ }^{272}$ It includes the period of the two states, the Kingdom of Serbs, Croats, and Slovenes (1918-1923; SHS) and the Kingdom of Yugoslavia \{1923-1943(5)\} essentially ruled by the same king. For more, see Krijestorac 2015(b), p.5.

${ }^{273}$ The 1919 Treaty of Saint-Germain vaguely obliged the Kingdom of SHS to protect minorities (which could include Muslims), and asked the Kingdom to adopt regulations allowing for family and individual matters to be arranged in line with Muslim (minority) customs (see Australasian Legal Information Institute, 1999; and Salkić 2008, p.441).

${ }^{274}$ Yet, since all other independent sources of religious authority at that point had been suffocated, Muslim society was completely dependent on them, and when they failed, the whole society failed, as indeed it did in the period preceding, and especially during WWII. In his 1952 book, Balić made the same comment, calling the period between the two world wars the worst period of life for Bosnian Muslims.

${ }^{275}$ For example, see the description of the horrifying crimes against Muslims in Eastern Bosnia and Sandžak in Balić 1952, pp. 36-37.
} 
functionaries mostly failed, and left their people without any clear guidance. ${ }^{276}$ To make matters structurally even more difficult for Muslims, this was also the time when the Vidovdan Constitution of 1929 designated the Bosnian-based Islamska Zajednica (Islamic Community) as only a part of the Islamska Vjerska Zajednica (Islamic Religious Community), which was declared in charge of the entire Yugoslavia by the Constitution. The subsequent law regarding the Islamic Religious Community of Yugoslavia brought the whole institution under the firm control of Serbian interests and moved the seat of the Rijaset from Sarajevo to Belgrade. Since that meant the incorporation of all other Muslim ethnic groups, with significant differences among them in terms of economic base, language and life-style, into one structure, it became even more complicated to come up with a unified strategy of development and action for Bosnian and other Yugoslav Muslims. $^{277}$

As a result, Bosnian Muslim religious elites were even more stagnant and undecided as to which direction to take, whether to be champions for all Muslims in those South Slavic (Yugoslav) projects, or to act only for themselves. Their structural

\footnotetext{
${ }^{276}$ This was also the period when the infamous Jerusalem Mufti, Al Huseini, came to Bosnia under the auspices of Nazi Germany to agitate for the creation of a Muslim SS Division (but under Croatian command). Although the Bosnian Muslim ulama issued several decrees which essentially forbade Bosnian Muslims from cooperating with the Ustaša regime, they did not offer any alternative or guidance on what to do. That led some Bosnian Muslims to support the idea of Al Huseini, who promised that such a large and well-armed Muslim military unit could save Bosnian Muslims from horrendous massacres by their neighbors, since, according to him, the unit was to remain in Bosnia. The whole experiment with Germans ended in disappointment for Bosnian Muslims (for more, see Hoare 2013, pp.51-4). Some of the conscripted Muslim and Croat soldiers in 1943 even staged a mutiny against their German SS officers. A few of those soldiers escaped and sparked the French resistance in the city of Villefranche-de-Rouergue, for which the city erected a monument to commemorate their rebellion, although it was labeled "under the slightly one sided title of "la revolte des Croats" (Malcolm 1994, p.191), neglecting the Bosnian Muslim participation in the revolt.

${ }^{277}$ The Mufti of Belgrade, for example, fought against the establishment of the office of the Reis-ul-Ulema to be in charge of the entire Kingdom (see Salkić 2008, p.442).
} 
educational situation somewhat decided the dilemma, since most Bosnian Muslim religious workers would be schooled within $\mathrm{BiH}$, while most of those from Southern Serbia, Macedonia, and Kosovo, would go to medresas in Skopje, Macedonia or Kosovo. Muslim functionaries from Sandžak would go both ways. They preferred Bosnian schools, but often could only afford one in Skopje since it was less costly. ${ }^{278}$ But that was not enough to bridge the different circumstances in which all Muslims from the former Yugoslavia lived, and the even more different aspirations which they dreamed of. Bosnian Muslims and their religious elites were primarily concerned with issues pertaining to Slavic Muslims living in the territory of $\mathrm{BiH}$, and Albanian Muslims in Serbia and Macedonia were concerned about Albanians in their territories, while the other Muslim minorities were concerned with the mere issue of survival. Yet at that point, in addition to the IZBiH, Bosnian Muslims also had the Jugoslovenska Muslimanska Organizacija (Yugoslav Muslim Organization; JMO) to champion their needs and aspirations. This political organization worked in close cooperation with the religious hierarchy but was nevertheless separate from it. After political maneuvering by the JMO, the seat of the Reis-ul-Ulema was eventually returned to Sarajevo in 1936; however, all the other issues stemming from the Slavic unification project of Yugoslavia, that the $\mathrm{IZBiH}$ and IVZ had to face, remained unresolved.

The third phase of the religious functionaries' interactions with the state was during the time of the Communist-ruled Yugoslavia. All political parties and organizations besides the Communist Party were banned, including the JMO, and the

\footnotetext{
${ }^{278}$ Jovanović (2013) notes that in 1940 half of the graduates of the madrasas in Skopje were from Sandžak.
} 
IZBiH became the only organization specifically made up of Muslims. In a one-party state there was not much room for any other ideology, and especially not for any alternative laws. The IZBiH functionaries understood that well ${ }^{279}$ and acted appropriately, ${ }^{280}$ and sometimes even urged believers to give up religious norms and duties and adopt those proposed by the Communists. ${ }^{281}$ The Islamic law and courts were completely abolished on March 5, 1946 (Hoare 2013, p.373), and the official sphere took over the private sphere almost completely. With that, family laws and norms also became a matter of the official sphere exclusively, and religious practices became problematic even in the personal sphere. Basically, Sharia law completely ceased to have any positive judicial authority (ius positum) for Bosnian Muslims, and it was completely transformed into the realm of customs and tradition and, somewhat, ethical principles ${ }^{282}$ which played a role (when they did) in smaller private settings, and only occasionally in small villages, or in selected social spheres. ${ }^{283}$

\footnotetext{
${ }^{279}$ On the occasion of his inauguration as the first post-war Reis-ul-Ulema, on September 12, 1947, Ibrahim Fejzić gave a speech in the central Sarajevo Mosque and said, "Comrades, brothers and sisters! As I assume this position ... knowing your wishes, I direct my first thought to our beloved Marshal Tito and ask Allah for his long and happy life and blessing of all our peoples of FNRY. It is our duty to remember our beloved leader and teacher on every occasion ..." (Salkić 2008, p. 451).

${ }^{280}$ For example, Trhulj (1995, p.21) reports an instance in 1949 when the Director of the Madrasa, Sulejman Kemura, personally seized and reported to the authorities a young madrasa student who was handing out (Mladi Muslimani-made) Islamic pamphlets, who was then interrogated and killed by the Communist secret police. A few years later, Kemura became Reis-ul-Ulema himself.

${ }^{281}$ Hoare (2013, p.373) notes that after WWII, Reis Fejzic endorsed the Communist-driven campaign against the woman's veil, followed by other Muslim religious authorities, who finally declared in 1947 "that the veiling of women is not required by religious code" (p.374). The veil was finally outlawed by state law in 1950, the same year when religious schools, mektebs were also officially closed down. Hadžišehović (2003, pp.116-24) describes well the upheavals those changes caused for Muslims.

${ }^{282}$ Karčić 2006, p.58.

${ }^{283}$ For example, see Hadžišehović 2003, p.123.
} 
The role of the ulama and the space in which it could play a role, therefore, were severely limited. Furthermore, with the agrarian reforms of 1949 and 1959, when any large landowners were dispossessed of their land tracts, the IZBiH's main financial base of vaqfs was taken away and the religious hierarchy crippled. ${ }^{284}$ That removed even the semblance of autonomy, and the IZBiH became almost completely dependent upon state subsidies and contributions and direct giving by the people who attended mosques and services. ${ }^{285}$ It took time for the IZBiH to adjust to these new budgetary circumstances, but eventually it did, by becoming closer to ordinary men and women and their culture, and by adopting many folk practices for which they could receive financial compensation, and in that way they further developed the syncretic "people's religion" of Bosnian Islam. ${ }^{286}$ In this situation, and as also preferred by the Communist regime, they became the interpreters and arbiters primarily of Bosnian Muslim tradition, and less of the (high) Islamic tradition. With this opening of a socio-theological sphere, as time passed, through continued improvements (islah) adopted as a method early during the time of the Habsburg takeover, ${ }^{287}$ the IZBiH also learned to balance between the religious norms and

\footnotetext{
${ }^{284}$ Although the IZBiH remained owner of the mosques and religious school buildings, the land was taken away from it. For more, see Haore 2013, p.373.

${ }^{285}$ Zachary (1984, p.441), noted the IZ source reports that the state provided 7\% of the operating budget of the IVZ between 1945 and 1947, and that the support increased to 73\% between 1948 and 1950.

${ }^{286}$ A good example of their "learning and adapting" is the way the IZBiH used funds from sadaqul-fitr also called zakät al-fitrah, the giving of food (or nowadays, money) at the end of the month of fasting, Ramadan, that is traditionally given to the poor so that they can take part in the holiday festivities. After 1969 those funds were diverted to finance the building and operating of the University of Islamic Studies in Sarajevo. This is a very liberal interpretation of how the money from zakāt al-fitrah may be used. For more on zakat al-fitrah, see al-Shiekh and Stewart 2009.

${ }^{287}$ Karčić 2006, p.55.
} 
the state-regime's scientific-based ideology. ${ }^{288}$ The IZBiH (as part of the IVZ) often tended to the needs of the state, to the point where the Reis-ul-Ulema would meet foreign dignitaries to support the Yugoslav state's non-Alignment foreign policy project. ${ }^{289}$

The uneasy nature of relations between the state and the IZBiH may also be observed from the other end. Although the regime played an active role within the IZBiH, especially in appointing the leaders of the organization, it tried very hard to interact with the religious hierarchy outside of the public view in order to keep up the appearance of the separation of the state from religion. Furthermore, the Communists were aware that direct confrontational contacts would benefit the religious hierarchy and could even provide them with the legitimacy of a people's tribune. ${ }^{290}$ Rather, conversations with those deemed problematic would usually initially be held informally, in a restaurant over a cup of coffee. It was only after a few such "conversations" that direct and decisive action might be taken, along with the appropriate propaganda spin that was orchestrated to frame the particular interaction of the state and the religious hierarchy in the desired way. ${ }^{291}$ Furthermore, the separation of state and religion was only apparent in public, while in fact the state actively intervened in matters of religious concern. That may have been done indirectly, when the regime urged imams to advocate some aspects of religion

\footnotetext{
${ }^{288}$ For an example of this evolution, see Hoare 2013, p.356.

${ }^{289}$ Zachary (1984, p.442) notes how the Islamic hierarchy emphasized the scientific Communist approach as Islamically appropriate and compatible.

${ }^{290}$ See Ćimić 1967, p.158.

${ }^{291}$ For example, in an interview, Dr. Halil Mehtić, who became the Mufti of Zenica after BiH independence, describes this process in the case of his 1987 arrest (See Islam My Life TV, 2016).
} 
more than others, or directly, when the regime steered things in the direction that worked for them. ${ }^{292}$

As the state and the IZBiH both learned how to interact with and tolerate each other, such relations continued until the early 1990s, when the collapse of the regime became obvious, and the religious hierarchy publicly challenged the state and openly declared its direct support for the Muslim political party led by the dissident Alija Izetbegović, and its indirect support for the independence of $\mathrm{BiH}$ in the referendum held on March 1, 1992.

With such open support of certain options, the IZBiH signaled that it was ready to play an active role in any new state which might develop, yet with the understanding that the state would be only the main framework for those future relations. During the first months of the Bosnian war, the newly independent state of $\mathrm{BiH}$ provided the means for the IZBiH to separate from the IVZ of Yugoslavia, to discontinue its relations with the Skopje-born Reis-ul-Ulema Jakub Selimovski, and to bring to Sarajevo and nominate the new Reis-ul-Ulema of the IZBiH, the University of Chicago graduate Dr. Mustafa Cerić. With the official split from the Yugoslav-based IVZ, an interesting new realization came to light. The IZBiH completely adapted to the model of its relations with a new type of state, and now views the very legitimacy of the state as the main source of validity for its existence. In a text published by the newspaper Ljiljan, considered the main voice of Bosnian Muslims nationalism at the time, and closely aligned with the IZBiH during the

\footnotetext{
${ }^{292}$ When the Reis-ul-Ulema Kemura issued the fatwa in 1950's providing religious justification for women to take off the hijab and go to mixed schools.
} 
war, Turčić (1993) ${ }^{293}$ explained that the end of Yugoslavia also ended the legitimacy of the IVZ as the religious hierarchy of the Muslims in the region. The text further argued that the efforts of the former Reis-ul-Ulema Selimovski to establish a new Islamic hierarchy for the entire region of the Balkans in 1993, therefore lack the legitimacy provided by a state. As such, it was no longer the 1880 decree of the Sheikh-ul Islam appointing Mufti Omerović which established the legitimacy of the $\mathrm{BiH}$ religious hierarchy, since its legitimacy was now to be based on the international sovereignty and the legitimacy of a nation-state. With this approach, the full circle of the $\mathrm{BiH}$ religious hierarchy adjusting its role to the non-Islamic, Weberian-defined, rational-legal state is completed.

And today, as Karčić (2008) notes, the official Bosnian Islamic hierarchy has finally "learned" how to function in those new circumstances of a secular state, and "when today the secular state is discussed in $\mathrm{BiH}$, as an adequate model for multireligious societies, that should not mean a return to the past, but the acceptance of the highest modern development of such a model" (p.57). Therefore, the official Islamic hierarchy in $\mathrm{BiH}$ expects the state to define secularity as "neutrality with respect" (p.57), and not as a complete absence of religion. In the words of Reis-ul-Ulema Cerić, "we are in favor of a state that is separated from religion in its form, but we are against a state that is separated from religion in its content." ${ }^{, 294}$ So it should not be as it was with the secular

\footnotetext{
${ }^{293}$ See Turčić 1993. However, at that time, some people wrote for Ljliljan under different pen names. The name Šahbaz Turčić might also be the pen name of a person who wished not to be identified as the author of the text, especially since it appears to be written from Macedonia, where the influence of the old Reis, Selimovski, was still strong at that time.

${ }^{294}$ Bougarel 2007, p.115.
} 
Communist-led state, where the state tolerated but discouraged religion; rather, now there should be not only toleration of religion, but also neutrality in terms of preference and respect for a religion, in this case Islam. The first step towards that goal occurred when the IZBiH wrested back its ability to independently select its own leaders, while the second step occurred when it regained ownership of the vaqf properties throughout $\mathrm{BiH}$.

It seems that the lines between the official and social spheres in such multireligious states should be blurred. The official IZBiH basically would like to retain its autonomy in financial and normative matters, while the religious hierarchy would like to be much more apart from the state hierarchy. ${ }^{295}$ Yet, in their view the Islamic laws and norms were to be a significant part of the individual and social spheres, while the official sphere was to support the religious hierarchy as an alternative law-giver as well as a lawdecipherer, only not a law enforcer. ${ }^{296}$ The IZBiH prefers what international relation observers note as the Kantian type of state. As Karčić (2008) continues, "although religious institutions are structurally and functionally separated from a state, they do have a right to comment about public issues" (p.57), and their role and direct responsibility within the state is along the line of "deciphering of the religious norms (ifta), upbringing

\footnotetext{
${ }^{295}$ An example is that in 2016 the IZBiH finally signed an agreement with the BiH state regarding the vaqf properties, which were either to remain under IZBiH control, or those which were not, were to be returned or the IZBiH was to be re-compensated for their value. Additionally, in the same agreement the IZBiH wanted to be included in the education curriculum as the exclusive provider of religious instructors for pupils who would choose to study Islam electively, rather than civics, in public schools. Finally, the official imams wanted to receive all the benefits of social welfare such as health care and the right to education, but not to contribute through taxes, since their sources of income as vaqf are tax-exempt and theoretically could only increase.

${ }^{296}$ As examples, see the 2016 decree about "illegal mosques" or as the IZBiH calls them, "quasi-jamaats" (see Muftija 2016); or the previous, 1952, official decree providing for the Communist shutdown of Sufi orders (see Buturovic 2015, p.26).
} 
and education ( $a d a b)$, and alternative solutions for the conflicts among Muslims, such as finding peaceful resolutions (sulh) and arbitrations (tahkim), among others" (p.58).

With such a relationship, the state is becoming what Migdal (1988) saw as a mélange of social organizations often competing for influence by creating their own unitspecial strategies of survival, rather than a hierarchy of power relations. In such a state, contrary to Piscatory (1991, p.13), despite claims that politics is independent of religion, the separation between the two may not be so neatly delineated since both are actually instruments of the religious hierarchy. The $\mathrm{IZBiH}$ in such relations then plays the role of mediator of the religious, social and even, to some extent, political order within and outside of the group. The political order might be concerned with hard politics (as when Reis-ul-Ulema Emeritus Mustafa Cerić became a direct candidate for the $\mathrm{BiH}$ presidency, ${ }^{297}$ or when the IZBiH-appointed Mufti of Sandžak, Muamer Zukorlić, was the direct candidate for the Presidency of Serbia ${ }^{298}$ ); or with soft party politics (as when the IZBIh supported the Stranku Demokratske Akcije (Party of Democratic Action) (SDA), or softly advocated a referendum vote for $\mathrm{BiH}$ independence). But, the political order may also involve participation in discussions over the decision of the Bosnian Constitutional Court about women's right to wear a hijab in public institutions, or which mosque is legal and which one is not, as is currently happening. Finally, the IZBiH is the decisive arbiter in selecting which practices are part of the Bosnian Muslim tradition and which are not, and in such a way, entangled within the web of state social and political structures, it is

\footnotetext{
${ }^{297}$ For more, see Gadzo 2014.

${ }^{298}$ For more, see Barlovac 2012.
} 
instrumental in pushing for a specific manifestation which feeds the feeling of religious difference and particularism for Bosnian Muslims, and which is now part of the Bosnian Muslim nationalism project and its salient Bosniak identity. ${ }^{299}$

\section{5-5: Bosniaks, Bosnian Language or Language of Bosnia and Herzegovina}

The third type of Bosnian Muslim elites which developed particularly well during the years of Communist rule was the intelligentsia, composed of intellectuals, journalists and educators. ${ }^{300}$ For them the most frequently emphasized factor of Bosnian nationalism and Bosniak identity was the Bosnian language. There are two ways in which the Bosnian language came to be very important for Bosnian Muslim nationalism.

The Bosnian language should be viewed as a separate element of Bosniak identity that provides an anchor and historical stability for the community, because it is the most easily noted form of expression of the group that can be pointed to by people within and without the Bosnian Muslim community. Furthermore, the Bosnian language is often presented by intellectuals from the community as a feature that can be traced as proof of their existence in the past and in the present, and in the two worlds in which they simultaneously exist: the larger religious community of world Muslims, where the

\footnotetext{
${ }^{299}$ In 2012 the official Bosnian Islamic Organization (IZ) issued a declaration that Bosnian Muslims must identify themselves as Bosniaks in the then-upcoming 2013 census, and not as Bosnians or Muslims, as they used to do. For more, see Rijaset (Nov, 2012).

${ }^{300}$ Some argue that the beginning of the Yugoslav "third estate," built along the lines of the technomanagerial structure, started in 1965 when executive power was taken from the President (Tito) and the Savezno Izvršno Vjeće (Federal Executive Board) began to run the SFRY (See Savezna Narodna Skupština 1963, p.314-15). However, as a result of the particularly harsh policies of Alexander Ranković (Midžić 2007, p.299), and the strong Serbian nationalistic hold on the BiH (and Yugoslav) state apparatus, the rise of the Bosnian Muslim political and technocratic elites was crippled for a long time (see Abazović 1999, pp.70-113), and 20 years after the end of WWII new, socialism-groomed, intellectual elites could begin to form. For more see Malešević 2006, pp.191-201 and pp.214-5.
} 
primary diacritical marker is their Slavic Bosnian language; and the immediate geographical neighborhood where they live, where the assertion of the Bosnian language as their mother tongue is the most important link that ties them to the Bosnian land. The language itself, and sometimes its name, is often contested by their neighbors who have seen (Bosnian) Muslims as "(br)others" ${ }^{301}$ so often in the past few centuries. ${ }^{302}$ The contestation has been expressed in different ways, ranging from denial of the existence of the language itself, or denial of the attribute "Bosnian" for the language that Bosniaks speak, ${ }^{303}$ to denial of the right of a group to physically exist, which resulted in frequent genocidal attempts to eliminate them from the region during the last century and a half. Although both Serbs and Croat intellectuals do it, the Serbs are more aggressive in attempting to deny the existence and name of the language. Perhaps that is because the

\footnotetext{
${ }^{301}$ Hajdarpasic (2015) coined the amalgam "(br)others" to describe the position of Bosnian Muslims vis-àvis their Slavic neighbors in the Balkans. For more, see Hajdarpasic (2015), especially pp. 15-18.

${ }^{302}$ Vuk Karadžić basically arbitrarily and singlehandedly, decided that the particular local, Štokavian, dialect of Slavonic languages spoken in East Herzegovina in his time should be the standard for what he named the Serbian language. By doing that, Vuk not only outran neighboring people's nationalisms by putting his name-claim first, but also provided a long-term direction for future Serbian nationalism projects and determined which population should be targeted to be nationalized into the project of the Serbian nation. Obviously, since many people who spoke the Štokavian dialect in the region were not Orthodox Christians (which only later became the essential element of Serbian identity), Vuk referred to them as Roman Catholic Serbs, or Muslim Serbs living in Bosnia. The process resembles today's European games of branding certain foods and recipes so there is now a lively discussion, at least in the Balkans, of whose baklava it is: Turkish or Greek? Or whose coffee is being served with it, Serbian, Bosnian or Turkish? It is assumed that the winners of those debates will have some advantage over other local people who have made and eaten baklava with coffee for centuries without a second thought about whose recipes are behind them. Vuk did achieve an advantage over other local Balkan peoples whose language was called "Serbian" without their knowledge, or their comprehension of the consequences of such naming, even though at that time "the term Serb was a vague ethnic term, and the spatial distribution of Serbs was even vaguer" (White, 2000 , p.182). However, today this language name designation has serious political implications for various nationalist projects. For illustrative examples of the ongoing "battles" over baklava and coffee, see Schleifer (2012) and Kakissis (2013).
}

${ }^{303}$ Alexander (2006) notes that "a devoted and diligent group of Bosniak intellectuals undertook the more or less parallel task [to that of their Croatian colleagues] of establishing a language that would also be distinct from Serbo-Croatian - a language which they call Bosnian, but which many outside Bosnia believe should bear the name Bosniak" p.425. 
dialect spoken primarily in the region of Herzegovina was singlehandedly chosen in the $18^{\text {th }}$ century by Vuk Karadžić $(1787-1864)^{304}$ to be the model on which the Serbians' literary language and their nationalism were built. ${ }^{305}$ The different systematization of that same central Štokavian Slavonic dialect now, therefore, endangers Serbian nationalist projects, built along the lines of the folkloric German approach (Plamenatz 1976), where the core language and its name play a significant role. ${ }^{306}$

For Bosniaks, the Bosnian language is their mother tongue. The narrative of Bosniak intellectuals and nationalists is that $\mathrm{BiH}$ used to be inhabited by interconfessional people who shared the local version of the Slavic language, which was called Bosnian after the territory where it was spoken. ${ }^{307}$ As mentioned earlier, $\mathrm{BiH}$ was inhabited by some people who were nominally considered Catholics, followers of the

\footnotetext{
304 "Vuk chose ijekavian, the East Herzegovinian speech of the region where he himself originated, an area which was known to be a stronghold of traditional epic singing. He would not allow in the grammar of this new language any word or form that did not exist naturally in this East Herzegovinian speech" (Alexander 2006, p.382), a specific dialect of the local Slavonic language. The Serbian Church tried to resist Vuk's effort to impose an essentially foreign accent onto Serbian spoken language arguing that in that way Serbian people were being distanced from their history and the tradition of the Church and of the people. As an illustration of how much the Vuk-selected language norm was different from the spoken Serbian, Alexander (2006, p.383) notes that at that time for Serbian people around Novi Sad, East Herzegovinian speech was almost a completely foreign language. Yet, Vuk's approach culminated in the 1899 publication of Tomo Maretic's "Gramatika i stilistika hrvatskoga ili srpskog knjizevnog jezika" (Grammar and Stylistics of the Croatian or Serbian Literary Language), and was eventually supported by the Serbian state when it prevailed and was adopted as the norm for the Serbian and Croatian language. Interestingly, both Croats and Serbs did continue to speak a different version of the language, and in practice never truly adopted Vuk's model. For more, see Alexander 2006, pp. 382-386.

${ }^{305}$ Banac (1988) refers to this program as "Karadzic's linguistic Serbianism" (pp.79-81). For more on Vuk as a "man of the people" who wrote extensively about Herzegovina, while never actually being there, see Hajdarpasic 2015, pp.20-38.

${ }^{306}$ As is obvious from the attempt by the Serbian national academic institution Matica Srpska (Serbian Heritage) to deny the name "Bosnian language." In a widely distributed 2014 recommendation they stated that "use of the term Bosnian language is not acceptable for the Serbian culture" (see Matica Srpska 2014).

${ }^{307}$ White (2000, pp.180-182) notes that until then people identified the language they spoke by the regions they were from (e.g. Bosnian, Dalmatian, Slavonian).
} 
dualist-type Bosnian Church, and with not very many Orthodox Christians except for a small number in the southern parts of Herzegovina and among the Vlachs, ${ }^{308}$ who were mainly shepherds. In the Balkans, Vlachs were people on the move looking for the best grazing lands for their flocks of sheep, basically nomads for a good part of the year - as some of them still are - and who often came from Serbia, Montenegro, or Bulgaria. ${ }^{309}$ After the Ottoman Conquest, the Bosnian Church disappeared, and the new religious group of converts to Islam, the local Slavic Muslims, emerged. All these groups at that time spoke the language named Bosnian after the territory, while not necessarily writing in that language. ${ }^{310}$

On the heels of the Ottomans, the land of $\mathrm{BiH}$ also become the new destination for many Serbs, who moved onto the land under the guise of their association with the Vlachs, who were permitted by the Ottomans to freely move throughout the territory of the Empire. Since they were religiously mostly Orthodox Christians, those Vlach groups were served by Orthodox Christian priests from the Serbian Church based on the doctrines established by Saint Sava, nowadays the patron saint of Serbian schools and

\footnotetext{
${ }^{308}$ As mentioned in the first part of this work, nowadays "Vlach" is sometimes used as a pejorative term for non-Muslims in $\mathrm{BiH}$, mainly to denote Serbs. The term should not be confused with the actual Vlach people who lived throughout the region in medieval times. Fine (1975, p.388) gives very informative and useful information about the Vlachs. They were a specific ethnic and linguistic group, which was eventually Slavicized in language and gradually "swallowed" by the larger Slavic ethnic groups. Over time, the term "Vlachs" came to designate "shepherds" and under the Ottomans it gained a new significance as a particular status, which provided a right to relatively freely resettle throughout the region, and pay a set tax in cash rather than in kind.

${ }^{309}$ For more see Malcolm (1994), pp.70-81; or Fine (1975), p.381.

${ }^{310}$ For example, Omerbašić (2008) quotes the journal published by the institute of Takribul-mezahbi, which noted that "among hajis of Bukhara and Bosnia in the eighteenth century, it was easier for the members of both groups to communicate with Turk in a Turkish dialect, than in the Turkish [Ottoman] literary language" (p.204).
} 
universities. ${ }^{311}$ Serbs began effectively and significantly to appear in $\mathrm{BiH}$, initially in Herzegovina and medieval Zeta, after they lost the Battle of Kosovo in 1389, and after the Ottoman conquests of Bosnia. Their resettlement was also made possible because of the Serbian Orthodox Church's somewhat privileged position by the Ottoman Porte since its seat was within the Empire, as opposed to the seat of the Catholic Church, which was in Rome. ${ }^{312}$ The priests promoted the idea that all people of the Orthodox Christian faith in BiH should also be hierarchically tied to the Serbian Church. ${ }^{313}$ Since ethnicity was the primary social unit at that time, and a structured hierarchy tied to a church was the most important pillar of many ethnicities, Orthodoxy began to mean Serbianism in the ethnic

${ }^{311}$ Born as Rastko, Saint Sava (1174 -1236) lived and rose into prominence at the onset of the Ottoman Conquest of the Balkans and Serbia, which most likely permanently influenced the development of particularization within the Orthodox Christianity (see Emmert 1981). At the time, Saint Sava was an embodiment of strong ties of religious and political powers in the Serbian states of Hum and Raška (the territory of present-day Sandžak). Coming from the regional ruling family of Nemanjić, he pushed for the establishment of an autonomous Orthodox Christian Church, initially against the wishes of the central Byzantine Bishop. However, Sava was not only a priest; he was also a diplomat and briefly even the ruler of the state of Hum. He also wrote the document Zakonopravilo (the Rules and Laws), which Serbs now refer to as the oldest Serbian Constitution. After he established the independent church, he was canonized and venerated by the same church and its followers. His teaching significantly influenced local practices and understanding of Serbian Orthodoxy. Papo (2015) notes that for the Serbs "Jesus is saintly, but not divine [and Jesus is] reduced to a mere saint. Even if holding the position of the chief of all the saints, Jesus does not seem to be the focus of Serbian folk religion and peasant imagination" (p.30). Rather, Saint Sava is. So when animosity towards the Croats overpowers an ordinary Serb, he may venerate Saint Sava above the figure of Jesus, because Jesus is often evoked by the "enemies," the Catholic Croats, even in their everyday greeting of "Hvaljen Isus" (Praise Jesus). For those types of people and situations, even "God is Serb" (see Jovanović 2013; or more entertaining, see the song "Zivece ovaj narod" by the popular Serbian singer Baja Mali Knindža available on many YouTube channels). Sava's obvious strong ties to both the political and religious worlds permanently influenced the Serbian version of Orthodox Christianity and provided a fertile ground for Serbian nationalism to blossom along the lines of the Serbs' own version of religion. In her travel book, Seierstad (2006) notes about Saint Sava that "he established the doctrine that the Serbian Orthodox Church and the Serbian people are the same, a doctrine later to be used by bishops to emphasize Serb supremacy" (p.84).

${ }^{312}$ Fine (1975) lists four main reasons for the spread of Orthodoxy among the inhabitants of medieval Bosnia: "vernacular liturgy; Ottomans preferred them to Catholics; Orthodox did not previously seriously persecute Bosnian [Church] heretics; the Orthodox were linked with the Serbs (fellow Slavs), not with the hated Hungarians" (p.344).

${ }^{313}$ In fact, Donia and Fine (1995) argue that "the translation of one's religious denomination to Serb or Croat nationality also had no relevance to the area's population, since Bosnians before the nineteenth century had not described themselves as either Serbs or Croats" (p.73). 
sense as well. This is an interesting twist of the norm that in Serbia works the other way. There, Serbianism means the Saint Sava version of Christian Orthodoxy, while outside of Serbia, in the lands where similar Šhtokavian dialects of the Slavonic language are spoken, and where teachers, priests and bureaucrats were supplied by Serbia, Christian Orthodoxy means Serbianism. ${ }^{314}$ The same relations locally work between Catholicism and the Croats. This idea worked well, in part due to the Ottoman system of governing that saw the religious group as a primary political unit, often before ethnicity. Later, in the $18^{\text {th }}$ and $19^{\text {th }}$ centuries, when early nationalism began to develop among the Serbs, the idea of all coreligionists as one nation was additionally promoted by the parochial schools and teachers imported from Serbia into $\mathrm{BiH}$, to serve the Orthodox Christian community there. $^{315}$

The same thing happened among Bosnian Catholics. Their church leaders, who came initially from Bosnia, were eventually replaced by Franciscan priests, first from the Italian peninsula, and then from Dalmatia and other regions of Croatia. ${ }^{316}$ Those local priests also spoke a similar version of the Štokavian dialect and also, in the $19^{\text {th }}$ century,

\footnotetext{
314 In her truly revealing essay Balić (2009, pp.123-128) also noted that the similar question of who exactly was considered a Serb in BiH was not clear even during WWII.

315 Jelavich (2003) notes that prior to the First World War (and even after that) "Serbian students were taught Serbianism, as their parents and grandparents had been" (p.96). Those students did not necessarily need to be Serbs to be taught Serbianism. The same education was provided to all students in schools run by Serbs. Jelavich also notes that everywhere in the Habsburg Empire the Croatian side taught Croatianism to the pupils under their care with the goal of instilling "in the students love for Croatia, its history and traditions" (p.97).

${ }^{316}$ For more see Malcolm 1994, p.40.
} 
advanced the idea that coreligionists must be of one nation, ${ }^{317}$ for them Croats. ${ }^{318}$ As that shift happened, Orthodox Christians learned in their religiously segregated schools that the language they spoke was called Serbian, while Catholics learned to call their version of the same Slavonic language Croatian. The only group that continued to use and call their language Bosnian, was the Bosnian Muslims. Since they were an important Muslim group, they even managed to have the name of their language mentioned as one of the official languages of the Ottoman Empire. So that memory of the name of the language spoken in Bosnia is now important to Bosniaks as a reminder that they were one of the original groups inhabiting the land. At the same time, it is a reminder to the other two groups that by abandoning the name of their language, they also abandoned the idea of $\mathrm{BiH}$ as their land.

The Bosnian language is not equally important for all of the people who adopt the identity of Bosniak. For the Bosniaks of $\mathrm{BiH}$, it serves to reassert their claim to the country; for the Bosniaks of Sandžak, Macedonia and Kosovo, it serves to assert their tie to the region of the Balkans, and it is a factor with which they try to assert themselves politically in the newly independent states that are now their homes. So for them, it is not a claim to the country in which they live, but it is a claim to the history of which they are

\footnotetext{
${ }^{317}$ Malcolm 1994, p.149. For that reason, sometimes even nowadays Bosnian Muslims and Bosnian Serbs derogatorily call Bosnian Catholics and Croats "cunning Latins" (lukavi latini), tying them to the Church of the Latin language.

${ }^{318}$ Purivatra (1974, p.551) noted that the Croatian nationalist Stjepan Radić, on the occasion of the centennial celebration of the Croatian Kingdom in Krašić in 1924, attacked Catholic Church bishops for their official letter in which they demanded that the celebration have an exclusive religious character. Radić claimed that with such a letter, the bishops "excluded around eight hundred thousand Muslim Croats" who lived throughout Southern Yugoslavia. In this way, claimed Radić, by a stroke of the pen, the priests downgraded and cut by a quarter the number of Croats in $\mathrm{BiH}$, to a "negligible minority," and with that delivered $\mathrm{BiH}$ to the Serbs. However, a few lines later, Purivatra also noted that on another occasion, in 1927, Radić referred to Bosnian Muslims as Turks.
} 
part when Bosniaks and the Bosnian language were visibly recognized. While they might not be recognized as Sandžaklije who now live outside of $\mathrm{BiH}$, or as Našenci, Goranci, or Pomaci - who all have their own versions of the Slavonic language, which is different from Bosnian, and which they speak at home and in their social spheres - in the official sphere and in schools they insist on using the Bosnian language. ${ }^{319}$ For the same reason, where the Bosnian language implicitly stakes a claim to the land of $\mathrm{BiH}$, now a state, some of the Bosniaks in Montenegro refer to their language as Bosniak, rather than Bosnian. When I ask them why, they explain that they do not want to be tied to a country in which they do not live. However, most Muslims in all those countries who refuse the name of the Bosnian language, usually also prefer an identity other than Bosniak.

During Ottoman rule, the Bosnian language existed under that name as an official category, and under the Habsburgs it was actually reinforced as an important foundation that the Bosnian administrator Kallay wanted to use to support unitary Bosnian nationalism. ${ }^{320}$ After Kallay's death, in 1903, the Austro-Hungarians abandoned both the project of the Bosnian nation and, after 1909, the name of the Bosnian language as well. However, its use was discontinued only in official documents, while Bosnian Muslims continued using it under that name in their interactions, ${ }^{321}$ until $\mathrm{BiH}$ became part of the

\footnotetext{
${ }^{319}$ See Saliji 2014; or see the OSCE Mission in Kosovo 2009.

${ }^{320}$ Pinson (1993, p.103) also notes the same about the Bosnian language factor. It may be added that in 1890, for example, even a grammar of the Bosnian language with Latin alphabet was issued for Bosnian high schools.

${ }^{321}$ At the same time as the abandonment of the unitary Bosnian nation project, in 1903 Bosnian Muslims created their own pro-Western, self-help cultural society Gajret, sometimes credited as being a progenitor of the modern Bosnian Muslim intelligentsia class (see Pinson 1993, p.110). Seen also as pro-Serbian, Gajret continued to exist until 1941, when Croat Ustašas shut it down and forced the creation of a new Bosnian Muslim organization.
} 
new South-Slavic state. The new state was based on the unity (narodno jedinstvo) of Croats, Serbs and Slovenes, with each group named for its version of the local Slavonic language, and all united as a result of the Vienna Literary Agreement of $1850 .^{322}$ During that time, Bosnian Muslims were seen by the two dominant groups, Serbs and Croats, exclusively as a religious group which was part of their respective nations. Reluctantly recognized as Slavic “(br)others," Muslims were urged to choose whether they were Croats or Serbs. Many Bosnian Muslim intellectuals at that time began to declare themselves as Serbs or Croats, or sometimes both. ${ }^{323}$ Thus Bosnian Muslims were once more left leaderless, to fend for themselves.

The policy of denial of nationhood to Bosnian Muslims, along with denial of the Bosnian language, continued under the Communist version of South-Slavic nationhood. ${ }^{324}$ Eventually, with the so called Novi Sad Agreement in the 1950's, a new language combination was standardized under the name Serbo-Croatian or Croato-

\footnotetext{
${ }^{322}$ Banac 1984, p. 211; Hajdarpasic 2015, p.41. It should be added that the Vienna Literary Agreement was also made without Bosnian Muslim representatives.

${ }^{323}$ The first president of the Bosnian Muslim organization Gajret, the great Bosnian Muslim poet Safvetbeg Bašagić, famously first declared himself a Serb, and then changed his mind and publicly became a Croat. The next Gajret leader, Osman Đikić, is still celebrated as a great Serbian national and even has a street named after him in the elite part of Belgrade. Other notable Bosnian Muslim intellectuals publically declared themselves Serbs, such as Meša Selimović, while his brother chose to be a Croat. The great poet Mehmedalija Mak Dizdar decided to be a Croat, and the list goes on.

${ }^{324}$ Although ideologically paradoxical, many previous nationalist policies towards local Muslims of the "old era" were often continued by the new, progressive Communist Parties throughout the Balkans. Myhtar May (2014), for example, documents policies of continuous Christianization of Muslim Pomaks by the Bulgarian Communist Party. In the case of $\mathrm{BiH}$, and even Yugoslavia, the Communist Party was composed of many illiterate and barely literate people, who were overwhelmingly Serbs. In 1949 in BiH, some 20\% of them had no schooling, while over $57 \%$ had only the basic four years of elementary school, while in 1954 these categories were $12.18 \%$ and $54.42 \%$ respectively (Abazović 1999, p. 363). So they were not conscious vanguards of the society; rather, they were mostly expedient local people who joined the Communist Party to advance themselves. Such people mostly followed policies and practices they knew from the old, pre-Communist Yugoslavia, and they kept the old attitudes towards Bosnian Muslims.
} 
Serbian as the official language of the central part of the former Yugoslavia (Slovenia and Macedonia had their own languages). ${ }^{325}$ Again, Bosnian Muslims were not invited to that meeting, and the decision was made without them. In the 1960s, some Bosnian Muslim intellectuals tried to reassert the specificity of the spoken Bosnian language, but without much success. And then in the National Census of 1991, instead of being given the previously preselected choices for language, each person was offered an option to name her or his own mother tongue. Almost a third of the total $\mathrm{BiH}$ population, and possibly $85 \%$ of Bosnian Muslims, named as their mother tongue the Bosnian language. ${ }^{326}$

As mentioned, the issue of the Bosnian language is primarily important to the more or less secular Bosnian Muslim intelligentsia, which formed during the Communist era and was part of the state bureaucracy. ${ }^{327}$ During the late stages of the Ottoman era, the three types of elites (military, landowning, and religious) coexisted among Bosnian Muslims. With the Habsburg takeover, the military elites disappeared, replaced by a small number of new bureaucratic elites, who continued to coexist with the remaining two groups. ${ }^{328}$ When $\mathrm{BiH}$ became part of the South Slav unification projects embodied in the Kingdom of Serbs, Croats and Slovenes (KSHS), the religious elites were

\footnotetext{
${ }^{325}$ With this, the use of the names Serbian and Croatian languages was also discontinued in official practice.

${ }^{326}$ See Alihodžić 1993 , who also notes that over $65 \%$ of the population, chose to identify their language as other than the official Serbo-Croatian. The overwhelming majority of the Bosnian Serb population chose to identify their language as Serbian, Bosnian Croats chose theirs as Croatian, while Bosnian Muslims identified theirs as Bosnian.

${ }^{327}$ See Pirić 1993, or Malešević 2006, p. 197.

${ }^{328}$ Initially this was a very small number of bureaucrats, since there were only a few Latin-alphabet-literate Bosnian Muslims at the time of the Austro-Hungarian takeover. Neumayer and Schmidl (2008, p.96) report that in 1910, some $94.65 \%$ of Bosnian Muslims were illiterate, which means they could not use the Latin alphabet, which became dominant with the Habsburgs' takeover of $\mathrm{BiH}$.
} 
handicapped by the state, while the other two groups, the landowners and bureaucrats, continued to be influential, although the landowners were significantly crippled by the new state-implemented land reforms. Simmons (2002) notes that the 1919 land reform of the new Kingdom was a significant factor in the redistribution of wealth in Bosnia. Christian serfs were freed and received legal title to the land they worked. "Agrarian land reform resulted in the virtual impoverishment of many Bosnian Muslims. A people who had owned eighty percent of the land, who had great wealth, were transformed suddenly, by means of the laws on agrarian reform, into, one could say, beggars" (Simmons 2002, p.625). As a consequence, the descendants of formerly wealthy Bosnian Muslim landowners often sought professional training and education in the West. They joined their (ethnic) Croatian and Serbian counterparts in studying abroad, to form a growing class of professionals and intellectuals who were affected by the secularizing influences of the West. That time, therefore, may signal the beginning of the process when the new Bosnian Muslim elites, professional bureaucrats, began to have the upper hand over the landowning elites. Furthermore "in the long run, the decline of the Muslim ruling [landowning] class in $\mathrm{BiH}$ set the stage for economic and political equalization" (Simmons 2002, pp.629-30), a necessary precondition for nationalism to grow within the group.

In Communist-led Yugoslavia, when religious elites were further crippled and only still relevant culturally, Bosnian Muslim bureaucrats became the most significant 
group within the population, ${ }^{329}$ while the landowners disappeared completely. This is the moment when "the shift from class to mass" 330 began. With the landowners" disappearance, class and status consciousness disappeared as well, and only then did the Communist-based ideas of equality and horizontal solidarity finally flourish among Bosnian Muslims. Those ideas of horizontal solidarity were first directed towards Yugoslavianism, but with the strengthening of Serbian nationalism during the Ranković era, and the subsequent 1968-events of the so-called anti-bureaucratic student protests in Belgrade; as well as the Croatian nationalistic response seen in the events of the 1971 Croatian Spring, Bosnian Muslims also began to speak aloud about themselves as a separate group. ${ }^{331}$

The first result of this group's awakening was its decision to champion the name of "Muslim" as a national designation, without emphasis on the specific territory, but rather, just on Slavic Muslim cultural history and folklore. With focus on a culture and community, the secular intelligentsia "became interpreters and translators for and within their community" (Malešević 2006, p.200), and this is where they encountered religion

\footnotetext{
${ }^{329}$ As a result of what Curry (1995) calls the "industrialization legacies" of the mass rural-urban population movement (pp.60-63).

${ }^{330}$ Riall $(2009$, p.404) noted the phrase and urged investigators to pay attention to that shift, as a significant moment in the process of any nationalism. Furthermore, she suggested that a "mass" could be conceptualized as an "urban middle- and lower middle-class 'public' of enthusiasts" (p.404) that shares interests and solidarity. Such a mass for Bosnian Muslims could emerge only after the Communist takeover of Yugoslavia and the final demise of the Bosnian Muslim landowning elite's class and status.

${ }^{331}$ See, for example, the four important discussions on the question of Bosnian Muslim national identity by Redžić (1970), Suljević (1970), Ćerić (1971), and the collection of various views by Hadžijahić and Purivatra (1970) which interestingly, in 2016, I could find only in the IZBiH-run library and nowhere else in Sarajevo. Although all these authors could not agree among themselves on a specific name for the group, their very open and frank discussions about the issue signaled that the group has emerged into a new stage of national awakening and consciousness. This was a significant public steppingstone for Bosnian Muslim elites as a group that was almost invisible until then.
} 
and the religious hierarchy which entered the community sphere first through continued maneuvering, while improving their organizational structures (islah). As was established earlier, the religious hierarchy had been there, in the realm of culture since it gradually withdrew from religious universalism into norms, customs and resolutions about Bosniak traditions, during the first two phases through which Bosnian Muslims had passed since they became a distinct local group. So the new secular intelligentsia, composed mainly of bureaucrats, educators, and other literary people, picked another people's issue, the Bosnian language, as their torch to carry.

The first significant assertion of the name "Bosnian language" was in the 1991 book on the language of Bosnian Muslims, Jezik Bosanskih Muslimana, by Dževad Jahić, while the dictionary published in wartime of the characteristic words of the Bosnian language, authored by Alija Isaković (1991), resonated more strongly with the public. Another important contribution on the issue of language was also made by Muhsin Rizvić, with his book that also reiterates the historical right to the language used by the people of Bosnia over centuries, and its Bosnian name. In his introduction, Isaković (1991) noted that Bosnian Muslims as "people ... have named their language spontaneously, as all independent people do - both the greatest and smallest - as they did not disappear at any historical time, did not leave, nor did it get dissolved into other people, [and now] the descendants of [those] ancient Bosnians are still using the Bosnian language" (p.9). With these words, Isaković reaffirmed the Bosnian Muslim people's right to name their own language, an essential sign of being someone in the world, and, in this case, of uniting themselves with the particular history they chose and wanted to inherit. The name was 
further promoted by the Bosnian weekly Ljliljan, the prime media outlet for Bosnian Muslim intellectuals during the war. From 1993 through 1995, Ljiljan published a slew of articles which all argued that the Bosnian language had existed historically primarily as the language of Bosnian Muslims, which further decreased the chances for the other two groups to call their version of the same language "the Bosnian language". ${ }^{332}$ Eventually, the term took hold and, even the voice of the Socialist Union of Workers, the daily Oslobođenje began to use the name Bosnian language in print. That signaled not only that the name of the people's language was fully accepted by the group, but also that the Bosnian Muslims had finally asserted themselves as a distinct local national group which was to play a decisive role in $\mathrm{BiH}$ once again. The Bosnian language was then mentioned also in the international Dayton Peace Agreement signed in $1995 .{ }^{333}$ However, there are still many uphill battles to be won before it is fully accepted on the ground locally in the Serbian-dominated side of $\mathrm{BiH}$, and even in the many localities outside of $\mathrm{BiH}$, where Bosnian Muslims, as Bosniaks, now live. ${ }^{334}$

\footnotetext{
332 Among many, see, for example, Ćeman 1993; Durić 1993; Pirić 1993; Latić 1994; Isaković 1995; Nanić 1995.

${ }^{333}$ Right above the signatures, at the bottom of the General Framework of the Agreement signed in Paris on November 21, 1995, it is indicated that the Agreement is written "in the Bosnian, Croatian, English and Serbian languages, each text being equally authentic.” The Agreement can be viewed at http://peacemaker.un.org/sites/peacemaker.un.org/files/BA_951121_DaytonAgreement.pdf

${ }^{334}$ As of 2013, the refugee service organizations in the U.S., as well the official USCIS, did not have the category of Bosniak nationality/ethnicity, or Bosnian language in their files. Therefore, for those refugees from $\mathrm{BiH}$ of ethnic Serbian origin, the files would note the country of origin as BiH, ethnicity as Serb, and language as Serbian. For BiH Croats, again the country of origin would be noted as BiH, ethnicity as Croat, and language as Croatian. Only for Bosnian Muslims would the country of origin be BiH, their ethnicity listed as (the nonexistent) Bosnian and Herzegovinian (but none of them would note Bosniak), and their language, chosen from the drop-down computer-generated menu as "Serbo-Croatian," but not the Bosnian language. When I inquired about these designations, the responding people acted as if they had only first heard of this issue. Yet, according to their estimates, over ten thousand refugees from $\mathrm{BiH}$ have been processed by the same institutions, with the overwhelming majority of them being Bosnian Muslims,
} 
With this, the three factors of Bosnian Muslim nationalism - BiH territorial integrity, Bosnian Islam, and the Bosnian language - were therefore firmly established as the group elites began to actively foster the sense of togetherness during the $20^{\text {th }}$ century. Although these issues became important on the level of the elites, and were used by them to build and further Bosnian Muslim natiaonalims project, the impact of that nationalism is to be observed at the group's ground, ordinary people, level, as suggested by the Hobsbawm (1990) when he wrote that nations are "dual phenomena, constructed essentially from above, but which cannot be understood unless also analyzed from below, that is in terms of the assumptions, hopes, needs, longings and interests of ordinary people" (p.10). Therefore, as mentioned in the previous chapters, an occurrence of increased groupness such as nationalism should be seen as a contingency event and process, and as such it should be tested with real case studies, in this case, with the data gathered from the Bosnian Muslim population sample under diaspora conditions in the U.S., and based on the survey constructed on the issues stemming from the history of the Bosnian Muslims mentioned here.

Bosniaks, who speak the Bosnian language. The same not familiar response was received from the historian at the Department of State when asked about its Bosnian war history web page, where neither Bosniaks nor the Bosnian language are noted, even after its acknowledgment of the potential shortcoming (see the personal communication with Cabrera Sept. 18, 2015). 


\section{VI: MAPPING THE BOSNIAN MUSLIM DIASPORA SAMPLE}

\section{6-1: Materials and Procedure}

The empirical part of this study designed to test the relationship between nationalism and the salient identity of a group is based on the external surveys collected from a sample of the population of Bosnian Muslim diaspora groups at sites throughout the Midwest and Eastern United States where they have large enough populations with their own religious, cultural and social centers. Bosnian Muslim participants from those sites were selected based on a quasi-random, snowballing sampling method, usual for hard-to-reach populations such as diaspora groups (Handcock \& Gilet, 2011; Atkinson \& Flint, 2001; Faugier \& Sargeant, 1997). To help minimize homophily biases inherent in a snowballing sampling, the data was collected at ten sites. Each time a respondent comes from a different location, it may be viewed as a "new wave" of respondents, which minimizes the bias inherent in quasi-random sampling. Per Heckathorn (2011), the increasing number of waves eventually eliminates such bias from the initial selection of seeds, because bias is reduced at a geometric, rather than arithmetic, rate and having multiple sites helps in that regard. Finally, since this is only an experimental study designed to test the proposal of the relationship between nationalism and identity, conclusions are to be treated cautiously and conditionally in connection with the inquiry discussed in this work.

A Dillman et al. (2009) tailor-designed questionnaire generated specifically for this study with a focus on case study issues related to Bosniak nationalism and identity was used to collect the data (see Appendix C). To reduce the rate of incomplete 
questionnaires, particular attention was paid to the order of questions in the survey in terms of difficulty and the level of engagement of the respondents necessary to answer the questions. Although the rate of collected surveys, $37 \%$ may be considered low to moderate for an external survey, the rate of completion of those collected is high, over $95 \%$, with only a dozen partially completed surveys. ${ }^{335}$ To further increase the rate of collection and completion, two versions of the same questionnaire were printed, in the Bosnian and English languages, and participants chose whichever they preferred. Of those collected, 604 are in Bosnian, while 60 are in English. ${ }^{336}$

Most of the surveys were distributed and collected between August 2013 and May

2014. That means that responses were collected immediately before, during and after the first post-war census in BiH, held in November 2013, when Bosnian Muslims for the first

\footnotetext{
${ }^{335}$ This rate was also affected by the first IRB requirements for data acquisition, which stipulated a written consent signed by each participant. Many of the initially willing participants became reluctant after they were told the IRB mandated information about the study, and were asked to sign the consent form. At that point many of them returned or refused to take the questionnaires. As observed by others as well, in postCommunist societies, research which requests a person to sign a consent to participate immediately increases suspicion about the "true" intention of the researcher and dampens willingness to participate. Those reservations are present, or even increased, when the researcher is perceived as a member of the same group, as in my case (for a well-described example of such fears among another post-Communist group, see Vamanu 2012). For Muslims from those countries, the Communism-inherited fears were exacerbated by the post-9/11 anti-Muslim atmosphere in the U.S. Any attempt to recruit such Muslim participants for the research and to ask them to sign the consent was usually met with reservations. So those two qualms combined, significantly affected the survey collection rate for this study as well. At one of the collection sites, a pub in Astoria, Queens, I explained to the group of potential participants the whole procedure and why it was better for them to talk to someone through an IRB-mandated procedure, than to someone seeking information without such a procedure, as they claimed was previously done on several occasions. Yet, my effort to clarify the IRB process was still met with hesitation, and only a few of the people did agree to sign the consent and participate. This suspicion was widespread, regardless of gender, education or class. Even a very prominent Bosnian Muslim journalist refused to sign the consent for the interview. The same thing happened with a U.S.-based Bosnian Muslim diplomat. They both agreed to participate if it could be done without their signing the consent, but due to the IRB requirements, they could not be included.

${ }^{336}$ This ratio between the languages was not always a matter of individual preference, but also an issue of the availability of the questionnaires at the time. In general, many more Bosnian language copies of the questionnaire were printed, and so they were more readily available for the respondents. See Appendix C for the English, and Appendix D for the Bosnian language survey booklets.
} 
time in their history had a chance to identify themselves as Bosniaks in an official way. ${ }^{337}$ For that reason, there was an active campaign to popularize the identity of Bosniaks to the Bosnian Muslim population in the homeland and the diaspora, as the best strategic choice for the group at that time. Hence the responses in this sample were also affected by that campaign. ${ }^{338}$

The front page of the survey booklet, with the heading "Bosniak Identity Survey Questionnaire," explained the purpose of the study, guaranteed confidentiality of the participants, and provided the researcher's contact information (see Appendix C). In addition, over $80 \%$ of the surveys were accompanied with a signed consent letter, which was later separated to insure complete anonymity, while the remainder, collected in 2014 through the mail-in method, was done with verbal consent only. An entire survey took between 30 to 45 minutes to complete, and any participant's questions concerning the purpose and the nature of the study were fully answered during or following completion.

Two dozen questionnaires were completed with my assistance, mostly those of older responders who could not do it by themselves. About the same number of respondents were contacted again and asked to complete their surveys, since they had initially skipped some questions; only a few of them wished to leave those questions

\footnotetext{
${ }^{337}$ For more, see Brunnbauer (2004).

${ }^{338}$ As an example, the campaign Važno je biti Bošnjak (It is important to be Bosniak) may be noted. The campaign was especially focused on Bosnian Muslims living in $\mathrm{BiH}$, and others who could potentially take part in the BiH 2013 Census. During the fieldwork, I attended several panels and events propagating Bosniak identity, usually held at Bosnian-run mosques. The campaign was also carried out through various media channels, from Bosnian newspapers and TV stations to YouTube channels and social media such as Facebook pages. The campaign was particularly intensive during the last month before the census, the same time I was collecting data at the first two sites, Atlanta and Chicago. Because of the campaign, I often had to reiterate to the participants that my research was in no way connected to the official Census. For an example of the U.S. campaign see Sabah 2013, p.3.
} 
unanswered. Altogether, 1,800 copies of the thirteen-page, 68-question surveys were distributed to willing participants. Of the 670 returned surveys, 101 were from the New York City Metropolitan area, 182 from St. Louis, MO, and 189 from Chicago, IL, while the remaining 192 survey responses came from all other sites combined. All of the participants were volunteers, and no incentive was offered for their participation. Six surveys were filtered out of the analysis, since the respondents were determined not to be part of the (Bosnian) Muslim population. As suggested by the central limit theorem, a large number of valid survey responses allows the use of data with reasonable confidence, as well as the possibility to draw inferences from the statistical tests. ${ }^{339}$

The targeted segment of the diaspora population was respondents over forty years of age. The mean age of the participants was 44.8 years $(\mathrm{SD}=12.4)$, with the youngest participant being 18 and the oldest 92 years old. This segment was targeted since they are the people who lived and experienced the previous political system and organization, and who had the previous national identity of "Muslim" during their formative years. Therefore, the assumption was that vacillations over the new identity should be felt most intensely among this segment of the population, since they are the ones who are living the change and are the prime group that is actually facing the choice to ascribe the new salient identity, or to keep the previous one. Although $8.7 \%$ of the participants left their homeland before 1990, most of them, 90.4\%, left after that (see Figure 6.1). Therefore, the majority of this sample of the population experienced the group's nationalism, which

\footnotetext{
${ }^{339}$ For more on sample size and central limit theorem, see Myers 2010, pp.99-100.
} 
began to be fostered in the 1970 s and matured by the 1990 s, before they left the homeland.

All of the questionnaires were coded and inputted into SPSS software for further analysis. ${ }^{340}$ Since the 64 questions were organized to collect the maximum of information, responses were coded and organized as a set of 115 items, as some of the responses contain multilayered information. ${ }^{341}$

\section{Figure 6.1: Frequency of Years When Participants Left Homeland}

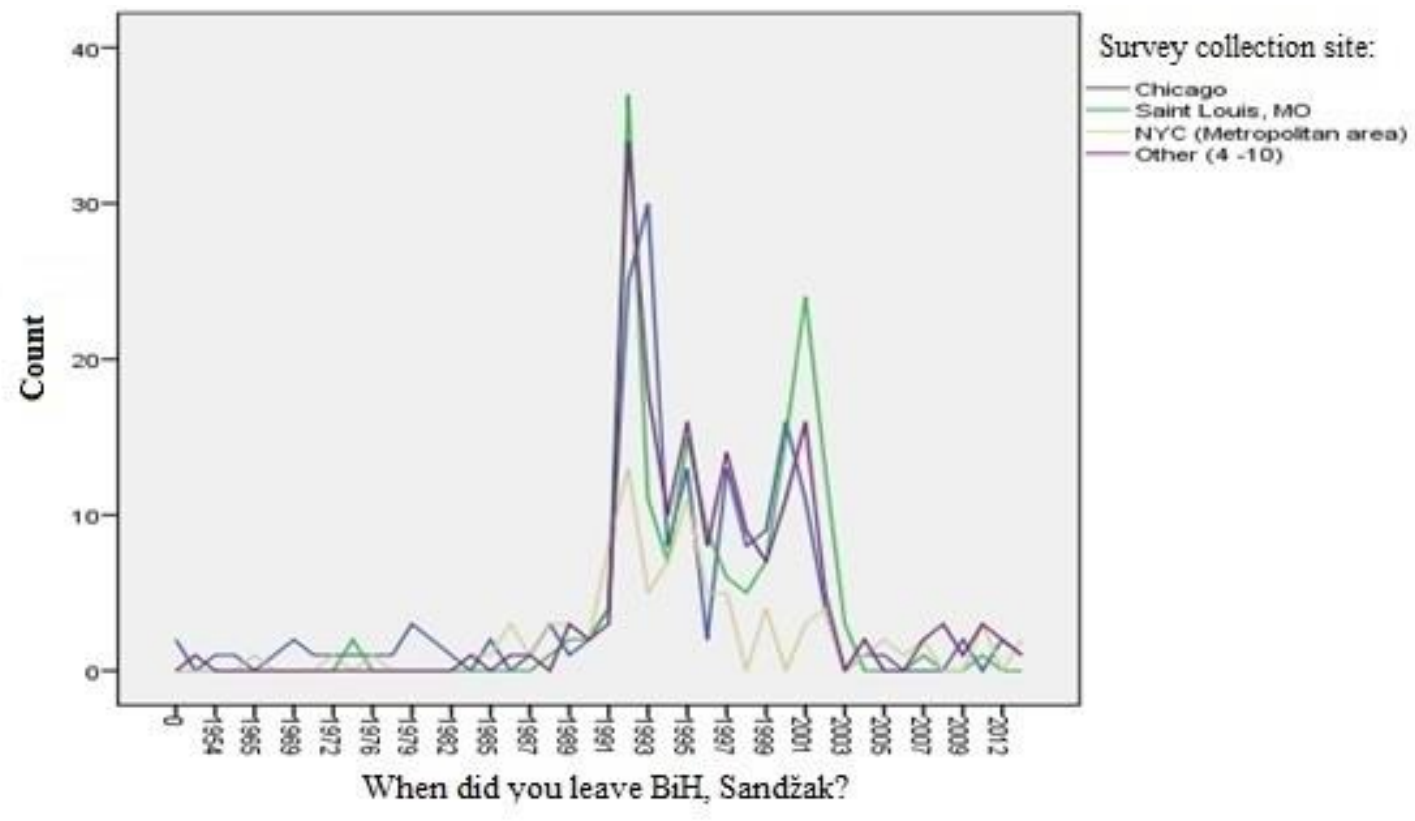

Although the survey was designed to collect the maximum of information about the group, the discussion and data description provided in the following two closely related chapters will be limited only to the questions used for this inquiry. Chapter Six

\footnotetext{
${ }^{340}$ For a good reference guide on SPSS, see Pallant 2007.

${ }^{341}$ For example, survey question Number 4 requested that the responder indicate a place of school attendance for the three levels of schooling. So that question contains information about the level and amount of education, the place of education, experience of non-BiH school systems and languages, and level of exposure to other regional school systems and languages (for more, see Appendix C).
} 
provides the working definition of diaspora and a brief discussion of the sites where data was collected. The following chapter will provide the tie between the discussions about the collection sites and the representativeness of the population sample, and provide frequencies and distribution of the responses to the questions used to construct the empirical model for this inquiry about the relationship between nationalism and salient identity.

\section{6-2: Defining Diaspora and Population Sample}

Since the population sample comes from a diaspora group, it is useful to provide a working definition of the concept of diaspora for this study. In what Hockenos (2003) calls the "elastic definition," diaspora is seen as a group of people dispersed from their homeland, but clustered and connected in communities outside of their homeland. In that way they consist of all members who wish to be part of a diaspora, and who conform to some common elements of groupness in the particular situation, elements that might not be universally accepted by all existing diaspora groups from the same homeland community. Acceptance depends on the conditions in which each diaspora group finds itself when they collectively adjust and adapt to the new context. But what is necessary for a group to be considered a diaspora, in agreement with the above-mentioned elastic definition and with Barth's (1969) approach to groups used in this work to define identity, is that individual members of such groups need to be connected with other members of the same group at more or less regular intervals. In that way they evaluate each other's performance based on their in-group understanding of the original group's value orientations and, based on those criteria, determine individual membership. So 
members might be connected and do any of these multiple things: they may "pay dues to one of the many diaspora associations, or may subscribe to émigré periodicals, attend religious services at their national churches, follow events in the Old World, and communicate regularly with relatives in the homeland. In these ways they keep alive emotional ties with the Old Country and, through the institutions of the diaspora, sustain a degree of cohesion in the community" (Hockenos, 2003, p.8). In the social sciences, institutions are defined as any regular interactions that occur and reproduce themselves between individuals and groups of people. In the words of Turner (1997), social institutions are "a complex of positions, roles, norms and values lodged in particular types of social structures and organizing relatively stable patterns of human activity with respect to fundamental problems in producing life-sustaining resources, in reproducing individuals, and in sustaining viable societal structures within a given environment" (p.6). Therefore, the survey collection sites were places with such institutions that provide possibility for the members of a group to have regular interactions (see Table 6.1). In that way such-defined members of the diaspora familiarize with (and possibly internalize) groups' normative collective process of preference elicitation to assess reality in which they live and, have a possibility to similarly evaluate the questions of the survey.

At each site there are certainly some individual members who stay away from the local Bosnian Muslim community, and who do not interact with it. Those individuals are not discounted from the Bosnian Muslim group; however, they are not considered a part of a diaspora group (by their own choice), and so they were not targeted for recruitment for the study. 
Table 6.1: Respondents interactions with other Bosniaks \& homeland culture*

\begin{tabular}{|c|c|c|c|c|c|}
\hline $\begin{array}{l}\text { a: How often do you read Bosnian } \\
\text { literature, watch Bosnian films/TV: }\end{array}$ & Never & Rarely & Occasionally & Often & $\begin{array}{l}\text { Very } \\
\text { often }\end{array}$ \\
\hline Literature & 5.6 & 17 & 32.1 & 23.5 & 21.8 \\
\hline Film or $T V$ & 8.4 & 21.4 & 28 & 17.2 & 22.3 \\
\hline \multirow[t]{2}{*}{$\begin{array}{l}\text { b: In which media do you mostly } \\
\text { read/watch news about BiH? }\end{array}$} & & $\mathbf{B i H}$ & $\begin{array}{c}\text { Regional } \\
\text { (non BiH) }\end{array}$ & U.S. & None \\
\hline & & 83.6 & 2.4 & 4.7 & 9.3 \\
\hline \multirow{2}{*}{$\begin{array}{l}\text { c: How often do you talk to } \\
\text { someone In Bosnia/Sandžak? }\end{array}$} & Never & Rarely & Sometimes & Weekly & Everyday \\
\hline & 1.4 & 4.4 & 26.7 & 40.5 & 26.1 \\
\hline \multirow[t]{2}{*}{$\begin{array}{l}\text { d: How often do you travel } \\
\text { To Bosnia/Sandžak? }\end{array}$} & Never & Occasionally & $\begin{array}{c}\text { Every } \\
\text { other year }\end{array}$ & $\begin{array}{r}\text { Every } \\
\text { year }\end{array}$ & $\begin{array}{r}\text { I live in } \\
\text { there }\end{array}$ \\
\hline & 8.3 & 47.2 & 27.2 & 15.1 & 2.1 \\
\hline
\end{tabular}

The selection of sites for data collection was consistent with the working definition of diaspora for this research. These are the sites where Bosnian Muslim institutions exist, and where Bosnian Muslims regularly interact with each other in Appadurai-type (1995) neighborhoods across the U.S., and where Bosnian Muslim localities are re-realized. As mentioned above, each site has at least one Bosnian Muslim mosque, a cemetery, an ethnic food store, a few restaurants and often much more than that. The three main sites, Chicago, St Louis, and New York, also have several Bosnian mass media programs and other institutions where Bosnian Muslims interact and their language dominates. Mass media is one of the prime elements for dispersion of a culture, so without its own mass media, a community cannot effectively maintain its culture. As Fenneme (2004) noted, ethnic mass media strengthens vertical and horizontal relationships among the members of a group and enables a "we feeling" among members. 
Therefore the existence of a Bosnian Muslim media outlet was considered an important factor in the selection of each data collection site.

\section{6-3: The Collection Sites}

The surveys were collected through a mixed mode of on-site and mail-in methods. The majority of surveys were collected in person on site at the three main locations discussed below. The remaining 189 surveys were collected in person and by mail. Of these, 137 survey questionnaires were collected in person, with 23 from Atlanta, GA; 33 from Detroit, MI; 28 from Grand Rapids, MI; 33 from Erie, PA; and 20 from Elmwood, NJ. The remaining 55 survey questionnaires were mailed back to me. Of these, 36 were from Waterloo, IA, and 19 from Lincoln, NE. All these responses were grouped together and noted as the fourth collection site, "Other." A brief overview of the three main sites where $71 \%$ of data was collected is useful at this point.

\section{6-3-1: Chicago Metropolitan Area}

The main component of the inquiry is a quantitative statistical analysis of the survey data collected at multiple U.S. sites with large diaspora groups. Bosnian Muslims have been coming to the United States for over a century. Their first formal organization, Dzemijetul Hajrije (The Benevolent Society) of Illinois was formed in Chicago on May 1, 1906, Bosnian Muslims in the U.S. consider this the group's starting point in the New World. ${ }^{342}$ They have continued to immigrate to the U.S. ever since, and four of them

\footnotetext{
${ }^{342}$ Although the organization was formed on that day, it was officially registered by the Secretary of State on July 9, 1906 (Tanovic, 2005, p.119). A few months later they purchased a building located at $1637 \mathrm{~N}$ Clybourn Avenue, Chicago, which they still own (Saric, 2005 p.91). Many Bosnian Muslim immigrants have lived in the same part of Chicago (See Paral and Norkiewitcz 2003, p.41).
} 
were even on the famous Titanic when it sank in $1912 .{ }^{343}$ The Bosnian Muslim diaspora group in the city grew slowly, until the three larger waves of newcomers in the second half of the $20^{\text {th }}$ century began to arrive. The oldest still-living sub-group of Bosnian Muslim Chicago immigrants is composed of those who came right after WWII; they are part of a group that Hockenos (2003) describes as "pathological anticommunists.",344 Some of them are from families with members who fought on the wrong side in WWII and fled the country before Tito's Partisans. The second sub-group is made up of those people who came during the time when Communism and the SFRY were flourishing. There is permanent mistrust between those two groups due to their different positions towards Communist Yugoslavia (Zulfić 2003, p.85). The second sub-group is the only one which can be considered a voluntary (Bosnian Muslim) migrant Chicago diaspora subgroup. The other three sub-groups are all refugees, or involuntary migrants, and that is also an important distinction between in-group subcategories. ${ }^{345}$

The third sub-group is those who came during the 1990s Bosnian war, who were disadvantaged compared to the other two regarding their English language use, and who were often still poorly equipped to deal with the New World realities. ${ }^{346}$ Ultimately, since many of them viewed neither Yugoslavia nor Croat nationalists with much sympathy, due to their experience of ethnic cleansing, they came to differ more from the other two sub-

\footnotetext{
${ }^{343}$ See Bogucanin, 2005, p.87.

${ }^{344}$ They were part of the large Chicago pre-Bosnian-war immigrant population from the former Yugoslavia numbering some 80,000 people, including 2,500 Bosnian Muslims (Somach 1995, p.10).

${ }^{345}$ Among the differences, it is assumed that involuntary migrants have little or no choice as to where they are placed, while voluntary migrants have a choice (Nathansen 2013).

346 The same distinction was reported by the U.S. Department of State, Bureau of Population, Refugees and Migration Report. For more, see Somach 1995, pp.11-27.
} 
groups. Finally, the last sub-group of émigrés is composed of those who came through the resettlement program after the Bosnian war. Many of them came from Germany or another Western European country, but there are also some who came directly from $\mathrm{BiH}$ through the family reunion program. Based on participant observations, the fourth subgroup appears closer to those of the 1990s wave and somewhat distant from the first two groups. Yet due to their late arrival, they still have to catch up with everyone in terms of language and other skills to help them to establish themselves in the new place. Most of the places in Chicago where data was collected were to some extent exclusive to each of these Bosnian Muslim sub-groups, more so by immigrant patterns than by their regional origin, even though regional attachments do play a role as well.

Although each Yugoslav diaspora group had its own nationalistic dreams and aspirations, most of them shared what Hockenos (2003) properly called "pathological anticommunism" (p.10). Bosnian Muslims had their own staunchly anticommunist groups, and especially in Chicago, they aligned very closely with Croat émigrés and the Croat nationalistic circle. ${ }^{347}$ Although the post-WWII Bosnian Muslim diaspora was anti-

\footnotetext{
${ }^{347}$ This is the result not only of ideological closeness with them, but also because Chicago was a major center of the Serbian Chetnik diaspora (see, for example, Movement of Serbian Chetniks Ravne Gore 2016, for information on their activities in Chicago and the rest of the U.S.). Although Abazovic (1999, p.340) notes that a small number of Yugoslav Muslims in Toronto became close to those Serbian anti-Communist diaspora circles, generally Serbian Chetniks were considered the archenemy of Bosnian Muslims from back home, due to their horrendous policy of and attempt at complete annihilation of Muslims from the Balkans (see Dedijer 1990; Šarkinović 2012, pp.300-08). Both Yugoslav fascist groups, the Croat Ustašas and the Serb Chetniks were essentially anti-Semitic; however, Ustašas were a bit more selective and turned their anti-Semitism primarily against Jews and less against Muslims (although it should be noted that they did eliminate a number of Bosnian Muslims as well. In his book Halilbegović (2006) provides a detailed account of more than fifteen hundred Bosnian Muslims who were killed by Ustašas. For more on both groups' anti-Semitic policies, see also Bokovoy 1998, pp.11-14; Cigar1995, p.127). The Chetniks, on the other hand, treated both Jews and Muslims equally badly. These relations with the Chetniks also caused Bosnian Muslim hesitation towards the Tito-led Partisans during WWII. Chetnik ideas were very strong among Partisans till the end of the war, when the Germans were defeated and Communists were freed at last to solidify their leadership position in Yugoslavia. As a result of Chetnik influences among the
} 
communist, unlike Croats, they were not anti-Yugoslav. ${ }^{348}$ The Bosnian Muslims who arrived during the 1990s, on the other hand, were less anti-Communist, but more antiYugoslav, as the data reveals. Most participants think that life was good for Muslims under Communism in the former Yugoslavia, while a very few of them still feel Yugoslav. ${ }^{349}$ These latecomers were either disappointed, but generally indifferent towards Communism; ${ }^{350}$ or many of them were still sentimentally pro-Communist in their nostalgia for the "good old days" (see Croegaert 2011). These different realities of back-home conditions that each of the different waves of Bosnian Muslim immigrants

Partisans, during the war on some occasions the Partisans turned Jews away from joining their forces. Donia (2006) notes an instance remembered and described by a Partisan commander, Danilo Staka, when a group of 30 Jews were forced to return to Sarajevo after they unsuccessfully tried to join the Partisans. Return to Sarajevo meant certain death for them, and most of them were eliminated on their return. Donia (2006) indicates that some sources "blamed the decision on Chetnik influence among the Partisans" (p.179). On the other hand, the relations between Partisans and Muslims were also tenuous for a long time because of the same latent Chetnik influence among the Partisans. After the arrival of the Partisans' First Proletarian Brigade on January 28, 1942, in Eastern Bosnia, "Serb volunteers, including many who had previously served as Partisans, abandoned the Chetnik unit and flocked to join the Partisans. The Serb peasant volunteers thus voted with their feet for the force they believed would offer the staunchest resistance to Ustaša and German rule" (Donia 2006, p.180). However, despite everything, this "voting by feet" certainly caused strong reservations and hesitation in Bosnian Muslims about supporting the Partisans. For them, neither the Germans nor the Ustašas, rather than the Chetniks, were the existential enemy, and the Chetniks welcome by the Partisans kept the Muslims away. This antagonism was carried over to Chicago with those Bosnian Muslim emigrants who came after WWII and later. The Chetniks come out of the tradition of the Serbian Hajduk, an archetypal bandit-freedom fighter (Hobsbawm, 2000, p.p.77-90). Although Hajduks were present throughout the Balkan Peninsula during Ottoman rule, they are most celebrated in, and mostly attributed to Serbian tradition (Bracewell 2003). The same tradition produced a Serbian military approach in the wars of the dissolution of Yugoslavia, where Serbian troops looked and acted like patriotic bandits, very much like their people, and not like an army.

${ }^{348}$ To my surprise, during an interview, one of the pioneers told me that they were disappointed by the dissolution of Yugoslavia and that they had never wished for that. That sentiment was the continuation of the JMO policies under Mehmed Spaho, discussed in the previous chapter, who was supportive of the concept of Yugoslavia, but with a more equal position for Muslims in it (Spaho 1923).

${ }^{349}$ For more, see the next chapter's discussion of the Nationalism Strength Index.

${ }^{350}$ In her self-published memoirs, Seferović-Drnovšek (2013, p.241) talks about her hesitant leanings towards socialism during the Obama re-election campaign in 2011. Her book is not worth much in an archival sense but it is valuable as a document of a person's internal struggle with immigration. The book covers a time span of almost three decades, from the late 1980s to 2013, recounting the struggle of a woman from the former Yugoslavia who had to come to terms with the U.S. as her new country of refuge, and that is how it is being considered here. 
experienced, also created tensions among the current group's diaspora population. ${ }^{351}$ The four sub-groups of the Bosnian Muslim diaspora in Chicago are different not only in their ideological leanings but also in their socio-economic, and, more importantly, their educational levels. ${ }^{352}$

Since Chicago has the oldest Bosnian Muslim diaspora group, it has often been regarded as the political capital of Bosnian Muslims in the U.S. Since the motherorganization Dzematul Hujrijje was formed, many more organizations have sprung up in Chicago with ambitions to organize and represent Bosnian Muslims in the U.S. The first post-war Bosnian Muslim Chicago émigrés eventually managed to establish their own "Muslimansko vjerski-kulturni dom" (Muslim Religious and Cultural Home) (MVKD) and purchase their own building in 1956 (Zulfić 2003, p.95). In 1968, Bosnian Muslims reformed the MVKD and continued their work under the new name Bosnian-American Cultural Association (BACA), to indicate a stronger Bosnian national orientation (Zulfić 2003, p.167). That building and organization served as the major center for the entire U.S. Bosnian Muslim diaspora until 1976, when they moved into a new space in a suburb of Chicago. In 1981 the new Islamic Cultural Center of Greater Chicago, in Northbrook, became a home for the new Bosnian Imam, Mustafa Cerić, who in 1992 became the first Reis-ul-Ulema of the newly independent IZBiH. With that, the prominence of the Chicago center increased even more, and therefore its new Imam, Senad Agic (who

\footnotetext{
${ }^{351}$ For more, also see Sarić 2006, p.98.

352 "The pre-war diaspora communities tended to include simple working-class immigrants, many with rural backgrounds, most intent on blending in, and contributing to, their adopted states. The new émigrés, on the other hand, included Yugoslavia's disinherited bourgeoisie. In contrast to the diaspora old timers, they were often educated and urban: families associated with deposed royal houses, the military elites, and banned political movements" (Hockenos 2003, p.10).
} 
arrived in 1989), ${ }^{353}$ then became regarded, unofficially, as the head Bosnian imam for the entire U.S. Several years later, in 2003, Bosnian imams from all over North America finally organized themselves into a registered official organization, the Islamic Association of Bosniaks of North America (IABNA), with its headquarters in the same Northbrook Islamic center (Agić 2006, p.170). Both the imam and IABNA were replaced by a new Head Imam, now officially designated as such by the back-home IZBiH, and a new organization name, with headquarters in Phoenix, AZ. Another Bosnian Muslim religious organization, Udruženje Muslimana Sjeverne Amerike (Society of Muslims of North America), with its own activities in the Bosnian language throughout the U.S., also had its seat in Chicago between 2001 and 2006, when it dissolved.

At the time when data for this work was collected, Chicago had five Bosnian Muslim-run masjids, four of which were served by full-time imams and the fifth by a volunteer. Three masjids were in northern parts of the town, one was still in Northbrook, and the fifth, which is run by Western Bosnians, was in the suburb of Roselle. Services in each were held in the Bosnian language, and four of them also had weekend schools where pupils were taught the Bosnian language and Islam. The center in Northbrook even hosts a small "Bosnian-American Muslim Cultural Museum" with many photos, documents and exhibitions which document their struggle to establish themselves in the city (Zulfić 2003, p.257; Al Hari 2006, p.197). ${ }^{354}$ Although mosques also serve as

\footnotetext{
${ }^{353}$ Abiva 2006, p.106.

${ }^{354}$ Unfortunately, the museum is not open for regular visits anymore, but the Center's board members can provide access to researchers, as they did to me.
} 
cultural centers, there are other places that provide cultural and other types of programs for the Bosnian Muslim population. ${ }^{355}$

Chicago is also the home of the two most important Bosnian Muslim social and political organizations. The first is BACA, created to advance Bosnian Muslim cultural and social causes. ${ }^{356}$ The second is Kongres Bošnjaka Sjeverne Amerike (Congress of Bosniaks of North America) (KBSA), created in 2000 to organize and advance social and political goals of the Bosnian Muslim North American diaspora. ${ }^{357}$ Since then, the organization has split into two organizations, both of which now have headquarters in other parts of the U.S.

Chicago is also now the home of other former-Yugoslavia Slavic-speaking Muslims, mostly from around the Montenegrin coastal town of Bar. ${ }^{358}$ Montenegrin Muslims have their own mosque and Cultural Center, Rumija in the same neighborhood where many Bosnian Muslims live, and it is just two miles away from the Bosnian Islamic Cultural Center on Western Avenue. As observed from the field work, the two groups visit each other's centers but they remain separated nevertheless. ${ }^{359}$ The data

\footnotetext{
${ }^{355}$ Seferović (2006) provides a list of some of those (pp. 423-62).

356 Tanovic 2006, p.118.

${ }^{357}$ For more, see Erović 2010.

${ }^{358}$ See The Parliament of Montenegro 2016.

${ }^{359}$ They even frequent different social sites and restaurants. In one of them, Utjeha, where people from different former Yugoslav states sometimes come, each group occupies different tables. Although they talk to each other across the tables, they all stay seated with their own groups, as they clearly prefer people from their back-home regions. Utjeha means solace, and the café is named after a small town with beautiful beaches near the Montenegrin port city of Bar, as a clear association with "back home."
} 
frequencies discussed in the next chapter also show that Chicago Bosniaks have Montenegrin Muslim friends.

Finally, Chicago is also the site of numerous Bosnian Muslim media and cultural institutions. The oldest Bosniak diaspora radio program, "Radio Glas Bošnjaka" (Radio Voice of Bosniaks), began its regular broadcasts in 1964, and it still airs its program every Sunday ${ }^{360}$ During the Bosnian war, enthusiasts from the local BiH Club initiated another weekly radio program, "Slobodna Bosna i Hercegovina" (Free BiH). The third, perhaps most popular program currently broadcasts regularly from Chicago, "Radio Naša Rijec" (Radio Our Voice). Besides radio programs, Chicago has two satellite channel companies which bring homeland programming to viewers in North America, BosnaTV $^{361}$ and Bostel. ${ }^{362}$ Chicago is also home to a monthly newspaper, "Ujedinjena Bosna" (United Bosnia), as well as the Bosnian language journal "ZAMBAK BH Odjek" (ZAMBAK BH Echo), which no longer exists but was an important Bosnian Muslim diaspora voice during the $\mathrm{BiH}$ war. ${ }^{363}$ To end this report on the city's cultural offerings, it should be mentioned that the local Conrad Sulzer Public Library hosts a Bosnian Library with a relatively large collection of various books printed in the Bosnian language. The Bosnian Library also organizes many different cultural programs, exhibits and

\footnotetext{
${ }^{360}$ See Seferović 2006, p.458. It should be noted that the radio program used the term "Bošnjak" (Bosniak) in its name, and in that regard it represents an early advocate for the Bosnian Muslims' new identity, which became salient at last during the 1990s.

${ }^{361}$ For more, visit their web site: https://bosnatv.com/

${ }^{362}$ For more, visit their web site: http://bhbostel.net/

${ }^{363}$ See Seferović 2006, pp.71-77.
} 
promotions featuring Bosnian Muslim community members in Chicago. ${ }^{364}$ In response to Bosnian Muslim immigrants' demands, the Eugene Field Elementary School offers bilingual classes in English and Bosnian language to its students. ${ }^{365}$

There are at least a dozen restaurants and cafes owned by Bosnian Muslims, especially along North Western Avenue, and North Lincoln Avenue. An interesting and unexpected place where Bosnian Muslims spend time is on the corner of those two large Chicago avenues. A lot of Bosnian Muslim pensioners spend every afternoon together at a local McDonald's, where coffee is inexpensive and the temperature is pleasant.

The list of the activities of the Bosnian diaspora in Chicago is not completed here, but this many available activities clearly show that Chicago is the major center of the U.S. Bosnian Muslim diaspora. Although fragmented along many lines, Bosnians are active and organized, with various institutions to preserve the culture and boundaries of the group. As such, they provide a suitable pool for a sample of the Bosnian Muslim population for this research.

\section{6-3-2: St Louis, Missouri}

Since St. Louis is the U.S. site with the largest number of Bosnian Muslim immigrants, it was an obvious choice for data collection. Some like to exaggerate and claim that St. Louis became the site of "the largest population of Bosnians outside of

\footnotetext{
${ }^{364}$ The same library helped with this research by providing a space for the interviews during the field work. ${ }^{365}$ Seferović-Drnovšek 2003, p.92.
} 
Europe" ${ }^{366}$ in order to illustrate their numbers. While there are no solid figures, estimates

vary around the number of 50,000 people, a vast majority of them Muslims (Jelalzai 2011, p.104). ${ }^{367}$ Most of these people initially moved into St. Louis' South County, particularly the Bevo Mill neighborhood, where in a section of several blocks on Gravois Avenue (between Sigel and Taft Avenues), there are more than 20 businesses operated by and oriented towards Bosnian Muslims. At the time when data was collected there were eight Bosnian restaurants and cafes, four ethnic food grocery stores, an insurance company, a law firm, two hair salons for women, a carpet store, an auto repair shop, a chiropractic clinic, a medical clinic, a mosque of Masjid Nur, ${ }^{368}$ and the Bosnian-American Chamber of Commerce building. In the small park on the corner of Gravois Avenue and Morganford Road, the neighborhood is now decorated with a Sebilj. ${ }^{369}$ Just a few blocks

\footnotetext{
${ }^{366}$ Jelalzai (2011, p.104) quotes Muhammad Nur Abdullah, the former leader of the Islamic Foundation of Greater St. Louis, saying that. Yet, many more Bosnian Muslims now live in the Asian part of Turkey, and so it is a slight exaggeration to claim that St. Louis has the largest population of Bosnians outside of Europe. However, his claim does serve as an illustration that a large number of them live there.

${ }^{367}$ As Smith (2002) showed effectively, the numbers for some populations in the U.S. get easily inflated for various reasons. As for the number of Bosnians in St. Louis, referring to the International Institute of St Louis (IISL), the local Bosnian Imam claims that there are 75,000 Bosnians in the city. When I asked one of the Directors of the IISL where that number came from, he noted a local newspaper as a source. He then called the newspaper and asked about the source for the number, and they referred him back to the Bosnian community. So the circle was closed, while a credible source for the number of Bosnians in the city could not be established. The only credible number which can be used to further estimate population size is 11,087 people served by the IISL (from the limited data made available by the IISL exclusively to me). A similar number of 11,000 refugees who came between 1993 and 2001 is noted by Hume (2015). The USCIS report about the adjustment of status for permanent residence says that between 2002 and 2011, some 6,060 people born in BiH applied for the status adjustment (DARB, 2012). It should be noted that many people were eligible to adjust their status before 2002. Furthermore, the report I saw is from one of the USCIS offices in the states neighboring the St. Louis Field Office (MO, IL, and IN). At the bottom of the report it is noted that "Some of these applications may have been approved at a Service Center or at another Field Office. Some applications adjudicated at the St. Louis Field Office may not be included if the applicant resided in a state other than MO, IL, or IN." Therefore, the number of 6,060 Bosnian applicants cannot be considered a final indicator, yet it is clear that it is in the range of tens of thousands.

${ }^{368}$ For more information, visit their web site at http://stlic.org/

${ }^{369}$ A Sebilj is a replica of a Sarajevo Ottoman-style wooden fountain, often seen on posters and postcards of the city. For more, see Hume 2015, pp.6-12.
} 
away, there is another Bosnian Muslim Islamic Community Center (Medina Masjid) with a 107-foot-tall minaret. A few miles south of Bevo Mill, along the Lemay Ferry Road, another Bosnian Muslim community and its businesses have sprung up, along with the Bosnian Islamic Center St. Louis. ${ }^{370}$ The center is located just next door to the Fethullah Gülen-inspired Turkish American Society of Missouri, ${ }^{371}$ which has its own section that serves Bosnian Muslim youth. Both of the other two Bosnian Muslim mosques also acquired properties and began new mosque building projects in the same area (Townsend 2013). The acquisition of these new properties indicates the Bosnian Muslims' slow movement towards the suburbs, with more family-oriented neighborhoods and less crime.

These businesses and centers are not the only institutions in St. Louis which cater to the community in the Bosnian language. For example, there are numerous Bosnian Muslim ethnic media outlets in the city. As noted by Fennema (2004), ethnic media represents an essential part of the maintenance of an ethnic group in the diaspora. For that purpose, in St. Louis there are several weekly radio shows, in addition to a daily Bosnian language M-Radio program broadcasting back-home music and news at various times during the day and night at WEW 770 AM. The same owner, who is a local Bosnian folk music enthusiast, ${ }^{372}$ also runs a TV Station, (MiM TV), which broadcasts programs in the Bosnian language, mostly via their satellite channel, while many of the programs are also available via various internet platforms. ${ }^{373}$ Local Western Bosnians have their own radio

\footnotetext{
${ }^{370}$ For more, see Moore 2013.

${ }^{371}$ For more, visit their web site at http://tasom.org/

${ }^{372}$ For more, see the East European Folklife Center web page at https://eefc.org/teacher/mensur-hatic/

${ }^{373}$ For more visit their web site at http://mimtv.info/wp/
} 
program, "Glas Zapadne Bosne" (Voice of Western Bosnia), which broadcasts once a week on the same WEW 770 AM radio. There is another Bosnian language weekly program, "Glas Bašnjaka" (Voice of Bosniaks), which is run by other local Bosnian Muslim volunteers. From this media reality we can see that Bosnian Muslims in St. Louis are somewhat fragmented along the lines of back-home regionalism. Most, if not all, St. Louis Bosnians are refugees, not migrants, and that is an important aspect of their sameness. ${ }^{374}$ Perhaps that is the reason why St. Louis, although the place with the largest number of Bosnian Muslims, has no headquarter of any larger U.S. Bosnian Muslim organizations.

Figure 6.2: Front page of Sabah from Sept. 27, 2013

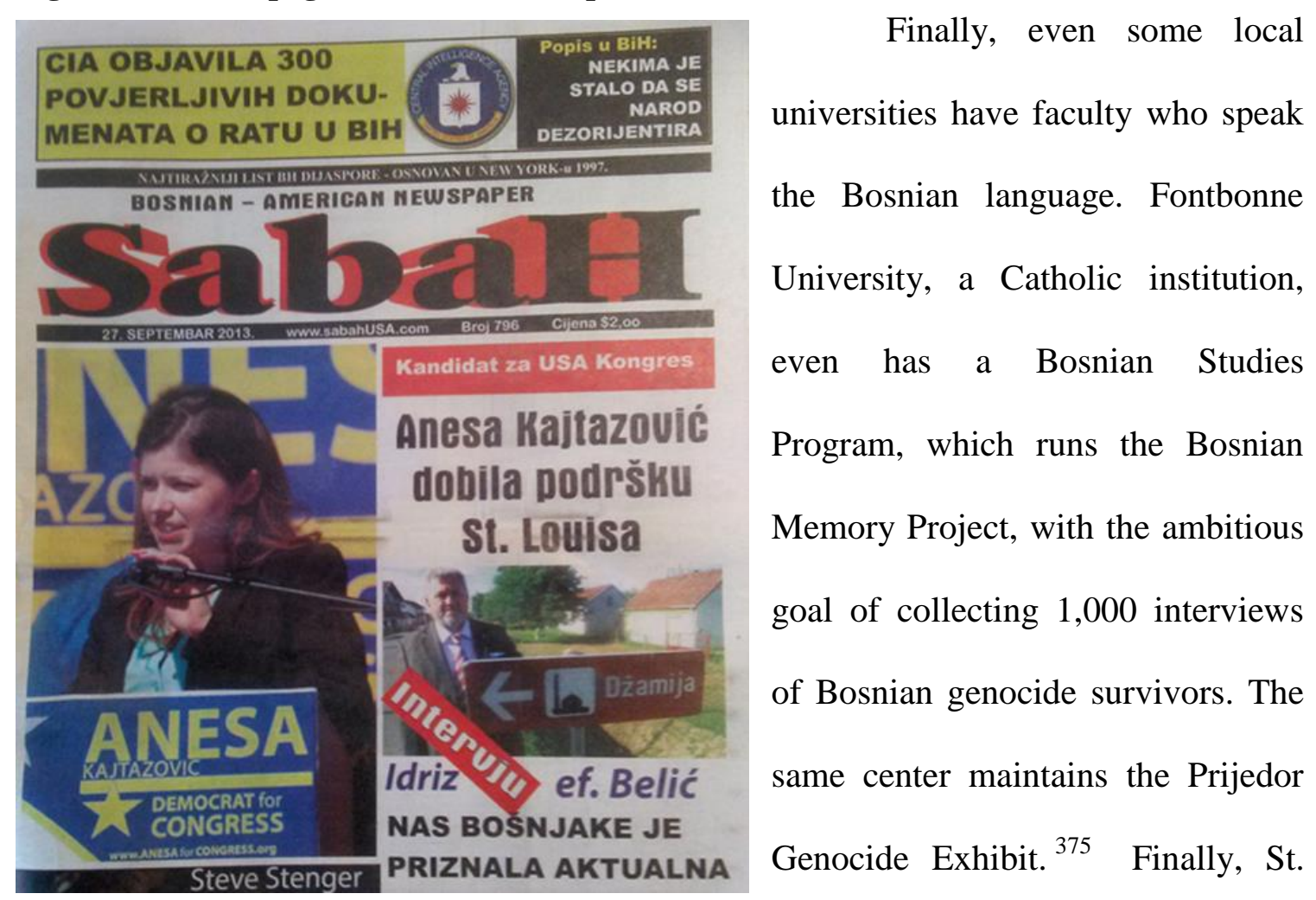

\footnotetext{
${ }^{374}$ A short, but in many ways very representative, account of the journey of a few Bosnian Muslim families to St. Louis is described in McCarthy and Maday (2000).

${ }^{375}$ For more, visit their web site at http://library.fontbonne.edu/bosnia/bmp
} 
Louis is now home of the most well-known U.S. Bosnian language weekly newspaper, "Sabah," which in its masthead claims that it is the newspaper with the largest circulation in the BiH diaspora (see Figure 6.1). The newspaper began in 1997 in New York, but it eventually moved to St. Louis to be closer to such a large number of readers, and it is run by a Muslim Bosniak family originally from Montenegro. All the places mentioned above were also the local St. Louis collection sites for the data acquired for this study.

\section{6-3-3: New York Metropolitan Area}

Thus far, almost nothing has been written about Bosnian Muslims from Plav and Gusinje who now reside in New York, despite the fact that for some time they have constituted a large majority of the Bosnian Muslims in the city. Plav and Gusinje are two small towns located in the foothills of the Prokletije mountain range, at an elevation of ca. 1,000 m. According to the Yugoslav census of 1991 (Grpković, 1993), both towns together had 19,300 people, of whom about $60 \%$ were Slavic speaking Muslims, while another $20 \%$ were Albanian Muslims. Almost everyone in those two towns knows of each other, and they are often connected through family ties as well. As I was told, three large family clans from back home dominate the New York population from Gusinje. Among those from Plav, a single family clan is dominant, since it has the most members and family ties among that town's diaspora population in New York. All this is to show how strongly interconnected those people in New York are, as they induced each other to come to New York, as is typical in many other cases of chain migrations in the U.S. ${ }^{376}$

\footnotetext{
${ }^{376}$ Chain migration played a role in the case of those Yugoslav Muslims who came before the 1990s war. For those who came later, chain migration played only a limited role, and the settlement sites were largely the result of options offered by a sponsoring resettlement agency.
} 
They provided support for each other when they came to the New World, and in turn created a diaspora cluster in the metropolis of New York City.

According to Alahari and Bogucanin (2006, p.146), Slav Muslims from Plav and Gusinje began to arrive in New York in the late 1960s, together with Albanians who were leaving the region through emigration refugee centers in Italy and Austria, escaping the draconian anti-Muslim policies of the Yugoslav Secret Police chief Aleksandar Ranković. ${ }^{377}$ In addition to repression, their two towns, hidden away in the pocket of Montenegro which protrudes into Albania (see Figure 1.1), were mostly neglected by the governments of SFRY and Montenegro, and residents could barely make a living. So many were forced to leave, and in search of a better life, some ended up in New York. From the trickle that left initially, by the 1970s the number had reached a few thousand. As they came, they mostly began working at manual jobs in buildings maintenance and the city construction industry. Although these waves of immigrants from Sandžak might be considered migrants, since there was no open warfare there as there was in $\mathrm{BiH}$, they were also exposed to various threats and pressures to emigrate, and it would be inaccurate to treat their migration as completely voluntary. Yet, unlike the Muslims from $\mathrm{BiH}$, they were not refugees, either.

As my interlocutors told me, the second wave came to New York during the 1980s, many through smuggling routes via Mexico. The final wave of Muslims from the two Montenegrin towns came during the war of dissolution of Yugoslavia during the 1990s. According to the guesstimates of community members, several thousand people

\footnotetext{
${ }^{377}$ For more on Ranković, see Krijestorac 2015 b.
} 
came during each wave of immigration. In an article in the New York Daily News, Levine (2001) quotes an imam from the community who claimed that some 20,000 Muslims from Plav and Gusinje then lived in the New York metropolitan area. ${ }^{378}$ Yet again, there is no firm number to back up those claims about their population size in New York. ${ }^{379}$ Nevertheless, it was obvious to me during the field work that a lot of them now live there and their organizations are well known in the diaspora for having contributed a lot to the national cause during the 1990 's struggle for $\mathrm{BiH}$ independence. ${ }^{380}$ Some of them live in Manhattan, where they work as superintendents of buildings so they do not have to pay rent for the apartments where they live. ${ }^{381}$ Yet, participants from that group were also recruited and surveys collected in Astoria, Queens, and in the borough of Brooklyn, where most of them live and where their centers, restaurants, cafes, and ethnic food stores are.

\footnotetext{
${ }^{378}$ Alahari and Bogucanin (2006, p.146) note the same number without any reference to a source.

${ }^{379}$ For example, Memić (2003, p.254) notes that it is "known that some 15,000 Bosniaks have left the PlavGusinje region, and that is more than the number which have been left back home" On the other hand, Rastoder (2010, p.210) quotes from a book from 1980 which notes that from the Plav region (at that time Gusinje was administratively part of the Plav municipality) some 389 people were working in the West. Yet these numbers should be taken with a grain of salt, since many families were reluctant to report to authorities the real destination of their members who left for work. The rulers of the country looked at all of them with suspicion; receiving a letter from a relative from the West could sometimes result in a visit from the police for an informal talk about the purpose of mail exchange and activities of the émigré, wherever he might be. Rastoder himself also notes that the number has grown drastically since then, yet without providing any exact estimate.

${ }^{380}$ Any Google search for "Plav, Gusinje, New York" will yield numerous web sites and entries on the activities of the New York diaspora group, with all kinds of community news. In his above mentioned work, Memić (2003, p.254) also lists many things that Bosniaks from Plav and Gusinje have done for BiH and for the Bosniak national struggle.

${ }^{381}$ One of them, Ekrem Jevric, even became a back-home celebrity via his music video clip with tens of millions of viewers on YouTube. The video for his song "Kuca, poso. Poso, kuca" (Home to work; work to home) describing with Zen poetry precision his life in New York, was partly recorded in one of the main diaspora social clubs in Astoria. For video, see Kolenovic 2010.
} 
Although people from Plav and Gusinje are a clear majority, the New York (Bosnian) Muslim diaspora group also has people from other $\mathrm{BiH}$ regions. To further emphasize reasons for a regional approach to the study of diasporas, it should be noted that Muslims from Plav and Gusinje have their two Islamic centers. One is a recently acquired former church property in Richmond Hill, in Queens. The other is the older and better known Islamic Unity \& Culture Center of Plav-Gusinje Mosques (a.k.a., Ali Pasha's Mosque), at 3133 12th Street, in Astoria Queens. The other Muslims from BiH, on the other hand, have formed a separate congregation and eventually established their own Bosnian-Herzegovian Islamic Center only two miles away from the Plav-Gusinje center, at 37-46 Crescent Street in Astoria. In another corner of Astoria, again less than a mile away from these two centers, there is a third, smaller, Bosniak Islamic Cultural Center, at 18-02 Astoria Boulevard, attended by another regional group of (Bosnian) Muslims, mostly from Kosovo and the Serbian parts of Sandžak.

The fourth Islamic center which also serves Bosnian Muslims is the Islamic Center of the Bronx, where Bosnian Muslims pray together with Muslims from Macedonia and the Muslim Roma population from the former Yugoslavia. Finally, PlavGusinje and other Muslims from Sandžak also formed another congregation in Brooklyn with more emphasis on high-Islam, yet where services are held primarily in the Bosnian language. ${ }^{382}$ Obviously, regionalism among Bosnian Muslims plays an important role in their interactions and even in the establishment of their religious institutions. Bosnian Muslims in New York have several weekly radio programs. The oldest, "Bosniak Muslim

\footnotetext{
${ }^{382}$ For more, see Gellner's 1992 explanation of the term.
} 
Voice," began in 1993 and is still running. ${ }^{383}$ New York is also the home of the best known Bosniak diaspora web media site, Bosnjaci.net which began in 2001 and serves as one of the main Bosniak media platforms for the entire U.S. and Canada Bosniak diaspora population. ${ }^{384}$ Finally, there are several Bosnian Muslim restaurants and ethnic food stores spread throughout Astoria, Queens, as well as other small businesses which are owned by and primarily serve the Bosnian Muslim community of New York, along with other immigrants from the former Yugoslavia (see Sietsema 2008). The data for this study was collected randomly at all these locations, in addition to using the snowballing method of personal recommendations by the initially recruited participants.

\section{6-3-4: Other Locations}

Like these three main sites, the other places where data was collected also have Bosnian Muslim centers and businesses, and all Bosnian Muslims at these sites are refugees who arrived in the U.S. after the dissolution of Yugoslavia. Lawrence, a suburb of Atlanta, for example, has two Bosnian Islamic centers, and several ethnic food stores and restaurants. The population is large enough that the local Walmart has a section with a few Bosnian ethnic-food items. For two years in a row, one of the Islamic centers in Lawrence has been the largest contributor of zakat (Islamically obligated alms-giving) money of all the Bosnian Muslim diaspora congregations in the world. ${ }^{385}$ It appears that, in addition to other factors, the chain migration driven by back-home regionalism among Bosnian Muslims is also beginning to play an important role in their choice of settlement

\footnotetext{
${ }^{383}$ For more, see Levine 2001.

${ }^{384}$ For more, see Bosnjaci.net

${ }^{385}$ See El-posta 2015 and 2016.
} 
and relocation within the U.S. For example, in Waterloo, Iowa, ${ }^{386}$ the dominant regional population is from West Bosnia, and as such they were targeted for recruitment for participation in this study as well.

This brief history and description of the places where data for this research was collected, clearly shows that the sites are indeed Appadurai-like locations where backhome spaces can be and indeed are reproduced, and where social instructions exist to support the existence of the group, although in new circumstances dictated by life in the different parts of the U.S.

\footnotetext{
${ }^{386}$ As in many other smaller cities where a Bosnian Muslim population has resettled and where data was collected (Lincoln, NE; Erie, PA; Grand Rapids MI; Detroit, MI; Elmhurst, NJ), they are mainly hired by local factories and the meat packing business as low skill laborers, in part to control local labor costs (see Warren 2007, p. 71). In Waterloo, IA, with a population of about 3,000 Bosnian immigrants (Edsall 2000), however, a young Bosnian Muslim woman, Anesa Kajtezovic, even became the Mayor of Waterloo in 2010. She also ran as a Democratic Party contender for Iowa Congressperson in the 2014 election. She lost that election, but she was very much noticed in the Bosnian Muslim community as someone from Bosnia who successfully entered American politics (for more, see Schrock 2014. Also see Figure 6.1, where she is featured on the front page of the newspaper).
} 


\section{VII: ANALYSIS OF U.S BOSNIAN MUSLIM DIASPORA SURVEY DATA: FREQUENCIES AND DISTRIBUTIONS ${ }^{387}$}

The following chapter will provide a short recapitulation of the methodological premise, and of how the concepts, variables, and processes are conceptualized for this study. It will then discuss the representativeness of the population sample, and provide frequencies and distribution of the responses to the questions used to construct the model between the explanatory and responding variables for this inquiry. Therefore, the chapter will contain information on the responses used to construct two independent variables (fourteen items used to construct the Nationalism Type Index, and seventeen items used to construct the Nationalism Strength Index), and the distribution and frequencies of the responses used to construct the responding variable of six variations of salient Bosniak identity (for visual representation of the model, see Figure 7.2). Finally, it will also provide a brief note on the five items treated as controlled variables.

\section{1: Discussion on Operationalization and Level of Analysis}

Before the empirical examination of the guiding idea for this inquiry, that nationalism is a mechanism for the imposition of new salient identity for a group which has to go through a change, a short recapitulation of the methodological premise, and of how the concepts, variables, and processes are conceptualized for this study, is useful.

Operationalization of this inquiry is rooted in the logic of the grounded theory approach, as described by Dey (1999), that suggests considering the phenomena under

\footnotetext{
${ }^{387}$ This part of the research was partly funded by the FIU Graduate School Dissertation Evidence Acquisition Fellowship.
} 
observation as a process, where the outcome emerges as the result of the interactions of the structure, at the group level, and of agency, at the individual level. The whole process is considered a temporal sequence (see Figure 7.1), which occurs in several stages, and which works differently among elites and commoners within the group, each entrusted with different nationalism tasks in helping the group evolve through nationalism into the new stage of its existence. ${ }^{388}$ This work is particularly concerned with the effects of nationalism on commoners in regard to the new salient identity ascription.

The extant literature notes that, to play its usual role, nationalism requires the antecedent conditions of mass literacy and base-line equality, which come before the interactions between structure and agency and which are not seen as part of those interactions (Dey 1999, p.184). When a group reaches those conditions of mass literacy and education (as a foundation for development of a common culture frame), and the group's members believe in baseline equality among each other (as a political principle of egalitarianism), in which nationalism can operate, the basic preconditions are therefore established. After that the interactions between elites and commoners can be considered as a situation of nationalism which seeks to push and facilitate the group's desires and goals.

As those preconditions are being fulfilled, elites seek to establish the parameters of the particular nationalism project antecedent appropriate for the group. Once those parameters of the basic social psychological process (BSPP) are established at the elite

\footnotetext{
${ }^{388}$ As noted above, nationalism's unintentional role as an organizing principle is "to place the community in its appropriate temporal and spatial context" (Smith, 2009, p.65) of the new world.
} 
level of the group, they reach out for an internationally "preformed" structure of nationalism ${ }^{389}$ - as a basic social structural process $(\mathrm{BSSP})^{390}$ - to drive the desired changes of identity among the commoners of a group. Individuals are therefore agents who are to respond (ideally) first through self-identification, and eventually, as the interaction between the two levels of the group continues, through self-investment to their new salient identity. ${ }^{391}$

For that reason, this work first provides an historical account of how elites were formed, how and why they picked the particular issues to especially care for, and how they formulated them to fit the group's project. Once those parameters were established, nationalism as a structure was ready to be imposed on the group, which then throughout the duration of the process responded to it by accepting (or not) the change and adopted a new salient identity to be chosen by the individual members of the group, and then (if it was accepted) carried it forward (see Figure 7.1). Therefore, although nationalism is an elite-conceived and driven process (it is a process since it has its beginning and its desirable end), the best time to measure the effects of nationalism is at the consequential

\footnotetext{
389 As mentioned in Chapter 2, Anderson (1992) remarked that once the concept was "invented," it became something that could be sought and replicated by political actors by means of many different forces and in different places.

${ }^{390}$ The elites are seen as the initiators when BSPP is first realized and initiated. Glaser (1978) describes BSPP as becoming, highlighting, personalizing, health-optimizing, and awe-inspiring. The BSSP is seen as a bureaucratization, routinization, centralization, and organizational growth admitting or recruiting procedures, succession, etc. For Glasier (1978) "it is likely the emergent mix would emphasize the BSPP (psychological process)" (p.104), and for this inquiry on Bosnian Muslims that mix consists of changes which have occurred with the decaying of the former Yugoslavia and the subsequent Bosnian war.

${ }^{391}$ As described above in detail in Chapter Three, self-investment means "a purposefully chosen categorization of the self and consequential investment into a group" (Reese et al. 2015, p.248).
} 
point of the process, at the level of the individual member of a group, which is the major concern of this inquiry. ${ }^{392}$

\section{Figure 7.1: Temporal Sequence of Three Stages of a Group}

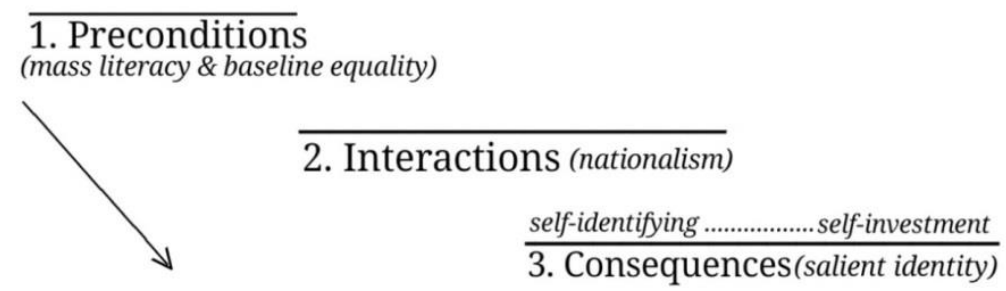

In order to make broader inferences about the effects of interactions between the structure acting upon the group and the agency of the individual actors, individual responses are aggregated, and the effects of the interactions are then measured on the group level. Therefore, the group is the level of analysis in this inquiry, while individual members of the group are the units of analysis, and the method is established by the grounded theory approach. In this case the methodology helps to observe the effects of the interactions between the structural dictate upon the group, and the individual group members' responses, to understand the direction of action, and test it with an experimental statistical analysis, as preferred by the grounded theory approach (Simmons, 2010, p.17). Obviously, this is a situation of continuing interaction between all those different levels with and without the group, and the process can stop and restart again as necessitated by the group's developments.

\footnotetext{
${ }^{392}$ The elite level measure perhaps is more appropriate to understand the texture and goals of each nationalism project, not discussed much in this inquiry.
} 
Responses are organized on the two lower levels of the group, the ground-level elites, and the level of group commoners. Although the elites are driving the nationalism, most scholars of nationalism suggest that the effects of nationalism are to be observed at the ground level. ${ }^{393}$ I propose that there is also a mezzo level, which should be distinguished and observed separately, to provide for a more comprehensive understanding of the whole process and in that way, possibly we can notice what level is affecting the intensity and texture of nationalism, and whether and when nationalism is diluted and discontinued. This is because it is not enough to notice that nationalism is a top-down project, in terms of the initiation, but we should also try to follow how intensity subsides and what level is instrumental in the process of turning it off. Observations on those three levels of a group could potentially give us such clues. ${ }^{394}$ For that reason, one of the controlled variables here is a person's social status, whether he is part of those ground-level elites, so that it may be measured whether that has any effects on nationalism and acquisition of identity among the population sample. This is particularly important when a sample is drawn from the diaspora which is often distant from the key circles of the group, and where those ground-level elites play an instrumental role in pushing for and implementing the group's collective projects and goals, and the new salient identity is one such collective goal. ${ }^{395}$

\footnotetext{
${ }^{393}$ For example, Hobsbawm (1990) notes that nations are "dual phenomena, constructed essentially from above, but which cannot be understood unless also analyzed from below" (p.10).

${ }^{394}$ Smith (2009, p.15), also considers a nation as a project formed between the levels of ordinary people and key circles of the group.

${ }^{395}$ As is discussed in depth in Chapter 3 of this work, Fominaya (2010, p.397) explained, identity as a product is a form of "a public good."
} 
The interactions between the two different levels of a group are measured by the responses to the questions posed in the survey. Respondents are asked to rank possible answers based on their preferences among the available options. As Slovic (1995) established the individual "values or preferences are commonly constructed in the process of elicitation" (p.364) of norms acquired from interactions with the group, which provides a frame of common culture and mores. Therefore, the recruitment of individuals who fit the definition of diaspora (provided in Chapter Six), and the collection sites, as spaces with institutions that provide the possibility for the members of a group to have regular interactions from which they can elicit preferences, is warranted. In that way, such-defined members of the diaspora familiarize with (and possibly internalize) groups' normative collective process of elicitation of preferences, to access reality in which they live and, have a possibility to similarly evaluate the questions of the survey as members of a same group.

Based on the author's theoretical sensitivity to the case and the literature, questions responses in the survey were grouped to create two nationalism index constructs. Cronbach \& Meehl (1955, p.283) and Messick (1995, p.746) recommend indirect constructs to measure social interactions and behavioral outcome, such as feeling of nationalism and ascription of salient identity. As the same authors note, the constructs are reflected in test performance, and in our case, observed through the survey responses. The constructs are Nationalism Strength, and Nationalism Type. An outcome variable is the particular construct of Bosniak Identity composed of responses to two questions: "What is your national identity?", and, "How strongly do you feel Bosniak?" Since the 
criteria for inclusion of questions in the constructs are vaguely defined in terms of whether a reasonably common-sense, nomological criterion will see them as some expression of nationalism, the EFE test was done to ensure that all the questions do in fact covary and that they together measure the intended phenomenon of nationalism. As it is reported in chapter eight, tests confirmed the reasonable homogeneity, with internal variability score for both constructs of $\alpha>0.65$ (for more, see Chapter Seven and Eight).

\section{7-2: Questions and Constructs}

Fourteen questions included in the constructs are grouped based on theoretical sensitivity about the characteristics of Bosnian Muslims. For Nationalism Type they involve questions regarding the internal group differences about local regional customs (R3), about perceptions about Bosnian Muslim culture which could be shared or not with the neighboring groups (CULT 10), parenting as source of group membership as a possibility for recruitment of new members (Nat 15, Nat 16), attitudes towards possible other identities (NAT 17b, NAT 17d), questions pertaining the individual social distance towards non-Bosniak and non-Muslim groups (SD 19, SD 20, SD 22r, SD 23), attitude towards group's membership based on a race (SD27), and religion (REL 48c) - (for more

details, see Appendix B). The final score for Nationalism Type is constructed out of combined homogenized Z-scores for each question combined together to create a bi-polar variable of Nationalism Type where the lower pole indicates an ethnic and the higher pole, a civic type of nationalism, with the range of 2.44 .

Seventeen questions included in the construct of Nationalism Strength include exposure to influences of the elites through education, media, and family-home 
environment (EDU6c, Cult 8b), cultural exclusivity (LAN 56c, LAN 57, REL 47) feeling of the sense of frustration regarding perceived group's cultural non-recognition (Lan 58C, MEM 50, MEM 51, MEM 52), political consciousness and involvement (PC 28a, PC 32c, PC 34, PC 35c, PC37c ) exposure and attitudes towards war (PC 29b, MEM 55) - (for more details, see Appendix A, and the discussion in Chapter 7). The final score is made out of combined homogenized Z-scores for each question, and Nationalism Strength is conceived as more or less with the range of 2.22 scores. The assumption for the test was that more of Nationalism Strength will influence desired identity ascription among respondents.

The dependent variable, desirable Bosniak Identity, is constructed out of the two questions in the survey, one that asked the respondent to choose his national identity out of nine options (NAT 13), and the other asking him to note how strongly he feels Bosniak (NAT 17a). Responses to those two questions were combined to construct the desired Bosniak identity.

Question NAT 13 asks: What is your nationality? For Question NAT 13, the respondents selected their own national identity out of eight possible non-ranked categories: Bosniak, Bosnian/Herzegovian, Muslim, Serbian, Croatian, Montenegrin, Yugoslav, American, and Other. In the final analysis, all responses were grouped into two categories of Bosniak or non-Bosniak, since Bosniak identity is the particular concern for this inquiry. Once reorganized, final responses were coded as dummy variable, with Bosniak as 1, and non-Bosniak as 0 . 
Question NAT 17a asked: How strongly do you feel Bosniak? Respondents could select from five Likert-scale response options: Very strongly, Strongly, Somewhat, Very little, and I don't feel so at all. Respondents were instructed to answer the question by checking one field which best represents their attitude regarding this identity. In the final analysis, all responses were grouped into three categories: Very Strong, Strong, and Weakest. Very strong included only those who responded "Very strongly", Strong included the two middle, mild, categories, and Weakest included the two weakest categories. Once reorganized, the final responses were coded as three-point nominal variables, Very Strong as 3, Strong as 2, and Weakest as 1.

Table 7.1: Outcome Variable with Identity Categories

\begin{tabular}{lcccc}
\hline & \multicolumn{3}{c}{ Feeling of Bosniak Identity } & \\
& & Very strong & Strong & Weakest \\
\hline Identity choice: & Bosniak Id & VSB* & SB & WB \\
\cline { 2 - 4 } & Other Id & OVSB & OSB & OWB \\
\hline
\end{tabular}

Once the answers to the two survey questions (NAT 13 and NAT 17a) were reorganized and recoded, they were combined to create six categories of nominal, unordered, discrete outcome variable (see Table 7.1). The six categories of possible combinations of the responses to these two questions are: Other/Weakest Bosniak (OWB), Other/Strong Bosniak (OSB), Other/Very Strong Bosniak (OVSB), Weakest Bosniak (WB), Strong Bosniak (SB), and Very Strong Bosniak (VSB), with the last category also selected to be the base value against which all other options were compared (for case processing summary, see Table 7.2). That means that each of the identity categories was 
compared to the nationalism-desired VSB category to determine whether the likelihood for the respondent to select that category was influenced by his Nationalism Strength, Nationalism Type and the controlled variables. Since the dependent variable is a categorical variable with more than two options and with no natural ordering, the appropriate model for the analysis was a multinomial logistic regression (Kinnear and Gray, 2010, p.565).

Table 7.2: Case Processing Summary for Bosniak Identity Data

\begin{tabular}{|c|c|c|c|}
\hline \multicolumn{2}{|c|}{6 Category Bosniak Identity } & $\mathrm{N}$ & Valid Percent \\
\hline & Strongest Bosniak Id & 388 & $59 \%$ \\
\hline & Strong Bosniak Id & 78 & $11.9 \%$ \\
\hline & Weakest Bosniak Id $\quad$ (WB) & 19 & $2.9 \%$ \\
\hline & Other Id/Strongest Bosniak (OVSB) & 69 & $10.5 \%$ \\
\hline & Other Id/Strong Bosniak (OSB) & 49 & $7.4 \%$ \\
\hline & Other Id/ Weakest Bosniak (OWB) & 55 & $8.4 \%$ \\
\hline \multirow[t]{3}{*}{ Education Level } & Elementary & 77 & $11.7 \%$ \\
\hline & High School & 303 & $46 \%$ \\
\hline & College & 278 & $42.2 \%$ \\
\hline \multirow[t]{2}{*}{ Gender } & Female & 261 & $39.7 \%$ \\
\hline & Male & 397 & $60.3 \%$ \\
\hline \multirow[t]{2}{*}{ BiH Home Ownership } & No & 294 & $44.7 \%$ \\
\hline & Yes & 364 & $55.3 \%$ \\
\hline \multirow[t]{2}{*}{ Promoter (Social) Status } & No & 594 & $90.3 \%$ \\
\hline & Yes & 64 & $9.7 \%$ \\
\hline Valid & & 658 & $100 \%$ \\
\hline Missing & & 6 & \\
\hline Total & & 664 & \\
\hline Subpopulation & 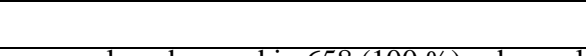 & $658^{\mathrm{a}}$ & \\
\hline
\end{tabular}

To investigate the likelihood of base category of identity ascription over another category among the responders, a multinomial logistic regression was used to model nominal outcome variables of different categories of Bosniak identity, in which the log odds (logits) of the outcomes were modeled as a multinomial logits estimate combination of the seven predictor variables. The starting point of the investigation was that the 
person's identity choice response was influenced by his intensity and type of nationalism, my main predicting variables, along with schooling level, economic attachment to the homeland, social status in the population, and gender as the controlled variables. The multinomial logistic regression is a discrete choice model allowing for multiple outcomes, and as such it is often used to measure the likelihood of preferences among discrete outcome choices.

\section{7-3: Representativeness of This Sample of the Bosnian Muslim Population}

Although previous chapters establish the usefulness of the diaspora for this type of study, it is nevertheless necessary to examine the composition of the population sample in order to have a clear picture of how representative it is for the particular case of Bosnian Muslim nationalism. It may be argued that even in cases where a diaspora is used in a research design, the sample should reflect as closely as possible the varieties of the "back-home" population. At least, any analysis should contain a report on the representativeness of the sample used for the study. In this way, such information by itself will be an important contribution to the body of knowledge on the case under examination for other researchers. Among the first issues in this regard to which special attention is paid here is the regional representation of the respondents. Regional representation is important even with studies where samples are drawn from the diaspora because diaspora clusters usually first mirror homeland regions, or occasionally some other forms of "back-home" groupness. Regions in this inquiry are listed based on 
traditional back-home identifications of the Bosnian Muslim population. ${ }^{396}$ There are a few more, even smaller, regional associations which are sometimes also meaningful for the Bosnian Muslim population, but for the sake of space in this research, the questionnaire offered seven regions and two sub-regions, a total of nine possible choices, to participants to self-select (for all options see Appendix A, Question 1).

\section{Figure 7.2: Nationalism and Salient Identity Model of Interactions}

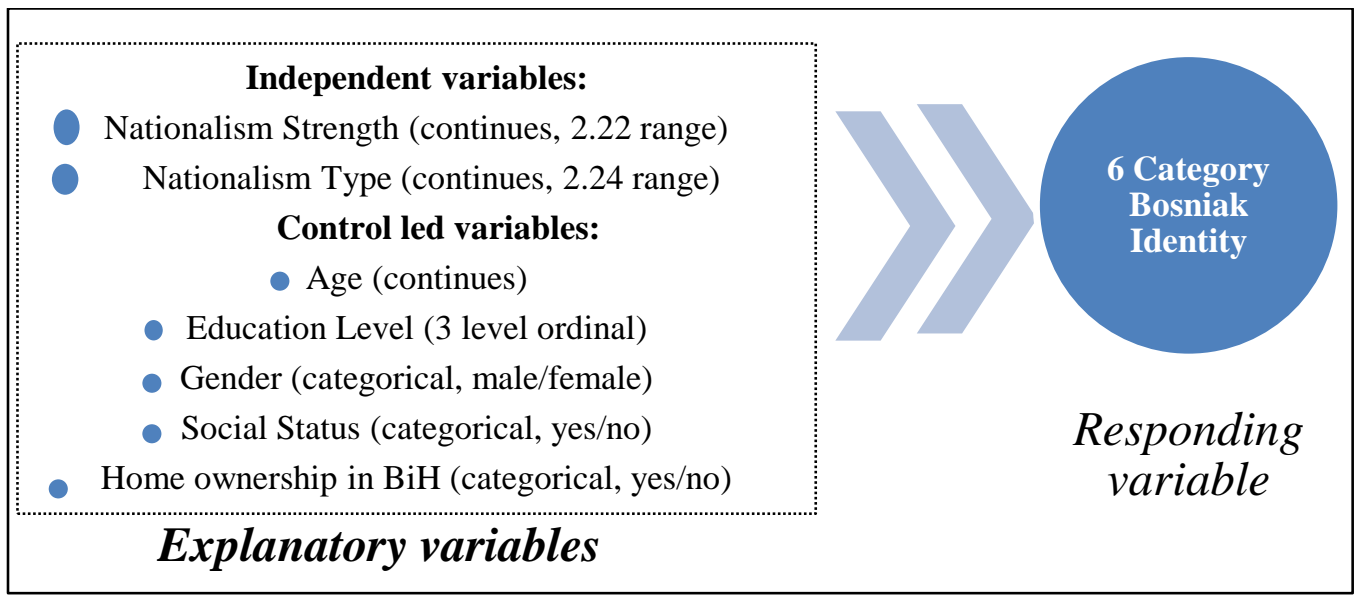

\section{7-4: Nationalism Constructs}

Since the phenomenon of nationalism contains two functionally different aspects, for this exploratory study it is divided into two constructs, one that measures the strength of nationalism and the other that measures the type of nationalism among the respondents. It is implied here that they work differently and that, of the two, the intensity of nationalism should be more of a factor in a new salient identity ascription, rather than the type. The construct of "Nationalism Strength" is created by combining the scores for 17 items from the questionnaire (see Appendix B). Since all the items have different scales

\footnotetext{
${ }^{396}$ Croegaert (2011) notes in her paper that for the people she talked to, those regional identifications were often the "distinctions that are at least as important, if not more so, than are the ethnic markers of Croat, Bošniak, or Serb” (p.474).
} 
of responses, the standardized Z-score was computed to homogenize the scores between the different scales for each item. The range of final scores for the Nationalism Strength index is 2.23 , with a minimum score of -1.34 and maximum of 0.89 . The mean score of Nationalism Strength for the population sample is $0.005(\mathrm{SD}=0.4)$. The median score is 0.06 , a slightly lower value of mean than the central tendency of median, while both of the positive signs suggest an overall moderate intensity of nationalism strength among this sample of the population.

Similarly, the third construct is a bipolar index of the Nationalism Type, created by combining the Z-scores for 14 items (see Appendix C). The Nationalism Type Index was measured between the civic and ethnic poles, and its range is 2.44. For the Nationalism Type contruct, the more ethnic the type of nationalism was, the lower the score, while the more civic the type of nationalism was, the higher the score. It should be noted that different results of the tests on relations between variables and the two nationalism constructs support the model's two-dimensional treatment of nationalism, and show that those two essential aspects of nationalism should be treated separately, which is usually never done.

A large number of valid survey responses provide us with the confidence to use the homogenized Z-score for both constructs, since the central limit theorem states that in population samples with a sufficiently large $\mathrm{n}$, the sampling distribution of the sample 
mean is approximately normally distributed, which is important for the Z-scores to work as intended. ${ }^{397}$

To check for evidence of the multidimensionality of the strength and type of nationalism among participants, two separate iterated principal factor analyses were performed on all items included for the two constructs and on all valid responses in the sample. The results showed a reasonable internal reliability for the items selected for the constructs, as discussed below. Finally, the preliminary tests showed no effects of interactions among the two independent variables.

\section{7-5: The Type of Nationalism Index 398}

For this sample of the Bosniak population $(\mathrm{N}=664)$ the mean score for the Nationalism Type construct is positive, $\mathrm{m}=0.21(\mathrm{SD}=0.4)$. The range of scores is 2.44 , with a minimum of -0.6 and a maximum of 1.83 . Again, it is useful for the construct to note that the median of the scores on Nationalism Type is 0.16 , and therefore results show that the mean, as the central tendency of all scores, is higher than the median. The positive signs for both, the median and the mean, suggest that the population sample is leaning moderately more towards the civic type of nationalism. ${ }^{399}$ The construct demonstrated a reasonable internal consistency reliability composite score $(\alpha=0.61)$ for

\footnotetext{
${ }^{397}$ As indicated by Myers et al. 2010, pp.100-02.

${ }^{398}$ The Type of Nationalism bipolar index is constructed with civic and ethnic poles of the Nationalism Type. Answers to the 14 items in the questionnaire are coded to measure for the strength of the civic type of nationalism (see Appendix C). That connotes that the higher the mean score is the more of civic type of nationalism it is, while lower and negative mean score suggests it is more of the ethnic type of nationalism.

${ }^{399}$ Myers et al. (2010) note that "unlike the mean, whose value changes if any individual score is changed, the median is considered a resistant statistic because it is unaffected by changes in the value of any single score... because of that, there are circumstances in which it provides a more representative index of the location of a distribution" "(p.24).
} 
the 14 indicators selected for the index of the Nationalism Type, and it shows that all those items from the data combined do measure the same concept intended to be measured. Again, the reliability score is slightly lower than the recommended $\alpha=0.70$ value for exploratory research (Nunnally, 1978, p. 245; Lance et.al., 2006, p. 205) like this one, but all the items included in the construct are theoretically important and have been kept. ${ }^{400}$ Additionally, the grounded theory approach for the study suggests including as many items as possible. Finally, more items provide higher score variability among the participants.

\section{7-6: Controlled Variables}

For the controlled variables, education level was measured by the respondents' declared level of education; respondents' economic attachment to the homeland was measured by their declared home-ownership back in $\mathrm{BiH}$; gender was the self-selected respondent choice; and finally, respondents' social status in the population was measured by a dummy variable of whether or not they have the role of identity promoter assigned to them by the investigator based on the social status of an influential person. Such social status was given to them in two ways, by the job they hold, or by participant observations, and therefore they may be seen as spontaneous or traditional leaders, as Breuilly (2011) would consider them. This type of spontaneous leader close to the population is

\footnotetext{
400 The EFA test showed that the score could be increased only slightly if more items were removed from the index however, the alpha will still remain under the recommended value of 0.70 .
} 
consistent with the intended bottom-up approach of the test and for a study in which the focus is on the horizontal connections among members of a group. ${ }^{401}$

The age of the respondents was treated in two ways. In the model, age was treated as a continuous variable based on birth year, with increments of one year. For lower level analysis, age was also treated as an ordinal variable where respondents were classified based on their birth-age into three categories: those born before WWII, those born during the Communist-rule era, and those born in the post-Communist era. The largest number of respondents comes from the group born during the Communist-rule era because they were the primary segment of the group targeted for this study.

Education level is treated as an ordinal variable, where respondents were classified based on their declared level of schooling: elementary, high school, or college. Gender was treated as a categorical variable, where respondents were either male or female. And social status and house/apartment ownership in $\mathrm{BiH}$ were treated as categorical values, with yes/no options.

\section{7-7: Nationalism Type - Frequencies of Fourteen Items}

\section{7-7-1: Regional Representation}

Sample respondents from rural areas totaled 51 percent, while the remaining 49 percent come from urban areas. Of the urban population sample, 20 percent are from the capital. ${ }^{402}$ Since one of the issues most nationalisms have to deal with is regionalism,

\footnotetext{
${ }^{401}$ For more on the different types of group organizations and connections among members, see Fennema 2004

${ }^{402}$ According to the CIA World Facts web site, $39 \%$ of the BiH population is from urban areas. That number is even larger for the Bosnian Muslim population, which historically has been mainly concentrated
} 
efforts should be made in studies to have appropriate representation from all the different geographical, cultural and political realities in which a population lives which often are expressed as a form of regionalism. In this regard, the case of (Bosnian) Muslims is particularly telling, since the population now occupies several different geographical regions, ${ }^{403}$ two in-group strongly confronted political factions, ${ }^{404}$ two political $\mathrm{BiH}$ subdivisions, ${ }^{405}$ and now, five independent Balkan countries. ${ }^{406}$

in urban settlements (for more, see also Donia 2006). Yet, the larger population of respondents from rural areas in this sample is probably due to the much more thorough implementation of ethnic cleansing in rural areas of $\mathrm{BiH}$, where Bosnian Muslims were much more vulnerable. According to the same source, the Sarajevo population comprises $20 \%$ of the total $\mathrm{BiH}$ urban population, and again, the percentage of Bosnian Muslims there is probably higher when it comes to Bosnian Muslims exclusively. Interestingly, the 1991 census report for SR Yugoslavia (composed of only Serbia and Montenegro) notes a frequency very similar to our sample frequency of rural-urban proportion of the Muslim nationality. Of the total Muslim nationality population of 336,025 who lived in SR Yugoslavia in 1991, only $49 \%$ of them were urban population. In Montenegro there was a very similar ratio: of 89,614 total people with Muslim nationality, 45\% were from urban areas. In Serbia, of 246,411 Muslims, some 50\% were from urban areas. Finally, in Kosovo, of 66,189 of Muslim nationality people, only 34 percent were from urban areas (for a complete list see Grpkovic 1993, p.8). Such difference between Muslims of the rump Yugoslavia and Muslims of $\mathrm{BiH}$ further shows the importance for the sample in a study to include people from all those locations.

${ }^{403}$ Spahić and Jahić (2014, pp.40-7) provide a detailed account of different BiH regional classifications over time. Most of them tend to agree with Ahmetbegović's (2014) geomorphological regionalization approach with at least four larger geographic regions and their respective sub-regional units. As he showed, the characteristics of each region impacted population distribution in $\mathrm{BiH}$. The four regions include: Northern Bosnia, or Krajina, surrounded by plains, with low horst mountains, characterized by generally low hypsometrical levels of 100-200 $\mathrm{m}$ above sea level. Five major BiH rivers flow through this region and serve as natural corridors for continental population movements. Central Bosnia is the region of the central Dinaric basin and valleys with mining and flysch mountains. Central Bosnia is characterized by many medium and high mountains. The capital city of Sarajevo is located within the same region; however, it is noted as a separate option in the survey due to its specifially urban situation. The third region of high karst covers the transitional area from the mountain basin to the Mediterranean area, represented through Eastern Bosnia. It separates Central Bosnia from the fourth region of lower Herzegovina, an Adriatic and subAdriatic zone (Mediterranean zone), where the population is oriented towards the coast. The inhabitants of each region cultivate different crops, and have different food ways. As a result, each region also developed different folklore. Regions in this survey follow to some extent these four basic BiH regions and their subregional units, with the addition of Sandžak, as an outside-of-BiH region with a significant Slavic Muslim population, and Western Bosnia, as a separate Krajina sub-region with a population resulting from specific political developments during the Bosnian war in the 1990s. Furthermore, Midžić (2009, p. 300) also notes that that region has a long history of autonomous tendencies. 
The importance of each of these circumstances is that almost all of the diaspora situations contain networks of friends, cultural groups, social organizations, or at least sports clubs based on those regional associations. Sometimes, more or less informal Bosnian Muslim groups are organized around certain Islamic practices, like Sufi order associations, or Salafi and Bosnian traditional mosques, but even within those groupings, a careful observer can notice social clusters which are usually regionally based. For that reason, effort was made to recruit participants from seven of those regions where Bosnian Muslims live (see Table 7.3). ${ }^{407}$

Table 7.3 shows the number of participants from each region, as well as the perception of a difference in customs between the $\mathrm{BiH}$ regions. The cross-table was created based on the responses to two questions from the survey (for complete

\footnotetext{
${ }^{404}$ The Bosnian Muslim peoples who were fighting for the idea of a so-called West Bosnia Autonomy (Zapadna Bosna), were led by Fikret Abdić, against the rest of the Bosnian Muslims who were for a unitary $\mathrm{BiH}$.

${ }^{405}$ The Federation of BiH, and the Republika Srpska. For more on BiH constitutional arraignments and Bosniak position in those two BiH sub-divisions, see Bardutzky 2010.

${ }^{406}$ Primarily BiH, Serbia, Montenegro, Croatia, Kosovo. Some (Bosnian) Muslims also live in other former Yugoslav states, but in these five they represent a large enough minority to be influential at least on the local or regional level.

${ }^{407}$ The data contains a sample of the population from each region, except for a sample of Bosnian Muslims (Bosniaks) from Macedonia, and a relatively small sample of Bosniaks from Kosovo. The population sample from Sandžak is disproportionally larger from the Montenegrin part of Sandžak, since people from Plav and Gusinje are the major Sandžak regional group that created its own diaspora niche in the New York metropolitan area, which for some time has served as a magnet for the constant flow of new people from "back home." Other sub-regions of Sandžak are not as strongly represented, since it is much harder for people from those other parts to come and remain in the U.S. without an immediate group support network. Furthermore, compared to Muslims from $\mathrm{BiH}$, those from Sandžak are without a legal path to the benefits of residency and citizenship, while Bosnian Muslims, escaping the immediate war in $\mathrm{BiH}$, received those benefits right from the start. Most Bosnian Muslims from $\mathrm{BiH}$ had the legal status of refugees, with employment authorization and permanent resident status right upon their arrival, while those from Sandžak did not (although that did not necessarily transfer to a tangible economic advantage, see Nathanson 2013, p.17). Since other Bosniak Muslims faced different circumstances on their arrival, they could rely only on their own group support networks, and that is how diaspora clusters formed.
} 
frequencies of R3 see Appendix B). From five options, where 1 means customs are "not different at all", and 5 means that they are "very different," the mean value for the sample of the population is $2.85(\mathrm{SD}=0.97)$. This value, slightly above half for this sample of the population, shows that there is a marginally higher sense of differences in customs among people from different regions. Yet, the last column of Table 7.3 shows the difference in percentage of participants within each regional group who chose to identify their own nationality as Bosniak from eight possible non-ranked options. From the numbers, it may be observed that the percentage of those respondents who are from West Bosnia and who have chosen to identify as Bosniaks, while slightly lower than percentages in the other groups, is still the majority of that regional group. Furthermore, the feeling of regional difference did not appear to be a statistically significant factor in participants selecting Bosniak identity vs. other possible identities. Yet, attitudes towards regional custom differences essentially provide the inquiry with the texture of nationalism and the sense of a group's homogeneity, factors that an investigation of nationalism should account for.

Table 7.3: Feeling of Differences in Customs among BiH Regions ${ }^{*}$

\begin{tabular}{lrccccr|c}
\hline BiH Region & N & Not at all & Not much & Somewhat & Significantly & Very & $\begin{array}{c}\text { Identify as } \\
\text { Bosniaks }\end{array}$ \\
\hline East Bosnia & 180 & 5.6 & 41.7 & 34.4 & 12.8 & 5.6 & $\mathbf{7 6 . 5}$ \\
Central Bosnia & 139 & 5.8 & 28.8 & 44.6 & 10.8 & 10.1 & $\mathbf{6 6 . 9}$ \\
Krajina & 87 & 3.4 & 27.6 & 48.3 & 18.4 & 2.3 & $\mathbf{7 5 . 9}$ \\
West Bosnia & 57 & 3.5 & 42.1 & 33.3 & 17.5 & 3.5 & $\mathbf{6 1 . 4}$ \\
Posavina & 32 & 3.1 & 34.4 & 46.9 & 12.5 & 3.1 & $\mathbf{9 0 . 6}$ \\
Hercegovina & 44 & 2.3 & 29.5 & 43.2 & 15.9 & 9.1 & $\mathbf{6 5 . 9}$ \\
Sandžak & 101 & 5 & 34.7 & 38.6 & 12.9 & 8.9 & $\mathbf{8 6 . 1}$ \\
USA \& other & 24 & 4.2 & 20.8 & 25 & 29.2 & 20.8 & $\mathbf{5 0}$ \\
\hline * all numbers are valid percentages of total within each region, except N & \multicolumn{7}{r}{}
\end{tabular}




\section{7-7-2: Regionalism and its Manifestations Among Participants}

As indicated in the chapter which discussed the pillars of Bosnian Muslim nationalism, the $\mathrm{BiH}$ territory is one of the important issues in their nationalism project. However, Bosnian Muslim nationalism and their salient Bosniak identity project are sometimes concerned with Slavic Muslims in other parts of the former Yugoslavia, who are occasionally also the target of other nationalizing nationalism projects. The contest of those different nationalizing nationalisms is particularly intense over the Muslims of Sandžak, a region now split between Serbia and Montenegro, whose Muslim populations are also targeted for recruitment into Montenegrin, and to a much smaller extent, Serbian nationalism projects and their respective national identities. ${ }^{408}$ Those Muslims from Montenegro are particularly aware of the competitions over them, and the possible implications of their decision to accept Bosniak identity. ${ }^{409}$ A few of them expressed to me uneasiness about Bosniak identity since it signals too strong a tie to Bosnia, where they had never lived before. ${ }^{410}$ Furthermore, the state of BiH does practically nothing for them. Even those Muslims from Sandžak who live in BiH are often treted as outsiders by the state, ${ }^{411}$ since they do not have an automatic rights to education, work, or other

\footnotetext{
${ }^{408}$ See Jenne and Bieber (2014).

${ }^{409}$ See Rastoder 2010, pp.481-3

${ }^{410}$ Karalić and Hadžić (2012) note that in the latest Montenegrin census $7.11 \%$ of people declared themselves Bosniaks, while 3.97\% were "old" Muslims, and noted that this split could have serious implications for the Muslims of Montenegro.

${ }^{411}$ It should be added here that some of the most prominent players in the $\mathrm{BiH}$ war of independence were Muslims from Sandžak, from the Mehmed Šemsikadić, the first leaders of Bosnia's resistance to AustroHungarian takeover (see footnote 175), to the first commander of the BiH Army, Sefer Halilović, to Ejup Ganić, the first person to replace BiH President Izetbegovic when he was briefly detained by the JNA. Both men were then long-term residents of Sarajevo, but also both were Muslims originally from Sandžak. Although Woodward (1995, p. 478) incorrectly considers Ganić a high level political figure in President Izetbegovic's pro-Muslim SDA party, the truth is that neither of them was part of the same party. Ganić, at
} 
benefits that other Bosnian Muslims enjoy in $\mathrm{BiH}$, despite their efforts to present $\mathrm{BiH}$ as a champion of their rights, ${ }^{412}$ and their sacrifices to help support its quest for independence. ${ }^{413}$ They are sometimes seen as different even by other Bosnian Muslims. ${ }^{414}$ Therefore, it is not a surprise that for Muslims from Sandžak the issue of Bosnianness, or eponymic Bosnian identity, is less salient, than for Bosnian Muslims from other regions (for more, see Appendix B, Question NAT 17B frequencies).

Such evident differences among the population, and their attitudes towards these Muslims from Sandžak, provide a possibility for this inquiry to account for the breadth and composition of Bosnian Muslim nationalism. Just like the question regarding regional differences in perceptions about customs, these attitudes towards Muslims from Sandžak essentially indicate the nature of their nationalism. Therefore, those questions are included in the Nationalism Type Index which tries to capture participants' attitudes towards those issues of social and political width and composition of the Bosnian Muslim nationalism program.

Question NAT 17B asked "How strongly do you feel Bosnian?," and participants had five options to respond: I don't feel so at all; Very little, Somewhat, Strongly, and

\footnotetext{
the time a declared Yugoslav, was a member of the BiH presidency as a representative from a left and proYugoslav party, while Halilović was not a member of any political party then (for more see Halilović 2005). Yet, all three were part of a Muslim bloc which came together to resist Serbo-Croatian joint attempts to destroy BiH integrity (Woodward 1995, p.216).

${ }^{412}$ For example, in the famous "Memorandum on the Establishment of a Special Status for Sandžak" issued in 1993 in Novi Pazar, while printed in Clifton N.J (close to one of the data collection sites for this study), initiators of the memorandum call for international verification of their demands with one of the signatories to be a representative of $\mathrm{BiH}$ (pp.9-10).

${ }^{413}$ See Kahrović 2001, pp.111-28; Crnovršanin 2001, p. 680

${ }^{414}$ See, for example, Halilović 2005.
} 
Very Strongly (for the total frequencies of the NAT 17B responses, see Appendix B). The largest number of those who do not feel Bosnian at all is from the region of Sandžak, $42.7 \%$, followed by respondents from the region of Herzegovina, with $25.6 \%{ }^{415}$ All other Bosnian regions have much smaller percentages of respondents who do not feel Bosnian at all (see Table 7.4).

Table 7.4: Association with Bosnia and Yugoslavia Among Regional Subgroups**

\begin{tabular}{|c|c|c|c|c|c|c|}
\hline \multicolumn{2}{|c|}{ How strongly you feel? } & \multirow{2}{*}{$\begin{array}{c}\text { I don't feel } \\
\text { at all }\end{array}$} & \multirow{2}{*}{$\begin{array}{l}\text { Very } \\
\text { little }\end{array}$} & \multirow[t]{2}{*}{ Somewhat } & \multirow[t]{2}{*}{ Strongly } & \multirow{2}{*}{$\begin{array}{c}\text { Very } \\
\text { strongly }\end{array}$} \\
\hline Option: & Region: & & & & & \\
\hline \multicolumn{7}{|c|}{ East Bosnia } \\
\hline Bosnian? & & 5.4 & 65 & 16.7 & 22 & 49.4 \\
\hline Yugoslav? & & 75.1 & 17.8 & 5.3 & 0 & 1.8 \\
\hline \multicolumn{7}{|c|}{ Krajina } \\
\hline Bosnian? & & 4.7 & 1.2 & 15.3 & 24.7 & 54.1 \\
\hline Yugoslav? & & 82.4 & 10.6 & 5.9 & 0 & 1.2 \\
\hline \multicolumn{7}{|c|}{ West Bosnia } \\
\hline Bosnian? & & 7.1 & 3.6 & 16.1 & 14.3 & 58.9 \\
\hline Yugoslav? & & 70.4 & 16.7 & 7.4 & 1.9 & 3.7 \\
\hline \multicolumn{7}{|c|}{ Central Bosnia } \\
\hline Bosnian? & & 6.6 & 2.9 & 14 & 18.4 & 58.1 \\
\hline Yugoslav? & & 78.2 & 12.8 & 5.3 & 3 & 0.8 \\
\hline \multicolumn{7}{|c|}{ Posavina } \\
\hline Bosnian? & & 3.4 & 6.9 & 13.8 & 24.1 & 51.7 \\
\hline Yugoslav? & & 65.5 & 27.6 & 6.9 & 0 & 0 \\
\hline \multicolumn{7}{|c|}{ Herzegovina } \\
\hline Bosnian? & & 25.6 & 18.6 & 11.6 & 16.3 & 27.9 \\
\hline Yugoslav? & & 74.4 & 18.6 & 7 & 0 & 0 \\
\hline \multicolumn{7}{|c|}{ Sandžak } \\
\hline Bosnian? & & 42.7 & 27.1 & 17.7 & 9.4 & 3.1 \\
\hline Yugoslav? & & 59.4 & 20.8 & 11.5 & 8.3 & 0 \\
\hline \multicolumn{7}{|c|}{ Other } \\
\hline Bosnian? & & 68.2 & 9.1 & 4.5 & 4.5 & 13.6 \\
\hline Yugoslav? & & 69.2 & 18.2 & 4.5 & 4.5 & 4.5 \\
\hline
\end{tabular}

\footnotetext{
${ }^{415}$ Herzegovina is another region which is sometimes seen apart from Bosnia, as even the binomial term "Bosnia and Herzegovina" for the name of the country indicates.
} 
At the other end, interestingly, from the same table it may be observed that among those who identify strongly with Bosnian identity are respondents who come from the region of West Bosnia (associated with autonomy and the Bosnian Muslim fratricidal war). West Bosnians have the largest percentage among all regions that feels very strongly Bosnian. Since Bosniak identity was adopted as an issue to be championed by the Bosnian Muslim nationalistic party, the SDA, which led the BiH government's side in the fratricidal war, ${ }^{416}$ Bosnian identity became particularly salient over Bosniak identity on the other side, which advocated West Bosnian autonomy within $\mathrm{BiH} .{ }^{417}$ Yet, as previously noted in Table 7.3, even within that regional group of respondents, the majority, 61.4\%, identified as Bosniaks as well (although, again, that is the lowest percentage of all the regional groups; see Table 7.3).

\section{7-7-3: Feeling Yugoslav, Yes or No?}

Another question in the Nationalism Type Index, NAT 17D, asks participants how much they feel Yugoslav, with the same five options to respond. From the table with regional breakdown it may be observed that the sense of Yugoslav identity is almost gone. Some $73.2 \%$ of the total "Do not feel Yugoslav at all," while 16.6\% feel "Very little," and only $10.2 \%$ still feel somewhat Yugoslav. The question was asked as a separate item to provide for a respondent's possibility of having and feeling multiple identities, Yugoslav being one of them. For that reason, this issue of possible layered identities

\footnotetext{
${ }^{416}$ The animosity caused by that war is still strong. For examples, see Nadarević 2013.

${ }^{417}$ This is so, despite the fact that their leader, Fikret Abdić, first advocated Bosniak identity together with Adil Zulfikrpasić and Muhamed Filipović at the outset of the $\mathrm{BiH}$ war, and before the SDA adopted it as well.
} 
which essentially do not exclude each other, was used as an item of the Nationalism Type Index. $^{418}$

\section{7-7-4: Friendship and Social Distance}

Another question measures the social distance of Bosnian Muslims from other ethnic and national groups, in this case from Bosniak back-home neighbors. Similarly to the question regarding family members, Question "SD19 Total-friends" asked participants to indicate if nowadays they have friends among Albanians, Croats, Serbs, Montenegrins, Americans, and other immigrants. For the purpose of the Nationalism Type Index, each friendship selection response was coded according to the history of each group's enmity and amity with Bosnian Muslims (for more, see the frequencies for Question SD 19 total-friends in Appendix B). Respondents were offered the opportunity to check multiple boxes to indicate all the friends that they might have among all the noted groups. The respondents in this sample of the population indicated that there was not many friendship interactions with other non-Bosniak groups in general, except with Americans and other immigrants. Among respondents $41.8 \%$ indicated that they have friends among other immigrants, while the majority, $80 \%$ of those friends from the other immigrant category are religiously Muslims. Even more respondents, 67.3\%, indicated that they have friends among Americans, and again, of those American friends, 58\% are religiously Muslims, while the remaining $42 \%$ are non-Muslim Americans. ${ }^{419}$

\footnotetext{
${ }^{418}$ For good sources on the effects of nested identity, see Herb \& Kaplan, 1999.

${ }^{419}$ As is well observed by Waters (2008), all questions which ask about, and compare immigrant minorities with "Americans," implicitly or explicitly carry some problematic assumptions about who those

"Americans" are. Although it is true that the term "American" can mean different things to different people,
} 
It is not completely clear if these numbers of current friendships among respondents are influenced by structure and opportunity, or by content and individual preference. We can speculate that they are influenced to some extent by both. The same "back-home" neighboring groups often settled close to each other in the diaspora as well, so the same network of ethnic stores, services and entertaining events ${ }^{420}$ supports all groups, and therefore there is still an opportunity for contacts between the different former Yugoslav groups in the diaspora as well. Furthermore, these numbers are somewhat consistent with O'Loughlin's (2010) research about friendship and social trust in $\mathrm{BiH}$. In his data, the more rural the population is, the less likely it is to have friends from other groups. Furthermore, the negative impact on friendship preferences for his Bosniak respondents was also dependent on whether or not they were forced to leave their homes during the war. Both of these categories (rural and expelled) have somewhat more representation in this sample of the diaspora population, and therefore the numbers about friendship here correspond to those numbers found in the back-home population. However, the numbers may also reflect the issue of an opportunity to meet regularly and become friends with members of other groups, which is much more limited in the group's diaspora situation. ${ }^{421}$ O'Loughlin (2010) also finds that even in the $\mathrm{BiH}$ context,

the term in this survey implicitly assumes Americans to be religiously undefined native-born white and black people. This approach comes from the personal knowledge of Bosnian Muslim in-group assumptions about Americans in general.

\footnotetext{
${ }^{420}$ As an example of what Al Ali et al. (2001) call "transnational cultural activities" (p.625), folk and rock music entertainers from "back-home" regularly perform across the U.S. in cities with large numbers of residents from the former Yugoslavia regardless of their nationalities. One Bosnian Muslim, who is a major U.S. promoter of such events, told me that he regularly advertises all those events across nationality lines in these cities, and that people who attend these events are indeed from all nationalities of the former Yugoslavia.
} 
opportunity does play a role in having or not having friends from different ethno-national groups. Therefore, these questions need to be further refined and researched in order to draw clearer conclusions regarding the reasons for low friendship of Bosniaks in this diaspora sample with back-home non-Bosniak groups. ${ }^{422}$

If these frequencies of friendship with Americans are to be used to sense how well Bosnian Muslims are integrated in the larger American society at those sites where data was collected, it may be observed that friendship with Americans, as well as with any other group, is the least frequent among the population sample in St. Louis (although even there, again, the largest number of out-group friendships are those with Americans. For more, see Table 7.3). Such a situation perhaps indicates that in conditions where a diaspora group is large enough to satisfy its own social needs, members tend to interact less with outside groups. ${ }^{423}$ Therefore, the issue of opportunity in such situations works in reverse, where an abundance of in-group members limits contact with out-group members in general. Furthermore, the St. Louis population sample overall is the youngest out-of-homeland sub-group among the four locations noted in this data set. Only $4.2 \%$ of respondents in St. Louis left their homeland before 1990. On the other hand, in Chicago, 14.3\% of respondents left BiH/Sandžak before 1990, and in the New York metropolitan area, slightly more, $18.3 \%$ of respondents, left their homeland before 1990 (for more on the frequencies of years when participants left their homeland, see Figure 6.1). So it may

\footnotetext{
${ }^{421}$ The percentages about friendship with Americans and Albanians support the notion of the opportunity indicator.

${ }^{422}$ For a discussion on structure and content of associations among members of a group, see Fennema 2004, p.436.

${ }^{423}$ For example, a similar situation is true of Cubans in Miami, and Somalis in Minneapolis.
} 
be that St. Louis's Bosnian Muslims need more time to learn the language and develop more ties with their American neighbors. ${ }^{424}$ Since, thus far, the majority of those friendship contacts are with American Muslims, that might be an early indication of segmented assimilation of a group into a section of the larger American society. ${ }^{425}$ In any case, the preference in this study for Muslim friends among Americans is consistent with the work of Jelalzai (2011, p.98), who found that in St. Louis over $60 \%$ of Bosnian Muslim participants in her sample experienced both personal and group discrimination after 9/11 (despite the fact, noted in the study, that Bosnians tend to downplay those instances of discrimination).

When it comes to friendship ties with Bosnian Muslims' Balkan neighbors in the diaspora, in this sample of the population the highest percentage, $42.5 \%$, is reported with Albanians. Most of these Albanians, 91.4\%, are Muslim, and only 8.6\% are non-Muslim. These numbers are somewhat skewed towards a higher percentage of friendships, due to a large population of respondents from Sandžak in New York, where $70 \%$ of respondents indicated that they have Albanian friends. This New York group of Bosnian Muslims lived and interacted regularly with Albanians back home in Sandžak's two towns of Plav and Gusinje. The same may also be happening in the New York City area, since there is a large Albanian diaspora group there, as well, and therefore opportunity seems to be the driving mechanism for the friendship indicators. Although Albanians do

\footnotetext{
${ }^{424}$ If they have no party affiliation in the U.S. (Jelalzai 2001, p.102), for Bosnian Muslims as a group the reality of still being a new immigrant group could be an explanation.

${ }^{425}$ For more on segmented assimilation, see Portes and Zhou (1993).
} 
live in Chicago and St Louis, as well (see Chapter 6), outside of New York far fewer respondents indicated that they have friends among Albanians (for more, see Table 7.5).

Table 7.5: Frequencies of Bosnian Muslim Friends at Research Sites*

\begin{tabular}{lcccc}
\hline Do you have friends among: & Chicago & Saint Louis & New York & Other Sites \\
\hline Americans Total & $\mathbf{7 2 . 3}$ & $\mathbf{5 8 . 8}$ & $\mathbf{7 8 . 2}$ & $\mathbf{6 4 . 6}$ \\
\hline Percent Muslim & 37.91 & 43.97 & 44.92 & 44.87 \\
Percent Non-Muslim & 62.09 & 56.03 & 55.08 & 55.13 \\
Albanian Total & $\mathbf{5 2 . 7}$ & $\mathbf{2 8 . 6}$ & $\mathbf{7 0 . 3}$ & $\mathbf{3 0 . 7}$ \\
Percent Muslim & 85.18 & 71.42 & 80.23 & 76.12 \\
Percent Non-Muslim & 14.82 & 28.58 & 19.77 & 23.88 \\
Croat Total & $\mathbf{4 0 . 4}$ & $\mathbf{3 1 . 9}$ & $\mathbf{4 1 . 6}$ & $\mathbf{2 8 . 6}$ \\
Percent Muslim & 18.18 & 26.86 & 23.91 & 29.31 \\
Percent Non-Muslim & 81.82 & 73.13 & 76.09 & 70.69 \\
Montenegrin Total & $\mathbf{5 5 . 3}$ & $\mathbf{2 0 . 3}$ & $\mathbf{6 1 . 4}$ & $\mathbf{1 8 . 7}$ \\
\hline Percent Muslim & 72.22 & 69.05 & 72.6 & 62.5 \\
Percent Non-Muslim & 27.78 & 30.95 & 27.4 & 37.5 \\
Serb Total & $\mathbf{3 7 . 8}$ & $\mathbf{1 9 . 2}$ & $\mathbf{3 3 . 7}$ & $\mathbf{2 8 . 1}$ \\
Percent Muslim & 21.51 & 24.39 & 27.91 & 30 \\
Percent Non-Muslim & 78.49 & 75.61 & 72.09 & 70 \\
Other immigrant & $\mathbf{5 0 . 5}$ & $\mathbf{3 4 . 1}$ & $\mathbf{5 3 . 5}$ & $\mathbf{3 4 . 4}$ \\
Percent Muslim & 60.16 & 59.74 & 63.89 & 67.42 \\
Percent Non-Muslim & 39.84 & 40.26 & 36.11 & 32.58 \\
\hline Bosniaks Total & 100 & 100 & 100 & 100 \\
\hline *all numbers are valid percentages of total number of participants & & &
\end{tabular}

In this sample of the Bosnian Muslim population, 36\% of the respondents indicated that they have Montenegrin friends, and $82.6 \%$ of those are Muslim, while $17.2 \%$ are non-Muslim. These numbers show that some Bosniaks do differentiate between themselves and other Slavic Muslims from Montenegro. Again, this is especially interesting in the case of New York, where, as noted earlier, most of the participants come from the two towns in northern Montenegro. Among them, $44.2 \%$ responded that they have Muslim Montenegrin friends, while 28.8\% noted non-Muslim Montenegrin 
friends. Therefore, they are ready to see Montenegrin Muslims as a distinct group, apart from Bosnian Muslims or Bosniaks. Yet that should not be a surprise, because even in the Sandžak part of Montenegro, the differences among those Muslims who see themselves as Bosniaks and those who are Montenegrins are sometimes expressed vocally. ${ }^{426}$

When it comes to friends who are Serbians, $29.3 \%$ of respondents indicated that they have Serbian friends. Of that number, $74.5 \%$ are non-Muslims, and $25.6 \%$ are Muslims. Again, about the same number of respondents see non-Bosnian Muslims as different from Bosnian Muslims.

In this sample of the population, $34.8 \%$ of respondents indicated having a Croat friend, and of them, $73.1 \%$ are non-Muslims while $26.9 \%$ are Muslims. As with their Serbian and Montenegrin friends, we can see the differentiation between Serbian and Croat Muslim friends, since the same question also contained a separate box for Bosniak friends. Even among those with Bosniak friends, some $10 \%$ of respondents indicated they have non-Muslim Bosniak friends. These responses correspond to answers to Question REL 49, asking if Catholics or Orthodox Christians can be Bosniak, to which some 65\% responded "Yes."

\section{7-7-5: Participant Attitudes Toward Traits of the Group}

Most respondents in the sample selected White as their racial category, while only $1 \%$ of respondents selected the non-white option. ${ }^{427}$ Another question dealing with race,

\footnotetext{
${ }^{426}$ Halep (2013) mentions the complaint of the Muslim Council of Montenegro (Muslimanski Savjet Crne Gore) that Bosniaks are trying hard to assimilate Montenegrin Muslims into Bosniaks. Also, see Rastoder 2010, p.483.

427 Two respondents selected Black, and five selected other.
} 
SD 27, used as an indicator of the Nationalism Type Index, is, "Can a non-White person be Bosniak?" (for more, see Appendix A, p.6, Question 27). Respondents were offered four choices, with $16 \%$ of them responding "No" another $15.4 \%$ selecting "I don't know" ${ }^{428}$ the next $17.9 \%$ responding "Yes, but under certain conditions" and the remaining 50.8\% responding "Yes" If the last two options are collapsed into one, it shows that a clear majority of $68.7 \%$ of respondents do not see Bosniak racial identity as exclusively White. ${ }^{429}$ The percentage grows to 84.1 if the last three options are combined. The initial reaction to this kind of population sample response is that such a racially open notion of Bosniak identity is probably influenced by life in the U.S., and exposure and interactions with other races. ${ }^{430}$ However, as noted by observers, some other groups, such as Irish or Italian, with a much longer presence in the U.S. and history of interactions

\footnotetext{
${ }^{428}$ The option "I don't know" is considered different from the option "No," because it is not the rejection of a notion. It is not an acceptance of it, either, but more importantly, since Bosnian Muslims are overwhelmingly white, the option "I don't know" is interesting in that it does not flatly reject the notion of a non-white person being Bosniak.

${ }^{429}$ This is particularly interesting, since it might be expected that Bosnian Muslims are affected by the racially exclusive attitudes of their neighboring Slavic nations of Croats, Serbs, Slovenes and Montenegrins. However, in these relations with their Slavic neighbors Bosnian Muslims are often seen as others, possibly as "blacks." Although some might argue that Bosnian Muslims will adopt the same in-group exclusive racial attitudes as their neighbors, from the results of this sample it is obvious that the opposite is the case. This could therefore indicate that Bosnian Muslim people's nationalism rejects Germanic and Uvarov's (and Khomyakov's) 1860s concept of a nation built upon the tie between race and religion, largely adopted by other neighboring Slavic groups. An example of such an approach is Khomyakov's conception that "the Slav cannot be fully a Slav without Orthodoxy" (Leatherbarrow and Offord 1987, p.1860). For more on Germanic and Uvarov's concepts of a nation, see the literature review chapter of this dissertation, especially notes on Perkins 2004, p.292, and Woolf 1996, pp.20-21.

${ }^{430}$ This also could be the result of the discrimination Bosnian Muslims face because of their religion. In the post-9/11 U.S., they are of the "right skin color [but of the] wrong religion," as Martin (2008) noted, and it could be that Bosnian Muslims in the U.S. internalized that ambiguity of what race they are, in the highly racialized reality of the U.S.
} 
with other races, do not have such racially relaxed attitudes towards their national identity. Therefore, an answer should be sought for elsewhere. ${ }^{431}$

Besides race, another set of questions was asked regarding acquired vs. given traits. To the question, "Can a person be Bosniak even if he or she does not have any Bosniak parent?" respondents were offered five choices. Some $23.2 \%$ responded with "No," followed by $7.2 \%$ who responded with "Not so easy," while $25 \%$ selected "Maybe yes," while the largest group, $42.9 \%$, responded "Definitely yes." If the last three answers, all possible versions of yes, are collapsed into one, then $75.1 \%$ of the respondents in this sample of the population view Bosniak identity as acquired and not as given (for more, see Question NAT 15 frequencies, in Appendix B).

\section{7-7-6: Bosnian Muslims as an Endogamous Group}

As a part of the Nationalism Type Index indicator of the perception of gender and Bosniak identity, Question NAT 16 asked, "Which parent is more important to be Bosniak?" Such a question might be especially interesting in light of the diaspora conditions that many Bosnian Muslims now live in around the world, with some of them even possibly living with non-Bosniak partners. Some $51.9 \%$ answered that both parents are equally important for a person to be seen as an a priori Bosniak. ${ }^{432}$ Almost $10 \%$ selected "mother" as more important, while $21 \%$ selected "father." "Neither is important"

\footnotetext{
${ }^{431}$ As discussed in the chapter on the history of Bosnian Muslims as a group, during the $18^{\text {th }}$ and $19^{\text {th }}$ centuries, when the ideology of nationalism began to reach Balkan shores, Bosnian Muslims had until that point been facing a different trajectory than their Slavic non-Muslim neighbors because of their different history. On the other hand, the Serbian view of a nation is based on Uvarov's ideas and Khomyakov's $19^{\text {th }}$ century epistle for a Slav nation, urging the exclusive unity of Slavs and Orthodox Christianity (to read the entire epistle, see Leatherbarrow and Offord 1987, pp. 93-4).

${ }^{432}$ The situation when a self-naming individual considers that his/her membership in a group does not entail any particular action, and as such, it is an a priori state of being, as Shills (1982) would argue. (p.19).
} 
was the response of $17.1 \%$ (for more details, see Question NAT 16 frequencies, in Appendix B). Therefore, if the first three options, that at least one Bosniak parent is important for a person to be Bosniak, are collapsed, $82.9 \%$ of respondents consider parentage important. On the other hand, responses may also be seen as $49 \%$ noting that having one or neither parent who is Bosniak is acceptable for a person to be an a priori Bosniak. If we can generalize from this sample of the population, it appears that Bosnian Muslims are somewhat ready to accept the reality of their current conditions, and to welcome as co-nationals new members and children from all those relationships. ${ }^{433}$ Such acceptance is more likely to be geared towards persons coming from relationships where the Bosniak parent is the father.

$\mathrm{BiH}$ is often described as a place of many ethnically mixed marriages. ${ }^{434}$ If that is correct, that possibility should be more commonly found among urban populations, where interactions are more frequent and such mixing is more possible. ${ }^{435}$ Since overall, Bosnian Muslims were more urban, compared to the other two largest $\mathrm{BiH}$ groups, then such phenomena should be more frequent among them as well. Furthermore, questions about marriage are usually asked as one of the factors of social distance, which is an

\footnotetext{
${ }^{433}$ Without reference to a source of information, in her interesting work, Simmons (2002, p.628) notes that the $\mathrm{BiH}$ capital, Sarajevo, had some $30 \%$ of mixed marriages, the highest percentage in the former Yugoslavia. If this information is correct, it might suggest that Sarajevo was very different from the rest of $\mathrm{BiH}$. But Simmons herself wonders "whether all Sarajevans or, perhaps more significant, whether all Bosnians (and Herzegovinians) shared these attitudes" (p.632). This is also potentially important, since other previous observers of Bosnian Muslims, as the now dominant group in $\mathrm{BiH}$, noted explicitly that they are an endogamous group. We can see that such a notion is changing, if it was ever completely accurate.

${ }^{434}$ Although a study done by Botev (1994) already effectively challenges that notion, showing that reports of mixed marriages in the former Yugoslavia were exaggerated. The same is suggested by O'Loughlin (2010, p.54) who notes only $6.5 \%$ of mixed marriages among Bosniaks in his study on inter-ethnic friendship in $\mathrm{BiH}$.

${ }^{435}$ In this sample, a large majority of respondents who are married to non-Bosniak/Muslim partners are from urban areas.
} 
important aspect of the type of nationalism since it may signal a group's norms of inclusion and exclusion. For this research questions about marriage were used as an indicator of the Nationalism Type Index as well; however, it is also relevant to evaluate the endogamous aspect of Bosnian Muslims as a group. ${ }^{436}$

The numbers in this study confirm Bosnian Muslims as an endogamous group, and further problematize the notion of mixed marriages in BiH. Question SD 18 asked, "If married, your husband/wife is?" with eight possible nationalities offered as answers. A majority, $66.4 \%$ of respondents, are married to Bosniaks. Another $20.9 \%$ are married to Muslims (who could be viewed as members of the same group). Only $0.8 \%$ are married to Serbs, and even fewer, $0.5 \%$, are married to Croats. Another $0.5 \%$ are married to Albanians. A slightly larger number, $1.2 \%$ are married to Americans, and lastly, $1.5 \%$ are married to someone from another background. Finally, $8.3 \%$ of respondents are not married. If the first two responses are collapsed, the percentage of respondents married within the group is an overwhelming $87.3 \%$. Again, in this sample of the population we have a larger number of participants from rural settings; however, the number of those with spouses who are group-outsiders is so small that even this rural/urban sample imbalance cannot make up for obvious endogeneity. ${ }^{437}$ Even if all cases of marriage to a group-outsider are combined, they still make up only $3.7 \%$ of respondents. These numbers about marriages could mean two things in terms of the data used for this study.

\footnotetext{
${ }^{436}$ Although many people could have been divorced and remarried after the war, the numbers of in-group spouses is overwhelmingly high, and this is more likely than not a condition which existed even before the war.

${ }^{437}$ Indeed, all of those married to Serbian spouses are from urban settings, while all of those married to Croats come from rural areas. Finally, in this sample of the population, those from urban areas are also those more commonly married to an American spouse.
} 
First, they could mean that the often-repeated notion about many mixed marriages in $\mathrm{BiH}$ is incorrect. However, they could also mean that people in these mixed marriages are not interacting with Bosnian Muslims in the settings where data was collected, and so they are unrepresented here. Perhaps those people in mixed marriages often interact with other couples like themselves, or with other Bosnian groups besides Bosnian Muslims. When they interact with other Bosnian Muslims, it is mainly in private settings, as was hinted to me by some participants. In any case, the low numbers of those married to a spouse from outside of the group in this data set further challenges the notion of $\mathrm{BiH}$ as a country with many mixed marriages.

The result from another question, SD 20, about family members, confirms such a group characteristic. Although participants were asked to check as many options as apply, and therefore a person might have checked multiple boxes, a consistently high choice of the response "no family members from outside groups" confirms the results of the previous question, as well as conclusions about Bosnian Muslims as an endogamous group and the problematic notion of the $\mathrm{BiH}$ mixed marriage situation. The largest nonBosniak group with whom this population sample mixes is Americans, with whom $20.1 \%$ of respondents have some family ties. That might be expected since this is a sample drawn from the group's diaspora situation, where there is no previous history of hostility between them and the national majority group. ${ }^{438}$ The other three groups of friends are from the neighboring homeland groups, and it is interesting that mixing is less common with Albanians (11.9\%) who are the closest mainly-Muslim nation, than with the other

\footnotetext{
${ }^{438}$ The same effect among different American communities is noted by Herb and Kaplan 1999, p.11.
} 
mainly-non-Muslim Balkan Slavic groups, the Croats $(16.8 \%)$ and the Serbs $(15.8 \%){ }^{439}$ The smallest number of respondents, $11.8 \%$, indicated family ties with people from other immigrant groups; however, they are mainly of the Islamic faith as well (almost $70 \%$ of them). Since these numbers are not exclusive for each group, and respondents could have checked more than one option, the same respondent could have ties with multiple groups, and that is why only these numbers of contacts for each group are reported separately here (for more detailed percentages, see Question SD 20 frequencies in Appendix B). Furthermore, even the previously discussed question on friendship indicates a larger social distance from their Slavic neighbors, and in such situations marriages are also less likely.

Another part of the Nationalism Type Index that might confirm the endogamous aspect and speaks about the level of social distance of the group is two hypothetical questions. The first, SD 22r, asks, "If you have a child, would you approve of him or her marrying a non-Muslim person?” A large majority of respondents, 87.4\%, answered no, while $12.6 \%$ answered yes. Approval was higher in response to the second question, SD 23: "If you have a child would you approve of him/her marrying a Non-Bosnian Muslim/Bosniak person?" meaning it could be another Muslim, just not a Bosnian Muslim (for more, see Appendix C, p. 6, question SD 23). A majority, 55.8\%, answered no, while $44.2 \%$ responded with yes. Although again the majority would not approve of marriage with an out-group person, the difference between the "yes" and "no" group is

\footnotetext{
${ }^{439}$ In fact, for both Serbs and Croats, a small percentage of Serb Muslims and Croat Muslims are indicated as family or friends. Those Bosnian Muslims who checked such options obviously see the difference between their group and other Slavic Muslims. It should be noted here that a marriage connection in a local context, for some, does not constitute a family tie with the spouse's family, as I was told by several participants.
} 
much smaller (for more details, see Appendix B frequencies for Questions SD 22r and SD 23). All these indicators of social distance suggest a higher sense of homogeneity among Bosnian Muslims as a group, as well as a strong sense of social distinctiveness for this sample of the population. Such a conclusion about the endogeneity and somewhat restricted rules of group membership might indicate a higher possibility of cooperation among members. ${ }^{440}$ Such conditions of a restricted entry/exit mechanism for the Bosnian Muslim group are particularly important for a group in diaspora conditions. All groups consist of vertical and horizontal associations. The main concern of this study is the horizontal associations of the Bosnian Muslim group. The main characteristic of these horizontal associations is a somewhat restricted entry/exit mechanism for members. Although ethno-national associations usually have built-in primordial-like or "given" elements, the penetration of modernity has significantly altered such elements (Habermas 1998, pp.115-7). This alteration of the foundational elements of a group is especially significant in the case of a group in the U.S. "melting-pot" diaspora situation, in which membership in a group is significantly more voluntary, and association increasingly more horizontal. Therefore, this finding regarding still restricted entry/exit mechanisms for the Bosnian Muslim diaspora group is an important factor, as it may suggest not only a possibility for group cooperation, but also a possibility for the further existence of the group.

\footnotetext{
${ }^{440}$ As Ahn et al. (2008) suggested in their experimental study on endogenous groups' entry/exit mechanisms. Although they limit their conclusions to midsize groups, and nations are certainly not that, some aspect of their conclusion may apply in this case as well.
} 


\section{7-7-7: Participants' Perceptions about Bosnian Muslim Culture}

Culture is the prime element of any nationalism, and several questions on the survey, which are included in the Nationalism Type Index, tried to gauge perceptions about Bosnian Muslim culture. One question, CULT 10, asked whether the culture is primarily Islamic, primarily Slavic, or both Islamic and Slavic. $43.4 \%$ of respondents perceive it as primarily Islamic, while only $2.1 \%$ perceive it as a primarily Slavic. The largest number of respondents, $54.5 \%$ thinks it is both Islamic and Slavic (for more, see Appendix B, Question CULT 10, frequencies). Answers to this question are potentially important for the measure of the social distance Bosnian Muslims feel from their Balkan Slavic neighbors. This is not surprising, since their Slavic Bosnian language is the primary expression of Bosnian Muslim culture, and even their Islamic heritage is internalized and expressed through that language, which is now one of the pillars of Bosnian Muslim nationalism.

To further explore perceptions of their culture, respondents were asked to rate the subjective importance of five common elements of culture: language, religion, literature and art, customs and tradition, and cuisine. Using a Likert-scale type option, respondents could select a number from one to five, with 1 being the most important, and 5 the least important. The most important element for this sample of the population is religion, followed by language, customs and tradition, cuisine, and the least important, literature and art (for more, see Table 7.6). Therefore, when we combine answers about the primacy of Islam vs. that of Slavness, and the importance of different aspects of culture, we get an interesting mix, where most participants feel that Bosnian Muslim culture is 
Islamic and Slavic, while the religion of Islam is the most important element of the same culture. It is not surprising, then, that to Question REL 50, also an item of the Nationalism Type Index, which asked, "How important is it that a Bosniak is religiously a Muslim?", only $15 \%$ of participants responded that it is not important, while $83.5 \%$ consider it important.

Table 7.6: Individual Ranking of Importance of Five Elements of Culture

\begin{tabular}{lccccc}
$\begin{array}{l}\text { (N=607) } \\
\text { a:Values }\end{array}$ & Language & Religion & Literature \& Art & $\begin{array}{l}\text { Customs \& } \\
\text { Tradition }\end{array}$ & Cuisine \\
\cline { 2 - 6 } Mean & 4.02 & 4.27 & 2.52 & 3.32 & 2.75 \\
Standard Error & 0.05 & 0.05 & 0.06 & 0.05 & 0.06 \\
Standard Deviation & 1.22 & 1.3 & 1.51 & 1.25 & 1.4 \\
\hline b: Respondent Percentages: & & & & & \\
Not so important & 5.2 & 4.2 & 25.7 & 16.3 & 20.9 \\
Least important & 7.7 & 9.3 & 23.3 & 9.1 & 36.6 \\
Important & 11.5 & 5.3 & 22.1 & 31.9 & 16.2 \\
Somewhat important & 29 & 13 & 10.5 & 19 & 7.2 \\
Most important & 46.6 & 68.2 & 18.4 & 23.7 & 19.3 \\
Missing & 6.6 & 6.2 & 8.1 & 7.4 & 8 \\
\hline *all numbers are percentages of total number of participants & & &
\end{tabular}

However, while religion is obviously an important pillar of Bosnian Muslim nationalism, it appears that it is not a restrictive factor for this population sample. Question REL 49c, also used as an item on the Nationalism Type Index, asked for the participant's opinion on whether a Bosniak could be a Catholic or an Orthodox Christian. While such a large percentage of respondents indicated that it is important that a Bosniak be religiously Muslim, their solidarity can go beyond religion, since more than half of them, 65.4\%, also responded that a non-Muslim could be Bosniak as well. These answers provide further evidence that, for the majority of respondents, acquired traits are more important than those which are "given" at birth and indicate a leaning towards the civic 
pole of the Nationalism Type Index in this population sample (for more, see Appendix B, frequencies for Question REL 48c).

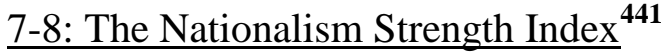

For this sample of the Bosniak population, the internal consistency reliability composite score for the seventeen indicators included in the Strength of Nationalism construct is acceptable $(\alpha=0.68)$, and it shows that all the items combined from the data do work together to measure the same concept intended to be measured. It is slightly lower than the often-mentioned exploratory study cut-off score of $\alpha=0.7$ (Nunnally, 1978, p. 245; Lance et.al., 2006, p. 205). However, since all of the remaining items are theoretically important, as such they were all kept as part of the construct. Furthermore, as suggested by Khamis (1988, p. 178), the large enough sample size might perhaps allow a slightly lower $\alpha$. The mean score on Nationalism Strength for the population sample is $0.005(\mathrm{SD}=0.4)$. The range is 2.23 , with a minimum score of -1.34 and a maximum of 0.89 . The median score is 0.06 , and the lower value of mean suggests an overall lower intensity of nationalism among this population sample, although the sign is still positive.

\footnotetext{
${ }^{441}$ Since variable values used for this construct of nationalism are on different scales, they were first standardized, where all means are computed as zeros, and then values of each item are given, based on the mean's standard deviations for each item. Therefore, while a Z- score mean indicates negative correlation, the true mean score for the construct is not necessarily negative. Although a Z-score computed in this way does not necessarily represent the true intensity of the variable, it does tell us whether a particular score is equal to the mean, below the mean or above the mean of multiple scores for an item, and whether the intensity of a phenomenon is higher or lower. Furthermore, since it is not the true score, it is useful also to report the median score because it allows a clearer picture of the tendencies towards the construct among the respondents. An homogenized Z-score can also tell us how far a particular score is away from the mean score for the item, and the direction in terms of the mean. Although Z-scores may be large, most of them are within the range between -3 and 3 , where the value of 0 is considered to be the mean score.
} 


\section{7-9: Frequencies of Nationalism Strength Index Items}

\section{7-9-1: Attitudes Towards Fellow Slav Muslims Outside of BiH}

The issues about Muslims from Sandžak, in a different way and with two other questions, are also part of the Nationalism Strength Index. Question PC 36c asked whether or not Muslims from Sandžak should be allowed to vote in $\mathrm{BiH}$ elections. Besides the texture and type of nationalism, the attitude towards Muslims from Sandžak is therefore also useful for measuring the intensity of nationalism among respondents. If the previous question, which asks how much a person feels Bosnian measures the participant's attitude towards Bosnia, this question provides a clue as to how $\mathrm{BiH}$ is seen by them, more precisely, to what extent they see $\mathrm{BiH}$ as their national state, and whether, driven by the intensity of that feeling, they include Muslims from Sandžak (and outside of $\mathrm{BiH}$ ) in that vision of $\mathrm{BiH}^{442} \mathrm{~A}$ majority of $67.1 \%$ responded yes, while a still large $32.9 \%$ answered no. These numbers provide a reason to see participants as having a healthy dose of nationalism since it shows that many view $\mathrm{BiH}$ as a Bosnian Muslim national state, even though it is shared by two other national groups. However, the relatively large percentage of "no" responses feeds the uncertainty among Muslims in Sandžak towards $\mathrm{BiH}$ as a crucially important factor for the Bosniak nation. ${ }^{443}$

\footnotetext{
${ }^{442}$ This question is based on the reality that the other two groups, by and large, can participate in the elections in their national states across the border. So 300,000 Bosnian Croats can participate in the elections in Croatia (Hockenos 2003, p.8), and many Serbs from Bosnia with very little bureaucratic maneuvering can participate in the elections in Serbia. Only Bosniaks from Sandžak cannot join their conationals in voting and participating in the elections in their imagined national state of $\mathrm{BiH}$, and so the question measures attitudes towards that issue.

${ }^{443}$ The prime example of those vacillations is the strongest Muslim party from Sandžak, led by Rasim Ljajić, which is one of the best-maneuvering parties in Serbian politics; their leader loses no opportunity to emphasize that Muslims from Sandžak are part of the Serbian state and that they see Serbia as their state as well. Furthermore, some imams even created a separate organization in Serbia, apart from the IZBiH, to
} 
Similar attitudes are observed in the responses to another question, PC 35c, which is also an item included in the Nationalism Strength Index. In response to the question "For you, Muslims from Sandžak, in terms of nationality, are?", out of eight options, 65.8\% of respondents see them as Bosniaks, and $28.5 \%$ see them as something else, while 5.8\% responded "I don't know." Again, these numbers reveal the desire to embrace fellow Muslims from outside of $\mathrm{BiH}$ into the Bosnian Muslims' national project, but it also shows a certain hesitation towards them as well. However, considering that $82.2 \%$ of all respondents who see them as Bosniaks are from BiH territory, such a reality provides further support for the first option that Bosnian Muslims want to embrace their fellow Slav Muslims from Sandžak into their national project. This is even more obvious in responses to Question PC 37c, on Bosnian Muslims' non-state national organization. To the question "Should Bosniaks/Muslims from Sandžak be allowed to vote in the elections for Bosniak/Bosnian Muslim national organizations?" an overwhelming $82 \%$ of respondents indicated yes, signaling that their community imagination extends beyond the border of BiH, and that they do see Muslims of Sandžak as their co-nationals (for more details on PC 35c, PC 36c and PC 37c, see frequencies in Appendix A).

\section{7-9-2: Regional and Schooling Frequencies}

Since many studies of nationalism consider schools as temples of nationalism, an effort was made to account for schooling within and outside of $\mathrm{BiH}$, considered to be the

\footnotetext{
represent their interests as Muslims from Serbia. Although they are challenged by another branch, led by a mufti appointed by the IZBiH, their effort certainly signals uneasiness in Muslims from Sandžak regarding the $\mathrm{BiH}$ state as their only option for a national state as homeland for Slavic Muslims or Bosniaks. Muslims from the Montenegrin part of Sandžak separated from IZBiH even before their colleagues on the Serbian side. Their IZ of Montenegro has its own unchallenged Reis ul Ulema and subsequent organizational structure, recognized by the state as the exclusive representative of Muslims in Montenegro.
} 
homeland of Bosnian Muslims (see Table 7.7). ${ }^{444}$ Education is measured by the selfidentified years and place of schooling of respondents. In $\mathrm{BiH}$, as in the rest of the former Yugoslavia, elementary school lasts eight years, high school four, and college can be finished in four years, even though for many it often takes longer.

Table 7.7: Respondent's Place of Schooling*

\begin{tabular}{lccc}
\hline & Elementary & High School & College \\
\hline BiH (outside of capital) & 64.9 & 44.7 & 5.9 \\
Sarajevo (capital) & 10.1 & 13.3 & 9.6 \\
Serbia & 7.2 & 6.5 & 3.8 \\
Montenegro & 8.6 & 6.2 & 0.6 \\
Croatia & 1.1 & 2.1 & 0.9 \\
USA & 3.5 & 10.1 & 16 \\
Other & 3.8 & 4.7 & 4.4 \\
*all numbers are percentages of the total number of participants & &
\end{tabular}

Of this sample of the population, 664 participants, only 29\%, studied exclusively in $\mathrm{BiH}$, while the rest were exposed to schools outside of $\mathrm{BiH}$. Of the $11.4 \%$ of respondents with elementary school only $75 \%$ attended school in $\mathrm{BiH} ;{ }^{445}$ of the $87.5 \%$ with high school, $66.3 \%$ attended school in $\mathrm{BiH}$. A relatively high number of participants, $41.9 \%$, have a higher education, and of that number, $37.7 \%$ studied in $\mathrm{BiH}^{446}$ while $16 \%$ studied in the USA. ${ }^{447}$ As mentioned earlier, the high number of those who attended college in the sample is the legacy of Communist rule, where education was not only free

\footnotetext{
${ }^{444}$ For example, in her dissertation, Naomi (2009) effectively argues that the place and context of schooling, as well as the language used in schools, do affect issues of group belonging, such as nationalism and identity ascription, among younger people in BiH today (pp.152-56).

445 Only 0.9 percent of them indicated that they are without any school.

${ }^{446}$ From the answers, we can assume that respondents finished school in the place they indicated; however, it is possible that a person might have started school in one place and finished it in another.

447 This is indicative information for those in the U.S who treat a college degree as an indicator of class status. Following preliminary observation by Hill (2016) and considering probable problems with such classification, this study refrains from such characterization and, rather, reports only their level of schooling, treating it as a controlled variable by itself without referring to it as an indicator of class.
} 
but encouraged. ${ }^{448}$ Only during the rule of Communism did Bosnian Muslims, as well as other nationalities in the former Yugoslavia, finally achieve very high rates of literacy. ${ }^{449}$ Education and literacy are those often-noted preconditions of nationalism, and they are certainly factors in the growth of national consciousness in Bosnian Muslims as well. It may be argued that a major reason that stronger nationalism could not happen earlier for them is precisely the very high levels of illiteracy and lack of mass education among Bosnian Muslims. Only after WWII did the Communists push hard to increase literacy in the population and enforce a mandatory school attendance policy for boys and girls. ${ }^{450}$ Public schools did exist before the war; however, Muslim children, and especially girls, rarely attended those schools, particularly outside of the big urban centers. ${ }^{451} \mathrm{With}$ the Communist takeover, that changed and school attendance became mandatory. The mean age of the sample population, 44.8 years $(\mathrm{SD}=12.4)$, shows that the main group of respondents is from the Communist-ruled era of mass education.

\section{7-9-3: Culture and Ties to the Homeland}

Since the sample of the population is drawn from a diaspora group, to measure the impact of the homeland's cultural effects on respondents, two questions, included in the Nationalism Strength Index, asked about how often they read Bosnian literature or watch

\footnotetext{
${ }^{448}$ A study conducted among the Bosnian diaspora in the U.S. by the Center for Applied Linguistics in 1996 found a similarly high number of participants, some 36\%, with a college degree, and $45 \%$ with a high school degree. For more, see Dimeo and Sumach 1996.

${ }^{449}$ Malešević (2006), for example, notes that the literacy rate in $\mathrm{BiH}$ “jumped from 55\% in 1948 to over $90 \%$ at the end of the $1980 \mathrm{~s} "$ (p.214).

${ }^{450}$ The distribution among those who have attended college is larger among women $(60.5 \%)$ than among men, while a larger percent of men attended elementary or high school only.

${ }^{451}$ See, for example, Vuković 2000, pp.35-7.
} 
Bosnian films or TV. The assumption is that the more often they see or read the news from back home, the more intensity of nationalism they might feel, since those news reports mostly use the language of nationalism to convey their messages. ${ }^{452}$ There were five options to respond for both questions: 1 = Never; 2 = Rarely; $3=$ Occasionally; $4=$ Often; and 5 = Very Often. The results for both questions are fairly similar. Regarding Bosnian literature, the mean is 3.39 ( $\mathrm{SD}=1.16)$, and for film or $\mathrm{TV}$, the mean is 3.24 $(\mathrm{SD}=1.27)$ (for more, see Table 6.1a). The results show that this sample of the Bosnian Muslim diaspora is still connected to cultural productions from the homeland and to the effects of what Anderson (1993) calls "print capital" in creating national imaginings, and the transformed nature of modern media has enabled that connection even further. ${ }^{453} \mathrm{~A}$ great number of viewers is needed to measure the impact of such structures on group maintenance. In that sense, information on how often group members watch news from back home, in addition to the number of local ethnic media outlets, is important. Furthermore, it is useful to ask whether they follows the news, not just any television programming, since watching info channels provides an increased possibility for political participation, even from a distance, while watching only entertainment decreases that likelihood. $^{454}$

Furthermore, such a connection was also observed in the responses regarding where they get their news about $\mathrm{BiH}$. An overwhelming number of respondents, $83.6 \%$,

\footnotetext{
${ }^{452}$ See Obradović et al. (2014).

${ }^{453}$ Džihana et al. (2012, p.29) note that, while newspaper reading was never widespread in BiH, TV dominance there slowly gave way to the increasing use of the internet and other digital media so, in that sense, the back-home population is becoming more like the diaspora population in terms of access to media sources.

${ }^{454}$ See Fenneme 2004, pp.442-3.
} 
indicated $\mathrm{BiH}$ media as a source of news (for more, see Appendix A, PC 32c frequencies). Although they were not asked, "How often do you read the news?," it may still be concluded that the significant number of respondents who do read the news, are informed about $\mathrm{BiH}$ news from the same media sources as the homeland population. It also means that this sample of the population, besides household interactions, has regular interactions with their mother tongue, ${ }^{455}$ which is one of the most important factors in Bosnian Muslim nationalism, as discussed above, and noted as well in their responses on the importance of elements of culture.

\section{7-9-4: Long-Distance Imagination and Engagement}

As argued in the chapter on extant literature, long-distance nationalism is a relevant approach to the study of the nationalism phenomenon, especially in the case of Bosnian Muslims, and particularly the possibility of absentee voting, which is predicated on citizenship in $\mathrm{BiH}$ and willingness to participate. ${ }^{456}$ "In fact, the transnational links of the Balkan diasporas [with their back-home national brethren] were strongest when used to further nationalist politics in the homeland" (Kostovicova and Basic 2005, p.588). In response to Question PC 34, 61.9\% of respondents indicated that they have voted in $\mathrm{BiH}$ elections at least sometimes. That suggests that they did have at least some contacts with back-home politics, an important factor for nationalism. Furthermore, since an

\footnotetext{
${ }^{455}$ Over $90 \%$ of respondents indicated that they speak the Bosnian language at home.

${ }^{456}$ In the literature on the logic of democracy, the cost of participation and the possibility of "free riding" are factors in individual deliberations on whether or not to participate in elections. Since such participation is irrational in terms of costs and benefits, participation is considered to be driven by the sense of nationalism, which Orwell (1953) correctly notes to be an irrational force. Therefore, the assumption here is that if participants have a strong sense of nationalism, they will assume the cost and participate in $\mathrm{BiH}$ elections. That is why this issue is part of the Nationalism Strength Index. For more on the logic of voting, see Dawns 1957, p.38; and on free-riding, see Olson 1971, p.21 and pp.60-65.
} 
overwhelmingly large number of participants, over 95\%, left the homeland after 1991, they have also experienced the initial wave of nationalism that swept the former Yugoslavia in the late 1980s and early 1990s, and might have participated in the first elections in $\mathrm{BiH}$, and more importantly, in the referendum for the independence of $\mathrm{BiH}$, which was held just before the war, on March 1, 1991. As mentioned in the previous chapter, the internationally recognized referendum was one of the most significant events in the recent history of Bosnian Muslims, one through which they regained the full ability to be the decisive factor when it came to the territory of $\mathrm{BiH} .{ }^{457}$ Finally, from the responses to Question PC 34, we can infer to some extent that the majority of the respondents themselves experienced the same traumatic experience of the Bosnian war as did the back-home population. More than $53 \%$ of the respondents lived in $\mathrm{BiH}$ during the Bosnian war, while an additional $12 \%$ lived somewhere else in the former Yugoslavia during the same period (for more, see Appendix A, Question PC 34 frequencies). These numbers indicate that this population sample is not far removed from the experience of the homeland population and that it may be used as a representative sample for the study of Bosnian Muslim nationalism.

\footnotetext{
${ }^{457}$ They lost their position of the most important population factor in $\mathrm{BiH}$ with the formation of the Kingdom of Serbs, Croats and Slovenes, and subsequent Yugoslavias in which the dominant roles were held by the Serbs and Croats, and where Bosnian Muslims were left only to declare themselves either Serbs or Croats, and in that way indirectly decide if $\mathrm{BiH}$ is Serbian or Croatian.
} 


\section{7-9-5: Bosnian Language and Intensity of Nationalism}

Since language is an important pillar of the Bosnian Muslim nationalism project, participants' attitudes about it are used as a part of the Index of Nationalism Strength. ${ }^{458}$ One more set of questions regarding the language further sheds light on the topic. Question LAN 57 asked, "How important it is for you that a Bosnian Muslim can speak the Bosnian language?" Participants had four options; "Not important at all," coded as 1; "Not important," coded as 2; "Somewhat important," coded as 3; and "Very important," coded as 4 . The sample mean of $3.81(\mathrm{SD}=0.52)$ suggests that this population considers language a strong factor for identification of Bosnian Muslims. An overwhelming 85.7\% of respondents answered that knowledge of the Bosnian language is very important. Additionally, for $88.7 \%$ of respondents, the Bosnian language is the primary language spoken at home. Only $4.8 \%$ of respondents speak English at home, and even fewer, $2.3 \%$ of respondents, selected Serbo-Croatian as the language spoken at home. Not surprisingly, most of the respondents, $95.8 \%$, answered that they can read and write in the Bosnian language, while only $46.5 \%$ indicated that they can read in English with no problem, 41.2\% can do so with difficulty, and $12.4 \%$ cannot read in English.

Another, bivariate question, LAN 58c, asked "Did it ever bother you that the name Serbo-Croatian language was the official language of the former Yugoslavia?" The majority, 54.5\% indicated "Yes," while the remaining $45.5 \%$ selected "No." Therefore, the issue of the name of the language does contribute to feelings of resentment and

\footnotetext{
${ }^{458}$ This is especially so since the diaspora population is aware - from the $\mathrm{BiH}$ media sources - that the issue of the language and its name is a contentious factor in $\mathrm{BiH}$ realities and many clashes occur over the right to call and use the Bosnian language in schools controlled by Serbs and Croats.
} 
suffering for this sample of the population. Since resentment and suffering are important factors that usually fuel any type of nationalism, this question about the name of the official language during the time of the three Yugoslavias ${ }^{459}$ may be one of the indicators for measure of resentment among the Bosnian Muslim population. ${ }^{460}$ Yet, the respondents see the Bosnian language as a "middle language," equally close to the Serbian and Croatian languages. When asked Question LAN 59r, "In your opinion, which language is closer to the Bosnian language?", 54.1\% responded "Both, Serbian and Croatian are close; the same." Serbian is closer was selected by $27.3 \%$, and Croatian by $8.3 \%$.

As there is no physical difference among the three peoples, differences are primarily religious and discursive, considerably less so linguistically, because the vernacular languages spoken by each different nation, for the most part, are mutually intelligible. Since the difference is partly discursive, the naming of a language becomes a crucially important factor because by asserting the right to name the language of their own group, that group asserts the right to its own essential form of groupness and the right to the land where they reside. It is not a surprise, therefore, that the name of the language becomes an issue that groups fight very intensely over, and they frequently

\footnotetext{
${ }^{459}$ Historically, the first was the initial Kingdom of Yugoslavia formed by King Alexander in 1921; the second was the Communist-ruled Yugoslavia, after 1945; and the third was the briefly lasting union of Serbia and Montenegro in the late 1990s, sometimes referred to as the "rump Yugoslavia" (for more on the rump Yugoslavia, see Crnobrnja 2002, p.228).

${ }^{460}$ This is especially the case for the peoples of the former Yugoslavia who all rushed to recreate and reorganize their languages to emphasize differences from previous language standards, and so old languages reappeared dressed with new structures and names. Each of the new states and constituting nations now has its own language and name for it, including Bosnian, Croatian, Montenegrin, and Serbian, while Macedonian and Slovenian were separate and official languages even during the time of SFRY. Furthermore, as pointed out by many different scholars, the issue of language was the primary pillar of all local Slavic nationalisms, even during the time of Austro-Hungarian rule of the region.
} 
deny the right of another group to name the language that they jointly use, after the name of that other group or territory. Bosnian Muslims feel the same way, especially since the standard on which the previously common language was built, actually originated in $\mathrm{BiH}$, and for that reason the question was included in the survey. ${ }^{461}$

\section{7-10: Controlled Variables Distribution and Frequencies}

\section{7-10-1: Gender and Representativeness}

The self-identified gender distribution of the population sample is $60 \%$ male and $40 \%$ female respondents. It should be noted that it was much harder for me, as a male investigator, to reach females. Most of the places where Bosnian Muslims interact socially, where I was trying to recruit participants, are usually male-dominated. ${ }^{462}$ The data reflect this gendered social reality, as may be observed from the participants' responses to a question regarding involvement with Bosnian organizations, since women

\footnotetext{
${ }^{461}$ The unity of the several main dialects of the local spoken Slavonic languages was declared a few times: first in Vienna in 1850, when Vuk Karadžić and Đuro Daničić, met with several prominent representatives of the Illyrian movement of Croatia and decided jointly to standardize all dialects of the language spoken by local Slavic peoples and push for their harmonization based on the standards of a middle dialect spoken in East Herzegovina. The second time was at the convention in Novi Sad in 1954, when they adopted the name Serbo-Croatian or Croato-Serbian for the name of the language in addition to some common standards for it. However, both times the decisions were made by representatives of the Serbs and Croats, without any Muslim member present. This is probably the result of their ambivalent perception of Slavic Muslims, who were often seen as "Turks," and at other times as "our Mohamadan brothers" (the adjective "our" is used to avoid saying whether they were specifically Serbs or Croats, or later Montenegrin, and to leave it open for Muslims "to decide"). For Bosniaks today the fact that they were left out of those deliberations about the common language represents an example of their neglect by both groups, and it is often noted by the national tribunes as an example of the Serbs' and Croats' intent to deny their group altogether (for more on the process of standardization, see Alexander 2006, pp.382-86).

${ }^{462}$ The same situation was actually carried-over from the back-home context, as noted by Croegaert (2011) "although increased urbanization and intensification of industry in Yugoslavia during the 1960s and 1970s drew more women onto the factory floor and into urban commercial life more broadly, public social spaces - streets, coffeehouses, and taverns-were still most often gendered male spaces. Women might work as servers and entertainers in such spaces but rarely occupied them as patrons" (p. 468). This was especially true in the small cities and towns in $\mathrm{BiH}$, where the majority of the general population of $\mathrm{BiH}$ Muslims has lived and from where the majority of this sample population comes (only about $10 \%$ are from Sarajevo, which was the only truly big city in pre-war $\mathrm{BiH}$ ).
} 
are much less likely to be involved with any type of organization than men (for more information, see Table 7.8). ${ }^{463}$ Furthermore, in mixed gatherings it was often difficult to talk and interact with women directly due to cultural norms that might consider such interactions with a stranger (researcher) problematic for the women, so they shied away even when I tried to engage them in conversation. So many female participants were recruited through their male counterparts. Female participation was slightly better when I tried to engage them in the social spaces where women are dominant, such as hair salons for women and women's social gatherings in restaurants and other settings. ${ }^{464}$

The critical literature has already warned us against an assumed stable groupness among a people going through the process of nationalism. The feminist approach, especially, argued persuasively that women and men do not respond the same to a crisis, and especially to the experience of nationalism. ${ }^{465}$ As women are very often disproportionately more the victims of the conflicts which usually accompany bursts of nationalism, ${ }^{466}$ it is important to consider their position vis-à-vis the group's nationalism

\footnotetext{
${ }^{463}$ Except for involvement with religious organizations where the percentage for both gender groups is relatively high, although still lower for female than male respondents. See Table 7.6.

${ }^{464}$ For example, during the field work, four gender-divided focus group interviews were conducted and women in those groups also completed questionnaires at that time. Also, some Bosnian mosques have women's study groups, and a few of them agreed to respond directly to the survey without male interlocutors. The analysis of the focus group discussions will not be reported in this dissertation.

${ }^{465}$ Although the focus of this inquiry is not to uncover the masculinity behind nationalism, which Enloe (2004, p.107) calls for, an effort is made to note how men and women respond to calls for collective action by a group by those who have a position of power, as well as differences in terms of the burden carried by women and men in the struggle to survive and assert oneself as a nation.

${ }^{466}$ This is especially true for Bosnian Muslim women, who were one of the primary targets of the Serbian and Croatian aggressions against the group. Sofos (1996) provides an example of the different gender experiences when she notes how the Serbian notion of nationalism saw male Muslims of Bosnia as those to be eliminated as "irremediable" souls, while Muslim females were potentially "remediable" by rape and impregnation.
} 
projects. ${ }^{467}$ Furthermore, if women were considered true members of a group and their voices and impact on a group's nationalism projects were considered of equal importance, many conclusions regarding nationalism perhaps would be different. This data also shows interesting differences in responses between male and female participants. For example, a much larger percentage of female respondents, $34.8 \%$, vs. $20.85 \%$ of men, selected other than Bosniak identity as a response to the question "What is your nationality?" A chisquare test between the two gender variables and choice preference for nationality shows that differences are statistically significant as well (chi-square with three degrees of freedom is 17.276 , with $\mathrm{p}<0.001)$. Yet the difference in intensity among those who selected Bosniak identity is not statistically significant. A question was asked about how strongly Bosniak respondents feel, and answers were collapsed to "Weak", "Strong”, and "Very Strong;" gender difference is statistically not important in terms of the responses to that question, and it may be concluded that both segments of the population sample are similar in that regard (see Appendix C, p.4, Q. 17).

Finally, women and men in this sample differentiate in terms of social engagement. Men are more likely to be engaged in at least one Bosnian Muslim organization (for more, see Table 7.8). Among 398 male respondents, $37.2 \%$ are not engaged in any organizations, while out of 265 female respondents, 46.4\% are not engaged with any Bosnian organization.

\footnotetext{
${ }^{467}$ A difference in nationalism-desired identity choice calculations among genders is also present for Bosnian Muslim women who cover their heads with the highly politicized piece of clothing, the hijab, because they have much less choice to hide their religious identity in the often hostile U.S. public sphere than their male co-nationals who, due to their whiteness, could if they do not speak, easily pass for just another white person. Robert Young described the U.S. situation well when he noted that "few items of clothing throughout history can have been given more meanings and political significance" than the Muslim women's hijab (as cited by Miskovic, 2007, p. 540).
} 
Table 7.8: Gender Distribution among Different Types of Organizations*

\begin{tabular}{lccccccccc}
\hline & $\mathrm{N}$ & Religious & Political & Social & Cultural & Sport & Professional & Other & $>1$ \\
\hline Female & 265 & 46.8 & 1.5 & 7.5 & 10.9 & 3 & 2.3 & 0.8 & 10.9 \\
Male & 398 & 53.3 & 5 & 10.8 & 11.3 & 9.8 & 2 & 1.5 & 17.8 \\
\hline *all numbers are percentages of the total number of participants of each gender group, except $\mathrm{N}$ & & &
\end{tabular}

Most of those women and men participants who are members of Bosnian organizations are part of religious organizations due to the nature of the religious structure of the IZBiH, which is a prime factor for the creation and maintenance of the sense of Bosnian Islam, which is discussed in a separate chapter. Furthermore, most, if not all, Bosnian Muslim-run mosques have a very structured membership culture. ${ }^{468}$ Those who are members do not have to be religious at all, but they regularly pay their dues (vazifa) which is usually a set amount of money per family depending on its size. In return, the $\mathrm{IZBiH}$, or in the case of the diaspora, a particular mosque, takes responsibility for the burial of any member of a family regardless of their religiosity. ${ }^{469}$ That is why in many sites where Bosnian Muslims came to live, they often bought property for a Bosnian Muslim cemetery before they built their mosques. Once they obtain property for the cemetery, the mosque then has a service to offer which is needed by everyone. In a way we can say that only after it acquires its own cemetery is the Bosnian Muslim mosque then truly open for business. ${ }^{470}$ The two primary services most Bosnian mosques

\footnotetext{
${ }^{468}$ An example of that structure is seen in regular reports about zekat (the yearly religious tax) collections, where ICNAB, the U.S. Bosnian jamaats (congregations) organization, for the last several years, has topped the list as the greatest contributors among all Bosnian Muslim world diaspora groups. For more information on ICNAB, visit their web site at: http://www.icnab.com. For zekat collections, see El-posta (2016).

${ }^{469}$ Bringa (1995) reported the same in her seminal work on Bosnian Muslims in BiH.

${ }^{470}$ In places in Europe closer to the homeland, instead of their own cemeteries, mosques would have strong relations with funeral service companies, "Bakije" or "Jedileri" (both operated by or in very close cooperation with the official $\mathrm{IZBiH}$ ), which provided transportation of the deceased person to $\mathrm{BiH}$ or
} 
offer are weekend schools for pre-K and elementary-school-age children (mektebs) ${ }^{471}$ and burial service. ${ }^{472}$ Besides these, most of these mosques now offer regular Friday and Bajram (Eid) prayers, and only rarely more than that.

Finally, in Table 7.8 we can see the overall engagement in formal and informal Bosnian Muslim organizations by the participants in this sample. Of the total number of participants, a large part $-44 \%$ - are involved with at least one organization, while $15.1 \%$ of the respondents are involved with more than one. These numbers combined show that more than half of this population sample are connected to other Bosnian Muslims through some type of organization, and those interactions recreate some backhome conditions of regular interactions among members. When that is considered in conjunction with the information on the sample's frequency of contacts with the backhome population, it becomes clear that both, U.S. and $\mathrm{BiH}$, populations are very much interconnected, and that ideas and norms of groupness may be and indeed are shared

Sandžak for burial back home. Vazifa that the member had been paying while he or she was alive covered most of the expenses for the funeral services at that time.

${ }^{471}$ Sometimes mekteb is also referred to as mejtef. The word mekteb is derived from the Arabic language term for elementary school. Mejtef, on the other hand is derived from the word mejt, meaning the body of a deceased person, and during the Communist era, often the same school space was used to keep the body of a deceased person, when needed, and to pray over it. Since the same spaces were used on weekends for schools, people began to refer to schools as mejtefs. It is an irony that religious weekend schools started to be referred to by such a term, yet the term has now persisted and those weekend schools are often referred to as mejtefs in addition to mektebs. Mektebs were officially outlawed by the Communist regime in BiH in 1950 (Hoare 2013, p.374), and they began operating again as weekend schools only on the eve of the Bosnian war.

${ }^{472}$ With the demand for these two primary mosque services, Bosnian Muslims and their Islam resemble the case of "Jewish ethnicism," where the majority of themalso "continue entering after birth the covenant of Abraham [with circumcision of boys and attendance at the basic school, mekteb], and finding after death a permanent resting place in a [Muslim] religious cemetery" (Baron 1971, p.241). 
among them regularly. ${ }^{473}$ This further supports the approach that nationalism should be studied in population diaspora situations, as well as among groups in the homeland (for more on the connections to the homeland population, see Table 7.9).

Table 7.9: Respondents Connection with Homeland*

\begin{tabular}{lrrrrr}
\hline $\begin{array}{l}\text { a: How often do you spend } \\
\text { time with Bosniaks? } \\
\text { (non-family members) }\end{array}$ & Never & Rarely & Sometimes & Weekly & $\begin{array}{r}\text { Every } \\
\text { Day }\end{array}$ \\
& 0.2 & 1.8 & 18.1 & 26.7 & 52.4 \\
\hline $\begin{array}{l}\text { b: How often do you talk to } \\
\text { someone in Bosnia/Sandžak? }\end{array}$ & Never & Rarely & Sometimes & Weekly & $\begin{array}{r}\text { Every } \\
\text { Day } \\
26.1\end{array}$ \\
& 1.4 & 4.4 & 26.7 & 40.5 & $\begin{array}{r}\text { I live } \\
\text { there }\end{array}$ \\
\hline $\begin{array}{l}\text { c: How often do you travel } \\
\text { to Bosnia/Sandžak? }\end{array}$ & Never & Occasionall & $\begin{array}{r}\text { Every } \\
\text { other year }\end{array}$ & $\begin{array}{r}\text { Every } \\
\text { year }\end{array}$ & y \\
& 8.3 & 47.2 & 27.2 & 15.1 & 2.1 \\
\hline *all numbers are percentages of total number of participants & & & & &
\end{tabular}

\section{7-10-2: Gender and Traits of Bosniak Identity}

The responses from this sample of the Bosnian Muslim population suggest that both genders have the same attitudes towards the acquired and given traits of Bosniak identity discussed earlier. However, a difference comes in the realm of political consciousness and perceptions of in-group differences, both important parts of any case of nationalism. For instance, both genders in this population sample answered the question on race similarly, where the majority in both gender groups think that non-white

\footnotetext{
${ }^{473}$ Individual membership in an ethnic organization constitutes a bonding type of connection (Putnam 2000), while membership in multiple organizations constitutes bridging connections (Fenneme 2004). Therefore, we can see that a larger number of members in only one organization, even if it is religion-based, provides a foundation to consider people of this sample strongly bonded, while less bridged across the community since the percentage of those who are members of multiple organizations is much smaller. Since bridging associations contribute to more cohesion while bonding associations contribute to more group fragmentations, it may be concluded that this Bosnian Muslim population sample is more fragmented then cohesive.
} 
persons can be Bosniak. In both gender groups a majority of respondents also think that non-Muslims can be Bosniak. Again, the majority of respondents in this sample of both genders also think that a person can be Bosniak even if they do not have Bosniak parents. The same preferences appear in the case of the marriage of a child, where neither gender group would approve of marriages with either non-Muslim, or non-Bosnian Muslim/Bosniak persons. Furthermore the statistical tests among all these situations and gender preferences showed that differences among them are not statistically significant (for frequencies of the responses to Question SD 22r, see Appendix B).

\section{7-10-3: Gender and Customs}

In this population sample, the difference between the two genders in perception of customs among different $\mathrm{BiH}$ regions is not significant. Yet the gender difference in perceptions of Bosnian culture is statistically significant (chi-square with two degrees of freedom $=10.076, \mathrm{p}<0.006)$. The majority of women respondents, $50.4 \%$ answered that Bosnian culture is primarily Islamic, while, $47 \%$ of women participants answered that Bosnian Muslim culture is both Islamic and Slavic. Among male respondents $38.7 \%$ think it is primarily Islamic, while $59.5 \%$ consider Bosnian Muslim culture as both Islamic and Slavic. This is perhaps especially interesting since the difference between genders is not significant when it comes to how often they pray. In this population sample, both genders are fairly similarly distributed among the five response options on how often they pray. 


\section{7-10-4: Religiosity and Representativeness}

In this population sample, $98.5 \%$ of respondents indicated their religion as Islam, while only $1.2 \%$ selected agnostic or atheist, and $0.3 \%$ selected unspecified other. It appears that this sample of the population is more religious than expected of Bosnian Muslims, who are usually described as not a very religious Muslim group. ${ }^{474}$ Only a small percentage of the respondents do not pray at all, while over half indicated that they observe the full daily Muslim prayer ideal of five times a day (see Table 7.10 a). ${ }^{475}$ That may be the result of three factors.

Table 7.10: Bosnian Muslim Population Sample's Religiosity ${ }^{*}$

\begin{tabular}{|c|c|c|c|c|c|}
\hline \multirow[t]{2}{*}{$\begin{array}{l}\text { a: How often } \\
\text { do you pray? }\end{array}$} & 5 per day & Sometimes & $\begin{array}{l}\text { Only } \\
\text { Friday }\end{array}$ & Only Eid & Never \\
\hline & 51.2 & 36 & 4.1 & 4.2 & 4.5 \\
\hline \multirow{2}{*}{$\begin{array}{l}\text { b: How often do you } \\
\text { go to the mosque? }\end{array}$} & Daily & Sometimes & Fridays & Only Eid & Never \\
\hline & 24.6 & 10.6 & 56 & 5.7 & 3 \\
\hline \multirow{2}{*}{\multicolumn{2}{|c|}{$\begin{array}{l}\text { c: In your opinion, could a Bosniak } \\
\text { be a Catholic or Orthodox Christian? }\end{array}$}} & & & No & Yes \\
\hline & & & & 34.7 & 65.3 \\
\hline
\end{tabular}

The average age of the participants, middle-aged, suggests that most of them come from the group who came as refugees during or right after the war, when many Bosnian Muslims rediscovered religion, perhaps as a need to realign their world and

\footnotetext{
${ }^{474}$ Yet, as observed by Bringa (1995), since the association with Islam for Bosnian Muslims is more cultural than religious, it does not necessarily translate into stronger religiosity.

475 Although, as Croegaert (2011) notes, a common pattern is for other immigrant groups like Italians and Hispanics is to religiously diffuse and assimilate and intermarry, Sherkat (2001) points out that some more recent immigrants, especially Muslims, show a higher degree of religious loyalty than the previous immigrant groups.
} 
make sense of the destruction and death they witnessed in their homeland. Once religion started to become important among the population, coming to the U.S., where religiosity is publicly welcomed and often encouraged, it increased. Furthermore, Bosnian Muslims looked closely at diaspora groups of their Balkan neighbors who were also primarily organized through their respective churches, which proudly displayed national colors to indicate whom they serve. So to mimic that, Bosnian Muslim mosques served not only as religious centers where Bosnian Muslims come to pray, but also as centers where most of their other social and cultural needs are met. Even their usual name, "Bosnian Islamic Cultural Center," signals that. Needless to say, their mosques also proudly display their national colors (see Figure 7.3).

Many Bosnian Muslims were assisted in their immigration to the U.S. by various Christian faith-based organizations which were contracted by the U.S. State Department to facilitate their arrival and adaptation to the new country, ${ }^{476}$ and so that could further facilitate religiosity among their U.S. diaspora population. At all the sites where data was collected, the first and primary Bosnian Muslim organization is their local mosque, and

\footnotetext{
${ }^{476}$ Just in the city of St Louis, MO, according to the data I was able to see, the Catholic Charities of St. Louis assisted with the immigrant needs of around a thousand Bosnian immigrants, and a vast majority of them are Bosnian Muslims (see conversation with Hennicke 2014). This situation where Christian organizations were contracted to bring them over to the U.S., while Christian forces back home expelled them from their houses, created some uneasiness among many Bosnian Muslims and increased their desire to uphold their religious identity. This apparent coincidence was also created by policies of admission to the U.S. which stated that "certain categories are not eligible unless referred by the UNHCR, such as Bosnian Croats (the program focuses on Bosnian Muslims); only two ways to get to the U.S. are by AOR [immigration officer's assessment of applicant] or by UNHCR referral (AORs must be Bosnian Muslim)" (Somach 1995, p.11). Croegaert (2011) reports about the same situation in Chicago, where other Christian faith-based agencies were contracted to help the resettlement process for Bosnian Muslims there. The 1996 Center for Applied Linguistics report notes nineteen different Christian-based organizations throughout the U.S. that were assisting Bosnian immigrants (see Dimeo and Somach 1996, p.4-5). Yet we should add that many Bosnian immigrants were also resettled throughout the U.S. by other types of organizations which are part of the non-religious structure of USCRI.
} 
as such, mosques often serve as primary agents of Bosnian Muslim nationalism, not only by emphasizing "Bosnian Islam," but also because they are the sites of many social and cultural gatherings where people discuss matters related to $\mathrm{BiH}$ and the culture and history of Bosnian Muslims. Finally, as the data reveals, a majority of respondents in this population sample are from rural areas, where religiosity is usually higher. More than $86 \%$ of those who never pray are, in fact, from urban settings. Furthermore, the results of the Pearson chi-square test indicate that there is a statistically significant relationship between Muslim daily prayers and rural/urban populations (chi-square with four degrees of freedom is 22.975 ; and $\mathrm{p}>0.001$ ).

Figure 7.3: Entrance of Tampa Bay Bosnian Muslim Mosque, with Flags and Sign of Bosnian Designation

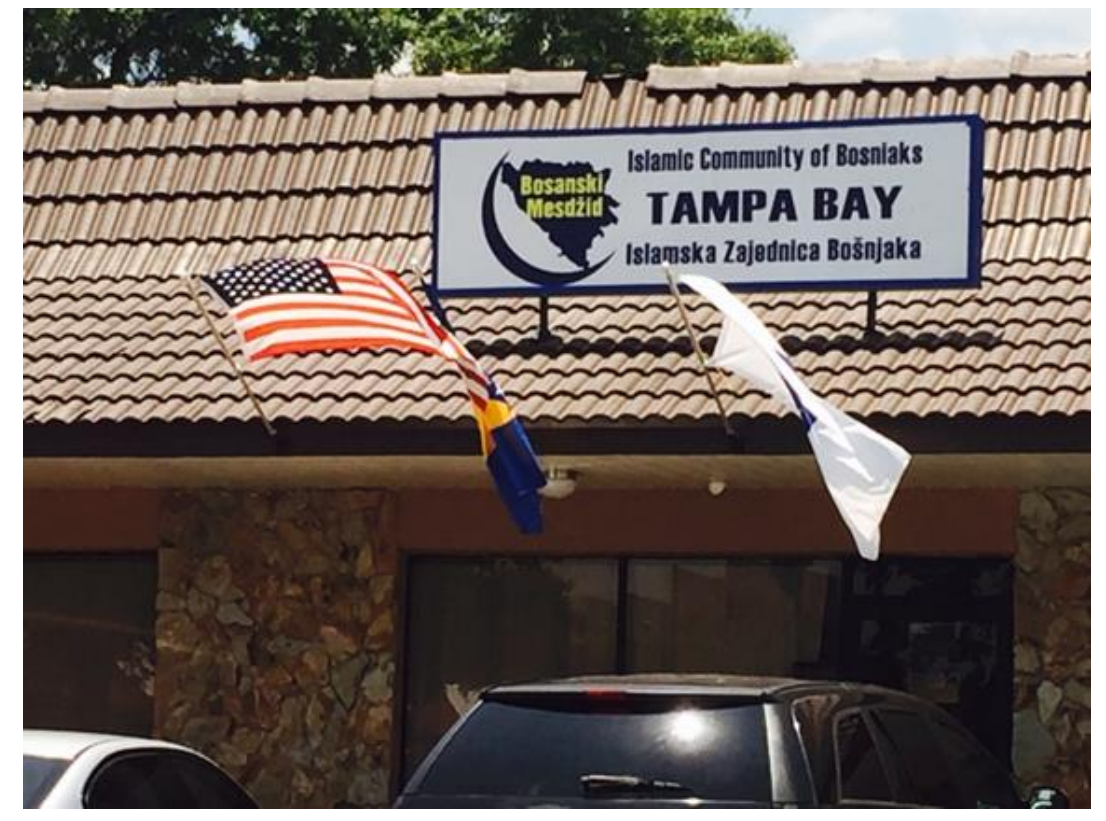

\section{7-10-5: Memory and Perception of Inequality}

Bad memories and perception of inequality in multiethnic countries often feeds a sense of nationalism and a desire by the unequal or unrepresented population to improve 
its situation through autonomy or independence. For that reason, three questions which ask about memory and perception of inequality are included in the Nationalism Strength Index. An interesting mix may be observed in the responses. More people feel that $\mathrm{BiH}$ in comparison with the other units of the former Yugoslavia was more unequal than equal, [38.5\% vs. 315] respectively, and even more, 55.6\% think that Bosnian Muslims as people were not equal with the other nationalities of the former Yugoslavia. Nevertheless, a majority, 53.6\%, think that life in the former Yugoslavia was mostly good. What their answers suggest is that the sense of a good life does not necessarily come from equality or adequate representation, but from other factors that a population might be experiencing (for more details on the answer distribution to questions MEM 50, MEM 1, MEM 52, see Appendix B).

\section{7-10-6: Passport Identity}

To comply with European Union-mandated rules, $\mathrm{BiH}$ has adopted biometric passport standards for its international travel documents. Because of the cost of a passport, responses to Question PC 28a, which asks what passport the person holds, are part of the Nationalism Strength Index. ${ }^{477}$ The requirement to uphold biometric standards significantly increased the cost of a $\mathrm{BiH}$ passport. This is so not only because of the higher administrative fee, but also because one must apply in person at one of only two official BiH diplomatic consulates in the U.S. ${ }^{478}$ Perhaps for that reason, the largest

\footnotetext{
${ }^{477}$ Furthermore, the possession of a BiH passport is also an indicator of BiH citizenship and the consequent ability to participate in homeland elections, which, as previously argued, is an element of Nationalism Strength.

${ }^{478}$ For more on passport requirements and $\mathrm{BiH}$ diplomatic offices in the U.S., see: http://www.bhembassy.org/Consular\%20services/Uputstva/Uputstvo\%20-\%20Izdavanje\%20pasosa.pdf (accessed on May 11, 2016).
} 
number of respondents, $44.4 \%$, do not have a $\mathrm{BiH}$ passport. The smallest number, $23.5 \%$, hold $\mathrm{BiH}$ passports only, while $33.9 \%$ have a $\mathrm{BiH}$ passport together with some other passport. Among those who hold other than $\mathrm{BiH}$ passports, most of whom hold a Montenegrin passport, 78.13\%, are from the New York City metropolitan region, since many Bosnian Muslims who reside there are from the two Montenegrin towns of Plav and Gusinje, as indicated before. A number of Muslims from Montenegro now also live in Chicago, and in this population sample, $18.75 \%$ of the Chicago respondents also hold a Montenegrin passport. From conversations with them, I can conclude that most of those participants from Chicago are from coastal areas and a few towns in Northern Montenegro, but not from Plav and Gusinje. Finally, 2.4\% of respondents who hold a Serbian passport are mostly from the Serbian side of Sandžak, and they are equally spread throughout the cities where data was collected. Not surprisingly, most respondents, 77\%, hold U.S. passports. Considering their time spent in this country, most people are eligible by now to have U.S. passports and this reality is reflected in these numbers. Again, respondents may have selected more than one choice, so they could be holding multiple passports (for more on the question of passports, see Appendix B, Question PC 28a).

\section{7-10-7: Other Relevant Data Frequencies}

This sample of the population includes $45 \%$ respondents who own property (a house or apartment) in $\mathrm{BiH}$, while as a separate category, $67 \%$ are property owners in the 
U.S. ${ }^{479}$ From the six categories describing the kind of work they do for a living, $10 \%$ are retirees, $14 \%$ are not working, $8 \%$ are working manual jobs, $22 \%$ are professionals or business owners, and the remaining $37 \%$ work in a service industry.

The frequencies of this data set show that conclusions drawn from this study of Bosnian Muslims' nationalism and their adoption of the new, Bosniak identity, are representative of their larger group, although the sample is from the diaspora situation. Further study with a population sample in the homeland situation, would supplement and enhance this study and provide the possibility of interesting comparisons between the groups in both situations, diaspora and homeland.

\section{7-11: Limitations of Data and Study}

This exploratory study, limited by budget constraints, has some drawbacks, such as the potential selection bias of the respondent population sample inherent in surveying the diaspora. Furthermore, like any other non-longitudinal study, this one lacks a point of comparison in time to better measure the effects of the process of nationalism. Yet this data will be very valuable with further studies and more data on Bosniak nationalism and identity.

\footnotetext{
${ }^{479}$ Paral and Norkewicz (2003) note that $45.4 \%$ of immigrants from BiH (not only Bosnian Muslims) owned property in Chicago when they did their study. Chicago is a site with a lot of Croats and Serbs, as well, but there are disproportionally more Bosnian Muslims, who had no place to return to, which provided further impetus for them to buy property and try to settle in these locations of their refuge. Although Chicago and the U.S. experienced a real estate bust in 2008, and many people lost property, the bust also caused the prices of homes to drop significantly, so many more Bosnians could afford to buy property (the same authors note that in 2003 some $73.4 \%$ of immigrants from BiH were at $200 \%$ or more of the poverty level and so they could not afford earlier sky-rocketing home prices). In fact, I was told that after the bust in St Louis, many Bosnian Muslims started moving out of South County to more affluent suburbs.
} 
The lower level analysis shows that correlation scores among variables are only low to moderate, and that suggests that those correlations should be treated cautiously. The low correlation scores are perhaps the result of the lower-than-commonly-used alpha scores, as suggested by Lance et al. (2006): "using less reliable measures lowers the expected observed correlation and the power to detect it with a constant sample size" (p.206). However, at this early stage of an exploratory research approach, even these slightly lower scores should be considered, and results may be seen as an indicator that further research, with more cases, is warranted. The same is suggested by the grounded theory approach that guided this study. ${ }^{480}$

Furthermore, the low correlation scores are perhaps the result of the homogenized standardized scores for nationalism instead of the "true" scores. So study suggests that those two indexes should be further refined to try to measure the "true" intensity, instead of standardized scores. Be that as it may, the primary intent of this study was to test the alternative premise that nationalism is the intervening variable for the development of an identity, and to decide whether this path about the direction of interaction should be pursued further. Now that there is evidence to support the proposition for the direction of interaction, further studies should better refine the instruments of measurement by developing scores for measuring nationalism that are more applicable to ongoing cases, and perhaps by developing a separate scale for measuring other cases, where both, nationalism and identity, have already been present for a while in a population.

${ }^{480}$ See Dey 1999, especially pp.10-11. 
The most serious empirical limitation of the study is the two-item measure of the desired identity. This condition produced results that are skewed to the right, with most respondents scoring high on the Likert-scale question, and that provides little variance to measure and compare the fine shades of identity ascription correlation with our variables.

Despite a relatively large data set, this inquiry utilized a single case study to test the relationship between nationalism and identity. Some scholars (Lijphart 1975, Flyvbjerg 2004) have already suggested that such a purposive case study done as experimental research is useful as a contribution towards building up the necessary indepth knowledge to offer an alternative explanation for a social phenomenon that has been considered in a different manner for so long. ${ }^{481}$ Seawright and Gerring (2008) defined a case study as "the intensive (qualitative or quantitative) analysis of a single unit or a small number of units (the cases), where the researcher's goal is to understand a larger class of similar units" (p.296). In this research the case study under intense observation is the situation of Bosnian Muslims as an autochthonous and distinct ethnoreligious Balkan group which is at the stage of emergence into a full-fledged European nation. Therefore, a single case and the group level is the appropriate level of analysis for this inquiry. As Flyvbjerg (2004) correctly stated, "good social science is problem-driven and not methodology-driven" (p.242), and this situation involves a case study of a group undergoing for the first time through the condition of the phenomena under observation.

\footnotetext{
${ }^{481}$ Perhaps the different and prevalent view of nationalism as a generic and natural force is an example of what Glaser (2010) properly called "socially structured fictions [in which] many people have large stakes in maintaining them" (p.10). Many things about nationalism, from how it starts, over how it operates and what it does, constitute a very much "socially structured fiction" in the popular (and often, in social science as well) discourse. In the same work Glaser also advises, when trying to suggest an alternative explanation to those socially structured fictions, to do it bit by bit, in a systematic and carefully considered way.
} 
Finally, this work does not claim to offer a theory on how things work; rather, its goal is much less ambitious. The intention here is to offer a possible avenue to observe the phenomena, and to suggest that such a case study is warranted, therefore it is quite within the guidelines provided by Fearon and Laitin (2010), who claim that "case studies are not designed to discover or confirm empirical regularities [while] they can be quite useful - indeed, essential - for ascertaining and assessing the causal mechanisms that give rise to empirical regularities in politics" (p. 773).

Brubaker and Cooper (2000) note that the term "identity" has been so widely used that it became irrelevant and impossible to operate with. However, precisely because of such a wide usage, political scientists should wrestle with both the term and its implications in political interactions. In that regard, this may be a step in that direction; an attempt to observe and empirically measure a relationship among the two important social science concepts of nationalism and identity. 


\section{VIII: RESULTS OF THE TEST OF INTERACTIONS BETWEEN NATIONALISM AND DESIRED SALIENT IDENTITY}

\section{8-1: Lower Level Analysis}

As a building block for the model, a lower level analysis among the individual explanatory variables and the outcome variable of six categories of Bosniak identity was done, with mixed results in terms of statistical significance. Both Indexes of Nationalism were tested for correlation with the controlled variables of age, gender, social status, education, and ownership of a house/apartment in $\mathrm{BiH}$.

Finally, as an additional level of analysis and to measure possible effects, the three constructs were tested for correlation with the previous identity of "Muslim" as a nationality in the former Yugoslavia, which is coded as an ordinal variable based on the 5-point Likert-scale type responses to Question Nat17C, "How strongly do you feel Muslim?"

Since variable values used for the constructs of nationalisms are of a different scale, they were first standardized, where all means are computed as zeros and values are given to each item based on the mean's standard deviations for each item. ${ }^{482}$ Therefore, while a Z-score mean indicates negative correlation, the true mean score for the Nationalism Strength construct is not necessarily negative. Although a Z-score computed in this way does not necessarily represent the true intensity of the variable, it does tell us whether a particular score is equal to the mean, below the mean, or above the mean. A homogenized Z-score can also tell us how far away a particular score is from the mean

\footnotetext{
${ }^{482}$ See the note on the central limit theorem and the Z-scores, above.
} 
score for the item and the direction in terms of the mean. Although Z-scores may be large, most of them are within the range between 3 and -3 , where the value of 0 is considered to be the mean score.

\section{8-1-1: Correlations of Nationalism Strength with Desired Identity, Previous}

$\underline{\text { Identity, and Controlled Variables Success }}$

For this sample of the Bosniak population the internal consistency reliability composite score for the seventeen indicators included in the Strength of Nationalism construct is acceptable $(\alpha=0.68)$, and it shows that all the items combined from the data do work together to measure the same concept intended to be measured. It is slightly lower than the often-mentioned exploratory study cut-off score of $\alpha=0.7$ (Nunnally, 1978, p. 245; Lance et.al, 2006, p. 205), but with all of the remaining items theoretically important and as such kept in the construct. Furthermore, as suggested by Khamis (1988, p. 178), the large-enough sample size perhaps could allow a slightly lower $\alpha$. As indicated above, a slightly lower value of the mean than the sample's central tendency of the medium suggests the overall moderate intensity of nationalism of this population sample.

\section{8-1-2: Correlations between Social Status Categories and Nationalism Strength}

The construct of Nationalism Strength was tested for the correlation significance between scores of the two groups among the population sample. Additionally, a test was done to access the significance of the mean difference between the two groups.

A T-test was done to compare the means of scores for groups of Promoters $(\mathrm{n}=$ 64) and non-Promoters $(n=600)$ on the Nationalism Strength Index, and it found that 
their mean differences were statistically only marginally significant (see Table 8.5). Therefore, the social status, or whether or not the person can be considered a member of a work group, has no effect on the nationalism strength. Perhaps this is the result of the selection process, where all members of local elites are included regardless of whether they support the Bosnian Muslim nationalism project or not, and some of them certainly do not. If data selection was designed to differentiate between those who support the process and those who do not, results would probably be different. As it is now, the mean difference between the two groups shows no significance.

\section{8-1-3: Correlations between Previous Identity and Nationalism Strength}

The correlation scores for all participants on Nationalism Strength and Feeling of Previous Identity were very slightly positively correlated, but this correlation was statistically not significant (see Table 8.5). Feeling of Previous Identity was measured by Question Nat 17C: "How strongly do you feel Muslim?" with four Likert-type scale response options, from lowest score for "Not at all," to highest score, for "Very Strongly."

\section{8-1-4: Correlations of Social Status and Previous Identity with Nationalism}

\section{$\underline{\text { Strength }}$}

The correlation between Nationalism Strength and feeling towards Previous Identity for Promoters, and for non-Promoters, was found to be statistically not significant. In that sense we can assume that both groups feel the same towards the previous identity of "Muslim" - as a former Yugoslav nationality (see Table 8.4). 


\section{8-1-5: Correlations of Level of Education and Nationalism Strength}

Table 8.1 shows the frequency distribution of schooling levels across the Bosniak identity groups in the population sample. As is obvious from the table in each category of Bosniak identity, most respondents have at least a high school education. This is not surprising since the population sample's mean age is 44.8 , and it is safe to assume that most of the respondents grew up and were educated in Communist Yugoslavia where education was emphasized and made mandatory for all.

\section{Table 8.1: Education among Sub-Categories of Population Sample}

\begin{tabular}{llllll}
\hline $\mathrm{N}=660$ & No school & Elementary & High school & College & TOTAL \\
\hline VSB & 0.3 & 6.1 & 28.6 & 56.8 & 58.9 \\
$\mathrm{SB}$ & 0 & 1.1 & 5.6 & 5.2 & 11.8 \\
$\mathrm{WB}$ & 0.2 & 0.5 & 1.1 & 1.2 & 2.9 \\
OVSB & 0.2 & 0.9 & 4.8 & 4.5 & 10.5 \\
OSB & 0.2 & 1.4 & 2.4 & 3.5 & 7.4 \\
OWB & 0.2 & 1.2 & 3.3 & 3.8 & 8.5 \\
\% of total & 0.9 & 11.1 & 45.9 & 42.1 & 100 \\
\hline
\end{tabular}

It is interesting to note that more than $50 \%$ of the VSB category of Bosniak identity respondents have a college education. Yet, the Pearson correlation test between education and Nationalism Strength shows that for this population sample, education level is not a statistically significant factor for Nationalism Strength scores (see Table 8.3). Although education is often referred to as an important factor in the rise of nationalism, the correlation results for education and intensity of Nationalism may be seen as a further indicator that Bosniak nationalism is still developing and is trying to find its own voice among the population that was educated by different national programs - mainly Serbian and Croatian - and under different ideological systems, Communism 
and post-Communism. This suggestion is further supported by the increased statistical significance when it comes to the correlation of education level and Nationalism Type.

\section{8-1-6: Correlations of Nationalism Strength and Age of Respondents}

Respondents were organized by age into three categories, those born before, during, and after the Communist era, to test for the correlation between age groups and Nationalism Strength. The correlation scores show a higher score on the Nationalism Strength Index among the older population, in one-way ANOVA between the age categories. The results show that age has a significant effect on the level of Nationalism Strength for the three age categories $[\mathrm{F}(2,659)=7.36, \mathrm{p}<.001]$.

Table 8.2: Nationalism Strength, Age Categories - ANOVA

\begin{tabular}{lcc}
\hline Within-Group Mean Difference & Mean difference & Significance $(p)$ \\
\hline Pre-WWII era Vs. Communist era & .16 & .17 \\
\hline Pre-WWII era Vs. Post-Communist era & $.52^{* *}$ & .001 \\
\hline Communist era Vs. Post-Communist era & $.36^{* *}$ & .003 \\
\hline$* *$ Correlation is significant at the $\mathrm{p}<.05$ level & &
\end{tabular}

Post hoc comparisons using the Tukey HSD test indicate that the mean difference on the score of Nationalism Strength between the pre-Communist (pre-WWII) and the Communist era categories is not significant, while the mean difference between the Communist and post-Communist era groups is significant. The mean difference between the pre-WWII era group and the post-Communist era groups is also significant (see Table 8.2). Therefore, we can see that the significance of age appears among those born in the late stage of Communist rule or after, and after the full cycle of Communist-induced development was over in $\mathrm{BiH}$. On the other hand, since there is no significance between 
those born in the pre-WWII and Communist era groups, those two categories of respondents may be considered as similar in terms of the Nationalism Strength (see Figure 8.1).

Figure 8.1: Correlation of Nationalism Strength with Age Groups

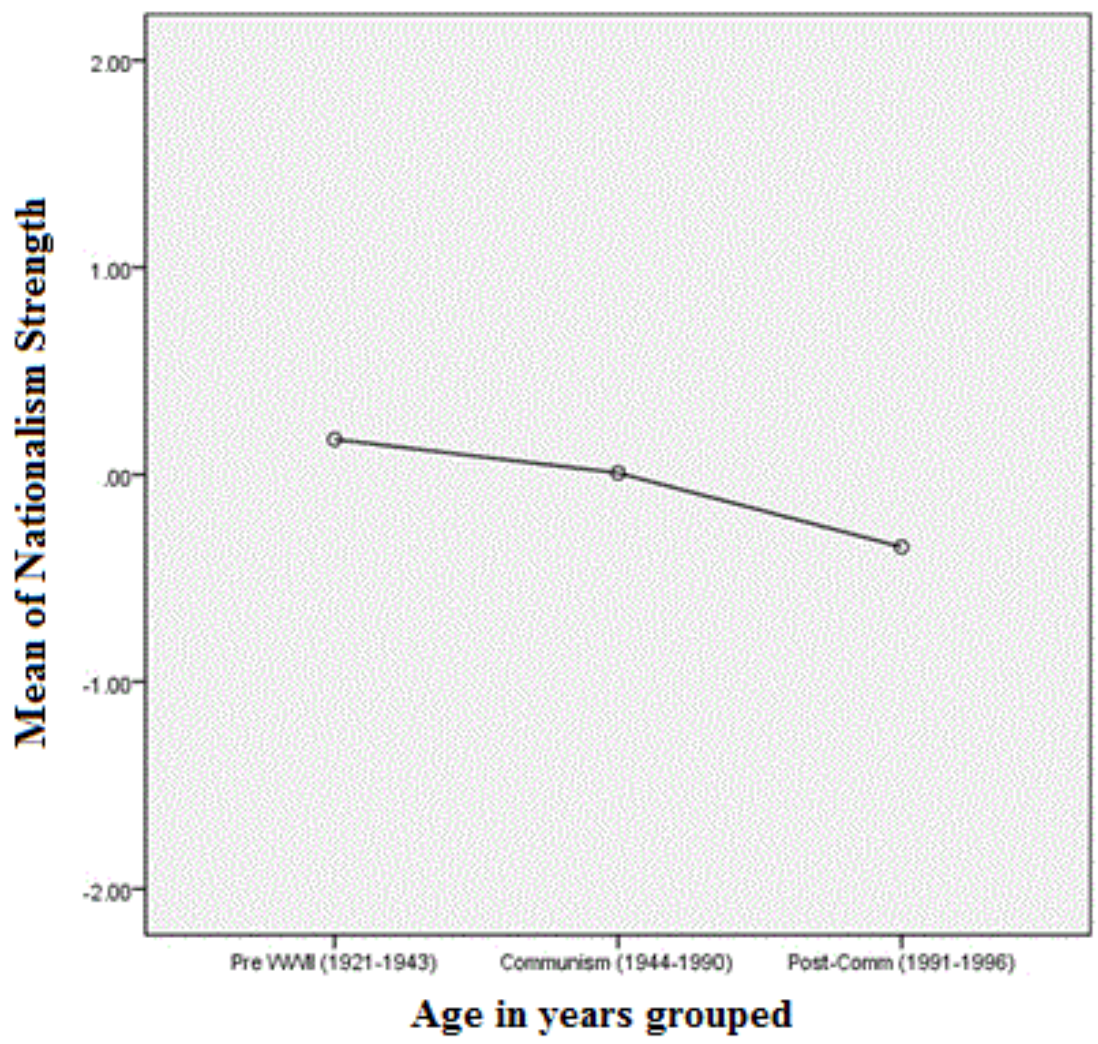

However, it should also be noted that the three age groups were not equally represented. With the sample population's mean age of $44.8(\mathrm{SD}=12.4)$, most of the respondents were from the Communist-era group $(n=628)$, while the flank groups, those born in the Pre-WWII era $(n=20)$, and the Post-Communist era $(n=14)$, are of somewhat similar size, but both less than 30, recommended by Khamis (1987, p.181). To address 
that shortcoming, an additional test for correlation between age and Nationalism Strength was done to reexamine the results of the ANOVA.

Also observed was the correlation between Nationalism Strength and the increase of age of participants, where age was treated as a continuous variable with increments of one year. Positive correlation shows that the increase in Nationalism Strength moderately correlates with increase in age. That correlation significance comes from the nonPromoters category of the population sample, while age is not a significant factor for the Promoters on their Nationalism Strength scores (see Table 8.3).

\section{8-1-7: Comparison of Nationalism Strength Across Gender Groups}

When Nationalism Strength is T-tested against the controlled variable of gender, the mean for men is higher than for women, and the difference is statistically significant (see Table 8.3). This statistically significant difference for Nationalism Strength between gender groups comes from the non-Promoter population sample (see Table 8.3). Among Promoters, gender is not a statistically significant factor for Nationalism Strength scores.

\section{8-1-8: Strength of Nationalism for BiH Property Owners}

When the relationship between Nationalism Strength and home-ownership in $\mathrm{BiH}$ is analyzed, the results show that owners scored higher in Nationalism Strength than nonowners, and that difference is statistically significant. From this we can deduce that economic interest in $\mathrm{BiH}$, as measured by home-ownership among respondents, does play a role in higher score in Nationalism Strength. 
Once again, the mean difference between property owners and non-owners comes from the non-Promoters, while it is not significant for the Promoters (see Table 8.3). From this we can infer that a short-term economic interest, such as property ownership, affects Nationalism Strength for ordinary people, but not for Promoters, who are lowerlevel elites in this sample of the population.

The same economic interest plays a different role in two Nationalism constructs. Table 8.3 helps us compare correlations between the Z-score-homogenized mean scores for Promoters and non-Promoters among those who own a house/apartment in $\mathrm{BiH}$ and those who do not, on the two constructs of Nationalism where it is clear that home ownership in BiH influences Nationalism Strength, but not Nationalism Type.

Table 8.3: Mean Differences for Nationalism Strength and Nationalism Type

$\begin{array}{lllllll}\text { Mean } & \text { Sig. } & \text { Male } & \text { Female } & \text { Sig. Home-owners Non- } & \text { Sig. }\end{array}$

\begin{tabular}{|c|c|c|c|c|c|c|c|c|}
\hline \multirow{2}{*}{\multicolumn{9}{|c|}{$\begin{array}{l}\text { Nationalism } \\
\text { Strength }\end{array}$}} \\
\hline & & & & & & & & \\
\hline $\begin{array}{l}\text { Population } \\
\text { sample }\end{array}$ & \multicolumn{2}{|l|}{.04} & .04 & -.05 & $.07 *$ & .08 & -.09 & $.001 * *$ \\
\hline Promoter & \multicolumn{2}{|l|}{.09} & .14 & -.02 & .12 & .16 & .04 & .23 \\
\hline Non-Promoter & -.004 & $.06^{*}$ & .03 & -.05 & $.03^{*}$ & .07 & -.10 & $.001 * *$ \\
\hline \multicolumn{9}{|l|}{$\begin{array}{l}\text { Nationalism } \\
\text { Type }\end{array}$} \\
\hline $\begin{array}{l}\text { Population } \\
\text { sample }\end{array}$ & \multicolumn{2}{|l|}{.21} & .23 & .17 & $.008 * *$ & .22 & .18 & .21 \\
\hline Promoter & \multicolumn{2}{|l|}{.43} & .37 & .59 & $.008 * *$ & .5 & .38 & .17 \\
\hline Non-Promoter & .18 & $.001 * *$ & .21 & .14 & $.003 * *$ & .2 & .16 & .34 \\
\hline \multicolumn{9}{|l|}{$\begin{array}{l}\text { Previous } \\
\text { Identity }\end{array}$} \\
\hline $\begin{array}{l}\text { Population } \\
\text { sample }\end{array}$ & 4.71 & & & & & & & \\
\hline Promoter & 4.73 & & & & & & & \\
\hline Non-Promoter & 4.61 & .37 & & & & & & \\
\hline
\end{tabular}


Table 8.3 also helps in comparing correlations between the mean scores for the two gender groups on both constructs of Nationalism, where we can see that female respondents scored lower on both constructs, and that mean difference among genders is statistically significant. It may be concluded, therefore, that gender plays a role for both Nationalism constructs, and that female respondents have a different, more ethnic, preference for Nationalism Type, and, at the same time, are less nationalistic than men. Furthermore, even among the social status categories, it is interesting to note that on both Nationalism constructs, both Promoter and non-Promoter female respondents' scores different from those of male respondents. In both social categories women score lower on Nationalism Strength, while, when it comes to preference of Nationalism Type, women Promoters prefer less of the ethnic type of Nationalism than the general female population sample and even than men.

Furthermore, these differences among Nationalism constructs reveal that the process of nationalism consists of at least these two essential aspects, which work differently in a population. As such, it is important to account for and report those differences in the tenacious process of nationalism in any cases under observation.

\section{8-2: Types of Nationalism Correlations ${ }^{483}$}

For this sample of the Bosniak population $(\mathrm{N}=664)$, the mean score for the Nationalism Type construct is positive $\mathrm{m}=0.21(\mathrm{SD}=0.40)$, while the median score is

\footnotetext{
${ }^{483}$ The Type of Nationalism Bipolar Index is constructed with civic and ethnic poles of the Nationalism Type. Answers to the 14 items in the questionnaire were coded to measure for the strength of the civic type of nationalism (see Appendix 1b). That means that a higher score means a more civic type of nationalism, while a lower score means a more ethnic type.
} 
0.16. As indicated in the previous chapter, we interpret that as the population sample's moderate leaning towards the civic type of Nationalism.

The construct demonstrated a reasonable internal consistency reliability composite score $(\alpha=0.61)$ for the 14 indicators selected for the Nationalism Type Index which shows that all the items from the data combined do measure the same concept intended to be measured. The score is slightly lower than the $\alpha=0.70$ value recommended for exploratory research. All items included in the construct are theoretically important and should be included. Additionally, the Grounded Theory approach for the study advocates including as many items as theoretically reasonable. Finally, more items provide higher score variability among participants.

\section{8-2-1: Types of Nationalism Correlations with the Controlled Variable of Age}

The Nationalism Type score correlates with age increase among the population sample, showing that higher scores for the civic Nationalism Type coincide positively with an increase in age. This correlation is very small, and the acceptable significance probably comes from the long range and large sample size of the age variable. Additional tests also confirm this conclusion.

No significant correlation was found when a one-way ANOVA was conducted to compare the effect of age. Respondents were organized into three age groups - those born in the pre-WWII era, the Communist era, and the post-Communist era. The three groups' mean scores were compared with scores on the Nationalism Type Index [F (2, $659)=0.20, p=0.82]$. The test of ANOVA again confirmed that there was no significant 
effect of age on the scores on the Nationalism Type Index for this population sample. Since the three age groups were not equally represented, which may cause a problem in comparisons, a new test was conducted to further evaluate the effect of age.

Nevertheless, the new test confirmed the result, and no statistically significant effect was found when the variable of age in an increment of one was tested against the Social Status categories of Promoters and non-Promoters (see Table 8.4). More specifically, when Promoters were compared with non-Promoters, age was not significantly correlated with the scores on the Nationalism Type Index among Promoters, while among non-Promoters the correlation with age had only marginal significance. Yet again, due to the large size of the non-Promoter population, such marginal correlation should be treated cautiously.

\section{8-2-2: Correlations of Type of Nationalism with the Controlled Variable of}

\section{$\underline{\text { Gender }}$}

The Nationalism Type score was also checked against the controlled value of gender, and an independent sample T-test showed different values of means for males and females, but with only marginal significance (see Table 8.3).

The same results were observed when scores for Nationalism Type were checked by gender of Promoters, where the difference between males and females showed the same marginal statistical significance (see Table 8.3). 
Therefore, both situations show that, despite small differences between the means for the two population samples, gender has somewhat marginal statistical effects on changes of scores on the Nationalism Type.

Among non-Promoters, the male vs. female difference is significant. An additional test shows that, again, difference in scores on Nationalism Type comes from the non-Promoter part of the Bosniak sample population (see Table 8.3).

\section{8-2-3: Nationalism Type and Years of Schooling}

The Pearson correlation test comparing schooling categories and Nationalism Type scores shows that education level is a statistically significant positive correlation factor (see Table 8.4). As mentioned in the discussion of the relationship between education and Nationalism Strength, where education level is not significant, these results demonstrate that in this case of nationalism, education plays only a small role when it comes to Nationalism Type.

\section{8-2-4: Correlations of House/Apartment Ownership in BiH with Type of}

\section{$\underline{\text { Nationalism }}$}

Finally, the Nationalism Type index score was checked against the controlled variable of House/Apartment Ownership in $\mathrm{BiH}$ and no significant correlations was found. The analysis shows that there is no statistically significant mean difference in the Type of Nationalism between Promoters and non-Promoters, regardless of their homeownership status (see Table 8.3). 


\section{8-2-5: Correlation of Nationalism Type with the Feeling towards Previous and}

\section{Desired Identities}

When the correlation between Nationalism Type and feeling towards Previous Identity is tested, the results show a statistically significant negative association between the two variables. It means that the more strongly respondents feel Muslim (nationally), the lower their scores on the Type of Nationalism Index scale, and the further away from the civic type of nationalism (see Table 8.4). Such expected results further support the Nationalism Type construct validity, as they show that the civic pole of the variable is opposite from the old, primordial, quasi-religious, association for Bosnian Muslims.

Therefore, we can see that among the non-Promoter sample of the Bosniak population, feelings towards previous identity again negatively correlate with the civic Nationalism Type; the stronger the feelings towards previous identity, the lower the scores on the civic Nationalism Type. Yet, these weak negative correlation scores towards previous identity suggest that those correlations should be treated cautiously (see Table 8.4). ${ }^{484}$

Finally, the T-test shows that the mean difference between Promoters and nonPromoters in the scores of the Nationalism Type is significant. This suggests that Promoters score stronger on the civic Nationalism Type than non-Promoters, whose scores are closer to the ethnic pole of our index for the Nationalism Type scale (see Table

\section{3).}

${ }^{484}$ Khamis (2008, p.157) suggests that associations smaller than .02 should be seen as weak correlations. 
The mean difference in feeling towards Previous Identity by Promoters and nonPromoters is not significant. Such scores suggest that Promoters and non-Promoters have different feelings towards Nationalism Type, but they feel the same towards Previous Identity (see table 8.3), and therefore we can expect different approaches to the selection of the identity category between those two groups. These results suggest that both groups have the same starting point, but they have different approaches to Nationalism Type, which might regulate group's member inclusion and exclusion.

Table 8.4: Correlations among Different Categories of Bosniak Population Sample

\begin{tabular}{|c|c|c|c|c|c|}
\hline & ion $(r)$ & Sig. & \multirow{3}{*}{$\begin{array}{l}\text { Nationalism Type } \\
\text { and Education Level }\end{array}$} & \multirow[t]{2}{*}{ Correlation $(r)$} & \multirow[t]{2}{*}{ Sig. } \\
\hline $\begin{array}{l}\text { Nationalism Strength } \\
\text { and Education Level }\end{array}$ & \multirow{3}{*}{-.03} & \multirow{3}{*}{.512} & & & \\
\hline Population Sample & & & & .243 & $.001 * *$ \\
\hline $\begin{array}{l}\text { Nationalism Strength } \\
\text { and Previous Identity }\end{array}$ & & & $\begin{array}{l}\text { Nationalism Type } \\
\text { and Previous Identity }\end{array}$ & & \\
\hline Population Sample & .02 & .65 & & -.14 & $.001 * *$ \\
\hline Promoter & -.04 & .75 & & .06 & .62 \\
\hline Non-Promoter & .03 & .46 & & -.16 & $.001 * *$ \\
\hline $\begin{array}{l}\text { Nationalism Strength } \\
\text { and Age }\end{array}$ & & & $\begin{array}{l}\text { Nationalism Type } \\
\text { and Age }\end{array}$ & & \\
\hline Population Sample & .11 & $.003 * *$ & & .08 & $.03 * *$ \\
\hline Promoter & .14 & .32 & & .07 & $.07 *$ \\
\hline Non-Promoter & -.13 & $.001 * *$ & & .19 & .14 \\
\hline
\end{tabular}

Table 8.4 may help us compare correlations between Nationalism Type with Age and Nationalism Strength with Age, Social Status, and feelings towards Previous Identity for this population sample. Additionally, it may be observed how the statistical significance and correlation matrix varies for both aspects of nationalism. So the level of education plays a role for the scores on civic type of nationalism, while it does not in terms of intensity. Also, feeling towards Previous nationality Identity again plays a role for the type, but not for the intensity of Nationalism, which may have some interesting 
implications in terms of further studies of nationalism as a type of collective action. Finally, although with different levels of statistical significance, age plays a role for both aspects of nationalism. However, for type of nationalism a negative correlation sign suggests that the older population tends to have a higher score on ethnic type of nationalism, while they also score higher on nationalism intensity. Since most of the correlation scores are very low, we cannot draw strong conclusions, yet they do suggest that further analysis is warranted. Nevertheless, statistical significance for the correlations provides us with the justification to examine how those variables will interact among each other in a higher model of regression.

\section{8-3: Multinomial Logistic Regression for Nationalism Strength and Nationalism}

\section{Type on Six Bosniak Identity Categories}

To investigate the likelihood of one category of identity ascription over another among the responders, the multinomial logistic regression is used to model nominal outcome variables of different categories of ascription of Bosniak identity, in which the $\log$ odds (logits) of the outcomes are modeled as a multinomial logit estimate combination of the seven predictor variables. The starting point of the investigation was that the responder's identity choices are influenced by their intensity and type of nationalism which are two main predicting variables. The regression controls for the effects of respondent's education level, economic attachment to the homeland, social status in the population, and their gender. The result of the Goodness-of-Fit test performed to evaluate the model, shows that the model is significant, meaning that at 
least a subset of the predictors have non-zero effects, and therefore it means that they do affect the identity category outcome (see Table 8.5 ).

Table 8.5: Model Fitting Information

\begin{tabular}{lr|ccc}
\hline & Model Fitting Criteria & \multicolumn{3}{|c}{ Likelihood Ratio Tests } \\
\hline Model & $-2 \log$ Likelihood & Chi-Square & Df & Sig. \\
\hline Intercept Only & 1716.01 & & & \\
Final & 1511.23 & 204.78 & 40 & .000 \\
\hline Correlation is significant at $\mathrm{p}<.001$ & & &
\end{tabular}

\section{8-3-1: Parameter Estimates for SB Relative to VSB}

Intercept - This is the multinomial logit estimate for the SB category relative to the VSB category when the predictor variables in the model are evaluated at zero. For the SB with zero as the score on Nationalism Strength, Nationalism Type, Age, Education and Gender, the logit for preferring the SB to the VSB category is $-2.24(\mathrm{SE}=0.73 ; \mathrm{p}<$ 0.002).

Nationalism Strength - If a subject were to increase his Nationalism Strength score by one point, the multinomial log-odds (logit) of preferring the VSB category to the SB would be expected to decrease by -1.56 unit $(\mathrm{p}<0.001)$ while holding all other variables in the model constant.

If a subject were to increase his Nationalism Strength score by one unit, the relative odds for ascribing the SB category to the VSB category would be expected to decrease by a factor of 0.21 , given that the other variables in the model are held constant $[\operatorname{Exp}(B)=0.21 ; p<0.001]$. So, given a one-unit increase in Nationalism Strength, the relative odds of being in the SB identity group would be 0.21 times more likely, when the other variables in the model are held constant. More generally, and since the score is less 
than 1, while the logit sign is negative, it may be said that if a subject were to increase his Nationalism Strength score, he would be more likely to ascribe the VSB identity category than the SB Identity category. At this level of comparison none of the other variables showed significance (see Table 8.6).

\section{8-3-2: Parameter Estimates for WB Relative to VSB}

Intercept - This is the multinomial logit estimate for the WB category relative to the VSB, when the predictor variables in the model are evaluated at zero. For the WB category with zero as the score on Nationalism Strength, Nationalism Type, Age, Education and Gender, the logit for preferring the WB group to the VSB category is $3.64(\mathrm{SE}=1.45 ; \mathrm{p}<0.012)$.

Nationalism Strength - If a subject were to increase his or her Nationalism Strength score by one point, the multinomial log-odds of preferring the WB to the VSB identity category ascription would be expected to decrease by -2.9 units $(\mathrm{p}<0.001$ ) while holding all other variables in the model constant.

If a subject were to increase his Nationalism Strength score by one unit, the relative odds for ascribing the WB category to the VSB would be expected to decrease by a factor of 0.06, given that the other variables in the model are held constant [Exp (B) $=.06 ; \mathrm{p}<0.001]$. So, given a one-unit increase in Nationalism Strength, the relative odds of being in the WB group would be 0.06 times more likely when the other variables in the model are held constant. More generally, and since the score is less than 1, it may be said that if a subject were to increase his Nationalism Strength score, it could be expected that 
he would be more likely to ascribe to the VSB category than the WB. At this level of comparison none of the other variables showed significance (see Table 8.6).

\section{8-3-3: Parameter Estimates for OVSB Relative to VSB}

Intercept - This is the multinomial logit estimate for the OVSB relative to the VSB when the predictor variables in the model are evaluated at zero. For the OVSB with zero as the score on Nationalism Strength, Nationalism Type, Age, Education and Gender, the logit for preferring the OVSB to the VSB is $0.05(\mathrm{SE}=0.73 ; \mathrm{p}<0.053)$.

Nationalism Strength - If a subject were to increase his Nationalism Strength score by one point, the multinomial log-odds of preferring the OVSB to the VSB category would be expected to decrease by -0.77 unit $(p<0.053)$ while holding all other variables in the model constant.

If a subject were to increase his Nationalism Strength score by one unit, the relative odds for ascribing the OVSB identity category to the VSB would be expected to decrease by a factor of 0.46 , given that other variables in the model are held constant. So, given a one-unit increase in Nationalism Strength, the relative odds of being in the OVSB identity group would be 0.46 times more likely when the other variables in the model are held constant. More generally, and since the score is less than 1, and the multinomial log is negative, it may be said that if a subject were to increase his Nationalism Strength score, it could be expected that he would be more likely to ascribe the VSB identity category than the OVSB. 
Table 8.6: Multinomial Logit for Five Categories of Bosniak Identity

\begin{tabular}{|c|c|c|c|c|c|c|c|}
\hline & & $\mathrm{B}$ & SE & Wald & $\mathrm{Df}$ & Sig. & Exp (B) \\
\hline \multirow[t]{9}{*}{ SB } & Intercept & -2.24 & .73 & 9.33 & 1 & .002 & \\
\hline & Age & 0 & .01 & .02 & 1 & .892 & 1 \\
\hline & Nationalism Type & .3 & .33 & .8 & 1 & .373 & 1.35 \\
\hline & Nationalism Strength & -1.56 & .37 & 17.62 & 1 & .001 & $.21 * *$ \\
\hline & Higher Education $^{1}$ & -.18 & .48 & .14 & 1 & .712 & .84 \\
\hline & High-School Education & -.03 & .29 & .01 & 1 & .922 & .97 \\
\hline & Gender (Female) & -.04 & .27 & .02 & 1 & .876 & .96 \\
\hline & BiH Home Non-Owner & .16 & .27 & .35 & 1 & .554 & 1.17 \\
\hline & Status: Non-Promoter & .59 & .51 & 1.35 & 1 & .246 & 1.8 \\
\hline \multirow[t]{9}{*}{ WB } & Intercept & 3.64 & 1.45 & 6.3 & & .012 & \\
\hline & Age & 0 & .02 & .00 & 1 & .993 & 1 \\
\hline & Nationalism Type & -.22 & .63 & .13 & 1 & .724 & .8 \\
\hline & Nationalism Strength & -2.9 & .63 & 21 & 1 & .001 & $.06 * *$ \\
\hline & Higher Education $^{1}$ & .28 & .75 & .147 & 1 & .701 & 1.33 \\
\hline & High School Education & -.37 & .57 & .414 & 1 & .52 & .69 \\
\hline & Gender (Female) & -.21 & .51 & .168 & 1 & .682 & .81 \\
\hline & BiH Home Non-Owner & .27 & .5 & .293 & 1 & .588 & 1.31 \\
\hline & Status: Non Promoter & .63 & 1.07 & .344 & 1 & .557 & 1.86 \\
\hline \multirow[t]{9}{*}{ OVSB } & Intercept & .05 & .73 & .005 & 1 & .944 & \\
\hline & Age & -.04 & .01 & 11.2 & 1 & .001 & $.96 * *$ \\
\hline & Nationalism Type & .36 & .37 & .984 & 1 & .321 & 1.44 \\
\hline & Nationalism Strength & -.77 & .4 & 3.74 & 1 & .053 & $.46^{*}$ \\
\hline & Higher Education $^{1}$ & -.02 & .51 & .00 & 1 & .965 & .98 \\
\hline & High School Education & .24 & .31 & .61 & 1 & .436 & 1.27 \\
\hline & Gender (Female) & .54 & .27 & 4 & 1 & .046 & $1.72 * *$ \\
\hline & BiH Home Non-Owner & -.17 & .28 & .35 & 1 & .552 & .85 \\
\hline & Status: Non Promoter & -.22 & .44 & .24 & 1 & .625 & .81 \\
\hline \multirow[t]{9}{*}{ OSB } & Intercept & -1.71 & .95 & 3.22 & 1 & .073 & \\
\hline & Age & -.03 & .02 & 3.82 & 1 & .051 & $.97 *$ \\
\hline & Nationalism Type & .51 & .42 & 1.45 & 1 & .228 & 1.66 \\
\hline & Nationalism Strength & -2.47 & .45 & 29.89 & 1 & .001 & $.09 * *$ \\
\hline & Higher Education $^{1}$ & .59 & .49 & 1.48 & 1 & .223 & 1.81 \\
\hline & High-School Education & -.11 & .38 & .08 & 1 & .773 & .9 \\
\hline & Gender (Female) & .84 & .33 & 6.48 & 1 & .011 & $2.32 * *$ \\
\hline & BiH Home Non-Owner & -.16 & .33 & .22 & 1 & .638 & .85 \\
\hline & Status: Non-Promoter & .37 & .65 & .32 & 1 & .571 & 1.45 \\
\hline \multirow[t]{9}{*}{ OWB } & Intercept & -2.81 & .95 & 8.79 & 1 & .003 & \\
\hline & Age & -.01 & .02 & 0.1 & 1 & .752 & 1 \\
\hline & Nationalism Type & .65 & .41 & 2.52 & 1 & .112 & 1.92 \\
\hline & Nationalism Strength & -4.47 & .48 & 86.56 & 1 & .001 & $.01 * *$ \\
\hline & Higher Education $^{1}$ & .5 & .56 & .79 & 1 & .374 & 1.65 \\
\hline & High-School Education & .28 & .4 & .49 & 1 & .485 & 1.32 \\
\hline & Gender (Female) & .41 & .35 & 1.4 & 1 & .238 & 1.51 \\
\hline & BiH Home Non-Owner & -.14 & .35 & .16 & 1 & .692 & .87 \\
\hline & Status: Non-Promoter & -.15 & .59 & .06 & 1 & .802 & .86 \\
\hline
\end{tabular}

\footnotetext{
** Significant at $\mathrm{p}<0.05 ; \quad *$ Significant at $\mathrm{p}<0.1$;

Note: The reference category is the VSB group.
}

${ }^{1}$ Elementary/No School is base category for comparison among schooling groups. 
Age - If a subject were to increase his age by one year, the multinomial log-odds of preferring the OVSB to the VSB identity category would be expected to decrease by 0.04 unit $(p<0.001)$ while holding all other variables in the model constant.

If a subject were to increase his age by one unit, the relative odds for ascribing the OVSB to the VSB would be expected to decrease by a factor of 0.96 , given that other variables in the model are held constant. So, given a one-unit increase in age, the relative odds of being in the OVSB identity group would be 0.96 times more likely when the other variables in the model are held constant. More generally, and since the score is less than 1 , and the multinomial log is negative, it may be said that as a subject ages, it may be expected that he will be more likely to ascribe the VSB than the OVSB identity category.

Gender (Female) - The multinomial logit for females relative to males is 0.54 units higher $(p<0.046)$ for preferring the OVSB to the VSB given that all other predictor variables in the model are held constant. In other words, females are more likely than males to prefer the OVSB category to the VSB.

For males relative to females, the relative odds for ascribing the OVSB relative to the VSB would be expected to increase by a factor of 1.72 , given that other variables in the model are held constant. More generally, and since the score is greater than 1, and the multinomial log is positive, it may be said that a female subject is more likely to ascribe to the OVSB identity category than the VSB category. In other words, females are 1.72 times more likely than males to ascribe a non-Bosniak national identity while still feeling 
very strongly towards Bosniak identity, as compared to males, who are more likely to ascribe a Bosniak national identity and also feel very strongly about being Bosniak at the same time. At this level of comparison, none of the other variables showed significance (see Table 8.6).

\section{8-3-4: Parameter Estimates for OSB Relative to VSB}

Intercept - This is the multinomial logit estimate for the OSB category relative to the VSB when the predictor variables in the model are evaluated at zero. For the OSB with zero as the score on Nationalism Strength, Nationalism Type, Age, Education and Gender, the logit for preferring the OSB to the VSB is $-1.71(\mathrm{SE}=0.95 ; \mathrm{p}<0.73)$.

Nationalism Strength - If a subject were to increase his Nationalism Strength score by one point, the multinomial log-odds of preferring the OSB to the VSB would be expected to decrease by -2.47 units $(p<0.001)$ while holding all other variables in the model constant.

If a subject were to increase his Nationalism Strength score by one unit, the relative odds for preferring the OSB identity category to the VSB would be expected to decrease by a factor of 0.09 , given that the other variables in the model are held constant. So, given a one-unit increase in Nationalism Strength, the odds of being in the OSB identity group would be 0.09 times more likely when the other variables in the model are held constant. More generally, and since the score is less than 1, and the multinomial log is negative, it can be expected that if a subject were to increase his Nationalism Strength 
score, he would be more likely to ascribe the VSB than the VSB Bosniak identity category.

Table 8.7: Cross Tabulation for Gender and How Strongly Bosniak

\begin{tabular}{lllllll}
\hline \multirow{3}{*}{ Gender } & & \multicolumn{4}{c}{ How Strongly Do You Feel Bosniak? } \\
\cline { 2 - 7 } & & & Weak & Strong & Very Strong & Total \\
\cline { 2 - 7 } & Female & Count & 35 & 60 & 171 & 266 \\
& \% within Gender & $13.2 \%$ & $22.6 \%$ & $64.3 \%$ & $100 \%$ \\
\cline { 2 - 7 } & \multirow{2}{*}{ Male } & Count & 43 & 69 & 289 & 401 \\
& \% within Gender & $10.7 \%$ & $17.2 \%$ & $72.1 \%$ & $100 \%$ \\
\hline
\end{tabular}

Age - If a subject were to increase his age by one year, the multinomial log-odds of preferring the OSB to the VSB identity category would be expected to decrease by 0.03 units $(p<0.051)$ while holding all other variables in the model constant.

If a subject were to increase his age by one unit, the odds for preferring the OSB identity group to the VSB would be expected to decrease by a factor of 0.97 , given that the other variables in the model are held constant. So, given a one-unit increase in age, the relative odds of being in the OSB identity group would be 0.97 times more likely than being in the VSB, when the other variables in the model are held constant. More generally, and since the score is less than 1, and the multinomial log is negative, it may be expected that if a subject were to increase his age, he would be more likely to be in the VSB identity category than the OSB.

Gender (Female) - The multinomial logit for females relative to males is 0.84 units higher $(p<0.011)$ for preferring the OSB category to the VSB, given that all other predictor variables in the model are held constant. In other words, females are more likely than males to prefer the OSB to the VSB identity category. 
Table 8.8: Cross Tabulation for Gender and Respondent Nationality Choice

\begin{tabular}{ll|ccccc}
\hline & & \multicolumn{5}{c}{ What is your nationality? } \\
Bonder & & Bosniak & Muslim & $\begin{array}{c}\text { Bosnian/ } \\
\text { Herzegovinian }\end{array}$ & Other & Total \\
\hline Female & Count & 172 & 45 & 37 & 10 & 264 \\
& \% within Gender & $65.2 \%$ & $17 \%$ & $14 \%$ & $3.8 \%$ & $100 \%$ \\
\hline Male & Count & 316 & 45 & 32 & 7 & 400 \\
& \% within Gender & $79 \%$ & $11.3 \%$ & $8 \%$ & $1.8 \%$ & $100 \%$ \\
\hline
\end{tabular}

For females relative to males, the relative odds for preferring the OSB identity category to the VSB would be expected to increase by a high factor of 2.32 , given that other variables in the model are held constant. In other words, females are more likely than males to ascribe the OSB identity category over the VSB, or females are less likely to ascribe the VSB identity than males. This may be interpreted to mean that females are following their male counterparts in terms of the nationalism project - however, with slight hesitation, as they claim to feel strongly and very strongly Bosniak, while at the same time also clinging to the old Muslim identity more than males. It appears that this group of women is more hesitant then men about the abstract concept of the new identity. This situation is partly explained by the well-known Gilligan-Kohlberg debate, ${ }^{485}$ which suggests that, in general, context influences women's reasoning more than men's. Women's thinking is generally more immanent than abstract, and so here it appears that this sample of women prefers the certainty of the old identity rather than the uncertainty of the new one, which is being pushed for by nationalism. At this level of comparison, none of the other variables showed significance (see Table 8.7).

${ }^{485}$ For more, see Gilligan 2003, p.160. 


\section{8-3-5: Parameter Estimates for OWB Relative to VSB}

Intercept - This is the multinomial logit estimate for the OWB relative to the VSB when the predictor variables in the model are evaluated at zero. For the OWB with zero as the score on Nationalism Strength, Nationalism Type, Age, Education and Gender, the logit for preferring the OWB to the VSB is $-2.81(\mathrm{SE}=.95 ; \mathrm{p}<0.003)$.

Nationalism Strength - If a subject were to increase his Nationalism Strength score by one point, the multinomial log-odds of preferring the OWB to the VSB identity category would be expected to decrease by -4.47 units $(p<0.001)$, while holding all other variables in the model constant.

If a subject were to increase his Nationalism Strength score by one unit, the relative odds for ascribing the OWB identity category rather than the VSB would be expected to decrease by a factor of 0.01 , given that the other variables in the model are held constant. So, given a one-unit increase in Nationalism Strength, the relative odds of being in the OWB identity group would be 0.01 times more likely when the other variables in the model are held constant. More generally, since the score is less than 1 , and the multinomial log is negative, it may be expected that if a subject were to increase his Nationalism Strength score, he would be more likely to ascribe the VSB identity category over the OWB. At this level of comparison, none of the other variables showed significance (see Table 8.6). 


\section{8-3-6: Discussion on Multinomial Regression for the Case of Bosniak Identity}

The results of the analysis show that the factor of Nationalism Strength is significant for the likelihood of identity ascription for each category relative to the VSB.

\section{Table 8.9: Nationalism-Strength-Based Hierarchy of Bosniak Identity Groups}

\begin{tabular}{|c|c|c|c|c|c|c|c|c|}
\hline & B & S E & Wald & $\mathrm{df}$ & Sig. & $\begin{array}{r}\text { Exp } \\
\text { (B) }\end{array}$ & $\begin{array}{r}\text { NS } \\
\text { Mean }^{2}\end{array}$ & $\begin{array}{r}\text { NT } \\
\text { Mean }^{3}\end{array}$ \\
\hline $\begin{array}{l}\text { Other-Very Strong Bosniak } \\
\text { (OVSB) }\end{array}$ & -1.56 & 0.37 & 3.74 & 1 & .001 & $.46^{* *}$ & .03 & .21 \\
\hline Strong Bosniak Id (SB) & -2.9 & 0.63 & 17.61 & 1 & .001 & $.21 * *$ & -.06 & .23 \\
\hline Other-Strong Bosniak (OSB) & -0.77 & 0.4 & 29.89 & 1 & .053 & $.09 *$ & -.22 & .25 \\
\hline Weakest Bosniak (WB) & -2.47 & 0.45 & 21.00 & 1 & .001 & $.06 * *$ & -.27 & .17 \\
\hline Other-Weakest Bosniak (OWB) & -4.47 & 0.48 & 86.56 & 1 & .001 & $.01 * *$ & -.52 & .34 \\
\hline
\end{tabular}

If a hierarchy of groups is created based on the intensity of how strongly respondents feel Bosniak, it may be seen that the likelihood of change to the Desired exclusive Bosniak Identity category based on Nationalism Strength, is statistically significant for each group. As the Nationalism score increases, the likelihood of stronger Desired Identity group selection changes correspondingly. This pattern is not followed when the scores for Nationalism Type and Desired Identity are observed, and that variance shows not only that those two concepts work differently, but that intensity of Nationalism for this group is a greater factor that encourages the ascription of a Desired Bosniak Identity (see Table 8.9). Furthermore, it should be noted that the Nationalism Type score indicates that the Bosniak identity group with the lowest level of Nationalism Strength, OWB, has the highest score on the civic type of Nationalism, while the group with the highest score on Nationalism Strength among the five categories, OVSB, has the 
highest score on the ethnic nationalism type. In fact, the correlation between the two variables indicates a small, but statistically significant $(\mathrm{p}=0.017)$ negative correlation, $\left(r_{\mathrm{s}}=-0.09\right){ }^{486}$ That means that for this sample of Bosniak population, the stronger the nationalism, the less of a civic type it is, keeping in mind that it is a weak correlation, and the preliminary tests showed no effects of interactions among the two independent variables.

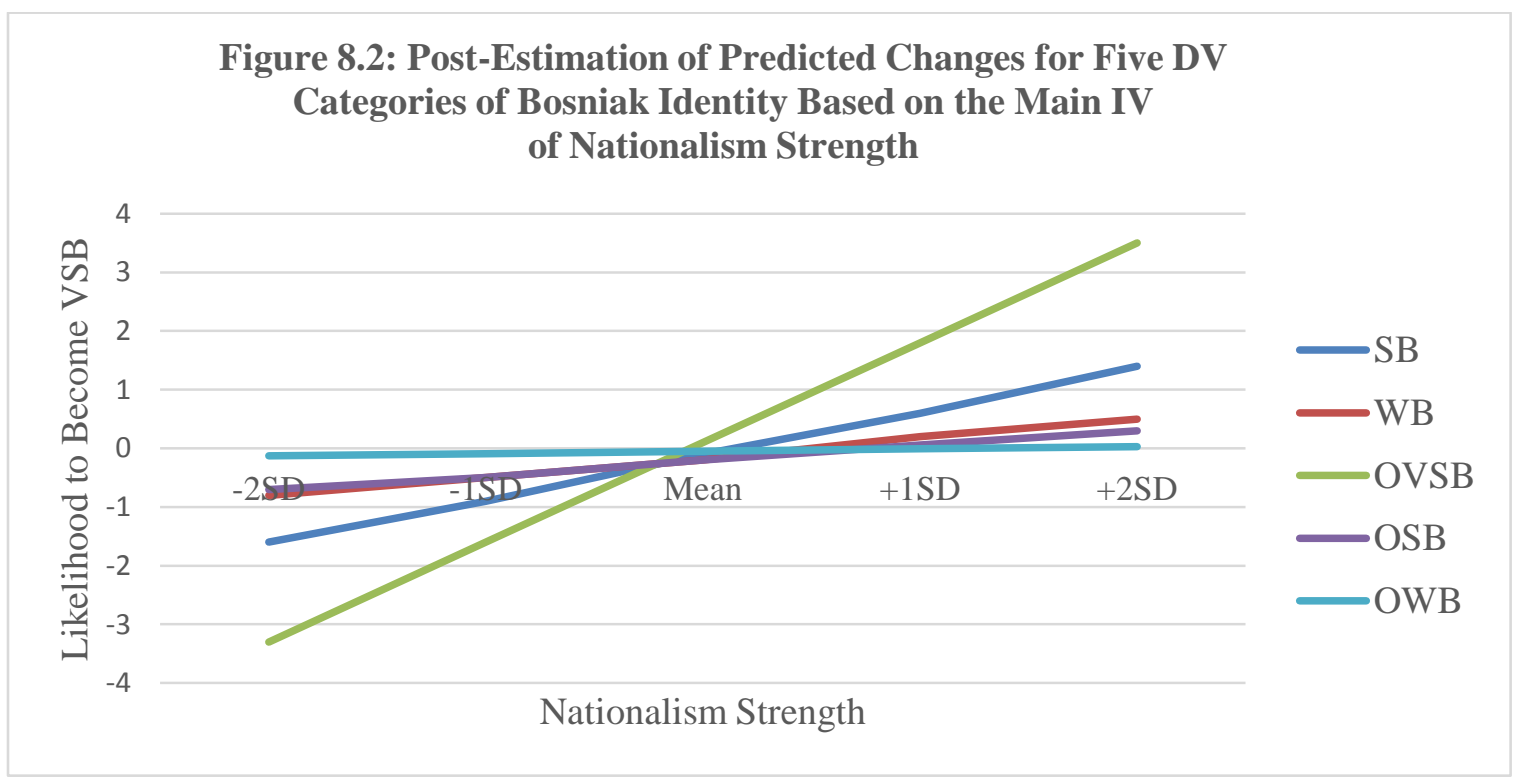

As recommended by Wulff (2014, pp.14-16) to graphically represent the results of multinomial logistic regression (MLR) together, in Figure 8.3 we can also visually compare post-estimated predicted changes among different categories of Bosniak identity based on the changes in Nationalism Strength, while holding all other variables constant. In this figure, five values of Nationalism Strength with the sample population's mean

\footnotetext{
${ }^{486}$ The Shapiro-Wilk test suggested that indexes are not normally distributed, so the Spearman Rho test was used to test the correlation between the two, as suggested by Shapiro and Wilk (1965).
} 
scores, and four changes based on standard deviations in each direction, are used for every category.

From this visual post-estimation, it may be inferred that the stronger the Nationalism Strength, the more impact it has on a person's likelihood of change into the Desired Identity category. On the other hand, the lower the Nationalism Strength a person already has, the more is needed to encourage him to ascribe the Desired Identity category. Therefore, Nationalism Strength is a factor in both cases. Furthermore, if identity is to trigger Strength of Nationalism, as is usually suggested by observers, previous Muslim identity would also be positively correlated with Nationalism Intensity, but it is not. So for the OVSB group, made up of respondents who selected other than Bosniak identity and who at the same time feel very little or not at all Bosniak, Nationalism Strength has the strongest effect, and even small increments of change in the score of that strength increase the likelihood for a person to be in the Desired Identity category. The same arrangement follows for each category.

Therefore, empirical evidence shows a stable correlation between Nationalism Strength and Desired Identity across all identity categories. This confirms the guiding hypothesis, as the results empirically support the model established for this exploratory study, and show that the direction of interaction goes from nationalism to identity. This direction is what this research set out to examine, as opposed to the common conventions regarding the interaction between the two. 


\section{IX: CONCLUSION}

Although for Bosnian Muslims the process of national emergence and the assertion of a new salient identity have been going on for over two decades, for the first time this work explains the significance of the whole process as well as the adoption of their new Bosniak identity. It provides an historical overview of Yugoslav and $\mathrm{BiH}$ Slavic Muslims' transformation from an ethno-religious group into a full-fledged distinct and independent national group. As shown in Chapters Four and Five, it took several centuries for them as an autochthonous local group to develop full self-awareness as a distinct national group, and, as pointed in Chapte Seven, to reach the stage of in-group base line equality and the necessary level of literacy for nationalism to emerge and play the role it usually does: the role of precursor and facilitator of a group's newly desired salient identity. Most observers gloss over this new identity of Bosnian Muslims and note only in passing that this group has adopted a new name, without much elaboration. What this study shows is that this group has adopted not only a new name but also a new significance and a new self-awareness expressed through nationalism that serve as a context for that new identity. Thus far, the whole phenomenon of this adaptation of a group has been largely glossed over by social scientists. This work fills the void and provides a much needed in-depth description of the change.

This exploratory study has been guided by a few basic premises that provide justification for further studies about the particular relationship between nationalism and identity: (1) that nationalism stimulates change of a group's salient identity; (2) that an increase in the sense of strength of nationalism in an individual, based on a sample of a 
Bosnian Muslim group, increases the likelihood of a strong ascription of a new, Bosniak, identity; (3) that nationalism possesses two essential characteristics, strength (intensity) and type (civic and ethnic); (4) and that these two aspects of nationalism have two different functions when it comes to identity ascription.

Nationalism has been seen as an elite-driven process that serves as a context which demands a new salient identity. Nationalism may be stronger or weaker, depending on the exposure to influences of the group's elites who steer the nationalism project and shape and encourage the targeted population to ascribe new salient identity through the group's internal and external power struggles. In a nuanced approach, this study treats the two main aspects of nationalism, strength and type, differently. Nationalism may be of two types, ethnic or civic, and these types provide their own textures for the phenomenon and an essential context for the breadth and character of the identity.

Identity is an outcome, a strategic role for both the group and the person. Identity is formed on the group level and then available for an individual to ascribe to and claim for himself. Identity has two levels of acquisition by an individual. The lower level, selfidentifying, is defined as "the perception by individuals that they are joined in a common category" (Turner, 1981, p.100); a person evaluates and accepts or rejects an identity and subsequently claims it or not for himself. The higher level, self-investment of identity, is a level that involves consciousness and investment in the social contract of the group. The level of self-investment occurs after the first stage is completed. 
This inquiry observed the first level, self-identifying, among a sample of the Bosnian Muslim population living in a diasporic condition. In these conditions, the identity adopted by the main, back-home, population still plays a role for evaluation of individuals in the interactions among members of the group. ${ }^{487}$ For this reason, Hockenos' (2003) elastic definition of diaspora was used to ensure that participants are indeed people dispersed from their homeland, but clustered and connected in communities composed of people from back-home with whom they interact at more or less regular intervals. Although the sample is drawn from sites with diaspora populations, it should be emphasized that these are places where homeland localities are reproduced and where many back-home situations are recreated, and so they can produce the necessary context for Bosniak identity to play a role in the social life of an individual. ${ }^{488}$ That is why it was noted above that a diaspora situation with long-distance nationalism is a situation where the object of nationalism may be distant, but sources of nationalism are not. ${ }^{489}$ Additionally, if nation is an imagined community, imaginations may be equally

\footnotetext{
${ }^{487}$ Sometimes even to assess who are the "soldiers, martyrs, traitors and exiles" among members of a diaspora, as Hepner (2009) well described the situation of another similar large diaspora group, with their own case of an ongoing nationalism identity project. For Bosnian Muslims in the diaspora, ascription (or not) of Bosniak identity does not yet have such severe connotations, but it does play a role in evaluations among different sub-groups of the population, as was discussed in the section about regional representations and populations from Sandžak and Western Bosnia.

${ }^{488}$ It should be noted that this study was designed primarily to measure whether or not, influenced by nationalism, Bosniak identity is being ascribed by the members of the Bosnian Muslims diaspora.

${ }^{489}$ Indeed, due to changes in the modes of communications and travel, now even the object of long-distance nationalism is not that distant anymore. This reality is confirmed by the recent report that a record number of 65,398 Bosnians in the diaspora (a jump from 42,139 people in 2014) have registered to participate in $\mathrm{BiH}$ local elections (see Centralna Izborna Komisija BiH 2016). Furthermore, statistical reports for the year 2016 note the ever-increasing number of foreign visitors in BiH (see Küçükkiremitçi 2010, pp.9-13; and the tourism report by Agencija za Satatistiku BiH 2016). If we combine these reports, it is safe to assume that most of those foreign visitors are actually people from the $\mathrm{BiH}$ diaspora who are coming back to visit the homeland. In our data set, over $70 \%$ of participants indicated that they have another passport besides a $\mathrm{BiH}$ one (44\% do not have a $\mathrm{BiH}$ passport at all), and so as they travel they are technically foreigners, while in
} 
strong or weak "here and there." Finally, even back-home localities are no more stable and undisturbed by new circumstances than diasporic ones, since the Bosnian Muslim homeland has been very much destroyed and the process of (re)construction is still ongoing, while a large number of the $\mathrm{BiH}$ population is still internally displaced (see Dahlman and O'Tuathail 2005), and many more are now also looking to emigrate to the West in search of jobs.

Since nationalism is antithetical to religious universalism, Bosnian Muslims had to adapt and wrestle with factors which distinguish their group from other groups. Although it is known that Bosnian Muslims adhere to the Hanafi School of jurisprudence, it is not so much discussed in the literature that the Bosnian Muslim official religious hierarchy tries to adhere to the Maturdi creed. And so, for the first time, this work provides an explanation of what exactly this combination of school of jurisprudence and creed means for the Muslim group in a volatile region of southeastern Europe. It describes the adaptation by the Bosnian Muslim religious hierarchy to four different types of secular state, an adaptation that has provided them with the possibility of fostering a sense of distinctiveness to assert themselves within the region and within the larger body of Islam, as well as in the contemporary world of nations.

Although the adjective "Bosnian" is used for Bosnian Muslims, it is commonly not well understood that Bosnian Muslims also live in regions outside $\mathrm{BiH}$. Perhaps that

fact they are part of the Bosnian Muslim diaspora. Finally, according to many news reports, the main contentious point regarding the publication of the last $\mathrm{BiH} 2013$ census, which took almost three years to be revealed, was the number of those who are in diaspora but who registered as residents in their pre-war localities. This trend is expected to continue, together with high economic emigration of the Bosnian population. All this demonstrates that Bosniak identity may be seen as an important factor by Bosnian Muslims in the diaspora, as it is by those in BiH and Sandžak. 
is one of the most important reasons why their nationalism demands the new salient identity of Bosniak, as a platform to enable all those other local Slavic Muslim groups to join in a single nationalism project. Since this group lives throughout the former Yugoslavia, the literature has thus far failed to provide an explanation of what exactly the territory of Bosnia and Herzegovina means to the Slavic speaking Muslims of Bosnia, Sandžak, Montenegro, and Kosovo. This is another issue explained in detail for the first time in this work for an English language audience.

Finally, the group adopted the Slavic language of Bosnia as its own, and now considers the Bosnian language its own national language. Yet the ascription of that name also implicitly stakes a claim to a territory and that is why Bosnian language, as a name and as a separate language, is being contested not only by other neighboring groups but, as shown in several chapters, even by some parts within the group.

Bosnian Muslims are not the only group that has gone through this transformation. It may be argued that all the other former Yugoslav groups went through a similar transformation, from subjects of a Communist state to citizens of a capitalist one. However, in the case of Bosnian Muslims, transformation also included adoption of a new name and a new political role in a newly emerged country. This is an ideal case of an historical social experience that calls for observation and understanding particularly of the relations between nationalism and the new salient identity. To provide that understanding, 670 surveys were collected over the course of several months from the Bosnian Muslim diaspora population spread throughout the Midwestern and Eastern United States. This unique data set of group members' responses about Bosnian Muslim 
nationalism and Bosniak identity was then used for empirical observation of the relationship. Furthermore, this rich data set provides a wealth of information about Bosnian Muslims' views and perceptions of their own culture and self-understanding that may be further utilized for deeper analysis of the group. Described in Chapter Six, this data collected from the diaspora population opens up the possibility for continuing investigation of the group's emergence, as well as for comparative study of the group in its homeland and in other diaspora situations. Most interestingly, it provides the possibility of empirically measuring relations between different aspects of nationalism and identity in a sample of a population, which is very rarely done.

This study has several wider implications. First is the unmasking of nationalism as a facilitator of new identity. A detailed review in Chapter Two of the well-known literature on nationalism accomplishes this through a novel, specific focus on the role of identity in those works. The argument proposed here is that nationalism, as a facilitator of change, actually demands a new salient identity, and as the literature review shows, such an approach does not contradict conclusions of previous studies.

Although empirical evidence from the inquiry discussed in Chapters Six, Seven and Eight shows that the guiding idea is warranted, it is perhaps still premature to make wide-ranging claims. Nevertheless, this work provides a new approach to the question of what exactly nationalism does for a group, as it shows that in the life of a group, nationalism serves as a mechanism to enable needed changes that groups must go through in their political life. 
To heed Gellner's (2008) warning against selecting cases where the condition of a case is used to help explain the emergence of that very condition in another case, and since context matters very much, especially in the case of identity selection (selfidentification), very careful consideration has been given to the appropriateness of the case study. Thus the case of the ongoing Bosnian Muslim nationalism project with the desired new salient identity of Bosniak, was chosen over some other cases. ${ }^{490}$ Bosniak identity was observed at the lower level of self-identifying, where participants selfascribed variations of Bosniak identity that were offered by the survey questionnaire. The participants in this study were seen as members of a group at such an early stage of the process of self-ascription that they lacked a clearly developed prototypical identity for comparison to rely on, as Leach et al. (2008) suggested would be part of the consideration on the lower level of ascription. The appropriate comparison, therefore, for this part of the research was done only among sub-groups of the population sample.

Since the research was done on a closed sample of a group instead of measuring just the two options of claiming identity or not, Bosniak identity was divided into six possible categories of the new salient identity ascription in order to capture shades and intricacies of its ascriptions. The six categories were based on the self-selected intensity of identity ascription, and nationalism strength was considered as a factor that moves an individual to choose a stronger or weaker identity category. The most intense ascription

\footnotetext{
${ }^{490}$ As established by the Bayesian analysis approach which stresses the importance of understanding the context and whether the case may be useful for the determination of whether the intervening phenomenon may be present to begin with.
} 
of salient identity was Bosnian Muslim nationalism-desired, while the least intensive was nationalism undesired.

As described in Chapter Eight, a multinomial logistic regression was used to test those propositions and compare ascription intensity among the sub-categories of the group. It found that the strength of nationalism did affect the possibility of the acquisition of a new group's salient identity, while the type of nationalism showed no statistical significance in that process, and therefore the type had no effect on the ascription of a new salient identity for this sample of the population.

This method was used because the whole nationalism process and its salient identity project is rarely a yes-or-no process. Rather, as explained in the introduction, it is an ongoing process where both groupness and identity are constantly being evaluated and adjusted to fit the circumstances which envelop both phenomena. Even if the group does not respond to the nationalist identity preference, it might continue to exist in some form, and with some other identity. That is why the test was designed to measure the greater or lesser likelihood of the desired identity ascription among the respondents. Therefore, this study does not suggest that every population exposed to nationalism necessarily responds to it positively by adopting all its goals, desires and preferences. Since nationalism is primarily an elite-driven project, the population still has the agency to respond to it, to accept, modify or reject its goals, as appears to be the case with Bosnian Muslims' preference for one type of nationalism. The likelihood of ascription of the desired salient identity versus other identity options was tested among subgroups of the population sample, whose preferences, essentially, were compared, and then conclusions were 
drawn. So unlike regular regression, where the intensity of the independent variable corresponds to the amount of the dependent variable, or when a comparison is made between two groups that choose exclusionary yes or no options, in this study the likelihood of the preferred (rather than the only) option was measured based on two independent and several controlled variables.

What this work essentially aims to show is that nationalism is not about a group's permanence, as primordialists and ethno-symbolists claim, or about a group's transience, which some modernists assert, but rather, that nationalism is about change which is occurring on the group level, which is implicitly allowed by all the different approaches. Furthermore this study's intention is to open that door even wider to see that nationalism as a value-oriented movement is the facilitator of change for the institution of identity, among other things. In his seminal work, Barth (1969) suggested that most of the cultural matters which are usually building blocks of nationalism vary, are (re)learned, and change, on both the individual and the group level. In fact, change is imbedded as an essential part of collective action, and nationalism is a prime example of that. ${ }^{491}$ As such, it is still an elite-driven project, guided by the values strategically selected by elites. Once the resulting change in collective action occurs, identity, as the strategic choice of an individual or a group, must correspond to the action and respond appropriately, and therefore a new identity (re)emerges to fit the changes. As shown in this work,

\footnotetext{
491 This is very important and often ignored aspect of collective action is based on Smelser's (1962) theory which states that, 'collective behavior 'lies outside this area of cultural prescription.' It is behavior which develops new forms of interaction to meet 'undefined or unstructured situations" (Smelser 1962 p.6). Therefore, he also emphasizes "change" as an important, and it may be argued, the essential element of collective action.
} 
throughout their history Bosnian Muslims have gone through different situations and changes and all those vicissitudes have been followed by adjustments and appropriate salient identities. When they finally emerged as a full-fledged nation on the local and international level, which partly came as the result of their nationalism project and the breakup of the previous order, described in Chapters Four and Five, they needed the new salient identity of Bosniak to satisfy those circumstances and reality.

The relationship between nationalism and identity corresponds with the initial assumptions guiding this inquiry. This may have implications for how nationalism is seen by both social science and by policy makers. Clearly understood, the possibility that identity may be modified, improved, or changed through the process of nationalism, essentially confirms Barth's (1969) often neglected position that a group's boundaries change while the group maintains itself despite all those changes, and that boundaries are negotiated and compromised at the time when a whole new group is formed out of previously disaggregated groups of people. My findings encourage further study of changes in the social world rather than of the permanence, which social science, guided by functionalism, often tends to implicitly suggest is its guiding standard.

Motivated by the idea of more or less groupness as an essential aspect of nationalism this study included not only the two main guiding hypotheses that nationalism stimulates change of identity, and that nationalism has two different components, but also included assumptions that age, gender, education, social standing, and economic attachment to the homeland, as controlled variables, would also impact nationalism strength and type among participants. A lower-level analysis confirms that 
interaction among some of the controlled variables with both aspects of nationalism does play a role in the case of this population sample. The results justify the variant-groupness approach, since it empirically shows that diverse segments of a group will experience and be affected by the intensity of nationalism differently. Lower level analysis found that:

(A) Age has a moderate-to-low effect on the intensity of nationalism strength among individuals, yet it makes no difference regarding the participants' preference of nationalism type.

(B) The social standing of a person considered a local identity promoter, and a member of a ground-level elite group, does not affect the intensity of nationalism, but it does affect nationalism type, since responders from that sample sub-group have higher preferences for the civic type of nationalism than does the general population. It should be added that both sub-groups prefer the civic type more than the ethnic type. In that sense it may be that ground-level elite group preference is instrumental in determining the type of preference of the rest of the people.

(C) Gender appears to play a role in determining the feeling of intensity of nationalism, while only marginally in determining the type of nationalism preference. Women tend to score lower on nationalism strength, and score closer to the ethnic type than their male counterparts. The different scores show the different levels of groupness within a sample of the population. Such results justify calls from those who urge for nationalism to be disaggregated as a process, and to be observed in various segments and levels of the population that experience it. 
(D) Economic attachment to the homeland, defined by property ownership in $\mathrm{BiH}$, is a statistically significant factor for a participant's nationalism strength, as it correlates with a higher nationalism strength score, but it has no statistical significance in determining preference for nationalism type.

This case of Bosnian Muslim nationalism and acquisition of the elite-desired new salient Bosniak identity, shows that case selection does matter and when measured under the ongoing condition of group identity self-selection, it may be seen that the relationship between nationalism and a group's national identity starts with the nationalism and ends with the identity. Although the group possessed previous forms of togetherness, it was with a different notion of boundary markers, not with the group's agreed-upon and universally accepted identity that sets them apart from other groups, nor with political consciousness of group status as a nation. As this study shows, all these elements emerged over time to be used as building blocks of Bosnian Muslim nationalism and to be formalized though the newly acquired Bosniak identity. This emergence has intensified particularly since the breakup of the former Yugoslavia, while it may be considered that the process began in the last years of the Ottoman Empire, and especially after its withdrawal from $\mathrm{BiH}$ in 1878, when Bosnian Muslims for the first time found themselves detached from the abode of Islam to fend for themselves. Their emergence occurred in four phases; (a) early on, through the Muslim institutions established and supported by the new occupying powers; (b) then by their new elites, who surfaced through different periods of the several Yugoslavias with their own primarily South Slavic and Muslim religious orientation; (c) through the initial realization of the need to 
avow themselves of a distinct Muslim group tied primarily to the territory of $\mathrm{BiH}$ and its Slavic language; and (d) finally to fully assert themselves as a distinct Bosniak nation after the collapse of the Communist regime and breakup of the last Yugoslavia, which served as the opportunity and strong springboard for Bosnian Muslim nationalism to play the role of new salient identity facilitator. Throughout all these phases, they tried hard to resist those neighboring nationalizing projects that attempted to absorb Sandžak and Bosnian Muslim (br)others into their nationalist-desired, yet much more restrictive, Serbian, Croatian, or Montenegrin identities as defined by their respective nationalisms.

During the group's 138-year history, the structural conditions on which Slavic speaking Muslims of $\mathrm{BiH}$ and Sandžak had little impact, organized the composition of their elites and directed their emergence strategies in a manner similar to those emergence strategies which occurred elsewhere in Europe, as described by Foucault (2003). Over time each of the three broadly defined elite groups, which came from among religious structures, the land-owning-political stratum, and the intellectual realm, picked their own issues to champion, and endeavored to make them to be important to the Bosniak nation. Throughout all this turbulent history, Bosnian (and Sandžak) Muslims managed to preserve the integrity of $\mathrm{BiH}$ as an entity and a territory on which they could make some claim. They managed to wrestle and tame Islamic universalism into a form of Bosnian Islam, now widely accepted as a particular Islam by the group's population. Finally, they managed to turn the language of the land into the language of the people, and now they have structured, formalized and claimed the Bosnian language as their group's own national language. 
Moreover, what may be observed from this history is that different forms of Bosniak identity were waiting in obscurity and resurfaced several times when stimulated by regional occupiers, elements of the group's elites, or individual notables, who urged various segments of the $\mathrm{BiH}$ population, not necessarily only Muslims, to accept this identity. However, it took the full-fledged Bosnian Muslim nationalism of the 1990s to fully enable this group to claim Bosniak identity as their own and demand acknowledgement as a Bosniak nation. ${ }^{492}$ Therefore, the occasional recurrence of historical observations and the occasional appearance in writing of "Bosniak" as a term for an identity in $\mathrm{BiH}$ that was rejected by the $\mathrm{BiH}$ population of the time, shows that nationalism is not triggered by a strong sense of pre-existing identity among a particular group. Rather, it is the other way around: elite-driven nationalism is the necessary context and mechanism for acquisition, definition, and even production of a new salient identity for an emerging group. Furthermore, nationalism is neither natural nor inevitable, nor should it be observed as either.

A full understanding of this process reveals how policy makers influence ascription of nationalism as the desired salient identity for a group, which then becomes an essential building block for further development and growth of the group. Until now, assumptions and observations have relied on the reverse order of interaction, as though only identity can influence the rise and strength of nationalism, and that is seen as an almost inevitable natural process. So, policies are designed and implemented to effect

\footnotetext{
${ }^{492}$ As confirmed by the results of this study, and the results of the recently published first post-war BiH census, where a large majority of Bosnian Muslims self-identified as Bosniaks and now make-up, according to the same census, $50.11 \%$ of the $\mathrm{BiH}$ population (see Agency for Statistics of Bosnia and Herzegovina 2016, p.54).
} 
higher levels of self-ascription of identity, instead of observing nationalism projects as an essential process on both the lower and higher levels of identity ascription.

Based on the historical account presented here, it may be argued that Bosnian Muslims' reactant nationalism has emerged somewhat late in comparison with the nationalisms of other peoples in the region. It emerged in the form of what Plamenatz (1976) described as the effort of people (finally) culturally equipped to assert themselves as equals in a civilization not of their own making, when they have had to make themselves anew, and to create a new salient national identity. Whenever Bosnian Muslims were treated by neighboring nationalism projects as Serbs-to-be or Croats-to-be, the new Bosniak identity was in part a response to those attempts. It took the strength of their own nationalism to assert themselves anew, and their preference for the civic type of nationalism now shapes the boundaries of their new salient identity. Interestingly, from conversations with members of the local elites and the measurements of the bipolar Nationalism Type Index in the sample, it appears that elites prefer Bosnian Muslim nationalism to be more the civic type than the ethnic, which is preferred by other contending neighboring nationalisms. Yet the nationalism of the ordinary Bosnian Muslim people appears to be more ethnic than that of the local leaders, and, therefore, it appears that the contending nationalisms have had some influence on the group, just like the nationalism being promulgated by the group's elites. Thus, future attempts to measure cases of nationalism and desired salient identities should take into account the neighboring and contending nationalisms of other groups and examine whether and what influence they have on the populations under observation. 
It should be no surprise to learn that the type of nationalism does not affect identity ascription, while intensity does, since both types of nationalism may be weak or strong, and it is their strength that primarily affects the ascription of a group's new salient identity. Yet, this apparent difference between the effects of the two aspects of nationalism also justifies the study's binomial functional approach, as it shows that these two traits work differently, and therefore also serve different purposes in the process of a group's identity ascription. Further study of the difference between these two aspects of nationalism should yield better understanding of the exact roles they play in relation to identity ascription. What may be inferred from the results of this study is that the type of nationalism plays a role in defining the boundaries and nature of identity, rather than a role in the process of ascription of identity by community members. However, more empirical evidence is necessary to support such a conclusion. This study opens up the possibility that the measure of nationalism type may be important for further understanding the possible parameters of the new salient identity. Furthermore, a clearer understanding of the impact of the type of nationalism of a group may be potentially important to better assess the possibility of democracy in situations where multiple groups share a state, as in the case of $\mathrm{BiH}$, with Bosnian Muslims, Serbs and Croats. ${ }^{493}$

In their recent work, the pioneers of the study of democratic transitions, Stepan and Linz (2011), also emphasize the importance of the relationship between democratic transitions and the possibility for democratic stability, on the one hand, and nationalism on the other. One can argue, again, that the possibility of a fine-tuned measurement of a

\footnotetext{
${ }^{493}$ In part, in another case, Kuru (2009) addresses in more depth this issue of different types of nationalism and their impact on democracy.
} 
group's nationalism type is instrumentally important in the situation of Stepan et al.'s (2011) state-nation model, which may correspond to the case of BiH. Such measurement has potentially important implications for their theoretical model of a state-nation that allows for state diversity, where each group cultivates its own different type of groupness. ${ }^{494}$ The possibility that in such a state's circumstances one of the containing groups builds its groupness on shared civic ideas and norms of mobilization, while the other containing group sees itself as a fixed ethnic category, theoretically provides the possibility for mutual coexistence, more so than if both groups cultivated the same civic types of nationalism. With such an approach to democracy in a culturally and ethnically diverse state, ethnic and civic types of nationalism could potentially co-exist and be institutionally organized to create a common "we feeling" and a constitutional patriotism, more so than if there were two or more cases of civic types of nationalism in a single state, but less so than in the case of two budding cases of the ethnic type of nationalism. In the case of a "pure multinational context" (Stepan et al. 2011, p.9), a BiH with three major groups, two of them with an ethnic and one with the civic type of nationalism, could potentially create such a mutually tolerant context. Such a context would demand appropriate salient identities, which are singular but not mutually conflictual, as long as they reach a consensus about policies providing for mutually accepted minimal patriotism and support of a state territory and institution, which are designed to ensure an asymmetrical federalism, as Stepan et al. (2011, pp. 9-10) prescribe.

\footnotetext{
494 "State-nation is a term introduced to distinguish democratic states that do not and cannot fit well into the classic French-style nation-state model based on a "we feeling" resulting from an existing forged homogeneity" (Stepan et al. 2011, p.7).
} 
Precisely because of that possibility of ensuring an asymmetric federalism, Bosnian Muslim nationalism's desired Bosniak identity provides room for a dual, but complementary, Bosnian identity to continue to operate as a common ground for all three BiH groups - Bosniaks, Croats, and Serbs - an identity to be voluntarily added as a layer to each group's own exclusive identity. So, contrary to normative suggestions by various observers of the BiH situation, who urge that Bosnian identity be adopted by Bosnian Muslims and others, such an outcome could move the whole BiH situation further away from the possibility of a state-nation where stability and democracy are plausible ${ }^{495}$ If one $\mathrm{BiH}$ group lays claim to an all-inclusive Bosnian identity, that group would, at the same time, remove a possible mutually complementary identity to serve as a foundation for a "we feeling" among members of each different BiH group. So instead of ordinary liberalism, where only the rights of an individual Bosnian citizen are respected, which many advocate for, ${ }^{496}$ but where a citizen has a unitary Bosnian identity and is loyal to a state, Michel Walzer's (1994, pp. 99-104) “Liberalism 2," where both group and individual rights are mutually respected and ensured, would provide more reason for optimism regarding democratic success and state stability in $\mathrm{BiH}^{497}$ It should be added

\footnotetext{
${ }^{495}$ Knutsen (1998) suggested a similar thing in another case where a different all-inclusive identity as a strategic choice for an individual "does not weaken the person's original [other] identity in the eyes of [other members of his group] nor does it meet with any envy from his group of origin or opposition from any aimed-at 'goal' group" (p.99).

${ }^{496}$ As the Soros-funded Open Society, for example, seems to be advocating and arguing for through the Seidić and Finci case in the EU Court of Human Rights decision about insurance of (their) individual rights in BiH (see Varenik 2008). In that locally well-known case, "Mr. Sejdić and Mr. Finci describe themselves to be of Roma and Jewish origin respectively. They have not declared affiliation with any of the 'constituent peoples' [Bosniaks, Serbs or Croats] and are therefore ineligible to stand for election to the House of Peoples and the Presidency" (Bardutzky, 2010, p.317). The EU court decided in their favor and demanded changes to the BiH Constitution to insure their individual rights. For more, see Bardutzky 2010.

${ }^{497}$ It appears that the official Islamic hierarchy in BiH now expects exactly that when it wishes for the state to define its secularity as "neutrality with respect" (Karčić, p.57). For more, see Chapter Five.
} 
that Bosnian identity is not the same as the previously rejected Yugoslav identity, because it is actually more historically grounded in the memory and tradition of all three groups. After all, those men from Bosnia who executed the Archduke were volunteer members of a secret society called "Young Bosnia," not "Young Yugoslavia," even though they came from all three $\mathrm{BiH}$ groups with a majority of Serbs, but also a few Croats and Muslims. Furthermore, the success of the Bosniak identity project puts an end to attempts to recruit Bosnian Muslims into Croatian or Serbian nationalism projects and thereby cause the reality of the careful $\mathrm{BiH}$ balance to tip towards either the Croatian or Serbian side, with devastating consequences, as it did in the past. 


\section{REFERENCES}

Abazović, M. D. (1999). Kadrovski rat za BiH: 1945-1991 [Bureaucratic personnel war over BiH]. Sarajevo: Savez logoraša BiH.

Abazović, M. D., \& Ćurak, N. S., Sead. (2007). Ethno-mobilization and the organized production of violence in Bosnia and Herzegovina: Conscious preparations.

Bolzano, It: The European Academy of Bozen.

Abderrazzaq, M. A. (2009). Abū ḥanīfa. In John L. Esposito (Ed.), The Oxford Encyclopedia of the Islamic World. Oxford University Press.

doi:10.1093/acref/9780195305135.013.1007

Abiva, H. (2006). The life of Imam Camil Avdic. In S. Agić (Ed.), 100 godina bošnjaka u americi [A centennial of Bosniaks in America] (pp. 103-109). Chicago: Bosnian American Cultural Association: The Islamic Association of Bosniaks in North America.

Adilović, Z. (2011). Metodološke smjernice za pravilan odnos prema zapadnoj misli [Methodological guidelines for the proper attitude towards Western thoughts]. Zbornik Radova Islamskog Pedagoskog Fakulteta u Zenici, (9), 17-39.

Adilović, Z. (2013). Modernisti i islam: Uticaj modernista na islamsku misao u svijetu $i$ kod nas [Modernists and Islam: The influence of modernists' on the Islamic thought in the world and here]. Zenica, BiH: Islamski Pedgoški Fakultet Univerziteta $\mathrm{u}$ Zenici.

Agencija za Statistiku Bosne i Herzegovine. (2016, August). Statistika turizma u BiH, Juni 2016 [BiH tourism statistics, June 2016]. ( No. 10.6). Sarajevo: Retrieved from http://www.bhas.ba/saopstenja/2016/TUR_2016\%20\%20M\%206\%20001_bos.pdf

Agency for Statistics of Bosnia and Herzegovina. (2016, June). Popis stanovništva, domaćinstava, $i$ stanova u bosni $i$ hecegovini: Rezultati popisa [Census of population, households and apartments in Bosnia and Herzegovina: Final results]. Sarajevo: Agencija za Statistiku Bosne i Hecegovine; Retrieved from http://www.popis2013.ba/popis2013/doc/Popis2013prvoIzdanje.pdf

Agic, S. (2006). Islamic Association of Bosniaks in North America - IABNA. In S. A. (eds), 100 Godina Bošnjaka u Americi: A Centenial of Bosniaks in America (pp. 171-181). Chicago: Bosnain American Cultural Association.

Ágoston, G., \& Masters, B. A. (2009). Encyclopedia of the Ottoman Empire. New York, NY: Facts On File. 
Ahn, T., Isaac, M. R., \& Salmon, T. C. (2008). Endogenous Group Formations. Journal of Public Economic Theory, 10(2), 171-194. Doi: 10.1111/j.1467-9779.2008.00357.x

Al, S. (2014). Elite discourses, nationalism and moderation: A dialectical analysis of Turkish and Kurdish nationalisms. Ethnopolitics, 15(1), 1-19. doi:10.1080/17449057.2014.937638

al-Ahari, M. (2006). The Museum. In S. A. (eds), 100 Godina Bosnjaka u Americi: A Centenial of Bosniaks in America (pp. 197-198). Chicago: Bosnian American Cultural Association.

Alahari, M., \& Bogucanin, F. (2006). Bosniaks from Sandžak. In S. A. (eds), 100 Godina Bošnjaka u Americi: A Centenial of Bosniaks in America (pp. 147-149). Chicago: Bosnian American Cultural Association.

Alahari, M., \& Bogucanin, F. (2006). Community Members from Montenegro. In S. A. (eds), 100 godina Bošnjaka u Americi: A Centenial of Bosniaks in America. Chicago: Bosnian American Cultural Association.

Alexander, R. ( 2006). Bosnian, Croatian, Serbian, a Grammar: With Sociolinguistic Commentary. Madison: The University of Wisconsin Press.

Algar, H. (1994). Persian literature in Bosnia and Herzegovina. Journal of Islamic Studies, 5(2), 254-267. doi:10.1093/jis/5.2.254

Aličić, A. S. (1996). Pokret za autonomiju bosne od 1831 do 1832 godine [The movement for Bosnian autonomy from 1831 to 1832]. Sarajevo: Orijentalni Institut u Sarajevu.

Alihodžić, B. (1993, November 10). Većina govori bosanski [The majority speaks Bosnian]. Ljiljan, pp. 26-27.

Anderson, B. (1991). Imagined communities: Reflections on the origin and spread of nationalism. London; New York: Verso.

Anderson, B. (1992). Long-distance nationalism: World capitalism and the rise of identity politics. Conference paper with general comments to the conference by the Kligman, Gail, Conference on Nation, National Identity, Nationalism. September 1012, 1992 (pp. 1-7). Berkeley, CA: Center for German and European Studies, University of California.

Appadurai, A. (1995). The production of locality. In R. Fardon (Ed.), Counterworks: Managing the diversity of knowledge (pp. 204-225). London, New York: Routledge. 
Archdiocese of St Louis. (2016). St. Joseph-Croatian (St. Louis) parish. Retrieved from https://archstl.org/app/directory/parishes/1000025

Atkinson, R., \& Flint, J. (2001). Accessing Hidden and Hard-to-Reach Populations: Snowball Research Strategies. Social Research Update(33).

Australasian Legal Information Institute. (1999). Treaty of peace between the allied and associated powers and Australia; protocol, declaration and special declaration [1920]. (Australian Treaty Series 1920 No. 3). Department of Foreign Affairs and Trade, Canberra.

Azīz, A., \& Fokas, E. (2007). Islam in Europe: Diversity, identity and influence. Cambridge: Cambridge University.

Azyumardi, A. (2002). The Bosnian crisis in the eastern Islamic world: The case of Indonesia. In R. W. Bulliet, \& M. Imber-Goldstein (Eds.), The Bosnian crisis and the Islamic world (pp. 134-148). New York: Middle East Institute, Columbia University.

Bajic, B. (February 9, 2009). The Bosniaks' Bosnia policy. Retrieved from http://bosnia.org.uk/news/news_body.cfm?newsid=2549

Balić, E. G. (2009). When Croatia needs Serbs: Nationalism and genocide in Sarajevo, 1941-1942. Slavic Review, 68(1), 116-138. doi:10.2307/20453271

Balić, S. (1952). Etičko naličje bosansko-hercegovačkih muslimana. [Ethical reverse of B-H Muslims]. Vienna: Buchdruckerei Emil Gottstein (Pachter Friedrich Geyer).

Banac, I. (1984). The national question in Yugoslavia: Origins, history, politics. Ithaca: Cornell University Press.

Banac, I. (1994). Bosnian Muslims: From religious community to socialist nationhood and postcommunist statehood, 1918-1992. In M. Pinson (Ed.), The Muslims of Bosnia-Herzegovina: Their historic development from the middle ages to the dissolution of Yugoslavia (pp. 129-153). Cambridge, Mass.: Distributed for the Center for Middle Eastern Studies of Harvard University by Harvard University Press.

Bardutzky, S. (2010). The Strasbourg court on the Dayton constitution: Judgment in the case of Sejdic and Finci v. Bosnia and Herzegovina, 22 December 2009. European Constitutional Law Review, 6(2), 309-333. doi:http://dx.doi.org.ezproxy.fiu.edu/10.1017/S1574019610200081 
Barlovac, B. (2009, April 9). Controversial mufti bids for Serbia's presidency. Retrieved from http://www.balkaninsight.com/en/article/serbia-s-mufti-joins-presidential-race

Baron, S. W. (1971). Modern nationalims and religion. Freeport, NY: Books for Libraries Press.

Barreto, A. A. (2012). Nationalism, collective action, and rationality. Nationalism and Ethnic Politics, 18(3), 316-336. doi:10.1080/13537113.2012.707498

Barth, F. [1969 (1998)]. Ethnic groups and boundaries: The social organization of culture difference. Prospect Heights, Ill: Waveland Press.

Barth, F. [1969 (1998)]. Pathan Identity and Its Maintenance in Fredrik Barth (Ed.) Ethnic Groups and Boundaries: The social organization and cultural difference (pp.117-134). Prospect Heights, Ill: Waveland Press.

Baum, G. (2001). Nationalism, religion, and ethics. Montreal: McGill-Queen's University Press.

Bennigsen, A., \& Lemercier-Quelquejay, C. (1967). Islam in the Soviet Union. London: Pall Mall Press.

Bennis, W. G., \& Shepard, H. A. (2009). A theory of group development. In W. W. Burke, D. Lake G \& W. J. Paine (Eds.), Organization change: A comprehensive reader (pp. 441-464). San Francisco: Jossey-Bass. (Original work published 1956).

Berger, P. L., \& Luckmann, T. (1966). The social construction of reality: A treatise in the sociology of knowledge. Garden City, N.Y.: Doubleday.

Bergholz, M. (2013). Sudden nationhood: The micro dynamics of intercommunal relations in Bosnia-Herzegovina after World War II. American Historical Review, 118(3), 679-707.

BH Bostel. (2016). BH Bostel home. Retrieved from http://bhbostel.net/

Bijedić, S. (1968). Ratne slike iz Cazinske Krajine [War images from the region of Cazin]. Sarajevo: Svjetlost.

Billig, M. (1995). Banal nationalism. London; Thousand Oaks, Calif.: Sage.

Biščević, V. (2006). Bosanski namjesnici osmanskog doba: 1463-1878 [Bosnian governors of the Ottoman era: 1463-1878]. Sarajevo: Connectum. 
Blank, T., \& Schmidt, P. (2003). National identity in a united Germany: Nationalism or patriotism? An empirical test with representative data. Political Psychology, 24 (2, Special Issue: National Identity in Europe), 289-312.

Bogucanin, F. (2005). Titanic Sinking Killed 4 Bosniaks. In S. Agic, 100 Godina Bosnjaka u Americi: A Centenial of Bosniaks in America (pp. 86-90). Chicago: Bosnian American Cultural Association.

Bokovoy, M. K. (1998). Peasants and Communists: Politics and Ideology in the Yugoslav Countryside, 1941-1953 (Pitt series in Russian and East European studies ed.). Pittsburgh: University of Pittsburgh Press.

Boračić-Mršo, S. (2012). Koalicija "1.mart" u borbi za prava povratnika u RS [Coalition "March $1^{\text {st" }}$ in the struggle for the rights of returnees in RS]. Retrieved from http://www.slobodnaevropa.org/a/kolacijia-prvi-mart-za-pravo-glasa-u-prijeratnimmjestima-prebivalsta/24806207.html

Bosanski Pokret Nacionalnog Ponosa. (2014). Statut pokreta - bosanski pokret nacionalnog ponosa BPNP. [Bosnian movement of national pride BPNP: By law]. Retrieved from http://www.bosanski-nacionalisti.org/statut-pokreta.html

BosnaTV. (2016). BosnaTV pocetna. Retrieved from https://bosnatv.com/

Bosnia Memory Project @ Fontbonne. (2016). Bosnian studies: Bosnia memory project. Retrieved from http://library.fontbonne.edu/bosnia/bmp

Bošnjak. (1993-94), Bosanski katolici održali sabor u Hrvatskoj [Bosnian Catholics held a council in Croatia]. Bošnjak: Nezavisni List Autohtonih Sinova i Kćeri BosneHercegvoine i Sandžanka, 7.

Botev, N. (1994, June). Where East Meets West: Ethnic Intermarriage in the Former Yugoslavia, 1962 to 1989. American Sociological Review, 59(3), 461-480.

Bracewell, W. (2003). The Proud Name of Hajduks": Bandits as Ambiguous Heroes in Balkan Politics and Culture. In N. M. Naimark, \& H. Case, Yugoslavia and Its Historians: Understanding the Balkan Wars of 1990s (pp. 21-36). Stanford: Stanford University Press.

Breuilly, J. (2011). Max Weber, charisma and nationalist leadership. Nations and Nationalism, 17(3), 477-499.

Brevik, A. B. (2011). 2083: A European declaration of independence. Unpublished manuscript. 
Bringa, T. (1995). Being Muslim the Bosnian way: Identity and community in a central Bosnian village. Princeton, N.J.: Princeton University Press.

Browner, W. S., \& Newman, T. B. (1987, May). Are All Significant P Values Created Equal? The Analogy Between Diagnostic Tests and Clinical Research. JAMA, 257(8), $2459-2463$

Brubaker, R. (1997). Nationalism reframed: Nationhood and the national question in the new Europe. New York: Cambridge University Press.

Brubaker, R. (2004). Ethnicity without groups. Cambridge, Mass.: Harvard University Press.

Brubaker, R. (2005). The 'Diaspora' diaspora. Ethnic and Racial Studies, 28(1), 1-19. doi:10.1080/0141987042000289997

Brunnbauer, U. (2004). Introduction. In U. Brunnbauer (Ed.), (Re)writing history: Historiography in Southeast Europe after socialism (Studies on South East Europe, v. 4. ed., pp. 9-31). Münster: Lit.

Bugajski, J. (2014). Conflict zones: North Caucasus and western Balkans compared (Ebook ed.). Washington D.C.: The Jamestown Foundation.

Burke, P. J., \& Stets, J. E. (2009). Identity theory. Oxford; New York: Oxford University Press.

Buturović, A. (2015). Carved in stone, etched in memory: Death, tombstones and commemoration in Bosnian Islam since c. 1500. Burlington, VT: Ashgate.

Cabrera, T. H., \& Krijestorac, M. (2015, Sept. 18). Question regarding the information from your web site (https://history.state.gov/milestones/1993-2000/bosnia) (personal e-mail conversation ed.). Office of the Historian U.S. Department of State: history@state.gov.

Calhoun, C. J. (1994). Social theory and the politics of identity. Oxford, UK; Cambridge, MA: Blackwell.

Cheah, H. W., Karamehic-Muratovic, A., \& Matsuo, H. (2013). Ethnic-Group Strength Among Bosnian Refugees in St. Louis, Missouri, and Host Receptivity. Journal of Immigrant \& Refugee Studies, 11(4), 401-415. doi:10.1080/15562948.2013.847684

Cigar, N. L. (1995). Genocide in Bosnia: The Policy of 'Ethnic Cleansing'. College Station: Texas A \& M University Press. 
Connor, W. (1994). Ethnonationalism: The Quest for Understanding. Princeton University Press.

Crnobrnja, M. (2002 (1996)). The Yugoslav Drama. Montreal: McGill-Queen's Universty Press.

Croegaert, A. (2011). Who Has Time for Ćejf? Postsocialist Migration and Slow Coffee in Neoliberal Chicago. American Anthropologist, 113(3), 463-477.

Curry, F.L. (1995) The sociological legacies of Communism. In Z. Barany \& I. Volgeys (Eds.), The Legacies of Communism in Eastern Europe. (pp. 55-84) Baltimore and London: John Hopkins University Press.

Ćeman, M. (1993, September 1). Petsto godina Bosanske (Muslimanske) knjizevnosti [Five hundred years of Bosnian (Muslim) literature]. Ljiljan, pp. 26-27.

Ćemerlić, H., Redžić, E., eds. (1968). Zemaljsko antifašističko vijeće narodnog oslobođenja Bosne i Hercegovine: Dokumenti. [National anti-fascist council of peoples liberation of Bosnia and Herzegovina: Documents]. Sarajevo: "Veselin Masleša": Institut za istoriju radničkog pokreta.

Čengić, M. (2015). Alija Izetbegović: Jahač apokalipse ili anđeo mira [Alija Izetbegovic: Rider of the apocalypse or angel of peace]. Sarajevo: KULT-B.

Centralna Izborna Komisija BiH (2016). Odluku o izmjeni odluke o utvrdjivanju i objavi broja birača upisanih u izvadak iz središnjeg biračkog popisa za glasovanje izvan Bosne i Hercegovine za lokalne izbore 2016. godine [The decision to amend the decision on establishing and to publish the number of voters registered in the excerpt from the central voters register for voting outside of Bosnia and Herzegovina for the local elections in 2016], (2016). Retrieved from http://www.izbori.ba/Documents/Lok_Izbori_2016/Biraci_Glasaci/DOC017_izmjeni -hrv.PDF

Cerić, M. (1995). Roots of synthetic theology in Islam: A study of the theology of Abu Mansur al-Maturidi (d. 333/944). Kuala Lumpur: International Institute of Islamic Thought and Civilization.

Cerić, M. (2007, January 5). Fetva o obavezi pridržavanja henefijskog mezheba [Decree on the obligation to comply to Hanafi jurisprudence]. Retrieved from http://vijecemuftija.islamskazajednica.ba/index.php/2015-12-08-13-41-32/fetve-irezolucije/148-fetva-o-obavezi-pridrzavanja-henefijskog-mezheba 
Cerić, M. (2007, January 5). Rijasetova dopunjena rezolucija o tumacenju islama u BiH [Rijaset's amended resolution on the interpretation of Islam in $\mathrm{BiH}$ ]. Retrieved from http://vijecemuftija.islamskazajednica.ba/index.php/2015-12-08-13-41-32/fetve-irezolucije/147-rijasetova-dopunjena-rezolucija-o-tumacenju-islama-u-bih

Cerić, M. (2013, September 14). Poruka Bošnjacima povodom popisa stanovništva u Bosni i Hercegovini 2013: Stari duh mlade nacije [Message to Bosniaks on the occasion of the census in Bosnia and Herzegovina 2013: The old spirit of the young nation]. Retrieved from http://bosnjaci.net/prilog.php?pid=50085

Ćerić, S. (1970). O jugoslovenstvu i bosanstvu. prilog pitanju: Jugoslovenska nacionalnost ili jugoslovenski socijalisticki patriotizam (osvrt na tezu envera Redžića o bosanskoj nacionalnosti musliman [On Yugoslavianism and Bosnianness: Contribution towards the question of Yugoslav nationality or Yugoslav socialist patriotism (Review of the thesis of Enver Redžić on Bosnian Muslim nationality)]. Sarajevo: Oslobodjenje.

Cheah, W. H., Karamehic-Muratovic, A., \& Matsuo, H. (2013). Ethnic-group strength among Bosnian refugees in St. Louis, Missouri, and host receptivity and conformity pressure. Journal of Immigrant \& Refugee Studies, 11(4), 401-415. doi:10.1080/15562948.2013.847684

Chernilo, D. (2007). A social theory of the nation-state: The political forms of modernity beyond methodological nationalism. New York: Routledge.

Cigar, N. L. (1995). Genocide in Bosnia: The policy of 'ethnic cleansing'. College Station: Texas A\&M University Press.

Cigar, N. L. (2001). Uloga Srpskih orijentalista u opravdanju genocida nad Muslimanima Balkana [The role of Serbian orientalists in justification of genocide against Muslims of the Balkans]. Sarajevo: Institut za istraživanje zločina protiv čovječnosti i međunarodnog prava.

Ćimić. E. (1967). Država i konfesionalne zajednice u Jugoslaviji [The state and confessional (religious) communities in Yugoslavia]. Jugoslovenska Politička Misao, 2, 155-165.

Coleman, J. A., \& Tomka, M. (1995). Religion and nationalism. London; Maryknoll, NY: SCM Press; Orbis Books.

Colic-Peisker, V. (2005). 'At least you're the right colour': Identity and social inclusion of Bosnian refugees in Australia. Journal of Ethnic \& Migration Studies, 31(4), 615638. doi:10.1080/13691830500109720 
Connor, W. (1994). Ethnonationalism: The quest for understanding. Princeton, N.J.: Princeton University Press.

Conzemius, V. (1995). Universal Christian faith and nationalism. In J. Coleman, \& M. Tomka (Eds.), Religion and nationalism (Concilium ed., pp. 14-22). London: SCM Press.

Crnovršanin, H., \& Sadiković, N. (2001). Sandžak - porobljena zemlja: Bosna, Sandžak $i$ Kosovo kroz historiju [Sandžak - enslaved land: Bosnia, Sandžak and Kosovo throughout history]. Wuppertal: Bosanska riječ - Bosnisches Wort.

Crnovršanin, H., \& Sadiković, N. (2007). Dr. Mehmed Spaho: Državnik i borac za BiH [Dr. Mehmed Spaho: Statesman and fighter for BiH]. Frankfurt am Main: Sandžačka riječ: Sandžak's Wort.

Cronbach, Lee J.; Meehl, Paul E. (1955). Construct validity in psychological tests. Psychological Bulletin, 52 (4), 281-302.

Dahlman, C., \& Ó Tuathail, G. (2005). Broken Bosnia: The localized geopolitics of displacement and return in two Bosnian places. Annals of the Association of American Geographers, 95(3), 644-662. doi:10.1111/j.1467-8306.2005.00479.x

Dayton Accord. (1995, November 21). General framework agreement for peace in Bosnia and Herzegovina (Dayton agreement).

http://peacemaker.un.org/bosniadaytonagreement95: United Nations Peacemaker.

D'Costa, B. (2006). Marginalizing identity: New frontiers of research for IR. In B. A. Ackerly, M. Stern \& J. True (Eds.), Feminist methodologies for international relations (pp. 129-152). Cambridge, UK; New York: Cambridge University Press.

Dedijer, V., \& Miletić, A. (1990). Genocid nad Muslimanima, 1941-1945: Zbornik dokumenata i svjedočenja [Genocide on Muslims, 1941-1945: Collection of documents and testimonies]. Sarajevo: Svjetlost.

Demmers, J. (2002). Diaspora and conflict: Locality, long-distance nationalism, and delocalisation of conflict dynamics. Javnost - the Public, 9(1), 85-96. doi:10.1080/13183222.2002.11008795

Deutsch, K. W. (1966, 1953). Nationalism and Social Communication. Cambridge: M.I.T. Press.

Dey, I. Grounding Grounded Theory: Guidelines for qualitative inquiry. Bingley, UK: Emerald Group Publishing Ltd. 
Dillman, D. A., Smyth, J. D., \& Christian, L. M. (2009). Internet, mail, and mixed-mode surveys: The tailored design method. (3rd Ed.). Hoboken, N.J.: Wiley \& Sons.

DiMeo, P., \& Somach, S. D. (1996). Bosnian refugee resettlement in the U.S. part II: Refugee response. (April). Washington, D.C.: Institute of Education Sciences, Center for Applied Linguistics. Retrieved from http://files.eric.ed.gov/fulltext/ED398316.pdf

Donia, R. J. (1981). Islam under the double eagle: The Muslims of Bosnia and Hercegovina, 1878-1914. Boulder; New York: [East European Quarterly]; Distributed by Columbia University Press.

Donia, R. J. (2006). Sarajevo: A biography. Ann Arbor, Mich.: University of Michigan Press.

Donia, R. J., \& Fine, J. V. A. (1994). Bosnia and Hercegovina: A tradition betrayed. New York: Columbia University Press.

Doty, R. L. (1996). Imperial encounters: The politics of representation in North-South relations. Minneapolis: University of Minnesota Press.

Downs, A. (1957). An Economic Theory of Democracy. New York: Harper Collins Publishers .

Đozo, H. (2006). Izabrana djela [Selected works]. Sarajevo: El-Kalem: Fakultet islamskih nauka.

Dungaciu, D. G. (2000). East and West and the "mirror of nature". Nationalism in West and East Europe - essentially different? Focaal: Tijdschrift Voor Antropologie, 35(3), 171-191.

Duranović, E. (2011). Elementi Staroslavenske tradicije u kulturi Bošnjaka: Odnos Islamskih učenjaka u Bosni i Hercegovini prema njima [Elements of archaic Slavic traditions in the culture of Bosniaks: The position of Muslim scholars in Bosnia and Herzegovina toward to them]. Bugojno: Grafika.

Duranović, E. (2015). Posjećivanje turbeta u Bosni i Hercegovini: Slučaj turbeta u grabljima, općina Busovača [Visiting tombs in Bosnia and Herzegovina: The case of tombs in the cemetery, municipality of Busovača]. Takvim, 80, 271-282.

Durić, R. (1993, November 3). Jezik naš svagdašnji [Our daily language]. Ljiljan, pp. 26.

Durkheim, E. (1997). The division of labor in society. New York: Free Press. 
Durmišević, E. (2002). Uspostava i pravni položaj rijaseta Islamske zajednice u Bosni $i$ Hercegovini: 1882-1899 [Establishment and legal position of the Islamic

Community in Bosnia and Herzegovina: 1882-1899]. Sarajevo: Magistrat.

Džihana, A., Ćendić, K., \& Tahmaz, M. (2012). Mapping digital media in Bosnia and Herzegovina. London: Open Society Institute. Retrieved Feb 28, 2016, from https://www.opensocietyfoundations.org/sites/default/files/mapping-digital-mediabosnia-20120706.pdf

East European Folklife Center. (2016). Mensur Hatić: Bosnian singing, accordion. Retrieved from https://eefc.org/teacher/mensur-hatic/

Eder, K. (2002). Collective identities in action: A sociological approach to ethnicity. Aldershot, Hampshire, England; Burlington, VT: Ashgate.

Edsall, T. B. (2000, January 15). Facing the Changing Face of Iowa. Retrieved from The Washington Post: https://www.washingtonpost.com/archive/politics/2000/01/15/facing-the-changingface-of-iowa/313a06b0-2746-49d8-89b3-26a38b2e5746/

Ehrman, B. D. (2003). Lost Christianities: The battle for Scripture and the faiths we never knew. New York: Oxford University Press.

Eickelman, D. F., \& Piscatori, J. P. (1996). Muslim politics. Princeton, N.J.: Princeton University Press.

Elliott, A. (2001). Concepts of the self. Cambridge, UK; Malden, MA: Polity Press; Blackwell Publishers.

El-posta. (2015, June 5). Rezultati prikupljanja zekata i sadekatu-l-fitra u 1435./2014. godini [Zekaat collection results for the year 1435/2014]. Retrieved from http://www.islamskazajednica.ba/vijesti/aktuelno/22522-rezultati-prikupljanjazekata-i-sadekatu-l-fitra-u-1435-2014-godini

El-posta. (2015, May 20). Rezultati prikupljanja zekata i sadekatu-l-fitra u 2015. godini [Zakat collection results for the year 2015]. Retrieved from http://www.islamskazajednica.ba/vijesti/aktuelno/23866-video-prikupljanje-zekata-isadekatu-l-fitra-u-2015-godini

Emmert, T., E. (1981). Kosovo - development and impact of a national epic. In I. Banac, J. G. Ackerman \& R. Szporluk (Eds.), Nation and ideology: Essays in honor of Wayne S. Vucinich (95th ed., pp. 61-86). Boulder; New York: East European Monographs; Distributed by Columbia University Press. 
Enloe, C. H. (2004). The curious feminist: Searching for women in a new age of empire. Berkeley: University of California Press.

Enslin, M. S. (1938). Christian beginnings. New York; London: Harper \& Brothers.

Erikson, E. H. (1968). Identity, youth, and crisis. New York: W. W. Norton.

Erović, M. (2010). 15 godina susreta, 10 godina Kongresa Bošnjaka Sjeverne Amerike. Chicago: Bosnia United, Inc.

Esposito, J. L. (2009). The Oxford encyclopedia of the Islamic world. Retrieved from http://www.oxfordreference.com

Faugier, J. \& Sargeant, M. (1997). Sampling hard to reach populations. Journal of Advanced Nursing(26), 790-797.

Fazlic, A., Borogavac, M., Balog, S., Sendijarevic, V., Kenan, S., Skokic, A., Habibovic, M. (2013). Sta je to bosanski kongres? [What is the Bosnian Congress?]. Retrieved from http://republic-bosniaherzegovina.com/index.php?option=com_k2\&view=item\&id=824:sta-je-tobosanski-kongres \&Itemid=517

Fearon, J. (1999). What is identity (as we now use the word)? Unpublished manuscript.

Fearon, J.; Laitin, D. Interpreting Qualitative and Quantitative Method, in Robert E. Goodin (Eds.), The Oxford Handbook of Political Science, New York: Oxford University Press, pp.756-779

Fennema, M. (2004). The Conceipt and Measurement of Ethic Community. Journal of Ethnic and Migration Studies, 30(3), 429-447.

Filipović, N. (2005). Islamizacija u Bosni i Hercegovini [Islamization in Bosnia and Herzegovina]. Tešanj: Centar za kulturu i obazovanje.

Fine, J. V. A. (1975). The Bosnian church: A new interpretation. A study of the Bosnian church and its place in state and society from the 13th to the 15th centuries. Boulder; New York: East European quarterly; Distributed by Columbia University Press.

Finkel, C. (2006). Osman's dream: The story of the Ottoman empire, 1300-1923. New York: Basic Books. 
Flesher Fominaya, C. (2010). Collective identity in social movements: Central concepts and debates. Sociology Compass, 4(6), 393-404. doi:10.1111/j.17519020.2010.00287.x

Flyvbjerg, B. (2006). Five misunderstandings about case-study research. Qualitative Inquiry, 12(2), 219-245. doi:10.1177/1077800405284363

Foucault, M. (2003). Society must be defended: Lectures at the Collège de France, 197576. New York: Picador.

Framework agreement for the federation (Washington Agreement). (1994, March 1). UN Department of Political Affairs. Retrieved from http://peacemaker.un.org/bosniawashingtonagreement94

Franz, B. (2005). Uprooted and Unwanted: Bosnian Refugees in Austria and the United States. College Station: Texas A\&M University Press.

Gadzo, M. (2014, August 16). Does religion have a role in Bosnia elections? - Al Jazeera English. Retrieved from http://www.aljazeera.com/indepth/features/2014/08/doesreligion-role-bosnia-elections-20148168188413365.html

Gazi Husrev-begova medresa. Laureati. Retrieved from http://www.medresa.ba/laureati/

Geertz, C. (1963). Old societies and new states; the quest for modernity in Asia and Africa. New York; London: Free Press of Glencoe Collier-Macmillan.

Gellner, E. (1983). Nations and nationalism. Ithaca: Cornell University Press.

Gellner, E. (1992). Postmodernism, reason and religion. London \& New York: Routledge.

Gellner, E. (1997). Nationalism. Washington Square, N.Y: New York University Press.

Gilligan, C. (1982). In a different voice: Psychological theory and women's development Cambridge, MA: Harvard University Press.

Glasier, B. Theoretical sensitivity. Mill Valley, CA: Sociological Press

Glessier, B. (2010) The Future of Grounded Theory. The Grounded Theory Review 9(2), $1-15$.

Goffman, E. (1959). The presentation of self in everyday life. Garden City, N.Y.: Doubleday. 
Grandits, H. (2014). Multikonfesionalna Hercegovina: Vlast $i$ lojalnost u kasnoosmanskom društvu (Herrschaft und loyalität in der spätosmanischen gesellschaft: Das beispiel der multikonfessionellen Herzegowina) [Domination and loyalty in late Ottoman society: The example of the multi-confessional Herzegovina] (N. Šećerović, I. Nevesinjac \& N. Osmanović Trans.). Sarajevo, BiH: Univerzitet u Sarajevu: Institut za istoriju.

Grpkovic, D. (. (1993). Popis stanovnistva, domacinstava, stanova i poljoprivrednih gazdinstava u 1991 godini: Stanovnistvo. Nacionalna pripadnost, detaljna klasifikacija. (Knjiga 3). Beograd, Serbia: Savezni zavod za statistiku.

Habermas, J.; Cronin, C. \& De Greiff, P. (1998). The inclusion of the other: Studies in political theory. Cambridge, MA: MIT Press.

Hadžijahić, M. \& Purivatra, A. (1970). Stav Muslimana Bosne i Hercegovine u pogledu nacionalnog opredeljenja: Studijski izvještaj. Sarajevo: Fakultet političkih nauka u Sarajevu. Institut za društvena istraživanja.

Hadžišehović, M. (2003). A Muslim woman in Tito's Yugoslavia (T. J. Butler, S. Risaluddin Trans.). College Station: Texas A \& M University Press.

Hajdarpasic, E. (2015). Whose Bosnia?: Nationalism and political imagination in the Balkans, 1840-1914. Ithaca: Cornell University Press.

Hale, H. E. (2004). Explaining ethnicity. Comparative Political Studies, 37(4), 458-485. http://dx.doi.org./10.1177/0010414003262906

Hale, H. E. (2004, May). Explaining identity. Comparative Political Studies, 4(37), 458485. doi:10.1177/0010414003262906

Halep, A. (2013, June 29). Vrše li Bošnjaci asimilaciju muslimana? [Are Bosniaks trying to assimilate Muslims?]. Retrieved from http://bosnjaci.net/prilog.php?pid=49394

Halilbegović, N. (2006). Bošnjaci u jasenovačkom logoru [Bosniaks in the Jasenovac (concentration) camp]. Sarajevo: Vijeće Kongresa bošnjačkih intelektualaca.

Halilović, S. (2005). Državna Tajna [State secret]. Sarajevo: Matica.

Handcock, M. S. \& Gilet, K. J. (2011). Comment: On the Concept of Snowball Sampling. Sociological Methodology(41), 367-371.

Handžić, A. (1975). Tuzla i njena okolina u XVI vijeku [Tuzla and its surroundings in the Sixteenth Century]. Sarajevo: Svjetlost. 
Hann, C. M. (2006). Introduction: Faith, Power, and Civility after Socialism. In C. M. Hann, \& The "Civil Religion" Group (Eds.), The postsocialist religious question: Faith and power in central Asia and East-Central Europe (pp. 1-26). Berlin; Piscataway, N.J.: Lit; Distributed in North America by Transaction Pub.

Heckathorn, D. D. (2011, August 1). Snowball Versus Respondent-Driven Sampling. Sociological Methodology, 41(1), 355-366.

Henig, D. (2012). "This is our little hajj": Muslim holy sites and reappropriation of the sacred landscape in contemporary Bosnia. American Ethnologist, 39(4), 751-765. doi:10.1111/j.1548-1425.2012.01393.x

Hennicke, M. B., \& Krijestorac, M. (2014, January 2). Catholic charities refugee services-STL, MO (personal e mail conversation). Catholic Charities Refugee Services: Resettlement Co-Director.

Hepner, T. R. (2009). Soldiers, martyrs, traitors, and exiles: Political conflict in Eritrea and the diaspora. Pennsylvania: University of Pennsylvania Press.

Herb, G. H., Kaplan, D. H., \& (eds). (1999). Nested Identities: Nationalism, Territory, and Scale. Lanham, MD: Rowman and Littlefield Publishers.

Hercus, C. (1999). Identity, emotion, and feminist collective action. Gender and Society, 13 (1, Special Issue: Gender and Social Movements, Part 2), 34-55.

Hill, K. A. (2016). Is Using Education to Measure Class Enough? Self-Identification, Occupation, Income, and Education as Measures of 'Class' in Political Research. 74 Midwestern Political Science Association Conference. Chicago.

Hilālī, T. a., \& Khan, M. M. (1998). Tafsīr ma 'ānī al-Qur'ān al-Karīm bi-al-lughah alInjiliziyah: Translation of the meanings of the noble Qur'an in the English language. Madinah, K.S.A.: King Fahd Complex for the Printing of the Holy Qur'an.

Hoare, M. A. (2013). The Bosnian Muslims in the Second World War: A history. New York: Oxford University Press.

Hobsbawm, E. (2000). Bandits. New York: The New Press.

Hobsbawm, E. J., \& Ranger, T. O. (1983). The invention of tradition. Cambridge; New York: Cambridge University Press.

Hobsbawm, E. J. (1990). Nations and nationalism since 1780: Programme, myth, reality. Cambridge [England]; New York: Cambridge University Press. 
Hockenos, P. (2003). Homeland calling: Exile patriotism and the Balkan wars. Ithaca, NY: Cornell University Press.

Horozic, A., \& Alispahic, N. (2000). Hasanaginica - prva bosanskohercegovacka opera [Hasanaginica - the first $\mathrm{BiH}$ opera]. Retrieved from http://vkbi.open.net.ba/Tribine/000408.html

Hume, S. E. (2015). Two decades of Bosnian place-making in St. Louis, Missouri. Journal of Cultural Geography, 32, 1-22. doi:10.1080/08873631.2015.1005880

Huntington, S. P. (1991). The third wave: Democratization in the late Twentieth Century. Norman: University of Oklahoma Press.

Huntington, S. P. (2004). Who are we?: The challenges to America's national identity. New York: Simon \& Schuster.

Hupchick, D. P. (2002). The Balkans: From Constantinople to Communism. Houndmills, Basingstoke, Hampshire; New York: Palgrave.

ICTY. ICTY remembers: The Srebrenica genocide (1995 - 2015). Retrieved from http://www.icty.org/specials/srebrenica20/?q=srebrenica20/

Imamović, E. (1995). Bogumilstvo - vjera naših predaka [Bogomil - the faith of our ancestors]. In E. Imamović (Ed.), Korjeni bosne i bosanstva [The roots of Bosnia and Bosnianness] (pp. 167-217). Sarajevo, BiH: Medjunarodni centar za mir.

Imamović, E. (2012). Ajvaz-dedin san: Historijski roman [Ayvaz-Dedo's dream: Historical novel] Sarajevo: Enver Imamović

Imamović, M. (1994). Osnovne historijske naznake Bosansko-muslimanskog nacionalnog identiteta [Basic historical indications of the Bosnian Muslim national identity]. In E. Imamović (Ed.), Ratni kongres Bosansko-Muslimanskih intelektualaca: 22 decembar 1992 [War congress of Bosnian Muslim intellectuals: 22 December 1992] (pp. 11-17). Sarajevo, BiH: Vjece kongresa bosanskomuslimanskih intelektualaca.

Ingrao, C. W., Samardžić, N., \& Pesalj, J. (2011). The Peace of Passarowitz, 1718. West Lafayette, Ind.: Purdue University Press.

Irwin, Z. T. (1984). The Islamic revival and the Muslims of Bosnia-Herzegovina. East European Quarterly, 18(4), 437-458.

Isaković, A. (1995, September 27). Malo dobre volje i malo samopoštovanja [A little good-will with a little self-esteem]. Ljiljan, pp. 32-33. 
Isaković, A. (1993). Rječnik karakteristične leksike u Bosanskome jeziku [Dictionary of characteristic words of the Bosnian language]. Wuppertal: Bambi.

İskenderoğlu, M. (2006). Maturidi, Abu Mansur. In O. Leaman (Ed.), The Biographical Encyclopedia of Islamic Philosophy: Continuum.

doi:10.1093/acref/9780199754731.013.0267

Islamska zajednica u Bosni i Hercegovini (2014, February 19). O islamskoj zajednici [About IZBiH]. Retrieved from http://www.islamskazajednica.ba/islamskazajednica/o-islamskoj-zajednici

Itzkowitz, N. (1980). The Ottoman Empire and Islamic tradition. Chicago: University of Chicago Press.

Iyob, R. (1995). The Eritrean struggle for Independence: Domination, resistance, nationalism, 1941-1993. Cambridge; New York: Cambridge University Press.

Jackson, R. (2006). Fifty key figures in Islam. London; New York: Routledge.

Jahić, D., A. (1991). Jezik bosanskih muslimana [Language of Bosnian Muslims]. Sarajevo: Biblioteka Ključanin.

Jelavich, C. (2003). South Slav education: Was there Yugoslavism? In N. M. Naimark, \& H. Case (Eds.), Yugoslavia and its historians: Understanding the Balkan wars of the 1990s. Stanford, Calif.: Stanford University Press.

Jalalzai, F. (2011). Anxious and Active: Muslim Perception of Discrimination and Treatment and Its Political Consequences in the Post-September 11, 2001 United States. Politics and Religion, 4, 71-107.

Jovanović, S. M. (2013). Orthodoxy in Serbia: A newfound religiosity. Humanicus: Academic Journal of Humanities, Social Sciences and Philosophy, (8), 1-10.

Jovanovic, V. (2013, August 15). Drzava i islamska verska zajednica na jugu [The state and the Islamic religious community in the south]. Retrieved from http://pescanik.net/drzava-i-islamska-verska-zajednica-na-jugu/

Juergensmeyer, M. (1993). The new cold war?: Religious nationalism confronts the secular state. Berkeley: University of California Press.

Kahrović, M. (2001). Kako smo branili Sarajevo: Prva sandžačka brigada. Sarajevo: Udruženje građana Bošnjaka porijeklom iz Sandžaka. 
Kakissis, J. (2013, April 27). Don't call it "Turkish" coffee, unless, of course, it is. Retrieved from http://www.npr.org/sections/thesalt/2013/04/27/179270924/dontcall-it-turkish-coffee-unless-of-course-it-is

Kamberović, H. (2009). Mehmed Spaho (1883-1939): Politička biografija [Mehmed Spaho (1883-1939): A political biography]. Sarajevo: Vijeće Kongresa bošnjačkih intelektualaca.

Kamberović, H. (2013). Džemal Bjedić i ravnopravnost Bosne i Hercegovine u jugoslovenskoj federaciji [Dzemal Bijedic and the equality of Bosnia and Herzegovina in the Yugoslav Federation]. Korak: Časopis Za Zaštitu Tekovina Borbe Za Bosnu i Hercegovinu, 11(30), 48-53.

Kamenka, E. (1976). Nationalism: The nature and evolution of an idea. New York: St. Martin's Press.

Karalić, F., \& Hadžić, A. (2012, October 20). Hitno otkloniti opasnosti koje nam donosi popis stanovništva [Urgently remove dangers that census brings to us]. Dnevni Avaz Retrieved from http://www.avaz.ba/vijesti/teme/kako-sprijeciti-da-hiljade-bosnjakapostanu-ostali

Karamehic-Oates, A. (2015, October 23-25). Identity negotiations of Bosnian natives in St. Louis. St. Louis, MO. (Paper presented at the Central Slavic Conference)

Karčić, F. (1990). Društveno-pravni aspekt islamskog reformizma: Pokret za reformu šerijatskog prava i njegov odjek u Jugoslaviji u prvoj polovini XX vijeka [The sociolegal aspects of Islamic reformism: A movement for the reform of Sharia law and its echoes in Yugoslavia in the first half of the twentieth century]. Sarajevo: Islamski teološki fakultet.

Karčić, F. (2006). Šta je to "islamska tradicija bošnjaka"? [What is "the Islamic tradition of Bosniaks"?]. In M. Prljaca (Ed.), Rezolucija islamske zajednice u Bosni i Hercegovini o tumačenju islama i drugi tekstovi (pp. 49-59). Sarajevo: El-Klalem.

Karić, E. (2004). Prilozi za povijest islamskog mišljenja u Bosni i Hercegovini XX stoljeća [Contributions to the history of Islamic thought in Bosnia and Herzegovina XX century]. Sarajevo: El-Kalem.

Karić, E. (2008). Islamski reformistički pokreti kod bošnjaka: Pregled bosanskomuslimanskih rasprava za i protiv reforme u XX stoljeću [Islamic reform movements among Bosniaks: A review of Bosnian Muslim debates for and against reform in the twentieth century]. Islamska Tradicija Bošnjaka: Izvori, Razvoj i Institucije, Persektive [the Islamic Tradition of Bosniaks: Sources, Development and Institutional Perspective], Sarajevo, BiH. 337-392. 
Karić, E. (2010). Narodna vjera bosansko-hercegovačkih muslimana: Kratak osvrt na islamsku modernističku kritiku narodne vjere bosanskohercegovačkih muslimana [The people's faith of Bosnian-Herzgovian Muslims: A brief overview of the Islamic modernist criticism of folk religion of Bosnian Muslims]. Novi Mualim, 11(42), 4148.

Kedourie, E. (1993). Nationalism. Oxford, UK; Cambridge, Mass., USA: Blackwell.

Kelen, C., \& Pavković, A. (2012). Of love and national borders: The Croatian anthem 'Our beautiful homeland'. Nations and Nationalism, 18(2), 247-266. doi:10.1111/j.1469-8129.2011.00529.x

Khamis, H. J. (1992). Deciding on the correct statistical technique. Journal of Diagnostic Medical Sonography, 8(4), 193-198.

Khamis, H. J. (1988). Statistics refresher II: Choice of sample size. Journal of Diagnostic Medical Sonography, 4(4), 176-183. doi:10.1177/875647938800400402

Khamis, H. J. (2008). Measures of association: How to choose? Journal of Diagnostic Medical Sonography, 24(3), 155-162. doi:10.1177/8756479308317006

Khomyakov, A. S. (1987). To the Serbs. An Epistle from Moscow. In W. J. Leatherbarrow, \& D. Offord, A Documentary history of Russian thought : from the Enlightenment to Marxism (pp. 1859-1860). Ann Arbor: Ardis Publishers.

Kinnear, P. R., \& Gray, C. D. (2010). PASW statistics 17 made simple. Hove, East Sussex; New York, NY: Psychology Press.

Ključanin, Z. (1993, November 10). Ni beg, ni fukara [Neither bey (mister), nor poor (wretch)]. Ljiljan, pp. 25.

Knutsson, K. E. [1998 (1968)]. Dichotomization and integration: Aspects of inter-ethnic relations in Southern Ethiopia. In F. Barth (Ed.), Ethnic groups and boundaries: The social organization of culture difference (pp. 86-100). Prospect Heights, Ill: Waveland Press.

Kolenovic, A. (2010, Mart 24). Ekrem Jevric gospoda - kuca poso .m2t [Ekrem Jevric: Home-job .m2t]. Retrieved from https://www.youtube.com/watch?v=MgNkJfTfHa4

Kondylis, F. (2010). Conflict displacement and labor market outcomes in post-war Bosnia and Herzegovina. Journal of Development Economics, 93(2), 235-248. http://dx.doi.org./10.1016/j.jdeveco.2009.10.004 
Kosterman, R., \& Feshbach, S. (1989). Toward a measure of patriotic and nationalistic attitudes. Political Psychology, 10(2), 257-274.

Kostovicova, D., \& Basic, N. (2005). Conference Report Transnationalism in the Balkans:The Emergence, Nature and Impact of Crossnational Linkages on an Enlarged and Enlarging Europe. Contemporary European History, 14, 583-590.

Krijestorac, M. (2015a). Mapping Muslim Communities in "Hispanicized" South Florida, in Logrono Narbona, M.M. Pinto, P.G. \& Karam,J.T. Crescent over another horizon: Islam in Latin America, the Caribbean, and Latino USA. Austin: University of Texas Press.

Krijestorac, M. (2015b). Role of an agent in (un)keeping the multiethnic state together: The case of the secession of Kosovo. Alternatives: Turkish Journal of International Relations, 14(2), 1-15. http://dx.doi.org/10.21599/atjir.59577

Küçükcan, T. (1999). Re-claiming identity: Ethnicity, religion and politics among Turkish-Muslims in Bulgaria and Greece. Journal of Muslim Minority Affairs, 19(1), 49-68. doi:10.1080/13602009908716424

Küçükkiremitçi, O. (2010, January). Bosnia and Herzegovina sector reports: Tourism sector. Ankara: Development Bank of Turkey, Directorate of Economic and Social Research. Retrieved from http://www.sarajevobusinessforum.com/projects/TOURISM_2.pdf

Kukavica, U. (2013). Politička i vjerska etnogeneza bosanskih muslimana: nacionalna identifikacija između islama i politike [Political and religious ethnogenesis of Bosnian Muslims: National identification between Islam and politics]. Behar Časopis Za Kulturu i Društvena Pitanja, 22(111-112), 6-16.

Kurjaković, N. (2015, October 25). Tribina: "Husein-Kapetan Gradašcevic u kulturi sjecanja" [Panel: Husein-Kapetan Gradaščević in cultural memories]. Preporod: Islamske Informativne Novine. Retrieved from: http://www.preporod.com/index.php/drustvo/kultura-i-nauka/2877-tribina-huseinkapetan-gradascevic-u-kulturi-sjecanja;

Kurtz, L. R. (May 1983). The politics of heresy. American Journal of Sociology, 88(6), 1085-1115.

Kuru, A. T. (2009). Secularism and state policies toward religion: The United States, France, and Turkey. New York: Cambridge University Press. 
Lacey, M. (2004, April 7). Since '94 horror, Rwandans turn toward Islam. The New York Times. Retrieved from http://www.nytimes.com/2004/04/07/world/since-94-horrorrwandans-turn-toward-islam.html?_r=0

Laitin, D. D. (1998). Identity in formation: The Russian-speaking populations in the new abroad. Ithaca: Cornell University Press.

Laitin, D. D. (2007). Nations, states, and violence. Oxford; New York: University Press.

Lakić, Z. (1992). Partizanska autonomija Sandžaka, 1943-1945: ZAVNO Sandžakadokumenta [Partisan's autonomy of Sandžak, 1943-1945: ZAVNO Sandžakdocuments]. Beograd; Nikšić; Bijelo Polje: Stručna knjiga; Univerzitetska riječ; Libertas.

Lance, C. E., Butts, M. M., \& Michels, L. C. (2006). The sources of four commonly reported cutoff criteria: What did they really say? Organizational Research Methods, 9(2), 202-220. doi:10.1177/1094428105284919

Latic, D. (1994, August 24). U dženetu će se najviše govoriti bosanskim jezikom [Bosnian will be the most spoken language in paradise]. Ljiljan, pp. 25.

Le Monde diplomatique. (2008, January) Populations croisées dans le Sandjak de Novi Pazar [Cross over populations in the Sanjak of Novi Pazar] Retrieved from http://www.monde-diplomatique.fr/cartes/sandjak

Leach, C. W., van Zomeren, M., Zebel, S., Vliek, M. L. W., Pennekamp, S. F., Doosje, B., Spears, R. (2008). Group-level self-definition and self-investment: A hierarchical (multicomponent) model of in-group identification. Journal of Personality and Social Psychology, 95(1), 144-165. doi:10.1037/0022-3514.95.1.144

Leaman, O. (2009). Māturīdī, Abū Manșūr ibn Muḥammad. In J. L. Esposito (Ed.), The Oxford Encyclopedia of the Islamic World.

doi:10.1093/acref/9780195305135.013.0963

Leatherbarrow, W. J., \& Offord, D. (1986). A documentary history of Russian thought: From the enlightenment to Marxism. Ann Arbor: Ardis.

Lewine, E. (2001, April 12). Radio Voice for Bosnian Muslims WNYE Speaks to People of Yugoslav Background. Retrieved from New York Daily: http://www.nydailynews.com/archives/boroughs/radio-voice-bosnian-muslimswnye-speaks-people-yugoslav-background-article-1.899745 
Levitt, P. (1998). Social remittances: Migration driven local-level forms of cultural diffusion. The International Migration Review, 32(4), 926-948.

doi:10.2307/2547666

Lijphart, A. (1975) The comparable-cases strategy in comparative research, Comparative Political Studies, 8(2), pp. 158-177.

Linz, J. J., \& Stepan, A. C. (1996). Problems of democratic transition and consolidation: Southern Europe, South America, and post-Communist Europe. Baltimore: Johns Hopkins University Press.

Lock, P. (2006). The Routledge companion to the Crusades. London; New York: Routledge.

Lord, C. (2013). Aristotle's politics. Chicago: University of Chicago Press.

Low, D. H. (1968). The ballads of Marko Kraljević (D.H. Low, Trans.). New York: Greenwood Press.

Lucic, I. (2012). In the service of the nation: Intellectuals' articulation of the Muslim national identity. Nationalities Papers, 40(1), 23-44.

doi:10.1080/00905992.2011.635642

Mahmutćehajić, R. (2000). Bosnia the good: Tolerance and tradition. Budapest; New York: Central European University Press.

Malajlić, M. (1994). Bosanski muslimani - na putu traženja spasa [Bosnian Muslims: In the quest for salvation]. In H. Kamberović (Ed.), Ratni kongres bosanskomuslimanskih intelektualaca: 22 decembar 1992 (pp. 51-52). Sarajevo, BiH: Vjeće bosansko'muslimanskih intelektualaca.

Malešević, S. (2006). Identity as ideology: Understanding ethnicity and nationalism. Basingstoke England: Palgrave Macmillan.

Martin, F. (2008, September 10/updated 2016, July 31). "Right skin color, wrong religion?". Retrieved from http://www.huffingtonpost.com/frankie-martin/right-skincolor-wrong-re_b_125532.html

Martiny, S. E., \& Kessler, T. (2014). Managing one's social identity: Successful and unsuccessful identity management. European Journal of Social Psychology, 44(7), 748-757. doi:10.1002/ejsp.2056 
Markovic, P.J., Kovic, M., \& Milicevic, N. (2004). Development in Serbian

Historiography since 1989. In U. Brunnbauer (Ed.), (Re)writing history:

Historiography in Southeast Europe after socialism (Studies on South East Europe, v. 4. ed., pp. 227-316). Münster: Lit.

Massad, J. A. (2001). Colonial effects: The making of national identity in Jordan. New York: Columbia University Press.

McCarthy, P., \& Maday, T. (2000). After the fall: Srebrenica survivors in St. Louis. St. Louis: Missouri Historical Society Press.

McCarthy, P. (2009). Writing diaspora in the West: Intimacy, identity and the new marginalism. Basingstoke, England: Palgrave Macmillan.

Memić, M. (2003). Bošnjaci (Muslimani) Crne Gore [Bosniaks (Muslims) of Montenegro]. Podgorica, Montenegro: Almanah.

Merati, S. E., "Russia's Islam: Discourse on Identity, Politics, and Security" (2015). Available from FIU Electronic Theses and Dissertations. Paper 1840. http://digitalcommons.fiu.edu/etd/1840

Merdjanova, I. (2013). Rediscovering the umma Muslims in the Balkans between nationalism and transnationalism. Oxford: Oxford University Press.

Messick, S. (1995). Validity of psychological assessment: Validation of inferences from persons' responses and performances as scientific inquiry into score meaning. American Psychologist, 50, 741-749.

Merton, R. K., Fiske, M., \& Kendall, P. L. (2003). The focused interview: A manual of problems and procedures. Enskede: TPB.

Midžić, F. (2007). Cazinska Buna 1950 - tajna dosijea 'Cazinski Ispad' sa aspekta postojecih povelja i konvencija UN-a (1945, 1946, 1948) [The Cazin Rebellion in 1950 - the secret dossiers of the 'Cazin Incident' in terms of the existing charter and UN conventions (1945, 1946, 1948)]. In H. Kamberović (Ed.), Revizija prošlosti na prostorima bivše jugoslavije: Zbornik radova. [Revision of history in the former Yugoslavia: Proceedings]. (Knjiga 4 ed., pp. 285-298). Sarajevo: Institut za Istorju u Sarajevu.

Migdal, J. S. (1988). Strong societies and weak states: State-society relations and state capabilities in the third world. Princeton, NJ: Princeton University Press.

Miller, D. (1988). The ethical significance of nationality. Ethics, 98(4), 647-662. 
MiM TV. (2016). Radio - MiM TV - St. Louis. Retrieved from http://mimtv.info/wp/

Ministarstvo za ljudska prava i izbjeglice Sektor za iseljeništvo. (2014). Pregled stanja bosanskohercegovačkog iseljeništva. [Review of the status of Bosnia-Herzegovina emigrants]. Sarajevo: Bosnia and Herzegovina Ministry of Human Rights and Refugees: Department for Diaspora.

Ministry of Justice of Bosnia and Herzegovina. (2012). Churches and religious communities (The law on freedom of religion and legal position of churches and religious communities in Bosnia and Herzegovina). Retrieved from http://www.mpr.gov.ba/organizacija_nadleznosti/uprava/registracije/crkve/default.as px?id=2298\&langTag=en-US

Minkov, A. (2004). Conversion to Islam in the Balkans: Kisve bahasi petitions and Ottoman social life, 1670-1730. Leiden; Boston: Brill.

Miskovic, M. (2003). "The construction of racial and ethnic identity of Balkan immigrants to the United States: A narrative analysis" (Doctoral Dissertation, Loyola University Chicago). Available from ProQuest Dissertations \& Theses Global. (3114138).

Miskovic, M. (2007). The construction of ethnic identity of Balkan Muslim immigrants: A narrativization of personal experiences. Qualitative Report, 12(3), 514-546.

Mojzes, P. (2011). Balkan genocides: Holocaust and ethnic cleansing in the twentieth century. Lanham, Md.: Rowman \& Littlefield.

Moore, D. (2013, Jun 22). Making St. Louis Home: The Bosnian Resetelment, 20 Years Later. St. Louis Post Dispatch. Retrieved from http://www.stltoday.com/news/multimedia/special/making-st-louis-home-thebosnian-resettlement-years-later/html_dafa620f-9408-5daf-b123-1b2ee29fda56.html

MTV Igman Pazaric. (2015, July 20). Emisija "sasvim iskreno" - gost: Bakir izetbegovic 17.07. 2015. - MTV Igman [The show "Quite Frankly" - guest: Bakir Izetbegovic 17.07. 2015 - MTV Igman]. Retrieved from https://www.youtube.com/watch?v=nf8D1DprfHM

Muftija travnički: Paradžemati cijepaju jedinstvo BH. muslimana [Mufti of Travnik: Paralegal jamaats split the unity of BH. Muslims]. (2016, January 16) Al Jazeera Balkans. Retrieved from http://balkans.aljazeera.net/vijesti/muftija-travnickiparadzemati-cijepaju-jedinstvo-bh-muslimana 
Munck, G. L., \& Leff, C. S. (1997). Modes of transition and democratization: South America and Eastern Europe in comparative perspective. Comparative Politics, 29(3), 343-362. doi:10.2307/422125

Muslim National Council of Sanjak. (1993). Memorandum on the establishment of a special status for Sanjak. Novi Pazar (printed by American-Sanjak Congress, Clifton N.J.): Muslim National Council of Sanjak.

Myers, J. L., Well, A. D., \& Lorch Jr, R. F. (2010). Research design and statistical analysis: Third edition. New York: Routledge.

Myuhtar May, F. (2014). Identity, nationalism, and cultural heritage under siege: Five narratives of Pomak heritage - from forced renaming to weddings. Leiden: Brill.

Матица Српска [Serbian Heritage]. (2014). Саопштење управног одбора Матице Српске о употреби назива босански језик [Statement of the Board of Serbian Heritage about the use of the term Bosnian language]. Retrieved from http://www.maticasrpska.org.rs/саопштење-управног-одбора-матице-срп/

Nadarević, Z. (2013). Zaboravljena djeca krajiine [The forgotten children of the Krajina]. (Ilhana Škrgić Trans.). Velika Kladusa: JU Centar za kulturu i obrazovanje "Zuhdija Žalić".

Naimark, N. M., \& Case, H. (2003). Yugoslavia and its historians: Understanding the Balkan wars of the 1990s. Stanford, Calif.: Stanford University Press.

Nanić, F. (1995, September 13). S muslimanima protiv Bošnjaka [With Muslims against Bosniaks]. Ljiljan, pp. 40.

Naomi, L. (2009). Learning National Identity: Schooling Effects in Post-Conlfict BosniaHerzegovina and Croatia. University of California, Berkley. (Doctoral dissertation) Retrieved from ProQuest Dissertations and Theses. (Accession Order No. 3410827), from http://search.proquest.com/docview/503564855

Nathanson, R. P. (2013). Twenty years and still becoming: Bosnian social and economic integration in St. Louis. (Unpublished master's thesis). Department of Urban \& Regional Planning University of Illinois, Urbana-Champaign.

Nećak, A. (2010, September 12). Synagogue in Milan Nedic Street. Retrieved from http://pescanik.net/synagogue-in-milan-nedic-street/

Neofotistos, V. P. (2008). "The Balkans' other within": Imaginings of the west in the republic of Macedonia. History and Anthropology, 19(1), 17-36. 
Neumayer, C., \& Schmidl, E. A. (2008). The emperor's Bosniaks: The BosnianHerzegovinian troops in the K.U.K. army: History and uniforms 1878 to 1918. Vienna: Militaria.

NIN. (2015, July 30). Наш највећи проблем је Додик [Our largest problem is Dodik]. NIN - Nedeljne Informativne Novine Retrieved from http://www.nin.co.rs/pages/article.php?id=95641

Obradović, N., Mitrović, M., \& Milovanović, I. (2014). Medijska promocija nacionalnih stereotipa u dnevnoj štampi Srbije, Bosne i Hercegovine i Hrvatske [Media promotion of national stereotypes in the daily press in Serbia, Bosnia and Herzegovina and Croatia]. In N. Dubravka Valić, S. Srđan, K. Nikola, \& G. Dinko, Uloga medija u normalizaciji odnosa na Zapadnom Balkanu,[The role of the media in the normalization of relations in the Western Balkans] Knjiga VI (pp. 327-342). Novi Sad, Serb.: Filozofski Fakultet

O'Donnell, G. A., \& Schmitter, P. C. (1986). Transitions from authoritarian rule. Baltimore: Johns Hopkins University Press.

Office of Performance and Quality (OPQ), Data Analysis and Reporting Branch (DARB), DL. (September 26th, 2012). U.S Citizenship and Immigration Services Application to Register Permanent Residence or Adjust Status (I-485): Approvals for Applicants with a Country of Birth of Bosnia and Residence in MO for Fiscal Years 2002-2011. CIS Consolidated Operational Repository (CISCOR).

Olzak, S. (2009). Contemporary ethnic mobilization. Ethnic Conflict, 1, 243-262.

O'Loughlin, J. (2010). Inter-ethnic Friendships in Post-war Bosnia-Herzegovina: Sociodemographic and Place Influences. Ethnicities, 10(26), 26-54.

Olson, M. (1971 (1965)). The Logic of Collective Action: Public Goods and the Theory of Groups. Cambridge: Harward Universtiy Press.

Omerbašić, Š. (2008). Bošnjaci u predosmansko doba [Bosniaks in the pre-Ottoman era]. Islamska Tradicija Bošnjaka: Izvori, Razvoj i Institucije, Perspektive [The Islamic Tradition of Bosniaks: Sources, Development and Institution, Perspectives], Sarajevo, BiH. 188-210.

Prosecutor vs. Ratko Mladic, IT-09-92-T 36238 (International Tribunal for the Former Yugoslavia 24 June 2015). Retrieved from http://www.icty.org/x/cases/mladic/trans/en/150624ED.htm

Orwell, G. (1953). Notes on nationalism. In G. Orwell (Ed.), Such, such were the joys (pp. 73-97). New York: Harcourt, Brace. 
OSCE Mission in Kosovo. (2009). Kosovske nevećinske zajednice u sistemima osnovnog i srednjoškolskog obrazovanja [Kosovo minority communities in primary and secondary education]. (Report). Pristina, Kosovo: Organization for Security and Cooperation in Europe.

Özkan, B. (2012). From the abode of Islam to the Turkish Vatan: The making of a national homeland in Turkey. Yale University Press.

Palairet, M. R. (1997). The Balkan economies c. 1800-1914: Evolution without development. Cambridge, UK: Cambridge University Press.

Pallant, J. (2007). SPSS survival manual: A step by step guide to data analysis using SPSS for windows ( ${ }^{\text {rd }}$ ed.). New York: Open University Press.

Paral, R., \& Norkewicz, M. (2003). The Metro Chicago Immigration Fact Book (Working Paper). Chicago: Institute for Metropolitan Affairs, Roosevelt University. doi:ISBN: 0-9632567-6-9

Pavlakovic, V. (2010). Defying the defeated: Commemorating Bleiberg since 1990. L'Europe En Formation, 37(Autumn), 125-147.

Perica, V. (2002). Balkan idols: Religion and nationalism in Yugoslav states. Oxford: Oxford University Press.

Perkins, M. A. (2004). Christendom and European identity: The legacy of a grand narrative since 1789. Berlin; New York: Walter de Gruyter.

Philips, B. A. A. (2006). The evolution of fiqh: Islamic law and madh'habs. New Delhi: Islamic Book Service.

Pinson, M. (1994). The Muslims of Bosnia-Herzegovina under Austro-Hungarian rule, 1878-1918. In M. Pinson (Ed.), The Muslims of Bosnia-Herzegovina: Their historic development from the middle ages to the dissolution of Yugoslavia (pp. 84-128). Cambridge, Mass.: Distributed for the Center for Middle Eastern Studies of Harvard University by Harvard University Press.

Pirić, A. (1993, January 18). Pitanje jezika - pitanje države [The question of language the question of state]. Ljiljan, pp. 24-25.

Piscatori, J. P. (1986). Islam in a world of nation-states. Cambridge [Cambridgeshire]: Cambridge University Press.

Plamenatz, J. (1976). Two types of nationalism. In E. Kamenka (Ed.), Nationalism: The nature and evolution of an idea (pp. 23-36). New York: St. Martin's Press. 
Polletta, F., \& Jasper, J. M. (2001). Collective identity and social movements. Annual Review of Sociology, 27, 283-305.

Portes, A., \& Zhou, M. (1993). The New Second Generation: Segmented Assimilation and Its Variants. Annals of the American Academy of Political and Social Science, 530, 74-96.

Pranger, R. J. (2011). The Milosevic and Islamization factors: Writing contemporary history in the Balkans. Mediterranean Quarterly, 22(1), 1-14.

Promitzer, C. (2004). Whose is Bosnia? Post-Communist historiographies in Bosnia and Herzegovina. In U. Brunnbauer (Ed.), (Re)writing history : Historiography in Southeast Europe after socialism (Studies on South East Europe, v. 4. ed., pp. 5494). Münster: Lit.

Prosecutor v. Ratko Mladic, IT-09-92-T 36238 (International Tribunal for the Former Yugoslavia 24 June 2015). Retrieved from http://www.icty.org/x/cases/mladic/trans/en/150624ED.htm

Prosecutor v. Mićo Stanišić, Stojan Župljanin - judgement, 120100 (International Criminal Tribunal for the Former Yugoslavia 27 March 2013). Retrieved from http://www.icty.org/x/cases/zupljanin_stanisicm/tjug/en/130327-1.pdf

Prvi Mart Coalition. (2013). Established U.S. chapter of the "Prvi Mart" coalition. Retrieved from http://www.stlbosnians.com/chapter-of-the-prvi-mart-coalitionestablished-in-st-louis/

Purivatra, A. (1977). Jugoslovenska muslimanska organizacija u političkom životu Kraljevine Srba, Hrvata i Slovenaca [Yugoslav Muslim organization in the political life of the Kingdom of Serbs, Croats and Slovenes]. Sarajevo: Svjetlost.

Purivatra, A., Imamović, M., \& Mahmutćehajić, R. (1991). Muslimani i bošnjaštvo [Muslims and Bosniakness]. Sarajevo: Izdavačko-trgovinsko preduzeće Biblioteka Ključanin.

Putnam, R. D. (2000). Bowling Alone: The Collapse and Revival of American Community. New York: Simon and Shuster.

Ramadan, T. (2009). Radical reform: Islamic ethics and liberation. Oxford: Oxford University Press.

Rastoder, Š. (2010). Bošnjaci/Muslimani Crne Gore: Između prošlosti i sadašnjosti. [Bosniaks / Muslims of Montenegro: Between past and present]. Podgorica, Montenegro: Almanah. 
Rastoder, Š . (2004). The development of historiography in Montenegro, 1989-2001. In U. Brunnbauer (Ed.), (Re)writing history : Historiography in Southeast Europe after socialism (Studies on South East Europe, v. 4. ed., pp. 201-236). Münster: Lit.

Ratni Kongres Bosanskomuslimanskih Intelektualaca: 22. Decembar 1992. (1994). In Kamberović H. (Ed.), Dokumenti. [War congress of Bosnian Muslim intellectuals: December 22, in 1992 - documents]. Sarajevo: Vijeće Kongresa Bosanskomuslimanskih Intelektualaca.

Raysūn̄̄, A. (2005). Imam Al-Shatibi's theory of the higher objectives and intents of Islamic law. London: International Institute of Islamic Thought.

Redžić, E. (1970). O posebnosti bosanskih muslimana [On the peculiarities of Bosnian Muslims]. Pregled, 4, 19-32.

Renan, E. (1996). What is a nation? In S. J. Woolf (Ed.), Nationalism in Europe, 1815 to the present: A reader (pp. 48-60). London: Routledge. (Original work published 1882).

Rijaset. (12 November 2012). Proglas Rijaseta islamske zajednice o popisu stanovištva [Proclamation of the Rijaset of the Islamic community on the census]. Retrieved from http://www.islamskazajednica.ba/index.php?option=com_content\&view=article\&id =15316:proglas-rijaseta-islamske-zajednice-o-popisu-stanovnistva\&catid=203:minavjesti-kat\&Itemid=459

Rioch, M. J. (2009). The work of Wilfred Bion on the group. In W. W. Burke, D. G. Lake \& J. W. Paine (Eds.), Organization change: A comprehensive reader. San Francisco: Jossey-Bass.

Rizvić, M. (1990). Novi prolozi istraživanju alhamijado literature [New contributions to research of Alhamiyado literature]. Fluminensia: Časopis Za Filološka Istraživanja, 2(January), 137-144. Retrieved from http://fluminensia.ffri.hr/en/

Rizvić, M. (1996). Bosna i Bošnjaci, jezik i pismo [Bosnia and Bosniaks, language and script]. Sarajevo: Preporod.

Rousseau, J. J. (1978). In Masters R. D. (Ed.), On the social contract: With Geneva manuscript and political economy [Discours sur l'oeconomie politique] (M. Judith R. Trans.). New York: St. Martin's Press. (Original work published 1762).

Rustow, D. A. (1970). Transitions to democracy: Toward a dynamic model. Comparative Politics, 2(3), 337-363. doi:10.2307/421307 
Šabanović, H. (1982). Bosanski pašaluk: Postanak i upravna podjela. [Bosnia pashaluk: Genesis and administrative divisions]. Sarajevo: Svjetlost, OOUR Izdavačka djelatnost.

Saeed, A. (2006). Islamic thought: An introduction. London: Routledge.

Saliji, A. T. (2014). Jezik i obrazovanje Bošnjaka na Kosovu [Language and education of Bosniaks in Kosovo]. Retrieved from http://sandzakpress.net/arsim-tarik-saliji-jeziki-obrazovanje-bosnjaka-na-kosovu

Salkić, M. (2008). Jugoslovenska politika prema islamskoj zajednici [Yugoslav policy towards the Islamic community (of $\mathrm{BiH})]$. Islamska Tradicija Bošnjaka: Izvori, Razvoj i Institucije, Perspektive [The Islamic Tradition of Bosniaks: Sources, Development and Institution, Perspectives], Sarajevo, BiH. 437-464.

Saltonstall, D. (1995, September 17). Far from home, Bosnians cannot forget hell they left behind. NY Daily News. Retrieved from http://www.nydailynews.com/archives/news/home-bosnians-forget-hell-left-behindarticle-1.701509.

Saric, S. (2005). A New World. In S. A. (eds), 100 Godina Bosnjaka u Americi: A Centenial of Bosniaks in America (pp. 91-94). Chicago: Bosnian American Cultural Association.

Šarkinović, H. (2012). Bošnjaci od Načrtenjija do Memoranduma. [Bosniaks from (Serbian) Nachertaniya to (Serbian) Memorandum] Podgorica, Montenegro: Matica Bošnjaka Crne Gore.

Savezna Narodna Skupština. (April 10, 1963). Zakon o organizaciji i radu saveznog $i z v r s ̌ n o g$ veća [The law on the organization and operation of the federal executive council]. Službeni List Socijalističke Federativne Republike Jugoslavije., 19(14), 314-315.

Schabas, W. (2009). Genocide in international law: The crime of crimes. Cambridge, UK: Cambridge University Press.

Schatz, R. T., Staub, E., \& Lavine, H. (1999). On the varieties of national attachment: Blind versus constructive patriotism. Political Psychology, 20(1), 151-174.

Schleifer, Y. (2012, April 4). The White House dessert that sparked a minor TurkishGreek conflict. The Atlantic. Retrieved from http://www.theatlantic.com/international/archive/2012/04/the-white-house-dessertthat-sparked-a-minor-turkish-greek-conflict/255439/ 
Schrock, L. (2014, May 6). The Bosnian War Influenced Refugee to Grapple with Iowa Politics. Retrieved from Think: http://www.think-mag.com/your-work/bosnian-warinfluenced-refugee-grapple-iowa-politics/

Schuessler, A. A. (2000). A logic of expressive choice. Princeton: Princeton University Press.

Schuessler, R. (2014, Feb. 22). Yugoslavia's children, grown up in St. Louis. Retrieved from http://america.aljazeera.com/features/2014/2/yugoslavia-schildrengrownupinstlouis.html

Seferović, S. (2006). Govor zavičaja: Kulturne aktivnosti u bosansko-hercegovačkoj zajednici 1991-2006 [Words of the homeland: Cultural activities in the BosnianHerzegovinian Community 1991-2006]. Chicago: Bosanska biblioteka Čikago.

Seferović-Drnovšek, S. (2013). Suceljavanje sa predrasudama [Confronting the prejudices]. Chicago: Self-published. doi:ISBN-13: 978-1482718874

Šehić, N. (1971). Četništvo u bosni i hercegovini (1918-1941): Politička uloga i oblici djelatnosti četničkih udruženja. [The Chetnik movement in Bosnia and Herzegovina (1918-1941): Political role and forms of activities of Chetnik associations]. Sarajevo: Akademija Nauka i Umjetnosti Bosne i Hercegovine.

Seierstad, A. (2006). With their backs to the world: Portraits from Serbia. New York: Basic Books.

Sekulic, D., Massey, G., \& Hodson, R. (1994). Who were the Yugoslavs? Failed sources of a common identity in the former Yugoslavia. American Sociological Review, $59(1), 83$.

Sells, M. A. (1996). The bridge betrayed: Religion and genocide in Bosnia. Berkeley: University of California Press.

Serbian Government. (2012, November 15). National symbols and anthem of the republic of Serbia. Retrieved from http://www.srbija.gov.rs/pages/article.php?id=5412

Serbian Orthodox Diocese of New Gracanica - Midwestern America. (2016). Holy trinity Serbian Orthodox church. Retrieved from http://www.serbianchurchstlouis.org/

Šerbo, R. (2010). Bošnjaci/Muslimani Crne Gore: Između prošlosti i sadašnjosti [Bosniaks / Muslims of Montenegro: Between Past and Present]. Podgorica, Mntg: Almanah. 
Seawright, J; Gerring, J. (2008). Case Selection Techniques in Case Study Research: A Menu of Qualitative and Quantitative Options, Political Research Quarterly, 61 (2), 294-308. doi: 10.1177/1065912907313077

Shapiro, S. S., \& Wilk, M. B. (1965). An analysis of variance test for normality (complete samples). Biometrika, 52(3), 591-611. doi:10.2307/2333709

Sherkat, D. E. (2001). Tracking the restructuring of American religion: Religious affiliation and patterns of religious mobility, 1973-1998. Social Forces, 79(4), 14591493.

Shils, E. (1982). The constitution of society. Chicago: University of Chicago Press.

Sietsema, R. (2008, January 1). A Pair of Bosnian Cafés Compete on a Queens Corner. Retrieved from The Village Voice: http://www.villagevoice.com/restaurants/a-pairof-bosnian-cafs-compete-on-a-queens-corner-6432183

Silva, E. (2000, August 16). Live to tell. Riverfront Times. Retrieved from http://www.riverfronttimes.com/stlouis/live-to-tell/Content?oid=2474051

Simmons, C. (2002). A multicultural, multiethnic, and multiconfessional Bosnia and Herzegovina: Myth and reality. Nationalities Papers, 30(4), 623-638. doi:10.1080/00905992.2002.10540510

Simmons, O. E. (2010). Is That a Real Theory or Did You Just Make It Up? Teaching Classic Grounded Theory. The Grounded Theory Review 9(2), 15-39.

Simon, B. (1992). The perception of ingroup and outgroup homogeneity: Reintroducing the intergroup context. European Review of Social Psychology, 3(1), 1-30. doi:10.1080/14792779243000005

Slovic, Paul (1995). The construction of preference. American Psychologist, 50 (5), 364371.

Smith, A. D. (1987). The ethnic origins of nations. Oxford, UK: B. Blackwell.

Smith, A. D. (1991). National identity. Reno: University of Nevada Press.

Smith, A. D. (2009). Ethno-symbolism and nationalism: A cultural approach. London; New York: Routledge.

Smith, T. W. (2002). The Muslim Population of the United States: the Methodology of Estimates. Public Opinion Quarterly, 66, 404-417. 
Snyder, L. L. (1977). The meaning of nationalism. Westport: Greenwood Press.

Sofos, S. A. (1996). Inter-ethnic violence and gendered constructions of ethnicity in the former Yugoslavia. Social Identities, 2(1), 73.

Somach, S. D. (1995). Meeting the needs of Bosnian refugees. Chicago, IL, February $27-$ March 2, 1995. (ED406496), 11-27.

St. Louis Islamic Center. (2016). STLIC dobrodosli. Retrieved from http://stlic.org/

Štulanovic, M. (2002). Islamski šarti (ruknovi) u BiH običajima i tradiciji: Etnološko šerijatska studija [Islamic pillars (conditions) in Bosnian customs and tradition: Ethnological sharia study]. Bihać, BiH: IPA Bihać \& Medresa Džemaludin Čaušević Cazin.

Suljević, K. (1970, September). Otpor tokovima muslimasnke posebnosti [Resistance to trajectories of Muslim specificities]. Pregled: Časopis Za Društvena Pitanja, 60(9), 255-266.

Ṭạ̣āwī, A. i. M., \& Yusuf, H.,. (2008). The creed of Imam al-Tahawi. Berkeley, Calif.; Enfield: Zaytuna Institute; Publishers Group UK [distributor].

Tanovic, B. (2005). Bosnian American Cultural Association. In S. Agic, 100 Godina Bosnjaka u Americi: A Centenial of Bosniaks in America (pp. 109-124). Chicago: Bosnian American Cultural Association.

Tajfel, H. (1979). An integrative theory of intergroup conflict. In W. G. Austin, \& S. Worchel (Eds.), The social psychology of intergroup relations (pp. 33-47). Monterey, Calif.: Brooks/Cole

Tajfel, H., Billig, M. G., Bundy, R. P., \& Flament, C. (1971). Social categorization and intergroup behaviour. European Journal of Social Psychology, 1(2), 149-178.

Tanjug. (2016, July 29). Izetbegovic: Važno institucionalno organizovanje bošnjaka [Izetbegovic: Important institutional organization of Bosniaks]. Retrieved from http://www.tanjug.rs/mobile/full-view.aspx?izb=260326

The Advisory Council for Bosnia and Herzegovina. (2016). Our mission. Retrieved from http://acbih.org/?page_id=24

The Movement of Serbian Chetniks in Ravne Gore. (2016). Chapters. Retrieved from http://www.ravnagorachetniks.org/board_e.html 
The Parliament of Montenegro. (14. February 2016). Mr. Mustafic meets emigrants in Chicago. Retrieved from http://www.skupstina.me/index.php/en/saradnja-saiseljenicima-aktuelnosti/item/4861-mustafic-u-cikagu-sa-iseljenicima

The Turkish American Society of Missouri. (2016). TAS home page. Retrieved from http://tasom.org/

Tolz, V. (1998). Forging the nation: National identity and nation building in postcommunist Russia. Europe-Asia Studies, 50(6), 993-1022.

Tomka, M. (1995). Secularization and nationalism. In J. A. Coleman, \& M. Tomka (Eds.), Religion and nationalism (pp. 22-33). London: SCM Press.

Tönnies, F. (1988). Community and society: Gemeinschaft und gesellschaft (C. P. Loomis, Trans.). Mineola, New York: Dover Publications, Inc. (Original work published 1887).

Townsend, T. (2013, April 29). Bosnian Muslims again battle St. Louis County over proposed mosque. St. Louis Post Dispatch. Retrieved from http://www.stltoday.com/lifestyles/faith-and-values/bosnian-muslims-again-battle-stlouis-county-over-proposed-mosque/article_3b50d200-4b6e-5049-8b658aab2a934212.html

Trepte, S. (2006). Social identity theory. In J. Bryant, \& P. Vorderer (Eds.), Psychology of entertainment (pp. 255-271). Mahwah, N.J.: Lawrence Erlbaum.

Trhulj, S. (1992). Mladi muslimani [Young Muslims]. Zagreb: Globus.

TrustSRB (2008, Aug. 2) Ratko Mladic in Srebrenica. Retrieved from https://youtu.beledFQTZpf8yM

Tunjić, A. (2015, July 23) Bez istine nema pomirenja [Without truth, there is no reconciliation]. Matica Hrvatska - Vijenac, (558-560).

Turčić, Š. (1993, November 3-10). Reis bez portfelja [Reis without portfolio]. Ljiljan, pp. 19.

Turner, J. C. (1981). Towards a cognitive redefinition of the social group. Cahiers De Psychologie Cognitive/Current Psychology of Cognition, 1(2), 93-118.

Turner, J. C. (1997). The Institutional Order. New York: Longman.

Ugrešić, D. (04/04/2010). Duh kakanijske provincije [Spirit of the Kakaniyan province]. Retrieved from http://pescanik.net/duh-kakanijske-provincije/ 
UNHCR. (May 30, 2000). Germany: UNHCR urges residency for Bosnians briefing notes. Retrieved from http://www.unhcr.org/3ae6b81d5b.html

U.S. Department of State Office of the Historian. (2013, October 31). 1993-2000 milestones: The war in Bosnia, 1992-1995. Retrieved from http://history.state.gov/milestones/1993-2000/bosnia

Vamanu, A. (2012). Learning Democracy? Political Distrust and Questioning of Authority among Immigrants from (Post)Authoritarian States. Midwest Political Science Association Annual Conference (pp. 1-28). Chicago: MPSA.

van Zomeren, M., Spears, R., Fischer, A. H., \& Leach, C. W. (2004). Put your money where your mouth is! Explaining collective action tendencies through group-based anger and group efficacy. Journal of Personality and Social Psychology, 87(5), 649664. doi:10.1037/0022-3514.87.5.649

Varenik, R. O. (2008, August 15). Third party observation. European Court of Human Rights, fourth section in the case of Dervo Sejdic and Jakob Finci against Bosnia and Herzegovina. (Third Party Observations No. 27996/06 and 34836/06). New York; Budapest: Open Society Justice Initiative. Retrieved from https://www.opensocietyfoundations.org/sites/default/files/written-comments20080815.pdf

Velić, B. (1993, March-April). Prije i sad [Before and now]. Bošnjak: Nezavisni List Autohtonih Sinova i Kćeri Bosne-Hercegvoine i Sandžanka, 12-13.

Velić, B. (1994, March-April). Čuvajte se onih koji ne znaju šta su [Beware of those who do not know what they are]. Bošnjak: Nezavisni List Autohtonih Sinova i Kćeri Bosne-Hercegvoine i Sandžanka, 16-17.

Viković, L. (2000). Škola u Brodarevu i školstvo u brodarevskom kraju u XX veku. [School and education in Brodarevo and its surrounding in the XX century]. Brodarevo, Serb: Osnovna Škola Svetozar Marković.

Vincent, A. (2002). Nationalism and particularity. Cambridge: Cambridge University Press.

Vjeće Kongresa Bošnjackih Intelektualaca. (2001, Dec. 1). Sevdalinka danas: "vrijeme ce pokazati da li ce 'sevdalinka otici u muzej' ili ce vjecno zivjeti u bosni" [Sevdalinka today: "time will tell whether 'Sevdalinka will go to the museum' or will live forever in Bosnia"]. Retrieved from http://vkbi.open.net.ba/Aktuelnosti/011201.htm 
Vlada Republike Srbije. (2004). Грб, застава и химна Републике Србије [The coat of arms, flag and anthem of the republic of Serbia - government of Serbia]. Retrieved from http://www.srbija.gov.rs/pages/article.php?id=12084

Vlahović, P. (1968). Brodarevo i njegova okolina. (Etnološka rasprava) [Brodarevo and its surroundings. (ethnological discussion)]. Belgrade: University of Belgrade.

Walzer, M. (1994). Comment. In C. Taylor, \& A. Gutmann (Eds.), Multiculturalism : Examining the politics of recognition (Expanded Paperback Edition, pp. 99-103). Princeton, N.J.: Princeton University Press.

Warren, W. J. (2007). Tied to the Great Packing Machine: The Midwest and Meatpacking. Iowa City: University of Iowa Press.

Waters, M. C. (2008). The Challenges of Studying Political and Civic Incorporation. Applied Developmental Science, 12(2), 105-107.

Weber, E. (1976). Peasants into Frenchmen: The modernization of rural France, 1870 1914. Stanford, CA: Stanford University Press.

White, G. W. (2000). Nationalism and territory: Constructing group identity in southeastern Europe. Lanham, MD: Rowman \& Littlefield.

Wilkes, J. J. (1992). The Illyrians. Cambridge, Mass., USA: B. Blackwell.

Wolff, L. (2003). The rise and fall of Morlacchismo. South Slavic identity in the mountains of Dalmatia. In N. M. Naimark, \& H. Case (Eds.), Yugoslavia and its historians: Understanding the Balkan wars of the 1990s (pp. 37-52). Stanford, Calif.: Stanford University Press.

Woodward, S. L. (1995). Socialist unemployment: The political economy of Yugoslavia, 1945-1990. Princeton, N.J.: Princeton University Press.

Woolf, S. J. (1996). Nationalism in Europe, 1815 to the present: A reader.

Wulff, J. N. (2014). Interpreting results from the multinomial logit model: Demonstrated by foreign market entry. Organizational Research Methods, doi:10.1177/1094428114560024

Yoder, D. (1974). Toward a definition of folk religion. Western Folklore, 33(1), 2-15. doi:10.2307/1498248

Zachary, I. T. (1984). The Islamic revival and the Muslims of Bosnia-Hercegovina. East European Quarterly, 17(4), 437. 
Zelić Bučan, B. (2000). Bosančica ili hrvatska ćirilica u srednjoj dalmaciji [Bosančica or Croatian cyrillic in Central Dalmatia]. Split: Državni arhiv.

Zulfić, M. (2003). Džematu-l-Hajrijrijje: 100 godina Bošnjaka u Čikagu . Chicago: Džemijetul Hajrije.

APPENDICES (supplemental files):

1. Appendix A: Nationalism Strength Index

2. Appendix B: Nationalism Type Index

3. Appendix C: Bosniak Identity Survey Booklet (English Language Version)

4. Appendix D: Bosniak Identity Survey Booklet (Bosnian Language Version) 
VITA

\section{MIRSAD KRIJEŠTORAC}

\section{EDUCATION, EXPERIENCE, AND AWARDS AND HONORS}

M.A., Florida International University, Political Science, 2012

Concentration: Comparative Politics

Minor: International Relations

Graduate Certificate: European Studies; Middle East \& Central Asian Studies

B. A. School of Journalism \& Mass Communication, Science of Communication, 2009 Concentrations: Print Journalism

Minor: Anthropology and Sociology

Certificate: European Studies

Associate of Arts, Broward College, 2006

\section{Florida International University, Miami, FL:}

Instructor and Adjunct Professor (2013 - Present)

Teaching Assistantship:

Department of Politics and International Relations (Fall, 2009 - Summer, 2013)

Broward College, North Campus, Coconut Creek, FL:

Adjunct Professor - Fall 2016 - present

Best Graduate Instructor in Political Science, 2013-14, Department of Politics and International Relations, Steven J. Green School of International and Public Relations

The national essay contest on Trans-Atlantic Relations sponsored by DaimlerChrysler, Second place. The Atlantic Council of the United States, 2007

Honors Institute, Broward College, Creative Writing Award, 2006

\section{PUBLICATIONS \& CONFERENCE PRESENTATIONS}

Book review: "Whose Bosnia: Nationalism and Political Institutions in the Balkans, 1840-1914” Edin Hajdarpasic. Cornell University Press, 2015. The Slavic and East European Journal. Vol. 60.1, Spring 2016 (pp. 167-8).

"Mapping Muslim Communities in 'Hispanicized' South Florida" in Crescent of Another Horizon: Islam in Latin America and Latino Islam in the US, edited by Maria del Mar 
Logrono, Paulo Gabriel Hilu Pinto, and John Tofik Karam., University of Texas Press. Fall, 2015. (pp. 276-304).

- Also translated and republished in China Muslim, Spring 2016, (5) pp.67-69.

"Role of an Agent in (un)Keeping the Multiethnic State Together: The Case of the Secession of Kosovo." Alternatives: Turkish Journal of International Relations. 14. 2 , Summer, 2015 (pp.1-15).

"Democratic Transitions in new Multiethnic States: Case Comparison of Macedonia and Montenegro" Istanbul Sebahattin Zaim University Journal of Social Science. Spring, 2013 (pp. 37-69).

"First Nationalism Then Desired Identity: The Analysis of US Bosniak Diaspora Survey Data" (New York City, April 2016). The Association for the Study of Nationalities 21st Annual Convention

"Imposing Particular Identities: Balkans As a Meeting Place of Ethnicities and Religions" (Saint Louis, November 2013). 51 th Annual Central Slavic Conference \& International Studies Association Midwest

"Keeping the Multiethnic State Together: The Case of Kosovo" (Chapel Hill, NC, October 2012). International Security Studies Section of International Studies Association Annual Conference

"Nationalism Before Identity: The Review of the Three Approaches to the Study of Eritrean Nation Under Construction" (Chicago, April, 2012) Midwest Political Science Association $70^{\text {th }}$ Annual Conference

"Theory of Critical Insecurity: Case of Catholic Christianity" (Atlanta, March, 2012). American Academy of Religion, the Southeastern Commission for the Study of Religion Regional Meeting

\section{INVITED TALKS \& PRESENTATIONS}

"Bosniak History as Memory, Memory as Destination" (March, 2014)

University of North Florida, Jacksonville, Fla.

"Bosnian Muslims: Bosniak Identity, Nation and State" (November, 2013)

Wheaton College, Wheaton, IL.

"Bosniak Identity in Saint Louis: Quantitative Approach through Ethnography" (November, 2013). University of Missouri-Saint Louis, St. Louis, MO.

"The Growth of the Muslim Community of South Florida and Their Adaptations of the Social Sphere" (April, 2013). The Bridging Cultures Bookshelf: Muslim Journeys the National Endowment for the Humanities at Barry University, Miami, Fla. 